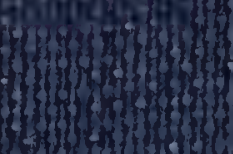


THE UNIVERSITY OF ILLINOIS LIBRARY 581.134 Midge Blologr 
Return this book on or before the Latest Date stamped below. A charge is made on all overdue books.

U. of I. Library

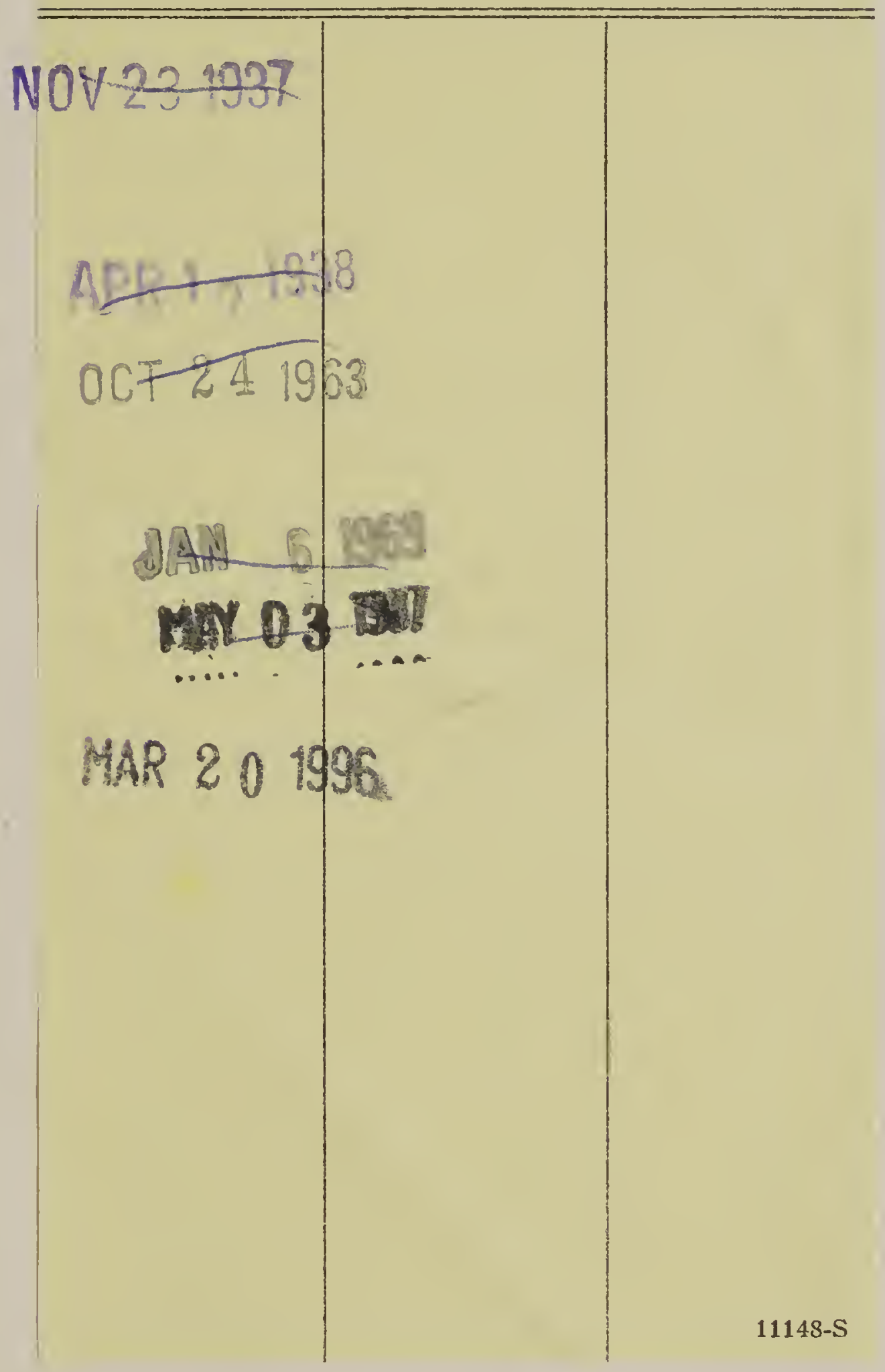







\title{
GROWTH IN TREES AND MASSIVE ORGANS OF PLANTS
}

\author{
DENDROGRAPHIC MEASUREMENTS \\ By D. T. MacDougal
}

THE GROWTH RECORD IN TREES

By Forrest Shreve

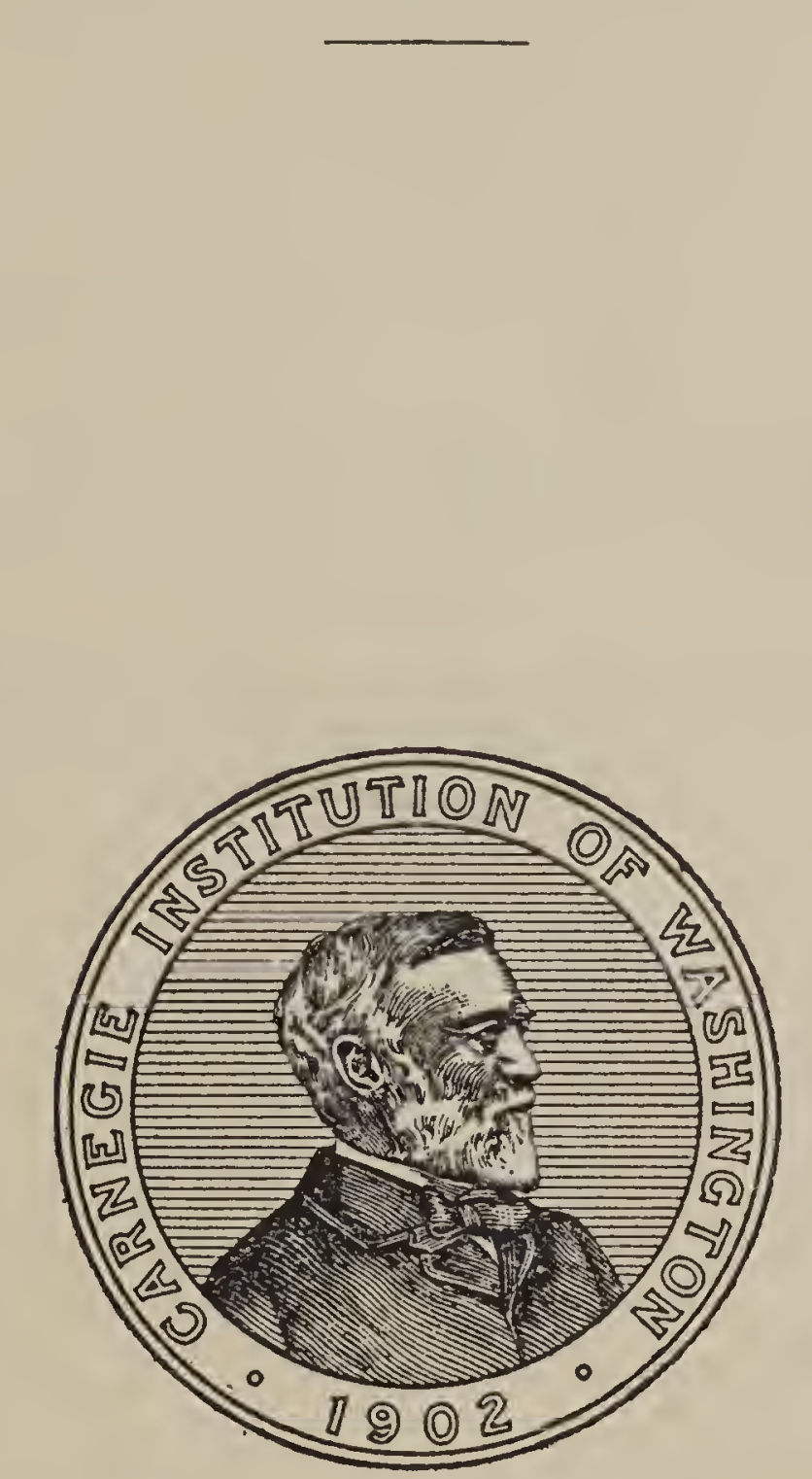

THE IIRRAPY Ni: :

\section{SFP 81924}

URIYEPSITY OF ILLINOIS

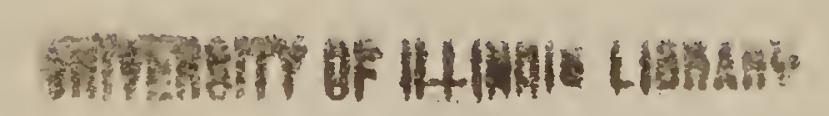

\begin{abstract}
som
Published by the Carnegie Institution of Washington

WASHiNGTON, MAY, 1924
\end{abstract}


CARNEGIE INSTITUTION OF WASHINGTON

Publication No. 350

$$
\begin{array}{|c|}
\text { Copies of this book } \\
\text { first issued } \\
\text { MAY } 161924
\end{array}
$$

WASHINGTON, D. C. 
DENDROGRAPHIC MEASUREMENTS.

BY

D. T. MacDougal. 


\section{CONTENTS.}

PAGE.

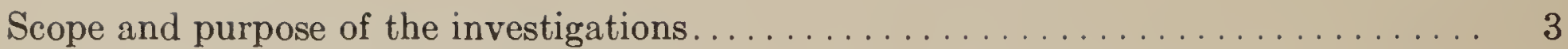

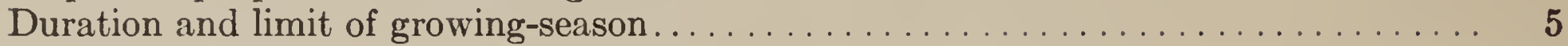

Growth of roots........................................... 9

Thickness of woody layers and length of growing season of No. $1 \ldots \ldots \ldots \ldots \ldots$

Seasonal activity and wood-formation in several Monterey pines. . . . . . . . . . . 10

Experimental investigations. . . . . . . . . . . . . . . . . . . . . . . . 13

Effects of breaking the conducting system by girdling $\ldots \ldots \ldots \ldots \ldots \ldots \ldots \ldots$

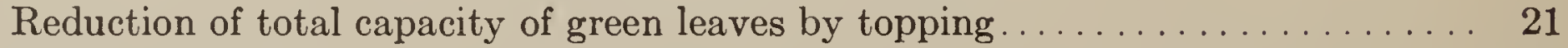

Effects of defoliation.............................. 24

Path and rate of movement of liquids in stems of Monterey pine . . . . . . . 29

Reversible variations in volume independent of growth . . . . . . . . . . . 35

Standardization of dendrograph for measurement of daily equalizing variations. . 37

Course of the daily equalizing variation in trees.................. 39

Daily variations in volume of inner woody cylinder of a Monterey pine tree. . . 41

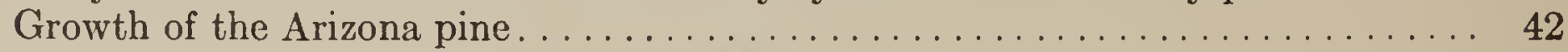

The Mexican white pine ................................ 43

Relation of Arizona, Mexican, and Chihuahua Pines to seasonal variations..... 44

The yellow pine.................................. 46

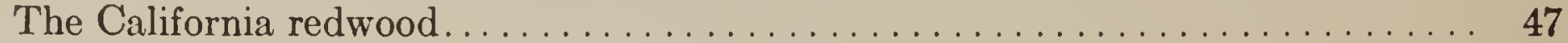

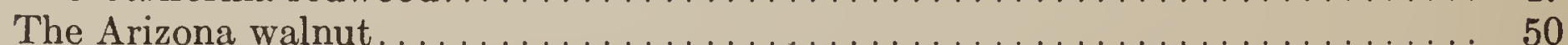

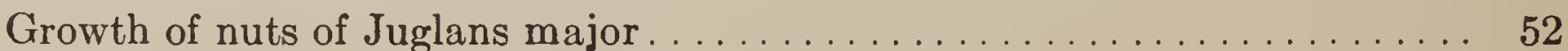

The Arizona ash. . . . . . . . . . . . . . . . . . . . . . . . . . . . 53

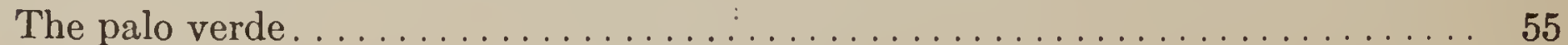

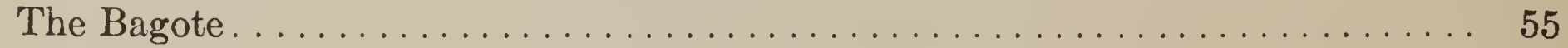

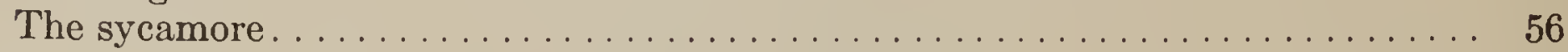

The Carolina poplar. . . . . . . . . . . . . . . . . . . . . . . . . 56

MacDougal's poplar............................... 56

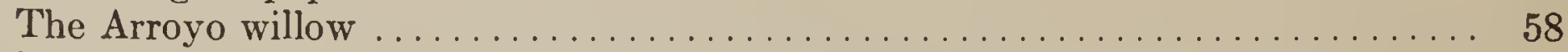

Measurements of yearly increase in circumference of tree-trunks by means of the

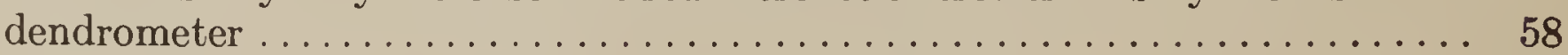

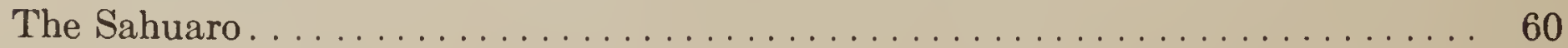

Growth of Opuntia............................... 68

Variations in leaves of Mesembryanthemum ................... 74

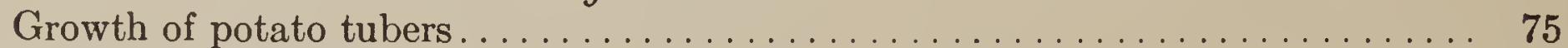

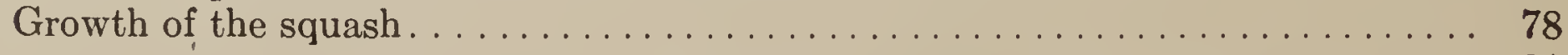

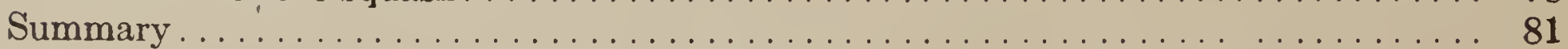




\section{DENDROGRAPHIC MEASUREMENTS.}

\section{SCOPE AND PURPOSE OF THE INVESTIGATIONS.}

Various features of growth in organs of widely divergent morphology have been discussed by the senior author in papers published since 1916 . Additional records and measurements of the changes in volume of mesophytic leaves, herbaceous stems, tree-trunks, succulent shoots of cacti, succulent leaves of Mesembryanthemum, leguminous pods, large berry-like fruits, melons, tubers, and nuts are presented in this paper.

These studies have been carried on concurrently with experimental work on the water relations of biocolloids, of interest in connection with the constitution of the plants, and some attention has also been paid to the influence of ions of the common salts on the permeability and growth of cells.

Interpretation of changes in volume due to growth has been made with reference to the distinctly two-phase aspect of this process in plants. The cell or protoplast of the plant is in its earliest stage a continuous or solid mass of jelly-like colloid. Additions to its mass are made by the formation of new particles of the materials of which it is composed. These include proteins or albumins, pentosans, soaps, and fatty substances. Despite the fact that the presence of substances of all of these groups is well known to all experimental workers, yet most of the literature dealing with the constitution of protoplasm treat living matter as if it were chiefly or entirely albuminous.

The additions to the mass of protoplasm have slight effect on the external measurements of a plant. The chief expansion of a cell-mass or of a growing organ is due to the distention of the cells. Clear spaces or vacuoles are formed by syneresis in the mass of living matter, and the substances dissolved in the water which fills these cavities act osmotically in pulling in more water, with a resultant expansion to a volume many times that of the embryonal mass. This distention is not accompanied by any notable increase in the amount of protoplasm; the distended cell may have actually less than the original.

The rate and amount of the distention or enlargement is determined by the osmotic potential of the substances in the vacuoles. Sugars, amino acids, etc., are present, and some salts. Whether the salts on the average furnish much of the osmotic pressure is somewhat doubtful. The larger part is probably due to sugars present. The rate and course of enlargement will, however, be determined largely by the permeability of the layers of protoplasm, and the wall to the substances in the vacuole. The permeability of these colloidal layers is largely determined by the ions of the salts in the medium or salt solution, and the implied relation is one of the most important in the life of the plant. It is understood, of course, that it is only cells, the external layers and walls of which are permeable to water, which would be capable of changes in volume. The larger particles of dissolved organic substances, such as sugars, may pass through them slowly or not at all, while the smaller and more swiftly moving ions of the electrolytes penetrate at various rates. 
It has been found that the electrolytes cause changes in the colloidal layers or "membranes" of the cell which alter its penetrability by other ions or substances, including those to which are due osmosis, turgidity, and the resultant enlargement of the cell. The material which may thus affect the rate and course of growth is complex, and its action is difficult to arrange under any simple formula.

A large share of the work described in the present paper was devoted to growth and changes in volume of the trunks of trees. This involved not only a study of the nature of growth as generally characterized above, but also made necessary a consideration of the mechanism of the body of a tree. The embryonal cell-masses form a thin sheet on the outside of the woody cylinder and run into the growing points of the stem and branches. As has been previously pointed out, this mass of growing cells does not act as a unit. Cell-division and distention of cells constituting growth may occur in some but not in all of the points with embryonic cells, and the sheet of cambium encircling the trunk may likewise show localized activity.

The assembling of the materials necessary for the organization of new protoplasm and the development of new cells in these massive bodies necessitates a complicated mechanism, the operation of some parts of which are but dimly comprehended. The electrolytes enter the roots in an amount and at a rate determined chiefly by the velocities and other characters of the ions, their mutual interferences, and their effect on the colloidal lattice of the surfaces of the root-hairs. The carbohydrates are formed in the leaves in connection with the entrance of carbon dioxide from the air. A movement of electrolytes from the roots to the leaves may be accounted for, but at the present time the passage of sugars and nitrogenous material from the leaves to the trunk and to the roots offers some problems in the physics of diffusion and conduction for which no possible or plausible solutions have been offered.

Necessarily much attention has been paid to the influence of climatic features upon these processes. Some attempt has been made to correlate climatic phases with the amount and character of wood formed in trunks, as ordinarily studied in cross-sections as "rings" by the climatologist interested in climatic fluctuations.

Dendrographic measurements of trees were begun in the autumn of 1918, and have been so extended that at present (close of the season of 1923) records of the growth of trees to a total of about 90 seasons, representing 21 species, are available, in addition to the continuous records of growth of tubers, fruits, and stems of other plants which are presented.

The dendrographic measurements made during the first three years of the observations were of a wide variety of species, and the information thus secured forms the basis of a possible comprehension of the behavior of treetrunks of various habits and morphological types. Later, attention was concentrated on the conifers, and the greater number of instruments were used on the Monterey pine (Pinus radiata), while some observations on the redwood (Sequoia sempervirens) begun in 1921 were continued and extended to include five trees, of which continuous records were made for periods of various lengths from one to two years. 
Analysis of growth of trees in different habitat complexes uncovers some correlations between daily variations and growth on the one hand, with stomatal action and meteorological phenomena on the other. Especial attention has been given to the direct effect of rainfall on the thickness of the layers of wood formed, which, as rings seen in cross-sections of trunks, are considered as records of climate by many investigators. That the thickness of the layers is not always primarily determined by the rainfall of the season in which they are formed might be expected. Various experimentally induced variations in the water-supply and conductive systems of trees have been made for the purpose of determining the relative and direct effects of the environic components and of the mechanism of food-supply. Unseasonable irrigation, mechanical girdling of trunks, killing of a basal section of trunks without removal or mechanical damage to the bark, decapitation, defoliation at various seasons, the injection of dyes, and other means have been used, with results as described on the following pages.

Measurements of the variations in volume of other organs, such as the flat joints of Opuntia, which display a behavior much like the trunks of the tree cactus (Carnegiea), of tubers of the common potato during their development, of the nuts of Juglans, coincidentally with observations on the trunks of the trees, and of the fruit of the squash (Cucurbita), have been added for the purpose of extending the study of the variations in growing organs caused by a fluctuating water-balance. The last-named material also illustrates the course of growth in a structure in which the proportion of water to the dry matter rises toward maturity.

\section{DURATION AND LIMIT OF GROWING-SEASON.}

The region of the Coastal Laboratory is at the upper margin of the frost belt, freezing temperatures occurring for only a few hours annually, and with some exceptions in which the thermometer does not fall so low. The principal part of the rainfall comes in the winter, or cooler season, so that growth begins with a rising temperature accompanied by a progressive decrease of soil moisture. The summer months, in which the soil moisture is at a minimum, is characterized by much fogginess, one period of 18 days without direct sunlight being recorded at the Coastal Laboratory.

A tree does not react as a simple, unified mass of living matter, as some organs may awake and show growth with the remainder of the body in a dormant condition. It is to be seen that in an equable climate, as that of Carmel, the opening and close of the growing-season may be very indefinite.

Thus, in the winter season of 1922 and 1923 the tips of roots of the Monterey pine lying within $10 \mathrm{~cm}$. of the surface showed elongation late in November, and also in December, and apparently were active throughout the rainy season; and shoots of young pines also showed elongation throughout the winter season, so that the total amounted to as much as $42 \mathrm{~mm}$. in some cases by January 8, according to notes furnished by Dr. W. A. Cannon. Enlargement of the stems of any of these trees, some of which were but $10 \mathrm{~cm}$. in diameter, occurred in November and December 1922, and growth for the season began January 3. The larger trees remained inactive in this member until much later, as may be seen in Table 2. 
Naturally, the close of the season is marked by similar irregularities, the different parts becoming inactive at different times, and this applies also to the upper and lower parts of the trunk. The sheet of cambium of the trunk apparently awakens at once so far as the observations bear on this point, but growth may cease in one part while it is still in progress in another place. These features are illustrated by the dates given in Table 1, in which the seasons of activity of Monterey pine No. 1 are given from 1919 to 1923 , inclusive.

The time at which the activity of the cambium resulted in enlargement of the trunk, and the time at which such accretion ceased in a diameter over a meter from the base of the tree, are given after $\mathrm{A}$, and the same dates are given after $\mathrm{B}$ for a diameter 8 meters higher on the trunk.

A dendrograph of the initial design was attached to the trunk at $\mathrm{A}$ in September 1918, and superseded by improved patterns in such manner that a continuous record could be maintained. A tracing for five complete years is now available (September 1923). The instrument was attached to the trunk at B in January 1920, and the record for four growing-seasons are available. The arrangement of the instruments was figured in Publication 307 (1921).

TABLE 1.-Seasonal activity of Monterey pine No. 1.

\begin{tabular}{|c|c|c|c|c|}
\hline & Year. & Beginning. & Ending. & $\begin{array}{c}\text { Duration } \\
\text { in days. }\end{array}$ \\
\hline & & & \\
A & 1919 & Mar. 30 & Aug. 31 & 153 \\
A & 1920 & Apr. 9 & Oct. 10 & 184 \\
B & 1920 & Do. & Oct. 1 & 175 \\
B & 1921 & Jan. 25 & Oct. 16 & 264 \\
A & 1921 & Jan. 26 & Oct. 10 & 257 \\
B & 1922 & Feb. 7 & Sept. 16 & 221 \\
A & 1922 & Do. & Aug. 9 & 182 \\
B & 1923 & Jan. 10 & Sept. 3 & 236 \\
& 1923 & Do. & Do. & 236 \\
\hline
\end{tabular}

The generalization that growth is initiated on the upper part of the trunk, and gradually extends downward, finds no support from the records given above. Enlargement of the trunk was seen to begin coincidentally near the base of the trunk and at a place 8 meters above it. On the other hand, cessation of growth might occur on widely separated dates in the two places.

Thus, in 1920 the cambium at the uppermost location in No. 1 ceased to enlarge 10 days earlier than that on the basal part of the trunk, while in 1921 this difference was but 6 days. The basal part of the tree had a growing-period 39 days longer than that of the upper location in 1922. About 5 weeks later some activity was shown in both places, which continued intermittently throughout the winter. The beginning and end of growth was simultaneous above and below in 1923.

The beginning date of growth was seen to vary through 73 days of the calendar at the base and 72 days at the upper location; the closing date 46 days at the base and 54 days at the upper location in the tree. The 
difference between the longest and shortest season at the base was 111 days, and 82 days in the upper location.

That other and extremely local and individual conditions are operative may be seen from the data given in Table 2, in which tree No. 10 is recorded as having begun growth 98 days later than No. 1, discussed above, although it stands not more than 30 meters distant from it, where the slope begins to fall away to the north and the exposure is to cool northwest winds. Tree No. 6, standing within 4 meters of No. 10, began growth in 1920 on March 19, or 21 days earlier than No. 1. These differences are among trees which have cut off the lower branches, are above 20 years old, but have not yet slackened terminal development. When young trees, such as Nos. 16, 17, $18,19,20,21,22$, and 23 , are considered, it was found that growth extends over a much greater part of the year and that not many weekly records are entirely devoid of record of some enlargement. As will be noted below, these young trees also show differences under apparently equivalent conditions. The diversity of behavior noted offers some features in contrast with those of the white pine (Pinus strobus L.) as recorded by Dr. H. P. Brown. ${ }^{1}$

TABLE 2.- Seasonal activities of several trees of Pinus radiata.

\begin{tabular}{|c|c|c|c|c|}
\hline Tree No. & Year. & Beginning. & Ending. & Period of activity. \\
\hline \multirow[t]{3}{*}{6} & 1920 & Mar. 19 & Aug. 24 & 158 days. \\
\hline & 1922 & Jan. 24 & Aug. 25 & 213 days. \\
\hline & 1923 & Jan. 19 & Sept. 1 & 225 days. \\
\hline \multirow[t]{3}{*}{10} & 1921 & May 4 & Sept. 19 & 138 days. \\
\hline & 1922 & Feb. 15 & June 4 & $\begin{array}{l}19 \text { days after decapitated } 11 \text { feet above } \\
\text { base (see No. 15). }\end{array}$ \\
\hline & 1923 & Feb. 10 & No action. & \\
\hline \multirow[t]{2}{*}{12} & 1921 & July 28 & Sept. 23 & 57 days. \\
\hline & 1922 & Apr. 20 & July 30 & 101 days. \\
\hline 13 & 1922 & Jan. 25 & Sept. 1 & 219 days; standing in swamp. \\
\hline \multirow[t]{2}{*}{14} & 1922 & Apr. 3 & Sept. 10 & 160 days; girdled May 18. \\
\hline & 1923 & Feb. 8 & July 14 & 156 days; dead. \\
\hline 15 & 1922 & $\ldots \ldots \ldots$ & June 12 & $\begin{array}{l}23 \text { days after being decapitated } 7 \text { feet } \\
\text { above base (see No. } 10 \text { ). }\end{array}$ \\
\hline 16 & 1923 & \multicolumn{3}{|c|}{$\begin{array}{l}\text { Growth not limited by seasons; girdled } 2 \text { meters above base March } 8 \text {; } \\
\text { topped May } 22 \text {. }\end{array}$} \\
\hline 17 & 1923 & \multicolumn{3}{|c|}{ Growth not limited by seasons. } \\
\hline 18 & 1923 & \multicolumn{3}{|c|}{ Growth not limited by seasons; topped March 8 . } \\
\hline 19 & 1923 & Jan. 3 & Defoliated M & $\operatorname{arch} 8$. \\
\hline 20 & 1923 & \multicolumn{3}{|c|}{ Growth not limited by seasons. } \\
\hline 21 & 1923 & $\begin{array}{l}\text { Dec. } 25 \\
1922\end{array}$ & Basal section & $\begin{array}{l}\text { killed by boiling oil June } 22 \text {; growth ceased } \\
\text { July } 14\end{array}$ \\
\hline 22 & 1923 & Feb. 18 & Aug. 13 & 176 days. \\
\hline
\end{tabular}

The 13 trees noted above were from 12 to 30 years old. Nos. 6, 10, 13, $14,15,20,21$, and 22 stood on the top of an old dune-hill, or on its margin within 100 meters of each other. No. 12 grew on a seaward-facing slope a few kilometers distant. Nos. 16,17 , and 18 were nearly identical as to age and stature, and stood in a swampy, sheltered valley a few meters distant from No. 22. No. 19 was midway on a north-facing slope.

1H. P. Brown. Growth studies in forest trees. Botan. Gazette, 59, 197-240. 1915. 
The periods given in Table 2 indicate the time over which the trunks were continuously, or almost continuously, in a state of enlargement, the interruptions being clearly due to excessive transpiration or some factor which masked but did not inhibit growth. Brief impulses which may cause the trunk to increase for a few days may occur at almost any time during the cooler or winter months, which, however, may have a total effect of increasing the diameter as much as 0.2 to $0.4 \mathrm{~mm}$. Thus, tree No. 6, which showed but very slight aftergrowth in 1920, made some accretion as recorded on three of the five weekly slips from the dendrograph preceding January $1,1923$.

The tendency to continuous growth is more marked in younger trees, and is illustrated by the records of Nos. $16,17,18,19,20$, and 21 . The first three stood in moist soil in a sheltered place, No. 19 was on the slope nearby, while Nos. 20 and 21 were on the flattened top of the old dune-hill on which the laboratory stands. All of these trees were active at the time the dendrographs were installed, the last week in October 1922, and nearly all of them made some growth every week during the winter months, except for brief periods of a few days, when enlargement would be stopped by low temperatures.

The longest stoppage was due to a storm late in January. Nos. 16, 17, and 20 were enlarging when the observations were begun in the last week of October 1922, and were still active at the corresponding time in 1923. The brief pauses noted above may not be laid to seasonal limits, and hence these trees may be said to grow the year round, except as interrupted by inclement weather.

No. 22, which was within 7 meters of No. 21, showed no accretion during November and December, and did not begin enlargement until 45 days later and until several days after the end of a period of low temperature. To the casual observer the difference in the situation of the two trees would not be discernible. This period of low temperature was characterized by maxima between $67^{\circ}$ and $63^{\circ} \mathrm{F}$., and of minima between 30 and 36 , and was accompanied by a total rainfall of 3 inches in 17 days. With the cessation of the storm, growth began with the rising temperatures in these five young trees, 10 days later in No. 22, 7 days later in No. 10, 2 days later in Nos. 6 and 14, and at both base and upper part of the trunk of No. 1. It would seem probable that the meteoric factors which tend to delay growth in a locality will be operative to some extent on all trees in the region. It is to be recalled, however, that growth is always under the control of a complex of which the three chief components are temperature, stored foodmaterial, and water-supply. The individual character of the stored foodsupply and the uneven distribution of ground-water may be determinative and be responsible for wide differences between neighboring trees.

The duration of the growth-period is also a function of the age of the individual. Thus, by reference to Table 2 it may be seen that growth began earliest and lasted longest in Nos. 16, 20, and 22, which ranged from 10 to 15 years of age, in contrast with Nos. 1, 6, 10, and 14, which ranged from about 25 to 35 years old. 


\section{GROWTH OF ROOTS.}

It has already been pointed out that the tips of roots may, like the shoot terminals, grow at almost any time during the cooler season. The correlation between such action and the thickening of the older and larger roots does not appear to be any closer than it is between the apices and the cambial layers in the trunks. A dendrographic lever set was placed in a small excavation 2 meters from the base of Monterey pine No. 1 on January 9,1923 , where it could be kept in bearing with a root about $4 \mathrm{~cm}$. in thickness. No change in diameter was detected until April 5, when a steady increase began, which continued for about a month, with a total accretion of $1 \mathrm{~mm}$. in thickness. The daily variations were very small, and of a type slightly different from those of the trunk.

The daily course of change consisted of a contraction beginning before midnight, which was gradual until daybreak, when it became more abrupt coincidentally with the contraction of the trunk. Shortly after midday, and not later than 2 p.m., expansion began which continued until nearly midnight, when the course of the pen was reversed and shrinkage ensued. The amplitude of these changes was much less than that of young stems of the same size, but seemed to bear something of the same ratio to the total diameter as the daily changes in old trunks.

\section{THICKNESS OF WOODY LAYERS AND LENGTH OF GROWING SEASON OF No. 1}

The general features of the varying thickness of layers of wood with respect to the distance from the base of the trunk are presented in the accompanying paper by Dr. Shreve. It will be profitable, however, to present the results derived from the dendrographic records of the two parts of the trunk of No. 1, a little over 1 meter from the base and 8 meters higher.

TABLE 3.-Annual increases in thickness and length of growingseason of Monterey pine No. 1.

\begin{tabular}{|c|c|c|c|c|}
\hline & \multicolumn{2}{|c|}{ Increases in diameter. } & \multicolumn{2}{c|}{ Length of season in days. } \\
\cline { 2 - 3 } Year. & A & B & A & B \\
& & & & \\
\hline & $m m$. & $m m$. & & \\
1919 & 8 & $\ldots \ldots \ldots$. & 153 & $\ldots \ldots \ldots$. \\
1920 & 10 & 11 & 184 & 175 \\
1921 & 26 & 19 & 264 & 257 \\
1922 & 19 & 13 & 221 & 182 \\
1923 & 8 & 8.3 & 236 & 236 \\
& & & & \\
\hline
\end{tabular}

A cessation of growth late in June 1920 being associated with a dry condition of the soil, the tree was copiously irrigated, as already described. The growing-season was thus lengthened and the amount of wood to be attributed to the renewed growth was about $4 \mathrm{~mm}$. in thickness, as confirmed by samples taken with the increment borer. 
The growing-season thus lengthened artificially and the longer growingseason of 1921 are fairly well correlated with the amounts of wood formed in each year. By a revised estimate, tree No. 1 was taken to be 36 years old at the close of the season of 1923. (This is in correction of erroneous statement made in "Growth in trees," Pub. 307, 1921, p. 22.) As has been previously pointed out, this tree has four easily identifiable secondary layers formed in late summer, accompanying heavy September rainfall, and one as a result of the irrigation given it in July 1920.

The measurements given by Dr. Shreve in a separate section of this paper show that at the age of this tree the zone of greatest accretion is generally in the upper half of the trunk, although several exceptions were noted.

The setting of the dendrograph was changed each year to measure a new diameter, and one which might be a few centimeters above or below that of the previous year.

It is to be noted further that in checking the totals calculated from the dendrographic record by cores secured by the increment borer, such samples are usually taken a few centimeters distant from the radii upon which the contacts of the instrument have been made, and more exact correspondence is not to be expected between the totals from the record and the measurements of the samples.

\section{SEASONAL ACTIVITY AND WOOD-FORMATION IN SEVERAL MONTEREY PINES.}

Monterey pine No. 6, on which measurements of the growth of 1920 had been previously described, was a tree still growing vigorously in the terminal shoot and at the close of 1922 had an age of 25 years (20 by an earlier estimate). This tree, with a growing-period of 158 days in 1920, had made an increase of $8 \mathrm{~mm}$. in diameter, and samples taken with an increment borer showed layers $3 \mathrm{~mm}$. in thickness. The growing-period in 1922 comprised 243 days, with an increase of $10 \mathrm{~mm}$. in diameter, which is identical with the readings of a sample taken near one of the points of contact.

The growing-season of 1922 was taken to be closed on August 25. Late in November, however, the slight impulses of enlargement, which are characteristic of the species in this region, were manifest, with repetitions in December, with a further total increase of 0.7 or $0.8 \mathrm{~mm}$. in thickness.

The growing-season of 1923 opened on January 19, and may be taken as terminating on September 1 . The total increase in diameter during the period of 225 days was $8 \mathrm{~mm}$.

Monterey pine No. 12 was a slowly growing tree which stood on a seaward slope facing southwest, 5 miles from the Coastal Laboratory. It had a height of 16 meters and a diameter of $22 \mathrm{~cm}$. at the place of attachment of the dendrograph. The growing-period for 1921 included only 57 days, in which an increase of $1.5 \mathrm{~mm}$. in diameter was made. In 1922 the growing-period was of nearly double length, being 101 days, in which an increase of less than $1 \mathrm{~mm}$. was made.

Monterey pine No. 13 was about 10 meters in height, $20 \mathrm{~cm}$. in diameter, and stood in the swampy portion of the garden, where the soil at all times had an adequate supply of moisture. It is to be noted that the length of 
the growing-season for this tree, however, was not as great as that of No. 6 , which stood on a dry slope. The layer of 1922 in a sample taken near the dendrograph had a thickness of about 8 or $9 \mathrm{~mm}$. The integration of the dendrographic record showed a gain of $13.6 \mathrm{~mm}$. in diameter, which would indicate a woody layer formed under the dendrographic bearings of lesser thickness than that found by the increment borer. This tree was irregular in form and stood in a leaning position. It forms the most notable example of a difference between the dendrographic record and direct measurement of cores taken from the trunk.

Three young trees standing in a group in the moist soil of the garden were selected for observation late in 1922 . All were under 18 years old, with a height 5 to 6 meters, and of diameters as indicated below. Nos. 16 and 18 were used as experimental subjects, as described in the following section of this paper, and No. 17 was used as a reference or control, its relations to the soil not being altered in any way, nor was any excision of branches practised. The trunk at a distance of $\mathbf{1 . 5}$ meters from the base had a diameter of $16 \mathrm{~cm}$. and showed layers in a sample taken by the increment borer at that height indicating an age of 16 years at the close of the season of 1923. Nearly all of the branches were still present, several large ones arising from the trunk below the dendrograph. Those of the upper part of the trunk were still leafy to the base. The trunk showed a thickening and flaking of the bark in the basal section below the dendrograph, but above this was still green and continuous.

A dendrograph was attached October 23, 1922, at which time some slight enlargement was in progress. Pauses between November 20 and 26, and December 4 and 26, were noted. Later the disturbance which affected many other trees caused this tree to stop growth between January 22 and February 7,1923 . The difference between the activity of this tree and that of No. 16 , which stood within 3 meters of it are to be noted.

The trunk of No. 17 made an accretion of about $1.3 \mathrm{~mm}$. during the October-November period of activity. An enlargement of $1 \mathrm{~mm}$. in diameter had taken place when growth was interrupted between January 22 and February 3 in all young trees. An actual shrinkage occurring during this time, which amounted to about $1 \mathrm{~mm}$., may be attributed to actual waterloss from the newly formed cells, and from cortical elements. A further growth or increase in the diameter of $19 \mathrm{~mm}$. had taken place by October 23, at which time enlargement was still in progress. It may be inferred that the contraction in the January-February pause was taken up by the subsequent distention of the cells affected, so that the net growth to October 23 may be taken as $20.5 \mathrm{~mm}$. This was in fair agreement with the measurements of layers in cores taken by the increment borer, although it was seen that some increase of the young bark would be included in the dendrographic record. The bark was still green and had not begun to form flakes, so that the bearings were taken from the outer surface. Here, as in No. 20, two or more layers of wood had been formed every year. It would appear that each serious interruption of growth would mark the limits of distinguishable layers of wood.

The record of Monterey pine No. 17, as given above, is to be taken as the first actual observation of growth in trees nearly continuous throughout 
the year. It is highly probable that the duration of activity described represents nearly the maximum duration of activity.

Monterey pine No. 20 stood on the level ground near a small glass house in a place where the soil-moisture was somewhat above that around trees Nos. 21 and 22, which were not far distant. The diameter of the trunk at a distance of $80 \mathrm{~cm}$. from the base was $9.5 \mathrm{~cm}$. at the close of the season of 1923 , while the height to the top of the leader of this season was about 6 meters. Nearly all of the branches were still present and all except those below the dendrograph still bore leaves clear to the base. Cores taken below the dendrograph showed that the age of the tree was about 12 years.

The instrument was put in place on October 25, 1922, at which time enlargement was in progress. Pauses were noted December 4 to 11 , and January 20 to 26,1923 , which was much shorter than that of No. 16 and No. 17, which were in a swampy situation 100 meters distant. Another pause was noted between March 30 and April 10, and between April 13 and 16, after which time enlargement was continuous and still in progress on the anniversary of the experiment. The total increase in the diameter of the trunk during the year was $19.5 \mathrm{~mm}$., and a state of active enlargement prevailed all of the year, except a total of 30 days.

The total accretion did not differ widely from measurements of the layers in cores taken with the increment borer. It is to be noted that the number of layers of wood as distinguished by the appearance of the wood was more than twice that of the actual number of years of existence, suggesting that the interruptions in growth, which have been noted above, would be denoted by differences which would give the appearance of additional annual layers. If the ages of the young trees were reckoned from the number of layers, a figure would be obtained which would be more than double that of the known age.

The interruptions to enlargement were not coincident with those affecting No. 17 and others. A pause, not directly referable to the weather, in December and one in April are noted, but neither of them might be taken as a seasonal limit. This tree would be coordinate with No. 17 in establishing a record for growth without seasonal limits.

Monterey pine No. 22 was a sparingly branched tree about 4.5 meters in height, with all of the lower branches cast off below a point 2 meters from the base. The diameter, 1 meter from the base at the place in which dendrographic bearings were made, was $9 \mathrm{~cm}$. at the close of the season of 1923 . An estimate made on the layers of wood in a core taken at the height of a meter showed that the tree was about 16 years old at the end of 1923. This tree was, therefore, older than No. 20, which stood within 75 meters and under conditions apparently similar, although long familiarity with the soil formation leads to the knowledge that its soil-water supply was less. Still other differences in the two trees became apparent when the dendrographic record for 1923 was integrated.

The instrument was attached on October 25,1922 . It was not possible to fix upon any week in which any definite or irreversible enlargement occurred, but an increase of about $0.5 \mathrm{~mm}$. in diameter had been made by the end of December. No increase whatever was discernible in the following 6 weeks, but an enlargement began on February 18 which may be taken as 
the beginning of the seasonal activity. Growth continued at varying rates until August 13, a total period of 176 days, which was shorter than that of the period of growth of Nos. 16, 17, and 20 by more than 100 days.

The total increase in diameter in this time was $7 \mathrm{~mm}$., which is in accordance with the measurements of the recently formed layer on cores taken by the increment borer. The trunk of this tree was seen to be much different from that of No. 20, notably in the fact that but one layer of wood is formed annually, while in No. 20 two or more may be formed in every year. Plans were therefore made to continue the record of both trees, to ascertain to what age this difference in activity would be held.

\section{EXPERIMENTAL INVESTIGATIONS. EFFECTS OF BREAKING THE CONDUCTING SYSTEM BY GIRDLING.}

Growth is, of course, closely connected with the translocation of material. Whatever may be the actuating forces which drive solutions from the roots upward and organic material downward through the stem, it is clear that this takes place chiefly in the layers of wood which have been formed within the last two or three years of the life of the tree. Recent contributions, particularly those of Dixon, lead us to ascribe a minor rôle to the bast or phloem in the movements of material. It has long been known, however, that the removal of the cortical and other cell-masses, including the bark, external to these layers caused serious interruptions in the translocation streams, although the wood was left unaltered except by the inevitable desiccation resulting from being laid bare. Some girdling experiments, with the effects on growth and the movements of material are described in the following paragraphs.

Monterey pine No. 14 stood on a north-facing slope near Nos. 6, 10, and 15. Its height was about the same as No. 6, being about 20 meters, and the trunk had a diameter of $20 \mathrm{~cm}$. at the place of attachment of the dendrograph. Its estimated age may be taken to be about 22 years at the close of the season of 1923 . The layer on a sample taken near the attachment of the dendrograph, formed in 1922, was not much over $2 \mathrm{~mm}$. in thickness, and the layers made in the two previous years were not more than double this amount. The integration of the dendrographic record showed an increase of slightly less than $5 \mathrm{~mm}$. in diameter during the time in which the observations were made, beginning April 3. Not much accretion could have been made before this date, however. Chief interest centers in the fact that a belt of bark, bast, and cambium $25 \mathrm{~cm}$. wide, with the lower edge $40 \mathrm{~cm}$. above the base, was removed on May 18, 1922. This girdling does not appear to have hastened the closure of the growing-period. The thickness of the layer of wood formed, however, was less than that in any previous year (fig. 1).

Growth began in 1923 on February 8, which was two weeks later than No. 6, standing near it and referred to as a control, but a week earlier than No. 10, the crown and most of the branches of which had been removed in the previous season as described below. Enlargement of the trunk continued until about March 1, and in the three weeks of activity an increase 
of $1.5 \mathrm{~mm}$. diameter was made. The daily equalizing variation, which had never been very marked, now almost disappeared, the pen tracing as nearly a straight line as ever occurs in such records. By mid-June the leaves showed a distinct yellow tone, which was most marked on the lower branches, and the tree appeared to be dying.

A final examination of the trunk on June 28 showed that the cambium was dead below the girdle and that the rays were practically emptied of starch. Above the girdle an average amount of starch was present in the dead and dying tissues for a distance of about a meter above the girdle; beyond this the rays were practically empty for a distance of 3 meters, which was examined and on which only short dead branches were borne. Just at this time a renewed enlargement of the trunk began (June 27), which continued with almost no daily variation until July 15 , when the record again became a direct line, with the daily equalizing variation not discernible. The total increase calculated from the record during this second period was about 1.2 $\mathrm{mm}$. It is notable that the daily variation is a function of living trees, even when measured on the inner part of the trunk, and that it disappears from dead trunks or from those which have been decapitated or defoliated.

The tree was felled by cutting the trunk near the base on July 25, 1923. The cambium was all dead except in a belt of callus above the girdle, which

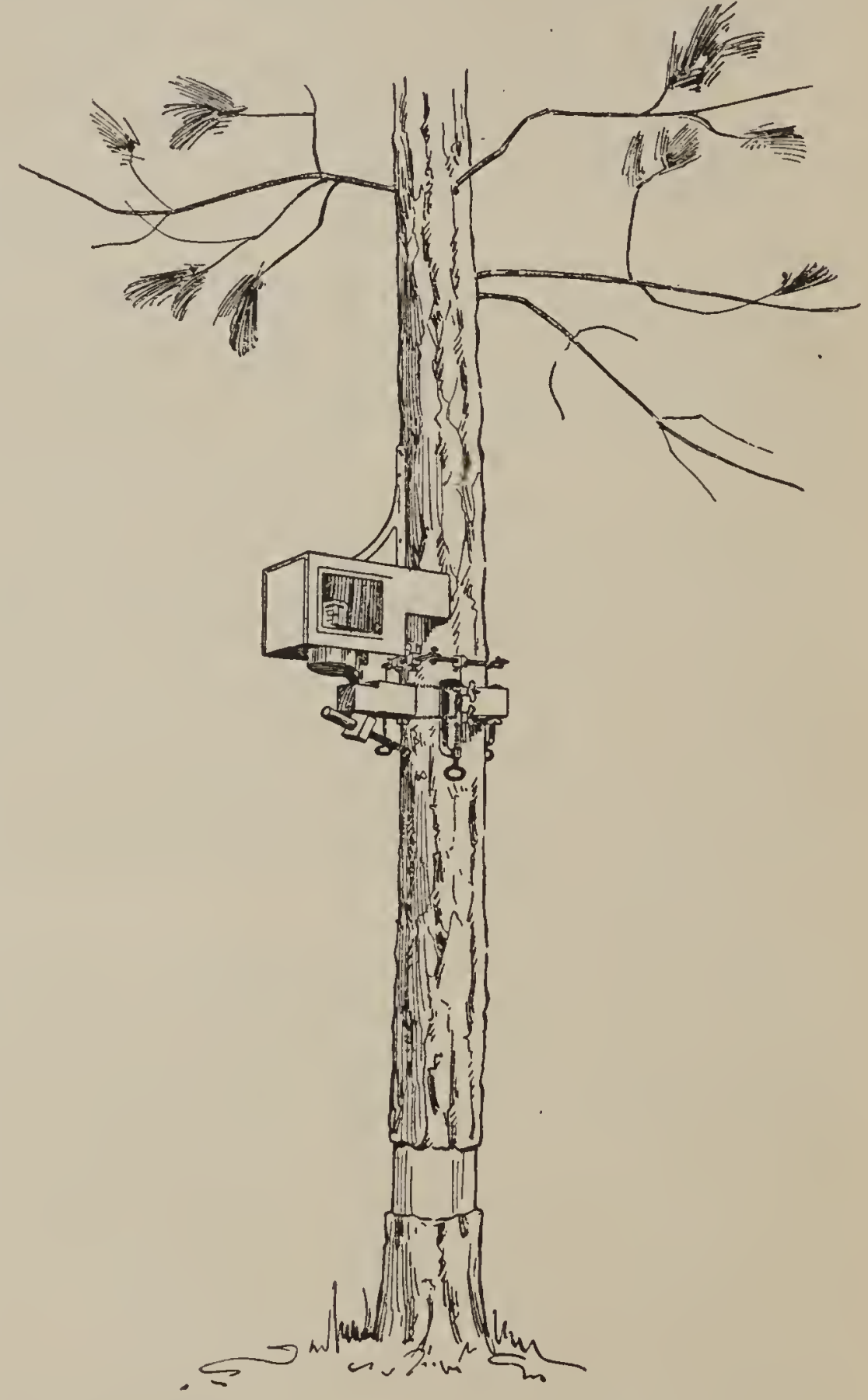

Fig. 1.-Monterey pine No. 14, girdled in May 1922. was only a few centimeters in width. This seemed to comprise all of the living cells in the tree, as the branches were brittle and dry and the rootsystem was completely dead. The trunk, however, was still high in watercontent. No starch was present below the girdle, and above the residues were sparsely and irregularly distributed in the medullary rays of the extreme outer layers. The boring beetle which inhabits this tree was abundant in the upper part of the trunk.

The tree was. cut into short sections and an examination of the layers of wood made by Dr. Shreve. The thickness of the layer of 1923 at different distances from the base were determined as follows: 
TABLE 4.

\begin{tabular}{|c|c||c|c|c|c|}
\hline $\begin{array}{c}\text { Distance } \\
\text { from base. }\end{array}$ & $\begin{array}{c}\text { Thickness } \\
\text { of layer } \\
\text { formed in } \\
1923 .\end{array}$ & $\begin{array}{c}\text { Distance } \\
\text { from base. }\end{array}$ & $\begin{array}{c}\text { Thickness } \\
\text { of layer } \\
\text { formed in } \\
1923 .\end{array}$ & $\begin{array}{c}\text { Thickness } \\
\text { Distance } \\
\text { from base. } \\
\text { formed in } \\
1923 .\end{array}$ \\
\hline meters. & $m m$. & meters. & $m m$. & meters. & $m$. \\
17 & 0.8 & 10 & 1.2 & 3 & 1.0 \\
16 & 0.7 & 9 & 1.3 & 1 & 0.8 \\
15 & 0.9 & 8 & 1.1 & 0.8 & 1.0 \\
14 & 1.0 & 7 & 1.5 & 0.3 girdle; nowood below. \\
13 & 1.0 & 6 & 0.9 & & \\
11 & 1.7 & 5 & 1.0 & & \\
\hline
\end{tabular}

As may be seen, the greatest amount of wood was formed in the zone immediately above the girdle and under the dendrograph in which part the greatest accumulation and residue of starch was also found.

The second experiment in girdling was made on a tree which was topped later in the season. A small tree, No. 16 of the trio which stood in the moist soil of the garden and which was very similar to No. 17, showed a diameter of over $15 \mathrm{~cm}$. at 1.5 meters above the base, near the point at which the dendrograph was attached. The tree retained nearly all of its branches, the lowermost touching the ground, and nearly all were leafy to the base. A half dozen of the largest arose from the trunk below the dendrograph, and the trunk in this part was beginning to show splitting and flaking of the bark. The dendrograph was attached on October 23, 1922, at which time the tree was in a growing condition. The dendrograph slip was not perfectly adjusted every week, but it was evident that the tree made some increase every week and that no actual cessations of enlargement could be noted, except between December 8 and 14, 1922, January 20 and 27, 1923, and January 29 and February 7, 1923. In addition to these disturbances, which may be assigned to low temperatures accompanying storms, the bark and phloem were removed in a zone $25 \mathrm{~cm}$. in width at a distance of 0.5 meter above the dendrograph and above a very vigorous whorl of large branches, on March 8, with the result that both growth and the daily variation were reduced to a minimum for 10 days. The tree was, therefore, in a condition of measurable growth for all of the year, except 35 days. Three pauses due to the influence of storms are noted and one to the effects of girdling. It is to be seen that the tree had made an increase of $18 \mathrm{~mm}$. in diameter, which is to be compared with that of No. 17 in the same period.

A zone of bark cambium and cortex $15 \mathrm{~cm}$. wide, the lower margin of which was $40 \mathrm{~cm}$. above the instrument, was removed on March 8. Growth ceased within 24 hours, and the daily variation which had caused the pen to move up and down 2 or $3 \mathrm{~mm}$. on the chart diminished so that the record was now a direct line. This inactivity continued until March 19, when some variation was noticeable, and actual enlargement began on the 23rd, and the growth which followed made a dendrographic record in which no unusual features were discernible. 
A second modification was now made. The main stem was cut off 1.5 meters above the dendrograph on May 22. The top removed was about 5 meters long and weighed $50 \mathrm{~kg}$., and was estimated to carry about half the leaves. The part of the tree remaining was 3 meters in height, and had been girdled a meter above the dendrograph as noted above. This length bore several large branches. Growth was not noticeably affected by the topping, and the increase which took place afterward and up to the middle of September amounted to $13.5 \mathrm{~mm}$. increase in the diameter. It is to be seen that this tree had made an increase in diameter of $18 \mathrm{~mm}$. in the same period in which No. 17 had made an increase of $20.5 \mathrm{~mm}$. Girdling and topping had apparently had no direct effect, except the stoppage of growth for a few days as described. Other experiments in topping are described elsewhere.

The cores taken by the increment borer show three layers in the 8 to 9 $\mathrm{mm}$. thickness of wood which may have been formed in the period under discussion. The outermost was not over $2 \mathrm{~mm}$. thick. The bark of this tree was green under the dendrographic bearings, which were made on its outer surface, and some thickening may have taken place which would be included in the record. This outermost layer and some bark may have been formed after the girdling, which was done in March.

An examination of a core taken from the girdled zone showed that a callus had been formed on its surface, which probably accounts for the resumption of growth. Beneath this were two layers each about $2 \mathrm{~mm}$. in thickness. The outermost was taken to represent the wood formed from about the time of the beginning of the observations and the girdling in March, as the total increase in diameter during that period had been $4 \mathrm{~mm}$. What causes delimited a period in which the layer underneath was formed can not be conjectured. This layer, however, is present in other parts of the trunk.

It is evident that in this tree, as well as in other young trees of the species, the formation of two or three layers of wood each year is a common phenomenon. These layers might be mistaken for annual layers when cut from the core of an older tree. Indeed, their appearance in the younger tree does not differentiate them. The age of the young trees being known by direct observation, and the yearly accretion determined dendrographically, the case is quite clear. The causes which are responsible for this multiplication of layers in this tree may be operative in tropical trees, in which also the conditions for growth are favorable during almost the entire year.

The effects of basal girdling were tested upon a tree still smaller, Monterey pine No. 21. This tree had a thickness of 6 to $7 \mathrm{~cm}$. at the base, being somewhat irregularly cylindrical. Its height was about 6 meters and its age about 15 or 16 years. Some of the lowermost branches had been lost, but most of the upper ones were still leafy to the base. It was enmeshed with the branches of a small tree of Quercus agrifolia, which afforded it mechanical support, and also cut its illumination somewhat.

The dendrograph was attached October 28, 1922, and it was soon seen that a slow enlargement was in progress. This ceased on December 11 , and was not resumed until December 25, which latter date may be taken as the 
beginning of the season of 1923. This late autumnal growth had resulted in an accretion of about $1.5 \mathrm{~mm}$. in diameter. An additional $2 \mathrm{~mm}$. laid on before the pause due to low temperature came as an effect of the storm late in January. This was not quite as marked as in the other young trees, as cessation of growth did not take place until January 29, and began again on February 6. A further increase of $7 \mathrm{~mm}$. in the diameter had occurred when the base of the stem was killed on June 22. The layer of wood of the implied thickness was recognizable in a core taken by the increment borer. It was seen that more than one layer had been formed every year, but the limits of these were not so definitely marked as in Nos. 16, 17, 18, and 20. Enlargement continued until July 12, in which an additional $0.8 \mathrm{~mm}$. was added to the woody layer.

Killing of a basal section was accomplished as follows: A sheet of thin lead was cut to form a truncated cone when placed around the tree. A length of adhesive tape, such as is used for making insulation in electrical wiring, was wound around the stem at a distance of $20 \mathrm{~cm}$. from the base to afford a bottom and a support to the cone. The margins of the sheet lead having been fitted with holes that registered, the sheet was curved around the tree, and the edges brought tightly together by means of small bolts and two strips of iron, one on the inner and one on the outer side of the junction. The small end of the inclosing lead cone was wired tightly against the belt of tape and some Canada balsam, made thin with cedar oil, was poured in to secure the seal.

Two liters of olive oil were now heated to $110^{\circ} \mathrm{C}$. and poured into the cone, immersing a length of $20 \mathrm{~cm}$. of the stem. A small immersion electric heater was thrust into the oil, and while an effort was made to keep the entire mass of oil at a uniform temperature by stirring, yet that at the lower small end of the cone remained below $100^{\circ}$, while the upper half was successfully maintained at $100^{\circ} \mathrm{C}$. or over for $2 \frac{1}{2}$ hours, beginning at $1^{\mathrm{h}} 30^{\mathrm{m}}$ p.m. on June 22, 1923.

The temperature of the stem $16 \mathrm{~cm}$. above the surface of the oil was $48^{\circ} \mathrm{C}$. at 4 p.m., and $24^{\circ} \mathrm{C}$. at $45 \mathrm{~cm}$. above. At $5 \mathrm{p} . \mathrm{m}$. the temperature at the lower position had fallen to $40^{\circ} \mathrm{C}$., that at the upper to $24^{\circ} \mathrm{C}$, while the reading of the thermometer at the same level as the dendrograph was $16^{\circ} \mathrm{C}$. It may be inferred that the temperature of the cambium layer under the dendrographic bearings was not raised more than $5^{\circ}$ by the use of the boiling oil on the zone lower down. Such a slight rise probably accelerated growth temporarily. That the entire cross-section of the stem was killed in the treated zone may be safely inferred from the results of similar treatment of tree No. 24, described below.

When growth ceased on July 12 a period of five days followed in which the daily equalizing variations showed unchanged dimensions; then a contraction began, accompanied by a diminution of the daily variations. The diameter decreased $2 \mathrm{~mm}$. in a week. The soil about the roots was now irrigated copiously on three successive days, but no increase in diameter resulted. This implied that water was entering the root-system in increased quantity and the root-system was undamaged, but that the amount passing the treated zone was not increased. The condition of this part of the trunk may be inferred from the results of a similar treatment of another tree (No. 24) of similar size. 
An examination of the effects of the treatment of the stem with boiling oil was made on Monterey pine No. 24. This tree was in a condition of vigorous growth and was comparable in every way with No. 21, the stem being $6 \mathrm{~cm}$. in thickness. A fitting of a truncated and inverted cone of sheet lead was made around the base, duplicating the arrangement described for No. 21, on July 7 , 1923. This was filled with boiling corn oil and olive oil from $1^{\mathrm{h}} 30^{\mathrm{m}}$ p.m. until 4 p.m. During this time the temperature of the oil was kept between $100^{\circ}$ and $110^{\circ} \mathrm{C}$. by means of an immersion electrical heater; 48 hours later the tree was cut down and a section, including the treated zone, examined. The outer corky bark remained intact, the chlorophyll was destroyed in a zone $23 \mathrm{~cm}$. wide, and a zone of dead cambium 22 to $23 \mathrm{~cm}$. wide was found beneath. The cortex was, of course, destroyed, as well as the rays. Starch, as is usual with these trees, was found almost wholly in the rays of the layer of wood formed in the previous year in addition to the current formation. Its presence was noted when the cells were treated with an iodine solution which accentuated the clumped condition of the protoplasm.

No alteration by heat could be detected in the wood-cells by direct observation with low magnification. When the killed section was split lengthwise it was noted that the wood was less moist to the touch than that immediately above and below the treated zone. A cross-section in the form of a disk was made $20 \mathrm{~cm}$. below the treated zone, another an equal distance above, and one was taken from the middle of the treated zone and placed in an oven at $70^{\circ}$ to $80^{\circ} \mathrm{C}$. for 48 hours. After drying for 48 hours the sections were weighed to ascertain the loss in weight. The trunk below the girdle had evidently lost none of its water as a result of the application of the boiling oil, as two samples in this region showed a water content which was driven off in the drying of 59 and 61 per cent. The outer wood of the upper portion of the treated area had lost much of its water by the treatment, as its weight was reduced by only 31 per cent in the oven. A sample at the extreme upper margin had a water content of but 25 per cent. It was evident that water did not pass freely through the zone killed by the heated oil.

The contraction of the stem of No. 21 recorded by the dendrograph may have been due to the death of the cambium layer under the bearings, or to the loss of water from the stem, in which the column may have been broken by the heated oil. In order to ascertain the effects of an increased supply to the shoot, five of the six branches which were borne on the young trunk on the part between the dendrograph and the treated section below were cut off and the stumps immersed in flasks of water on July 30 at 10 a.m. The lowermost, which arose a few centimeters above the treated zone, was dipped in a flask of Fuchsin S, 1 part in 1,000. The course of the dye in this branch was traced, with the idea that it would be similar to that of the stream of water taken up by the other branches.

At 1 p.m. 100 c. c. of water was necessary to replace the liquid which had been taken from the flasks of water and dye by the branches which dipped into them. Nineteen hours later, at 8 a.m. on July 31,325 c. c. of water was necessary to replace the amounts withdrawn from the flasks, including the one containing Fuchsin. A slight upward movement of the pen was 
discernible. The morning was foggy, and the day continued to be so, with the result that the total absorption on the following morning was but 225 c. c., and that day being overcast, the total on the next morning was but 175 c. c. August 2 being clear and warm, the absorption on the morning of the $3 \mathrm{~d}$ amounted to $325 \mathrm{c}$. c. for the previous 24 hours. The absorption in the 27 hours ending at noon on the 4 th was 250 c. c., a portion of this period being foggy.

The absorption in the $21 \frac{1}{2}$ hours ending $9^{\mathrm{h}} 30^{\mathrm{m}}$ on the 5 th was 200 c. c., the afternoon of the 4th being warm and clear, although it was overcast on the forenoon of this day.

Absorption for the $23 \frac{1}{2}$ hours ending at 9 a.m. on the 6 th was 200 c. c., the day being overcast and the morning cool.

Absorption for the 24 hours ending at 9 a.m. on the 7 th was 200 c. c., it being clear in the afternoon of the preceding day, but cloudy in this forenoon.

Absorption for the day ending at 9 a.m. on the 8 th was but 190 c. c.; foggy and overcast.

Absorption in the 24 hours ending at 9 a.m. on the 9 th was 200 c. c. A small branch, the daily absorption of which was on the average 25 c. c., was refitted to a water-system suitable for applying pressure, after the end had been freshly cut. At the beginning the water column applied to the end of the branch had a pressure of about $1.4 \mathrm{~cm}$. of water.

The total absorption at 9 a.m. on the morning of the 10 th was 190 c. c., of which but 17 c. c. had gone in through the branch fitted with the pressure apparatus. The vertical extension-tube of this apparatus was now filled with mercury, so that a pressure of 1.7 meters of mercury was exerted on the end of the branch. The day had been overcast and was damp, with no sun on this morning.

Total absorption of the five branches dipped in open flasks was 175 c. c., while that of the branch with pressure applied was about 50 c. c., or double its usual amount, bringing the total absorption by the tree up to $225 \mathrm{c}$. c., as measured on August 11 .

Total absorption of the five free branches was 160 c. c.; that of the one under pressure was 47 in the 24 hours ending August 12 at 9 a.m., the sky being foggy and overcast.

The above rate of absorption of water continued until August 16, at which time it was apparent that the trunk had regained about one-fourth of the loss by contraction following the cessation of growth. The amount of water taken in daily now showed a decrease day by day, so that but 160 c. c. was taken in during the first 15 days of September. The tree was taken down October 1, at which time a further intake of 120 c. c. had occurred. The total amount which had been taken through the ends of the branches was not as much as 5 liters, which, of course, was much less than the actual transpiration of the tree during the two months in which the ends had been dipped in water.

The tree showed a progressive dying and desiccation of the leaves from the lowermost branches upward, so that at the end of September green leaves were seen on the branches of the upper half of the tree and only at the ends of the branches, denoting that it was only leaves formed during 
the present year which were still alive. The tree was now taken down for examination and dissection. The young trunk was dry to the touch in the vicinity of the killed region, but the percentage of moisture appeared to increase toward the top and also below the treated part. The leaves were of a yellowish tinge and it was obvious that the whole tree was approaching death.

The three cases of girdling described above represent the effects of three different sets of experimental conditions. The removal of the bark and phloem from a basal section of the Monterey pine is a type of classical operation which has been practised by many workers and a wide variety of results have been secured. Girdling in this manner is used to deaden trees preliminary to burning in the clearing of forest lands. This treatment presumably does very little direct damage to the rays and the wood-cells. If cells capable of division remain, a callus may be formed and the tree may resume growth. This usually takes place in many young trees, and in some species at any age.

A second feature which may affect the result of the girdling is the presence of vessels and elongated conduits in the stem, along which liquids might move with speed. Such conduits are lacking in the pine, in which, however, the perforations in the membranes of the bordered pits offer a passage for minute particles as described by Bailey. ${ }^{1}$

Girdling in the above manner is followed by results in this tree which are in fair agreement with those recently described by O. F. Curtis, who experimented with Prunus, Cornus, Pyms, Acer, Syringa, and Ligustrum. The increase of carbohydrates in the zone above the girdle and in the weight or thickness of the bark found by Curtis is in agreement with the starch above the girdle and continued growth in that zone. Curtis finds lessened transpiration in girdled trees. ${ }^{2}$

The death and desiccation of the basal part of the tree and death setting in at the tip of the shoot is a distinctive feature in the Monterey pine. Girdling higher up in a young tree checked growth below for a short time, but it was renewed with the formation of a callus over the girdle.

The severer treatment, by which the entire stem was subjected to a high temperature which would kill all cells and alter the condition of the walls, though not visible, resulted in the speedy cessation of growth above the girdle and a gradual desiccation and death of leaves from below upward. Branches above the girdle soon lost capacity for taking in water through their cut ends. Killing and girdling may disrupt or disturb the passage of water upward, and the diffusion of electrolytes principally in the same direction and the movements of organic material with large molecular particles in both directions. That any phase of such transfers takes place exclusively through the phloem is by no means clear. That the phloem can not be destroyed or removed without some disturbance is equally clear. It is also true that in addition to the electrolytes, carbohydrates and proteins are found in the woody tracts. The tests with Fuchsin, described in another

\footnotetext{
1I. W. Bailey. The structure of the bordered pits of conifers and its bearing upon the tension hypothesis of the ascent of sap in plants. Botan. Gazette, 62, 133-142. 1916.

${ }^{2} \mathrm{O}$. F. Curtis, The effect of ringing a stem on the upward transfer of nitrogen and ash constituents. Amer. Jour. Bot., 10, 361. 1923.
} 
section of this paper, show that colloidal material with large colloidal particles may move freely through wood in either direction, but that this movement is much greater in some parts of the recently formed layers than in others. That such differentiation is identical in different trees is not probable. ${ }^{1}$ It is suggested that the difference in the conducting capacity of the separate layers of wood may rest upon the condition of the membranes of the bordered pits and upon the size of the perforations. Both might be altered by the treatments described above. Direct measurement of the perforations in the Monterey pine and of changes which may be produced by experimental methods will be necessary for any further progress in the solution of this problem. It is to be seen that the ascent of sap and the movement of material in dicotyledonous stems with vessels of relatively large caliber, and in conifers where the free passages are minute perforations in thin elastic membranes, deals with a wide range of surface tensions.

\section{REDUCTION OF TOTAL CAPACITY OF GREEN LEAVES BY TOPPING.}

One experiment has already been described by which a part of the stem and the upper branches were removed without immediate effect on the growth. This was in a tree in which the branches were numerous and densely leaved. Such an operation, of course, lessens the transpiring surface and also photosynthetic capacity of the tree. One experiment was carried out in which the branches and leaf surfaces were removed entirely, and as but little water would be evaporated from the cut surface of the trunk or through the bark, the movement of material upward must have been stopped, while the supply of soluble material which could move downward was, of course, cut off.

The trunk of Monterey pine No. 15 was cut away at a height of 2.2 meters from the base on May 18, 1922. The trunk had a diameter of 12 $\mathrm{cm}$. and was about 20 years old, being referable to No. 6 as a control. A dendrograph had been put in place a few days previously, its contacts being about $50 \mathrm{~cm}$. below the cut, and the trunk was found to be in a state of vigorous enlargement. No branches remained on the trunk after the operation (see fig. 2). Enlargement continued for 19 days, during which time an increase of $0.6 \mathrm{~mm}$. in diameter was made. The core made by an increment borer showed that the total addition to the wood during the season varied between 2 and $3 \mathrm{~mm}$. in different places.

An examination at the end of the season, in October, showed that the wood was light in weight, but an abundance of starch and other material was still to be seen in the rays and thin-walled cells. Some shrinkage followed the cessation of growth. The bast and cambium were found to be dead in a length of $6 \mathrm{~cm}$. in the terminal portion of the stem on July 28, over 2 months after decapitation.

The presence of the food-material suggests that inactivity and death was not due directly to the lack of building material. The decapitation would cut off the supply of products of the activities of leaves and these may have

${ }^{1}$ I. W. Bailey. The structure of the bordered pits of conifers and its bearing upon the tension hypothesis of the ascent of sap in plants. Botan. Gazette, 62, 133.1916. 
included substances which activated the enzymes. Their absence made the starch present unavailable to the growing cells. The upward movement of material from the roots would, of course, be stopped, but the failure of the supply of some unknown substance formed in the leaves and translocated directly down the stem would be a theoretical explanation of the stoppage of growth.

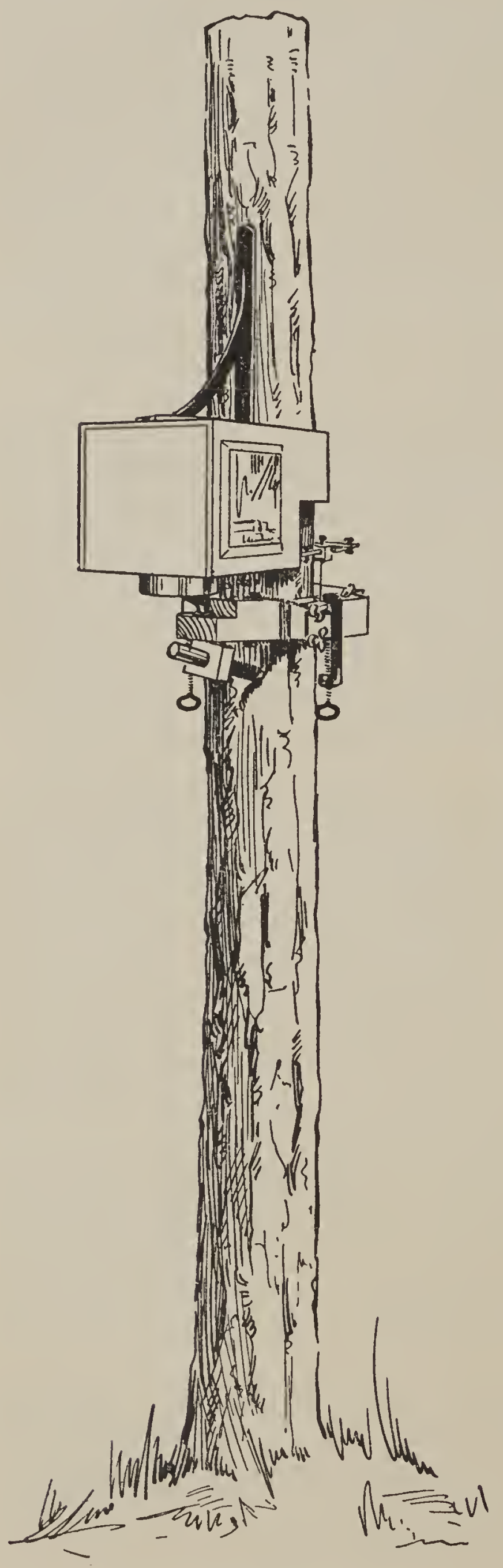

FIG. 2.
Fig. 2.-Monterey pine No. 15, the trunk of which was cut 2 meters above base in May 1922.

FIG. 3.-Monterey pine No. 10, the trunk of which was cut a few meters from base and above some small branches.

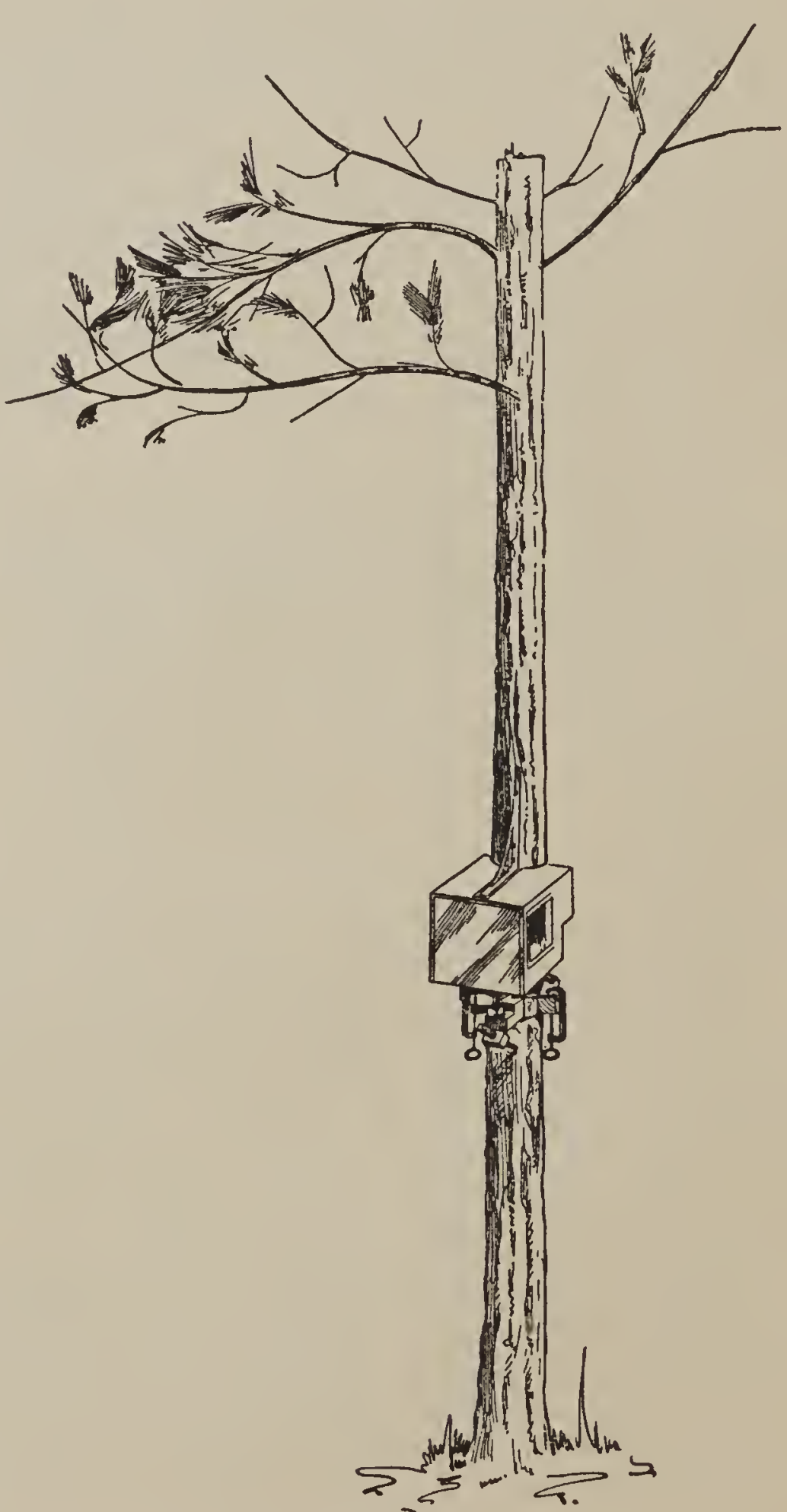

FIG. 3 
The behavior of such trees as Sequoia and other kinds in which the removal of all or part of the trunk causes buds to start on the roots or the stump must be taken to indicate the presence of such an activating or unlocking substance in all parts of the plant at all times. That the activity of the full crown of the tree may be necessary to furnish a supply of this material in the Monterey pine is suggested by the behavior of the trees when nearly all of the branches and leaves are removed, as was done with Monterey pine No. 10.

The trunk of this tree was cut squarely across at a point 3 meters from the base on May 15, 1922. The trunk was $13 \mathrm{~cm}$. in diameter at the point at which the dendrograph was attached in 1922. The tree stood on a northfacing slope, with a scanty soil-moisture supply, and appeared to form but one layer of wood annually. The estimate of age based on the count of the layers in a core taken by the increment borer made the tree to be 25 years old at the end of 1923 .

Growth was measured continuously from February 28, 1921. The layer of wood formed in 1921 was 3 to $4 \mathrm{~mm}$. in thickness in samples taken by the increment borer, and the dendrographic record for that year at a point 1.25 meters above the base showed an increase of $7 \mathrm{~mm}$. with a growing period of 138 days.

This tree stood on a north-facing slope and is referable to No. 6 as a control, being under much the same conditions as No. 14 also.

Enlargement began on February 15 in 1922, as compared with a beginning date of May 4 in the previous year. It was, therefore, well in the middle of a vigorous growing-season when it was decapitated on May 15, 1922. The trunk was cut squarely across at a point about 3 meters from the base. Five small branches, with an average length of a meter, arose from the terminal $30 \mathrm{~cm}$. of the stump. Below this was a larger and heavier branch, and below this a smaller branch, all within $70 \mathrm{~cm}$. of the end of the stump. (Fig. 3.)

The daily contraction did not take place on the day following the removal of the top, and this feature of behavior was not noticeable to any degree until 2 months later, some fluctuation showing again in the records early in August. Enlargement at a diminishing rate showed during the following 18 days, when it ceased. The total accretion for the season, which lasted for a period of 108 days, amounted to $5 \mathrm{~mm}$., of which $0.5 \mathrm{~mm}$. was after topping. The cambial layer remained alive to within $1 \mathrm{~mm}$. of the cut surface, according to the results of an examination made in mid-July. Four of the five smaller branches near the stump died in 1922, but three remained alive and carried green leaves in the following year.

Growth began on February 10, 1923, coincidentally with that of the control. The increase was exceedingly slow and uncertain, with but very slight daily fluctuations. The enlargement became definite about midJune, at which time a total increase in diameter of about $0.5 \mathrm{~mm}$. had taken place. Growth continued for a short time only, no enlargement being visible after June 30. The total increase in diameter for the season amounted to about $0.8 \mathrm{~mm}$., and activity was seen to extend over a period of 140 days. The record in the latter part of the season was characterized by an almost entire absence of the daily fluctuating variation in diameter 
of the trunk, which is a marked feature of this species. This may be coupled directly with the reduction of the transpiring surface to a fraction of its original area.

The three larger and lower branches were alive at the end of September 1923. These were vigorous and were showing some upward curvature at the tips as would take place in any tree from which the top of the main stem had been removed. The soil-moisture content at this time was probably near the limit of availability, being very low.

Another experiment in the removal of part of the trunk and foliage of the tree was made with Monterey pine No. 18, which was in moist soil with Nos. 16 and 18. The results of girdling, and of removal of the upper part of the top of No. 16, have already been described.

No. 18 was about 17 years old and the bark had not yet begun to flake, being green under the dendrograph. Like Nos. 16 and 18, more than one layer of wood was formed every year. The trunk at the point of measurement had a diameter of $10 \mathrm{~cm}$. at the end of 1923 . The instrument was put in place October 23, 1922. Enlargement during the next few weeks was indefinite and ceased entirely between December 14 and 27. Growth was interrupted between January 25 and February 15, due to low temperatures accompanying a storm. A total increase of $1.7 \mathrm{~mm}$. had taken place by March 8, at which time the trunk was cut off $50 \mathrm{~cm}$. above the dendrograph and 2.2 meters from the base. Four vigorous branches over 1 meter long remained above the instrument, and three below, in addition to some smaller and more slender ones which soon perished. Enlargement ceased within 24 hours after the operation, and the daily variations decreased to nearly zero. The record was now a direct line, nearly horizontal, with some slight daily equalizing variation discernible in April, which became marked with the advance of the season. No further enlargement of the trunk took place during the season.

The chief feature of interest consisted in the development of adventitious buds at various places on the trunk, the elongation being greatest in those which were on the terminal part of the stump. The results in this tree were not essentially different from those obtained from No. 10. Despite the more abundant water-supply and the greater volume of leaves remaining on this tree, the layer of wood formed in the first year after topping was less than in No. 10. The trunk was cut much nearer to the base than in No. 10, however.

\section{EFFECTS OF DEFOLIATION.}

Topping, or the removal of any part of the shoot of a tree, not only lessens the transpiring surface, but removes accumulated food material and excitatory substances which might be in transit to growing regions in the trunk below. Defoliation, if properly carried, would lessen transpirational capacity and stop the formation of excitatory substances as well as constructive material. The removal of leaves from trees at various seasons was carried to obtain analytical information on this point. A small tree, No. 19,4 meters in height, $5.5 \mathrm{~cm}$. in diameter at the base, and about 10 years old, standing on a north-facing slope, was selected for the first test. A dendrograph was fitted to the stem near the base on October 23, 1922. Several impulses of enlargement occurred in October and November, but. 
none in December. Growth for the season, however, began on January 3, 1923, being interrupted the last week in January and the first week in February, as were a number of other trees already described. A total increase in diameter of $5.3 \mathrm{~mm}$. had taken place by March 8, the date on which defoliation was brought about.

All of the leaves formed previous to this season were plucked out by being pulled directly in their axis, in such manner as not to strip the stems in any degree, the scar being quickly sealed with resin. Some of the leaves were removed on the afternoon of the $7 \mathrm{th}$, and the customary contraction did not take place on the morning of the next day. Defoliation was completed in the afternoon and no further enlargement took place after its completion. The record was now a direct unbroken line with only very slight variations daily. A slight enlargement occurred in the week following March 26, but the total increase was very small.

Observations on the condition of the tree on May 18 showed that the terminals of the main stem and of one of the branches had undergone some elongation, but as no measurements had been made, the amount could not be determined. The leaves, which had attained a length of 3 to $4 \mathrm{~cm}$. on the terminals of the branches, stood out more nearly at right angles to the stems than in normal plants. Measurements on June 4 showed that the maximum length of the newly formed stems was $20 \mathrm{~cm}$., with most of them not more than half this length. The maximum length of the young leaves at this time was $5 \mathrm{~cm}$., and the "bottle brush" appearance of the young shoots was very striking.

Equalizing variations had been abolished by defoliation, but were again apparent during the last week in May, and were clear and decisive by June 14.

About this time some slight increase began, but at such a low rate that by the end of September the total was not more than $0.5 \mathrm{~mm}$. The daily fluctuating variations showed a very gentle reversal by which the stem changed but little in volume between 6 and 8 a.m., then contracted slowly until about 4 p.m., when, after a second period of no change, a swelling began.

The leaves had taken on a position more nearly normal by the end of September, with an average length of 7 to $9 \mathrm{~cm}$. The total area of leafsurface at this time was probably about one-third that of the tree in its normal condition with all of the leaves of previous seasons. The actual photosynthetic capacity of the foliage had probably been less than a fourth of the normal. Furthermore, the leaf-products made available to the tree were those of young and growing leaves. It is probable that these did not furnish to the growing regions in the stems construction material and excitatory substances of the same kind or identical proportions, as mature leaves might have done.

The effect of defoliation at a later stage of the season was tested with Monterey pine No. 23, which was about 12 years old. This stood near No. 19, on a north-facing slope, and was about 7 meters in height and $6 \mathrm{~cm}$. thick at the base of the stem. It was characterized by a leader of 1922 over a meter in length, and had made an extension during the present season of $60 \mathrm{~cm}$., with a whorl of 7 branches 40 to $50 \mathrm{~cm}$. in length. 
Some of the secondary branches showed no growth during the present season. A dendrograph was attached on May 28, 1923, and the stem was found to be in a state of rapid enlargement. The tree had probably followed a course similar to that of Nos. 17 and 19.

Defoliation was carried between 3 and 4 p.m. on June 4. Leaves of a total weight of $2.27 \mathrm{~kg}$. were removed, and as the average weight of 90 leaves was 1 gram, it was estimated that the total number removed was about 244,000 . Here, as in No. 19, the leaves on the newly formed shoots were left untouched. The larger branches above the middle of the stem had made elongations of as much as $40 \mathrm{~mm}$. and the young leaves borne on them were as long as $10 \mathrm{~cm}$.

The behavior of this tree was in vivid contrast with that of No. 19, which had been defoliated 3 months earlier. In this case, enlargement of the trunk and the daily fluctuations continued in a manner not noticeably different from that characterizing the action of the tree before the leaves were removed. The weight of the leaves removed was estimated to be greater than from No. 19, and the young leaves remaining had nearly double the length of those on No. 19. Furthermore, the removal of the leaves was not accompanied by the exudation of resin to an amount which was seen in No. 19.

The defoliation had deprived the tree of a large part of its transpiring surfaces, and it was now proposed to replace this to whatever extent might be possible by connecting an exhaust pump to the main stem of the plant. A staging had been constructed which provided a small platform on a level with the median part of the terminal shoot internode of 1922. A Nelson oil-vacuum pump had been mounted on this platform and belted to an electric motor of 0.25 h.p. A line of pressure tubing of $5 \mathrm{~mm}$. caliber was connected with a short section with large diameter, the end of which was fitted with an encircling clamp, to be tightened with a screw. The line was interrupted in the middle by $\mathrm{T}$-tube connecting with a perpendicularly supported mercurial barometer tube open at the upper end. A slight rain had come on the 14th and had begun again on the evening of the 15th, continuing overnight, so that on the forenoon on this day the customary daily contraction of the stem did not occur, thus furnishing the ideal conditions for the first test to be made. The apparatus being in readiness, the stem was cut in the middle of the internode, where the diameter, including the bark, was $25 \mathrm{~mm}$., first with a saw directly across, then the cut was made oblique by slicing away the wood with a sharp knife until about twice the circular cut surface was exposed. A layer of Canada balsam liquefied in cedar oil was applied to the bark immediately below the cut, the open end of the heavy tube was worked into place over the end of the stem until it was covered for a length sufficient to make a good seal, then the circular clamp was tightened. The pump being started at $9^{\mathrm{h}} 30^{\mathrm{m}}$ a.m., the mercury rose in the pressure-gage to $740 \mathrm{~mm}$. within a few minutes. The customary contraction of the stem began when the sky cleared after $11^{\mathrm{h}} 30^{\mathrm{m}}$ a.m., and was checked when over-clouding came on at 2 p.m. The pump was now stopped at $2^{\mathrm{h}} 30^{\mathrm{m}}$ p.m. No direct effect of the suction on the end of the stem could be detected. The pump was again put into action from 11 to 2 p.m. on the $22 \mathrm{~d}$ and again maintained a column of mercury of $745 \mathrm{~mm}$., 
appearing to accentuate the contraction of the stem as denoted by the dendrographic record.

A test was now made as to action of the pump on the stem. The connections being allowed to remain intact, the stem was cut off below the end in such a way that a length $20 \mathrm{~cm}$. long was allowed to remain connected with the pump. This was immediately dipped in a cylinder of water and the pump started at $3^{\mathrm{h}} 10^{\mathrm{m}}$ p.m. After a half-hour, 29 c. c. of water was necessary to replace the amount taken up in this manner and appearing in the exhaust tubes. It is to be seen, therefore, that the pump pulled water through this short section of stem at a rate about 10 times that which would result from the action of the top, which had been removed. It is not probable that the tree under any circumstances would transpire water through the foliage on the separated top at a rate more than double that noted above. Thus, the top might remove as much as 300 c. c. from stem in a day, while the pump pulled water through it at a rate which would conduct nearly 1,400 c. c. in a day.

The top cut from the tree as above was found to take from 100 to 150 c. c. of water daily from a cylinder. This went on for five days, when the rate fell off and the absorption was much less.

The pump connected with the top of the stem of the tree was run again from 9 a.m. to $2^{\mathrm{h}} 30^{\mathrm{m}}$ p.m. on the $26 \mathrm{th}$. A second operation of equal length was made on the 27 th. No effort was spared in the attempt to detect any possible effect of the suction on the stem on growth. It first appeared that some accentuation of growth had taken place, but this action was but little different from that shown by untreated trees of corresponding age and development.

The pump was refitted on August 10. At first the vacuum produced by its operation was equivalent to $760 \mathrm{~mm}$. mercury, but this soon fell to 720 and $730 \mathrm{~mm}$. A branch near the base, with its tip cut off and the stump thrust into water, took in $60 \mathrm{c}$. c. of water on the first day. The amount taken decreased day by day, so that but 20 c. c. were taken in on August 21. The pump was operated for $31 / 2$ hours on the 14th, but this did not increase the amount taken in by the branch with its tip in water. It was again operated on the 21st for 3 hours without discernible results as to water intake. On the other hand, the stem showed greater increases on the two or three days following the operation of the pump than before or after this time. Extended experimentation would be needed to make an exact estimate of the effect and to identify the physical disturbances caused.

Elongation during the summer was noticeable in nearly all of the branches, being greatest in the larger upper ones, in which the new axis was 5 or $6 \mathrm{~cm}$. long, with leaves about $2 \mathrm{~cm}$. long. The most striking feature, however, was that the new extensions were apogeotropic and assumed an erect position, a result, presumably, of the excision of the leader.

It was noted that at this time the tips of all of the branches were active and that all of them had turned their apices upward, some of them having attained a directly upright position. The conjunction of all of the buds in this action would not ordinarily be attributed to the effects of the excision 
of the leader. It seems reasonable to suppose that either the defoliation or the action of the pump had disturbed the flow of material. The lack of some substance ordinarily derived from the old leaves, or from the leader, or the removal of some material by the pump, may have altered the character of the geotropic equilibrium of the branches.

A cessation in the enlargement of the trunk came at the first of September, but was noticeable again on the 11 th; exactly equal diameters were registered on the 11th to 16 th, then a slow increase was visible which continued to include the 26th; now came another period of clear days and high temperatures in which the daily variations were equalized, the total increase in diameter since defoliation amounting at that time to $3 \mathrm{~mm}$. In any comparison that might be made with the activity of No. 19, which was defoliated in March, before the young leaves had attained half size and before more than a small part of the leaf-products of the old leaves were available, it is to be seen that in No. 23 the old leaves were active for 3 months longer and the young leaves had reached a much more advanced stage before defoliation. The supply of constructive material and of excitatory agents, as well as of material from the soil, would be more nearly normal because of this extended activity of the leaves.

The pump, which had been kept attached to the upper end of the trunk, was again operated for 5 hours on October 1 , the sky being overcast, which tended to cause some enlargement of the trunk. The increase which took place in 24 hours, however, was much greater than might be attributed to such a condition, the pen rising $3 \mathrm{~mm}$. higher on the record-sheet than on the previous day, indicative of an actual swelling of nearly $0.2 \mathrm{~mm}$. in 24 hours. Such an effect of the vacuum on the upper end of the stem is in agreement with results previously obtained and described above.

The third tree in this series, Monterey pine No. 25, was a smaller one, with a trunk $5 \mathrm{~cm}$. in diameter and with a height of about 4 meters. This tree was about 12 years old and retained nearly all of its branches, which were still leafy to their bases. The dendrograph attached to the basal portion on September 25, 1923, showed that the enlargement of the stem had come down to a very low rate, probably by reason of the low soil-moisture content. The leaves, including those formed in the beginning of the year, were removed on the afternoon of October 1 , being pulled directly out to avoid laceration of the bark. The day was overcast. The operation left the tree devoid of green surfaces or of any avenues for transpiration outside of the buds, lenticels, and rifts in the bark, the leaf-scars being quickly sealed by resinous excretion. The total weight of the leaves removed was $4.2 \mathrm{~kg}$.

The average weight of leaves was that of 54 to the gram, as compared to 90 to the gram in No. 23 in June, only the leaves of the previous years being included in the estimate of No. 19, while all were taken in No. 25. The number taken from No. 23 was 244,000 while the total stripped from No. 25 was estimated at 227,000 . It is obvious that the actual leaf-surface of the two trees was about equivalent. Nos. 19 and 23 had at all times one-fifth of their leaf-surfaces in a functioning condition, while the only chlorophyll in No. 25 after the stripping was that carried in the young bark. 
The daily variation, which had risen to a constant maximum for the preceding 5 days, had an amplitude of $0.3 \mathrm{~mm}$., or 1 part in 170 . This was reduced to a minimum on the day following defoliation. The stem had undergone a slow swelling during the night and only a minute contraction was to be seen at midday. The record now became a direct line, with barely discernible contractions in the mid-day period. The further behavior of this tree and of Nos. 19 and 23 will be discussed in a future paper.

\section{PATH AND RATE OF MOVEMENT OF LIQUIDS IN STEMS OF MONTEREY PINE.}

For the purposes of the present studies, the use of solutions of dyes seemed to furnish the best means of following the path of liquids through stems and along layers of wood. Reliance was placed chiefly in the use of Fuchsin S (Grübler \& Co.). This basic dye was found by Ruhland ${ }^{1}$ to have a high speed of absorption or penetration into cells. Its colloidal condition makes its movements through the layers of the cell depend upon its capillary activity rather than on ionic velocity.

The use of the dye here was one in which its diffusion through cell-walls and along intercellular spaces was concerned, and no effort was made to measure its penetration of the living cells of the medulla or its rays, or the cortex and cambium.

The first test was made in July 1923 with the shoot of a small tree which near its base had a diameter of $1 \mathrm{~cm}$. and 5 cylindrical layers of wood, indicating a low annual rate of growth. This tree was cut off a meter from the tip and the shoot immediately stepped into a vessel containing a Fuchsin solution, 1 part of the dye to 1,000 of water. The color was found at the extreme tip of the stem 48 hours later, 100 c. c. of the solution having been taken up. The basal part of the tree, which was also about a meter in length, was bent over and the cut surface immersed in a dye solution. Staining was visible downward for a distance of $90 \mathrm{~cm}$., there being no branches on this part of the stem. The above, however, does not represent the maximum rate at this season in such small shoots, which is always greater moving upwardly than the reverse, as another shoot $125 \mathrm{~cm}$. long conducted the dye solution to its tip in 48 hours.

Another small tree, $14 \mathrm{~mm}$. in diameter at the base and showing 5 layers, was cut off and the base set in some of the same solution, the leaf-system being left entire and active. In 20 hours the color was discernible at 125 $\mathrm{cm}$. from the base and $70 \mathrm{c}$. c. of the liquid had been absorbed. The severed basal part of another small tree of somewhat larger diameter was inverted with the stump of the terminal portion in a bottle of the dye. The portion of the tree used bore several vigorous branches. The dye had run to a length of $80 \mathrm{~cm}$. from the tip, and at this distance had passed the bases of most of the branches which would exert a pull by transpiration on the movements of the liquid, and some color had gone into them.

A tree about 3 meters in height and $22 \mathrm{~mm}$. in diameter at the base was cut off and the base of the excised shoot stepped in a vessel of dye at 4 p.m.

${ }^{1}$ W. Ruhland. Studien ueber die Aufnahme von Kolloiden, durch die pflanzliche Plasmahaut. Jahrb. f. Wiss. Botan., 51, 376-431. 1912. 
The stain was found at a height of $180 \mathrm{~cm} .44$ hours later. At this height the color had been diverted into the several members of a whorl of branches. The tip of a similar small tree being cut off, the stump was immersed in a dye solution and in the same time the color had gone down the stem $53 \mathrm{~cm}$., where it was diverted into a whorl of branches formed during the previous year.

A small tree growing on a northward-facing slope, which was in a thick stand, so that it was but $7 \mathrm{~cm}$. at the base and 8 meters in height, was cut off near the base on Saturday, July 14, the base of the trunk being stepped into a vessel containing the Fuchsin solution, while the trunk was kept in a position nearly erect, leaning on a larger tree. The annual layers at the base were 21 in number, showing that the tree must have been about 22 years old.

The absorption of the dye solution was so rapid at first that 700 c. c. was absorbed in 48 hours; the next 24 hours about 400 c. c. At the end of this 3 -day period the presence of the dye was discernible 3.5 meters from the base, the end of the colored zone being distinguished by the fact that the color could be seen only in the three outermost layers and also appeared in a thicker layer much nearer the center and separated from the other colored layers. Near the base the heart of about 8 layers remained totally uncolored.

A small tree about 3 meters in height was topped in July by cutting away the terminal half of the leader or extension of the shoot formed during the current season. It was left untouched at the base and the stump was thrust into a solution of the dye. Two weeks later the color had come down through the stem only so far as the first node or whorl of branches, passing through all of the wood which was of this season's formation without noticeable differentiation. But little of the color had gone out into the branches. In this case the stem was in full connection with the root system and the dye had passed down the stem to a point where it would have met a flow coming upward and going out into the branches and leaves. It is evident that in all of these cases the movement is the resultant of three factors: the capillarity of the dye, the upward stream from the roots, and the pull of transpiration from the leaves.

The downward movement of the dye was in no case equivalent to the rate upward, but in every instance the color was deflected laterally into branches. Furthermore, the cross-section of the stem increases downward, which would tend to lessen the rate of longitudinal movement.

It is obvious that with the constant absorption of the dye the maximum rates would be obtained by observations for short periods and for short sections of stems. The movement in the young tree 3 meters in height must have been very rapid at first, although at the end of 44 hours the total was $180 \mathrm{~cm}$., or about $4.4 \mathrm{~cm}$. per hour. The largest tree tested in this manner was $7 \mathrm{~cm}$. in diameter at the base and the rate calculated for 4 days was about $4 \mathrm{~cm}$. per hour. The maximum was $6 \mathrm{~cm}$. per hour in a length of $125 \mathrm{~cm}$. The maximum downward was $4 \mathrm{~cm}$. per hour. These rates are much less than those observed late in the season.

The path of solutions furnished the stem in this manner is seen to lie chiefly in the wood formed during the previous two or three seasons. When 
the base of a tree cut from its base is stepped into a vessel containing the dye, however, distinct upward movements may take place in some layers toward the center in a very unequal manner.

These tests were repeated in October, when nearly all of the trees had reached a quiescent stage as to growth, and attention was paid to the possible effects of the suctions exerted by a vacuum connected with the terminal part of the stem.

The principal experiments were carried out with four small trees. The stems were set in the solution of Fuchsin, as noted above, on October 8. One, which was $4 \mathrm{~cm}$. in diameter at the base, about 12 years old and bearing small branches, was connected with the Nelson vacuum-pump. The top was cut off below the uppermost whorl of branches, leaving an exposed end about $2 \mathrm{~cm}$. across. The end of a small section of pressure hose was clamped about this, and when the pump was started at $10^{\mathrm{h}} 15^{\mathrm{m}}$ a.m. the mercury quickly rose to $730 \mathrm{~mm}$. in the gage. A second tree, $4.5 \mathrm{~cm}$. in diameter at the base, about 5 meters in height, and bearing branches about equivalent to the one connected with the pump, was topped in the same way with the cut upper end left exposed. A third smaller tree, 5 meters in height, with numerous branches, only $4 \mathrm{~cm}$. in thickness at the base and about 14 years old, was set in the dye. This tree bore many small branches and would have a relative transpiring capacity much above the first two trees which had been topped. A fourth tree, still smaller, being only $2.2 \mathrm{~cm}$. in diameter at the base, 4 meters in height, about 12 years old, and with few branches and hence relatively small transpiring capacity, was included in the group. The day was warm, still, and sunny, with only an occasional cloud.

The pressure in the pump system fell to $620 \mathrm{~mm}$. of mercury an hour after the beginning, and to 520 at the end of the 5-hour test, due to a defective joint.

The test was ended 5 hours later and all of the stems examined for the presence of the dye. The rates shown by all were in excess of those noted above, which were measured during the season of rapid growth in June. The dye was discernible in a very faint stain in the control, which had been topped like the one under the pump at $57 \mathrm{~cm}$. from the base, ending at a node but by no means being in such quantity as to be traced out into a branch.

The tree to which the pump was attached showed the dye as strongly staining outer rings to a distance of $65 \mathrm{~cm}$. from the base, as it happened, near a node but not going out into branches.

The smaller tree with many branches showed the stain to a distance of $55 \mathrm{~cm}$. from the base, terminating at a node. The smallest tree, which had a diameter of only $2 \mathrm{~cm}$. at the base, showed the highest rate yet measured in any of these trees, the stain having traversed the stem to a distance of $80 \mathrm{~cm}$. The rates of conduction of the dye in sufficient quantity to be observable were, therefore, $11,13,11$, and $16 \mathrm{~cm}$. per hour. It was notable that while the stem subjected to the action of the pump did not greatly exceed the rate of its control, yet the amount of dye shown was many times greater. The stain in this tree was marked in the second and fourth layers of wood, in the control in the third and fourth, as also in the one with many 
branches. The smallest tree with the highest rate had the second ring which was formed in 1922 most heavily stained. It is possible that two layers of wood had been formed in 1923. The formation of two or more layers in a year by these young trees may be held to account for the apparent departure from the conclusion that conduction is greatest in the wood of the previous two years. It would seem that when two layers are formed in the same year they are not equal in their conducting capacity. The trees having been shortened by the lengths indicated above, they were set in the dye immediately to test the rate of conduction from 4 p.m. until the next morning, the pump not being operated. All of the trees had in the aggregate taken up 1,550 c. c. of liquid in 5 hours.

At 8 a.m. on the following morning, after 16 hours, the four trees had taken up 1,450 c. c. of dye. The one attached to the pump, which had not been operated during this time, had taken the dye up $60 \mathrm{~cm}$., its control $60 \mathrm{~cm}$., one node being passed in each tree, and the dye being seen farthest up the stem in the fourth layer in the one attached to the pump and in the fourth and fifth layers in the control. The stain had gone up $80 \mathrm{~cm}$. in the one with many leafy branches, the conduction being most pronounced in the first and fourth layers, after passing 2 nodes. The smallest tree had taken the dye upward to a distance of $70 \mathrm{~cm}$., past one node in the second and fourth layers. It was to be seen that the rate in the one attached to the pump was identical with the control during 16 hours when the pump was not in operation. The rate in the two largest was less than one-third that in the daytime, and also in the smallest. The rate in the one with many leafy branches was highest. The rates arranged in the same order as given previously were about $4,4,5$, and $4.4 \mathrm{~cm}$. per hour. The lessened rate may be connected directly with decrease in transpiration due to the narrowed stomatal slits of the leaves and the lowered temperature.

The pump being started at 8 a.m. on the following morning, a vacuum of 500 to $600 \mathrm{~mm}$. of mercury was set up, and the tree attached showed stain at a distance of $65 \mathrm{~cm}$. in the second layer after 7 hours. The distance traversed in the control during the same time was $50 \mathrm{~cm}$., the stain being in the second layer at the extremity. The leafy tree showed stain at a distance of $50 \mathrm{~cm}$. at the first node, which bore a number of branches. The stain was in the second layer. The smaller tree was stained to a distance of $65 \mathrm{~cm}$. in the second layer. The rates for this daylight period, given in the same order as before, were $9,7,7$, and $9 \mathrm{~cm}$. per hour. The dye was seen to travel farther than in the control, although it did so at night, when the pump was not operating. All of these rates were less than the day before. It is to be noted that the suction exerted by the pump was less than on the previous day. The highest rate continued to be shown by the small tree in which the woody layers were thinnest.

The conduction of the dye was taken again on October 10 at 8 a.m., after 16 hours with the pump not operating. The tree to which the pump was attached showed a rate of $3 \mathrm{~cm}$. per hour, which was near that of the control which was slightly higher. The greatest distance was reached in the fourth layer in both. The rate in the one with many branches was slightly less than $3 \mathrm{~cm}$. per hour in the second and fourth layers and it had not reached a node. The dye had penetrated clear of the last node into the leader at 
the rate of $3.5 \mathrm{~cm}$. per hour, staining the layer formed in 1922 in the internode below. The material was now set up for a daylight test. The smallest tree was discarded. The pump connection was shifted to the apex of the one hitherto used as a control, which had a length of 2.2 meters remaining. The vacuum showed above $740 \mathrm{~mm}$. of mercury on the gage at the beginning of the experiment. Five hours later the dye had been taken up to a distance of only $25 \mathrm{~cm}$. in the trunk connected with the pump, $65 \mathrm{~cm}$. in the one which had been previously under the pump, and $35 \mathrm{~cm}$. in the one with many branches.

In the succeeding 16 hours, including the night, the stem with many branches had conducted the dye upward to the last whorl of leaves, a distance of $25 \mathrm{~cm}$., which was at the rate of $1.5 \mathrm{~cm}$. per hour, the one attached to the pump on the previous day $20 \mathrm{~cm}$., and the one originally used as a control $25 \mathrm{~cm}$., all of which were seen to be much less than in any daytime period. After every test the stems were shortened, of course. All were now discarded except a short section of the one originally attached to the pump, of which a length of but $50 \mathrm{~cm}$. remained, and had two small branches, and the one originally its control, which was much longer for obvious reasons, having a length of 1.5 meters. The pump attached to this longer stem was started before 9 a.m. on October 11, the day being warm, still, and sunny. At the end of 5 hours the dye had been drawn in quantity through the stem, 1.25 meters in length, while it had gone only $10 \mathrm{~cm}$. in the other or shorter one. The effect of the vacuum on the end of a stem in accelerating the conduction of liquids is direct and marked.

The test was repeated with larger trees, both of which had grown near the north side of the laboratory and hence were slender and somewhat attenuated. One to which the pump was attached was $5.5 \mathrm{~cm}$. in diameter at the base, 8 meters in height, and about 14 years old. The leader and some of the internode of 1922 were cut away to secure suitable thickness for the pump connection, the stem remaining having a length of 6.5 meters, the base being set in a solution of Fuchsin 1 part to 1,000 of water. As a control, a second tree about 12 or 13 years old, $5 \mathrm{~cm}$. in diameter at the base, and 7 meters high, was cut and its base set in the same vessel of dye. This tree was not topped. The terminal which was removed from the other tree bore leaves which were estimated to weigh 800 grams, and as these would run 45 to 54 to the gram, it is to be seen that 40,000 leaves were removed, which were taken to constitute about one-fourth of the foliage of the tree.

The pump was, therefore, in the position of replacing one-fourth the foliage of the tree, and if an acceleration of conduction was found it would tend to show that the pump gave a "transpiration pull" equivalent to and in excess of that of the foliage and stems removed.

The control tree had taken the dye up to a distance of $75 \mathrm{~cm}$. from the base in the third and fourth layers at the end of 5 hours. The tree connected with the pump had taken the dye up to only $50 \mathrm{~cm}$. It was noted that this trunk was more highly resinous than the other one.

The control stem conducted the dye $130 \mathrm{~cm}$. in the 18 hours between 3 p.m. and 9 a.m., the color being farthest extended in the outermost layer on one side and in the third and fourth layers on the other. The rate during 
this period, including the evening, night, and morning, was $7 \mathrm{~cm}$. per hour as compared with $15 \mathrm{~cm}$. per hour during the initial daylight period of 5 hours. The dye diffused to an extent of $65 \mathrm{~cm}$. in the one attached to the pump, but which was not operated during this 18 -hour period. The rate was thus seen to be $3.6 \mathrm{~cm}$. per hour, and the color was principally in the second layer. The tree to which the pump was attached may therefore seem to have a lower rate than the control. That the vacuum at the tip had exerted some effect may be inferred from the fact that the daylight rate of the control was about twice that of the night rate, while the daylight rate of the one with the pump attached was nearly three times the night rate with the pump not in operation. After the above measurements had been made, the pump was set in operation at 9 a.m. on October 13 . The length of this stem was now about 4 meters, and the cutting away of the basal part in making the determinations as above had taken but few of the branches, so that its transpiration capacity would be but slightly lessened. The greater lengths cut from the control left a length of but 2.5 meters from the base to the tip of the leader, although the total number of leaves on this section was estimated to be but little below that of the stem attached to the pump.

After 5 hours of daylight the dye had stained the control to a length of $45 \mathrm{~cm}$., showing a rate of $9 \mathrm{~cm}$. per hour. The color had gone up the stem to which the pump was attached a distance of $25 \mathrm{~cm}$., showing a rate of 5 $\mathrm{cm}$. per hour. The acceleration in the control by daylight conditions was nearly 30 per cent; the acceleration of the stream in the one to which the pump was attached and operating under daylight conditions was over 40 per cent. The remaining lengths were placed with their bases in the dye at $2^{\mathrm{h}} 30^{\mathrm{m}}$ p.m. Twenty-four hours later the dye had passed up the control $90 \mathrm{~cm}$. in the outermost layer of wood and $80 \mathrm{~cm}$. in the one to which the pump had been attached but not operated. The first and third layers were stained in the last named specimen.

It is apparent that the rate of flow of solutions of stain may be much greater in the Monterey pine late in the season than in the stage of rapid growth. Furthermore, the well-known fact that the sap travels most in the wood of the two previous years is confirmed. In the trees which form two or more layers yearly the greatest conduction in the autumn is in the wood that was formed early in that year and early in the previous year, the intervening and interior layers being free from the stain. If, as the staining suggests, there is but little stain in this intermediate layer, a possibility is opened for the consideration of the clear layer as a possible path for a downwardly moving stream. That material might move both upward and downward in the wood was proposed by Jones, Edson, and Morse ${ }^{1}$ in 1903 in connection with the study of sap-flow in the sugar maple. This view of the possibilities has also been taken up approvingly by Professor H. H. Dixon. ${ }^{2}$ Some experiments dealing with this matter are to be carried out in this laboratory.

${ }_{1}$ Jones, Edson, and Morse. The maple-sap flow. Bull. Vermont Agric. Exper. Station. 1903.

${ }^{2}$ H. H. Dixon. Nature, 111, 236 and 547. 1922.

J. Adams. The translocation of carbohydrates in sugar maple. Nature, 112, 207, 1923. 
Still another association of facts is that the woody trunk of the tree assumes the greatest diameter in the course of the daily variations at the time the upward stream is moving at its lowest rate, which is simply another form of stating that the loss from the leaves is at a minimum and the amount of liquid to be moved to the top of the trunk is least at this time.

The actual rate of movement of upwardly bound solutions in the stems of this pine make it an especially favorable object for experimental modifications. The foregoing results are conclusive evidence that the maintenance of a vacuum which will hold up a column of mercury $740 \mathrm{~mm}$. in height in replacement of one-fourth of the leaves of a shoot will result in acceleration through a stem up to 6.5 meters and probably to greater lengths.

\section{REVERSIBLE VARIATIONS IN VOLUME INDEPENDENT OF GROWTH.}

That growing cell-masses, and that plant-members variously made up of living cells and woody structures, may undergo daily variations in volume has been found by all observers who have dealt adequately and accurately with measurement of growth. The shoots of mesophytic plants of the types ordinarily used for study have a ligher rate of transpiration in the daytime than at night. The stems and other organs of such plants may show a lessened rate of growth during the daytime, or in the case of mature tissues may actually contract. The observation of such facts was in all probability the basis for the mistaken conclusion that light retards growth, a notion which is still held by many physiologists with respect to the higher plants. As will be shown in subsequent sections of this paper, some plants, like the cacti, show the greatest enlargement in the daytime after a manner nearly the reverse of that of woody trees, fruits, and tubers. The contraction of a cell-mass may be due to the direct loss of water from its surface, or, as in other cases, including the tomato, the walnut, and the squash, the supply of water comes to these structures through the stems acting as a common conduit from which the leaves also draw water. A state of competition is set up and the leaves may show the greatest transpiration coincidentally with the fruit or nut, so that its shrinkage becomes accentuated by reason of an inadequate water-supply.

A third condition is represented by the tuber of Solanum. These structures are thickened lateral underground branches, are at the ends of stem conduits, and water must flow into them chiefly by imbibition of the newly and continuously formed carbohydrates from the main stems. The transpiration from the surfaces must be so low as to be negligible when the tubers are normally covered with moist soil. It has been shown, however, that when exposed to the air the direct water-loss may be so great as to give rise to variations of the same kind as those shown by the tomato. In all of these cases the shrinkage is greatest when the stomatal slits of the leaves are widest. The action of these organs has been found to be determinative, so that in some plants, such as the cacti, transpiration is greatest and shrinkage is most marked in the evening and at night, instead of during the period when evaporation from a free water-surface would be greatest. In other instances, such as the leaves of Mesembryanthemum, the effect of 
high temperatures and open stomata is to produce the greatest water-loss and resultant shrinkage at midday, at which time, however, the slits of the stomata begin to close and the shrinkage is lessened.

The trunk of the tree cactus (Carnegiea gigantea) consists of a central woody cylinder inclosing a large medulla, the diameter of which is not more than half that of the entire trunk. External to it is a very thick cortex, capable of hydration and dehydration to a marked degree, and having a capacity for growth which is not well defined or known. These conditions are to be taken into account in the consideration of the fact that this singular tree shows a behavior in equalizing variations almost opposite those of all other trees which show the greatest diameter at sunrise and the least in mid-afternoon.

The daily variations of the trunk of a woody tree illustrate the hydration and dehydration of living cells as in the foregoing types, and in addition display an action of the woody cylinder of the trunk which would have an inevitable intimate connection with the problems encountered in the study of the ascent of sap. As has been shown in the discussion of the daily variations in trunks, there is a shrinkage in trees in an inactive condition at sunrise, and it continues until mid-afternoon or evening, when recovery begins and the cylinder slowly returns to its maximum dimensions, which are reached at daybreak. Such an action in the Monterey pine is directly coincident with the general action of the stomata. According to observations made by Dr. F. T. McLean, July 6 and 7, 1922, the average width of slits stomata in the number of readings indicated was as shown in table 5 .

TABLE 5 .

\begin{tabular}{|c|c|c|c|}
\hline Time. & $\begin{array}{l}\text { No. of } \\
\text { readings. }\end{array}$ & $\begin{array}{l}\text { Width in } \\
\text { microns. }\end{array}$ & Remarks. \\
\hline $\begin{array}{r}4^{\mathrm{h}} 00^{\mathrm{m}} \text { a.m. } \\
615 \text { a.m. } \\
825 \text { a.m. } \\
12.00 \text { noon } \\
235 \text { p.m. } \\
635 \text { p.m. }\end{array}$ & $\begin{array}{r}75 \\
25 \\
135 \\
50 \\
50 \\
50\end{array}$ & $\begin{array}{l}1.0 \\
1.0 \\
1.8 \\
2.2 \\
2.8 \\
1.0\end{array}$ & $\begin{array}{l}\text { Widening of slit begun. } \\
\text { Widening of slit still in progress. } \\
\text { Widening of slit still in progress. } \\
\text { Closure since previous observation. }\end{array}$ \\
\hline
\end{tabular}

The temperature of the external layer of wood of a Monterey pine has not been seen to vary as much as $10^{\circ} \mathrm{C}$. in a day. At a distance of $10 \mathrm{~cm}$. from the surface the variation is not more than a third of this amount at the maximum variation. The warming effect of the morning sun would tend to cause an expansion of the trunk. In actuality, the trunk shows a shrinkage which begins at sunrise when the temperature of the trunk is at the minimum for the day or within a degree of it.

It seems clear, therefore, that the daily equalizing variations which take place in a tree-trunk are not due to direct water-loss from its surface, whether it be inactive or enlarging, and such changes are the reverse of what might be expected as direct reactions to temperature.

Of the materials in the growing layers or in the wood which might undergo reductions or increases of sufficient magnitude to alter the dimensions of the trunk, water is the one component to which attention may be 
profitably directed. This liquid is present as the hydrating or swelling agent in both the soft cell-masses of the cambium and bast as well as in the more rigid walls of the wood. The living cells of the growing layers will, of course, swell and shrink with the hydration and dehydration of the colloids which form the bulk of the protoplasm.

The water in the woody cells saturates the walls and fills the cavities, especially in the outer layers, in which the greatest change was found to take place. The watery solution begins with the surfaces of the absorbing organs in the root-system and extends as a continuous system to the evaporating surfaces in the loose tissues of the leaf. The cohesion tensions present are such, according to various observers, that any pull on the upper end of the system would result in an attenuation of the column. Bode ${ }^{1}$ has found that the diameter of a single vessel undergoes a measurable reduction as a result of the action of transpiration on the cohesion tension of the water-content. The irregular column of water in a tree-trunk which would extend upward principally through two or three layers would be subject to such contractions.

\section{STANDARDIZATION OF THE DENDROGRAPH FOR MEASURE- MENT OF DAILY EQUALIZING VARIATIONS.}

The measures that were taken to standardize the dendrographic apparatus to avoid errors in the observations which might confuse or obscure the nature of the daily variations should be described at this time.

The essential feature of the instrument is a rigid metal frame surrounding the trunk, with one fixed contact-point, and the second consisting of the short bearing-arm of a lever, the long arm of which carries a pen which traces the record. The higher temperatures of the daytime would tend to enlarge this frame, and if the tree remained unchanged, or nearly so, by reason of its much more slowly changing temperature, the record would show an apparent shrinkage if the floating frame were made of iron. To lessen such an error, the floating frames have been constructed in some cases of "bario," in others of "invar," and in others of "permant." The temperature coefficients of these alloys are well known to be small and much less than that of platinum; so small, in fact, that the error which might be produced would be equalized by the coincident expansion of the tree. It was, however, deemed desirable to ascertain what possible error might lurk in the instrument or arise from the mechanical arrangement of its parts.

A testing-set to determine the instrumental error which might be ascribed to the daily fluctuations in sunlight and air temperatures was arranged as follows: A base of blocks, such as that which ordinarily serves as a support to a dendrograph when employed in measuring a tree, was clasped around a short section of a trunk of the Monterey pine set upright in the open. A rod of fused silica was laid across the top end of the log in wooden saddles which raised it a few centimeters above the surface. A floating frame of permant bars $25 \mathrm{~cm}$. long was arranged as if to inclose a tree-trunk, and properly supported on flexible wire fingers. The contact-screw of the float-

${ }^{1}$ H. R. Bode. Beiträge zur Dynamik der Wasserbewegung in den Gefässpflanzen. Jahrb. $f$. Wiss. Bot., 62, 92-127. 1923. 
ing frame and the bearing-rod of the lever set were now brought into bearing on the opposite ends of a rod of fused silica representing the diameter of a tree. The system represented by this rod and the smaller rod of fused silica of the lever set had a length of $52 \mathrm{~cm}$. The two pairs of permant bars which formed the side members of the floating frame each had a length of $50 \mathrm{~cm}$. If the silica rod did not change in length and the permant frame did not alter its dimensions the pen would trace a straight line on the recording cylinder (fig. 4).

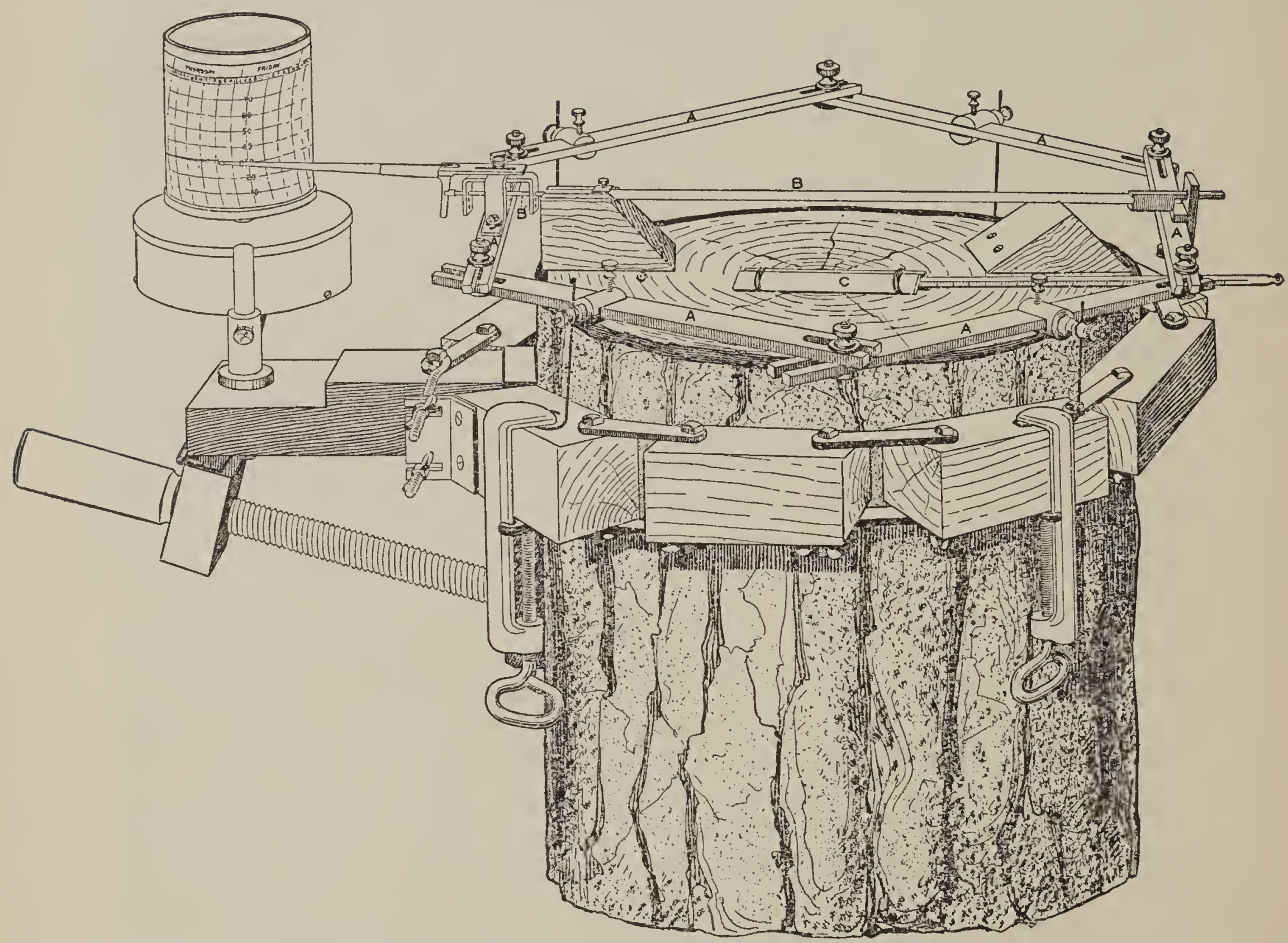

FIG. 4.-Dendrograph set on end of section of tree-trunk to test coefficient of temperatureexpansion of floating frame of permant. The supporting belt of blocks encircles the trunk near its end, the members of the floating frame, A, A, A, A, A, being held in place in the usual manner. A rod of fused silica, $B$, is placed between the bearing rod on right-hand end of sliding rod, $B^{\prime}$, of fused silica on left. This rod would represent the wood in diameter of trunk, the variations of which would be recorded in ordinary practice. As the variation of the fused silica rods is so small as to be negligible, any variation recorded would be that of the floating frame. C, bars of permant laid against bulb of thermometer.

In order to determine what changes in temperature took place in the members of the floating frame, the bulb of a mercurial thermometer was held between two permant bars by a rubber band and laid in a horizontal position on the end of the trunk. These bars, like the members of the frame, were in a horizontal position and hence would be exposed to the action of the sun in the same manner. In actual practice not more than three-fifths of the floating frame would be exposed to the sun at any time, but here it 
was all exposed, so that the error calculated below would be greater than that encountered in practice. Furthermore, it was assumed that the fused silica assumed a temperature equivalent to that of the metal, which is probably not correct; but here again the discrepancy would tend to exaggerate the error. The metal of the floating frame was found to range from $10^{\circ}$ to $40^{\circ} \mathrm{C}$. on a warm day at Carmel. The pen-tracing showed a deviation from a straight line of less than $1 \mathrm{~mm}$. with an amplification of 18 in the lever set. Briefly put, no deviation greater than $0.05 \mathrm{~mm}$. in the record could be attributed to the error of the instrument under the test conditions. The actual error in practice would be, of course, only a fraction of this amount.

The deviation as given above represented the difference between the expansion of the systems of two fused silica rods with a total length of $52 \mathrm{~cm}$. and the two pairs of permant bars with a length of $50 \mathrm{~cm}$. The coefficient of expansion of fused silica through the ranges of temperature indicated is 0.00000042 , from which it may be found by calculation that the expansion of the fused silica in the test would be no more than 0.00063 $\mathrm{mm}$. The coefficient of expansion of the permant, which is a nickel-steel alloy, with a probable higher proportion of nickel than is used in the composition of invar, was found to be 0.0000035 by Professor E. P. Lewis in determinations made in the physical laboratories of the University of California. The expansion of invar is expressed by the coefficient 0.0000007 , so that permant is seen to show 5 times as much expansion as invar, or about two-fifths that of platinum. The maximum elongation of the main axis of the floating frame constructed of permant which was used in the testingset would be $0.055 \mathrm{~mm}$., which would constitute a variation of about 1 part in 9,000 of the diameter of a tree which might be inclosed.

All of the experiments in which the daily equalizing variations were measured exactly were made with floating frames of invar in which the instrumental error would be less than that with permant. A floating frame of fused silica was used in the measurement of Monterey pine No. 4, and even this small error was eliminated in this case.

\section{COURSE OF THE DAILY EQUALIZING VARIATIONS IN TREES.}

Early in the course of the investigation it became apparent that the character of the reversible variations in the volume of a tree-trunk or of any other organ might vary according to the stage of growth or development, the advance of the season, or by the temperature, relative humidity, sunlight, and other complexes.

Furthermore, as might be expected, not all parts of the trunk of a tree contract and expand equally. The earlier measurements gave an apparent greater variation in the upper part of the trunk than in the lower. To confirm this the two instruments on Monterey pine No. 1 were calibrated to give duplicate amplifications in October 1922. On the warm autumnal days of the latter part of that month the absolute variation of the upper place ( 8 meters above the lower one) was 25 per cent greater than at the base of the trunk. Thus, on November 1 the recording-pen of the instrument at the base of the tree stood $3 \mathrm{~mm}$. lower on the sheet at $2 \mathrm{p} . \mathrm{m}$. than at 9 a.m. The instrument at the upper place on the same trunk moved the recording 
pen $4 \mathrm{~mm}$. lower in the afternoon, the diameter here being $37 \mathrm{~cm}$. and the amplification being 10 in both instruments. The diameter of the trunk had therefore shrunk $0.3 \mathrm{~mm}$. at the base and $0.4 \mathrm{~mm}$. in the upper part. The: upper part of the trunk was but $370 \mathrm{~mm}$. in diameter, and the coefficient of expansion was thus seen to be 1 part in 900 . The lower part of the trunk had a diameter of $500 \mathrm{~mm}$. and consequently a coefficient of expansion of about 1 part in 1,700, or less than six-tenths that of the upper part of the trunk.

This behavior of the woody trunk is to be compared with that of the heavier thickened roots a short distance away from the base of the trunk. Some description of the behavior of these members has already been given. Late in June a root which was $40 \mathrm{~mm}$. in thickness was showing a daily variation of 1 part in 364, which, of course, included the cambium: layer. The most notable fact concerning this matter is that the root exhibits a daily cycle notably different from that of the stem in that it begins to enlarge shortly after midday, while the expansion of the stem does not commence until 3, 4, or 5 hours later. Also that the root begins to contract. before midnight at a time when the entire system of the tree must be in a condition most nearly approaching satisfaction as to hydration.

The more complete picture, then, of a massive tree brings into focus the fact that the trunk of the Monterey pine contracts during the daylight period, in which the stomatal slits and the resultant transpiration are greatest, that the contraction is greatest in the upper part of the trunk, and that the roots begin to enlarge about the time the stems have reached their. minimum volume and many hours before they begin to expand.

The variations in the trunk seem to be invariably and closely connected with the transpiratory activity of the leaves. Extreme reduction of transpiration by removal of the leaves or disconnection with the water-supply are followed by a lessened amplitude of variation. The daily variation was reduced to a minimum in a tree defoliated early in the growing-season, with only half-formed young leaves remaining; on the other hand, the daily change was very marked in a tree defoliated in midsummer, with the newly formed leaves nearly mature, and probably having a transpiratory capacity equivalent to the amount taken in from the roots from a slowly drying soil. The variation was lacking for a few days in a tree girdled above the dendrograph, the girdle being callused later with a resumption of the variation. Girdling near the base of the tree early in the season had no direct effect on the variation during that year, but its amplitude was much reduced in the following season preceding the death of the tree in midsummer. The variation quickly disappeared from a tree topped below all of the branches, was much reduced in a tree topped with only a few branches remaining, and was not visibly affected in a tree in which topping removed about half of a tree which was densely branched and with ample foliage remaining. The variation disappeared within 10 days from a tree, the base of which had been killed by boiling oil.

That the daily variation depends chiefly upon the transpirational relations seems obvious from its seasonal aspects. In a young tree, such as No. 17, contraction does not begin until 8 a.m. in the autumn and winter 
and expansion is in evidence by 3 p.m. As soil-moisture and relative humidity increase with the winter rains and the activity of the guard-cells is lessened by low temperatures, the contraction is lessened and the period of lessening volume is shortened, until about January 1 it does not begin until 10 a.m. and expansion is visible by 2 p.m. The contraction is more abrupt than the expansion in any case, and during the entire year. Thus, in January, contraction is complete in 4 or 5 hours, while expansion may extend over 16 or even 18 hours. The greatest amplitude of the variation in this tree was $0.4 \mathrm{~mm}$. daily during the latter part of March and on warm days favoring transpiration. The least change was on rainy or foggy days and was seen in July and August, at a time when the trunk was in a condition of rapid enlargement. It is withal somewhat remarkable that the variation should be less at this time than in the cool, rainy season of December and January. The greatest coefficient of expansion of the entire trunk, including the green bark which had not begun to flake and had a diameter over all of $160 \mathrm{~mm}$., was thus seen to be 1 in 400 .

The generalizations as noted above also apply to an older tree, No. 1, which was about $50 \mathrm{~cm}$. in diameter at the base. The maximum variation daily in early April was $0.4 \mathrm{~mm}$., which would be 1 part in 1,250. The variation at a place 8 meters higher on the stem at this time was over $0.5 \mathrm{~mm}$., which was 1 part in 700 . It seems probable that the terminal part of the trunk would at a corresponding diameter have a coefficient of expansion equivalent to that of the basal part of a young tree. The amplitude of the expansion may depend upon some condition of the wood which may not be defined, except to say that the outer layers, through which liquids chiefly move, may show greater changes than the heart and inner layers. Some results as to the daily variations of the woody cylinder have already been published. The measurements were repeated and extended with an older tree.

\section{DAILY VARIATIONS IN THE VOLUME OF THE INNER WOODY CYLINDER OF A MONTEREY PINE TREE.}

An instrument of the new design was fitted on Monterey pine No. 4, which had been the subject of the earliest measurements made in September 1918. The present measurements were to be concerned with the variations in the woody cylinder only. On April 7, 1922, the layer formed during that season, as well as the wood formed in 1921, was removed over a small circular area about 3 to $4 \mathrm{~cm}$. across to allow the contact screw and the silica rod of the lever-set to rest on the wood of 1920. The diameter between the two points was about $42 \mathrm{~cm}$. The first floating frame was of bario, a second one of fused silica was substituted later, and finally one of permant, the consistent action of the tree in all three settings giving assurance that the variations described below are mainly of the woody cylinder and are not due to instrumental errors. This feature of the matter has been discussed on a preceding page.

The daily change in diameter amounted to $0.13 \mathrm{~mm}$. in April, and this increased to 0.17 late in June, and fluctuations of this amplitude continued until late in July, at which time the soil-moisture would begin to fall away notably and the transpiration reach a maximum. The next feature was 
that of the slow recovery following the daily contraction. Beginning of recovery set in shortly after noon in April and May; with the advance of the season recovery was belated, until in September the enlargement was not noticeable until 5 or 6 p.m., although the actual amplitude of the change was lessening, being at this time no greater than in April. The amplitude again increased in October and November until it was equivalent to that of June, the fluctuation being characterized by the abrupt contraction in which the full shrinkage was reached within two hours.

Some question as to the contacts of the instruments in January and February are allowable, so the record for this period is to be disregarded. Perfected adjustments were made on March 9. It is to be noted that now the wood of 1920 , on which the contacts were made, was overlaid by that of 1921 and 1922 on the entire part of the trunk, and the layer of 1920 probably represents the innermost layer in which transport of solutions takes place in any notable volume.

The daily change in March was slightly less than $0.2 \mathrm{~mm}$. and may be taken to be about equivalent to that found in April in the preceding year and also in April and May of this year. Decrease in variation continued until in the week beginning September 10, 1923. The record was a direct line, and the departure was probably not more than a fifth of the maximum, and, therefore, not to be estimated with any profitable degree of accuracy. The contraction was abrupt and the recovery slow, as in the measurements of the entire trunk, and the course of the fluctuations is seen to follow that of the entire trunk.

The maximum coefficient of expansion would be about 1 part in 2,000. This figure is to be compared to the ones obtained from a smaller tree measured in 1920 , in which the maximum contraction was estimated at 1 part in 1,750 and the minimum at 1 part in 8,750 , there being obvious agreement.

The woody cylinder of the tree last measured may be compared directly with that of the trunk of No. 1, which is slightly larger but probably about the same age. The ratio of expansion of the entire trunk of No. 1, as described on the previous page, had a maximum of 1 part in 1,250, which would indicate that the outer layers of wood and the bast and cortex have a higher coefficient of expansion than that of the woody cylinder, as might be reasonably expected.

\section{GROWTH OF THE ARIZONA PINE.}

Dendrographs were attached to the trunks of two Arizona pines (Pinus arizonica), growing at 8,000 feet in the Santa Catalina Mountains in southern Arizona, on March 24, 1922. No. 1 was near the bottom of a small lateral stream valley sloping to the northward, with an apparent good supply of soil moisture. The trunk was $18 \mathrm{~cm}$. in diameter; the tips of the branches had begun to elongate, but the bast and cambium were apparently inactive. The lever of the recorder was set to amplify the variation in the trunk 18 times. By means of a thermometer inserted underneath the bark it was seen that the growing layer was subject at this time to temperatures as low as $13^{\circ} \mathrm{C}$. Growth began on June 2 and continued until July 9, when a short period of warm weather was accompanied by 
great daily equalizing variations with no net increase. On July 18 the summer rains began, the daily variations were reduced to a minimum, and some enlargement followed which had definitely come to an end by September 1, with the season of growth being included in a period of 90 days. During this time the pen of the recorder had moved upward over $23 \mathrm{~mm}$. on the series of recording sheets, indicating a total increase of $1.2 \mathrm{~mm}$. in thickness. The temperature of the cambium layer had varied between $13^{\circ}$ and $19^{\circ} \mathrm{C}$. during this time.

The rate of growth had not been widely different from that noted in the previous 20 years, the age of the tree being about 55 to 60 years.

Tree No. 2 of this species was about 200 meters distant, on the southfacing slope of the main valley. The substratum was coarse, granular granite, in which the water-supply would be very limited. The exposure to the sun was such as to induce a maximum transpiration. The tips of the branches were beginning to elongate when the instrument was attached on May 24, and the dendrograph recorder was set to amplify variations 18 times. No enlargement could be detected until June 10, when an irregular increase began with very marked daily variations. No net increase could be detected between July 9 and July 18, in agreement with the behavior of No. 1 in response to the hot and dry weather. Temperatures of $30^{\circ}$ and $31^{\circ} \mathrm{C}$. of the cambium were noted. The beginning of the summer rains was followed by a renewed enlargement; which continued until September 6 . The period from the beginning of growth until its end included 88 days. The recording-pen moved upward over $32 \mathrm{~mm}$. spaces of the sheet, indicating an enlargement of about $1.8 \mathrm{~mm}$. in diameter. This tree had shown a slightly greater growth-rate during its lifetime than during the present year, its age being not widely different from that of No. 1 . The annual rings indicated an age of 65 to 70 years. The location is one which may be taken to be at the upper range of altitude of this tree. This being the case, No. 1 with its northern exposure was under conditions farther from the optimum than No. 2.

\section{THE MEXICAN WHITE PINE.}

The dendrograph was attached to the trunk of a Pinus strobiformis 35 $\mathrm{cm}$. in diameter, which stood midway between the two trees of Arizona pine, the activities of which have been described above. The soil conditions seemed favorable for an adequate water-supply. The dendrograph recorder was set to give an amplification of 20 times. The tips of the branches were beginning to elongate on May 24, when the record was begun.

Growth began about June 6 or 7 , but in a period beginning July 5 and lasting until July 17 no net enlargement was made. A second impulse of growth was shown which ended August 10, the total period in which growth took place thus being 65 days.

The recording-pen moved upward over $32 \mathrm{~mm}$. intervals and the net increase was therefore about $1.6 \mathrm{~mm}$. This would represent about the average increase for many years. The borings taken from the trunk did not reach the center of the tree, which must have reached an age well over a century. 


\section{RELATION OF THE ARIZONA, MEXICAN, AND CHIHUAHUA PINES TO SEASONAL VARIATIONS.}

The Mexican white pine (Pinus strobiformis) growing near the Arizona pines was also seen to show some activity early in June, after which a period of no increase followed. Actual enlargement began in mid-July, following the occurrence of the summer rains on the Santa Catalina Mountains, in which these pines were growing at an elevation of about 7,000 feet. The period from the beginning of growth to its end was inclusive of only 65 days. Growth was manifest on only 53 days. A Chihuahua pine (Pinus chihuahuensis) at a little over 6,000 feet showed some enlargement in a period of about 10 days beginning April 13, 1919, with a similar slight impulse a month later. A third slight increase took place in a few days at the end of May. The main part of the formation of wood for the season began on July 20, three weeks after the summer rains had begun. This period terminated August 23. A final brief period of increase occurred from September 14 to October 5. The time from the manifestation of the first enlargement to the end of the season was 174 days, but during this time the tree showed only active increase on about 80 days. (Growth in trees, Carnegie Inst. Wash., Pub. No. 307, 1921, pp. 28 and 29.)

The studies of the Arizona, Mexican, and Chihuahua pines were made on trees on the Santa Catalina Mountains, near Tucson, Arizona. These mountains are an "island" range in a region of aridity. The precipitation takes place in two periods, midsummer and midwinter in about equal proportions. That for three summer seasons, as furnished by the Forest Service, is from instruments which were installed within a short distance of the Arizona pines upon which the observations were carried out (table 6).

TABLE 6.-Summer rainfall in the pine forest, at 8,000 feet, Santa Catalina Mountains, Arizona.

\begin{tabular}{|c|c|c|c|}
\hline & 1921. & 1922. & 1923. \\
\hline $\begin{array}{l}\text { May ........ } \\
\text { June....... } \\
\text { July........ } \\
\text { August.... }\end{array}$ & $\begin{array}{c}\text { inches. } \\
0.0 \\
0.88 \\
15.79 \\
8.22\end{array}$ & $\begin{array}{c}\text { inches. } \\
0.11 \\
1.19 \\
\ldots \ldots \\
19.25\end{array}$ & $\begin{array}{r}\text { inches. } \\
0.24 \\
0.00 \\
7.93 \\
6.54\end{array}$ \\
\hline Total in season affecting growth & 24.89 & 20.55 & 14.47 \\
\hline
\end{tabular}

The advance of temperatures in May and June is accompanied by a progressive reduction of the soil-moisture content, the whole surface layer with the humus becoming so dry before the tropical rains of midsummer that many great fires occur in the forest at this time. This condition is such that when the soil and air temperatures are high enough for growth water is lacking and the relative humidity is very low. To such extremes have these conditions gone that growth does not begin until 2 or 3 weeks after the coming of the summer rains. Some time is necessary for the water of the rains to percolate to the depths at which the absorbing roots are placed, and further time is necessary for this water to enter the roots and ascend the stems to the cambium layers. 
The behavior of the trees of which dendrographic records have been made suggests that it is not to be assumed that the thickness of the layers of the wood on a trunk is a reliable index of the relative amount of precipitation of the season in which the wood is formed. It has been found that this is so in the case of the Monterey pine, and it may, therefore, not be taken for granted in the case of any species until confirmed by actual measurements for a term of years.

This is also suggested by facts recently uncovered in the Santa Catalina Mountains in Arizona, the habitat of the Arizona and Mexican pine. The dendrographic records of these two pines and the examination of cores taken by the increment borer showed that the layer of wood formed in 1922 did not differ markedly from that of previous years, although the rainfall, which might have been effective in promoting growth in 1921, was about as 25 to 20.5 in 1922 . During the preceding years, including 1922, the layers had a thickness of 1.2 to $1.8 \mathrm{~mm}$. Some cores were taken by the increment borer in September 1923; the layer formed in the summer season then closing was double that of previous years, and was greater than that of other layers, except in the part of the tree formed while young.

Now, the summer season of 1923, in the habitat of these pines, was characterized by the lowest rainfall of any since the record had been taken, 14.47 as compared to 19.25 in 1922 , and 10.21 as measured at the Desert Laboratory. Upon consultation with a number of people who have spent many summers in camp in the forested area of the mountains, I found the general impression to be that the summer of 1923 was one of great. cloudiness and continued high humidity and dampness, and the impression also prevailed in consonance with the records that the rainfall had been moderate or below the average. Unfortunately, no records of the evaporation had been taken for several years. In view of the fact that the rainfall totals do not correspond with the thickness of the woody layers formed on the pines in the Santa Catalina Mountains, it must be decided that these, as in the Monterey pine, may not be held as reliable indices of the precipitation factor in climate. The facts noted above, however, do suggest that pines which, like $P$. arizonica, $P$. chihuahuaensis, $P$. scopulorum, $P$. strobiformis, and perhaps $P$. ponderosa, inhabit regions in which the beginning and end of the growing-season seems to be determined by the percentage of soil moisture resulting from the precipitation of the current season, are in a critical condition with respect to this feature and to relative humidity as largely determined or accompanying cloudiness. Extension of the growing-season by earlier or later rains might reasonably be expected to show in the layers of wood, although the occurrence of early rains in 1922 did not show such direct effect. A favorable season would be one in which the soil moisture would be adequate, the temperature range within the limits of growth, and the illumination sufficient for photosynthesis, while the relative humidity would be such as to prevent excessive transpiration. In the case of the pines on the Santa Catalina Mountains, all of the conditions seem to range within favorable limits during July and August, except relative humidity. When that feature is increased by cloudiness, maximum wood-formation takes place. 


\section{THE YELLOW PINE.}

A dendrograph of an old design was attached to a yellow pine (Pinus scopulorum) near the forest experiment station in Fort Valley, near Flagstaff, Arizona, in the summer of 1920. The instrument was set to give a small amplification and the tree was nearly quiescent during the season, with the result that the records were indeterminate.

Instruments were attached to two trees near the same place on May 14, 1923, and the adjustments were made to give amplifications of 14 for No. 1 and 18 for No. 2. The location is at an elevation of over 7,000 feet, the soil is volcanic, and the rainfall total has an average of 23 inches. About 40 per cent of this comes in the winter and most of the remainder falls during the summer thunder-storms. Both trees were in the inclosure of the buildings of the station and the observations were carried out personally by Mr. G. A. Pearson, who has been in charge of the station for 15 years.

Tree No. 1 was about $40 \mathrm{~cm}$. (15.8 inches) in diameter, being still in a condition in which the elongation of the main stem was proceeding vigorously. No enlargement of the trunk was visible until June 1, which was two weeks later than No. 2, which stood only 400 feet away but was much younger. The daily equalizing variation at the time of beginning growth was about $0.3 \mathrm{~mm}$. daily, which amount sustains a much smaller proportion to the diameter of the trunk than the variation in No. 2. Growth was apparently continuous until about August 24. During this time the total recorded increase in diameter was about $4.5 \mathrm{~mm}$. An examination of a sample taken by the increment borer from a place near the contacts of the instruments showed two opposite layers, 2 and $2.5 \mathrm{~mm}$. thick. The daily variation ranged from 1 part in 1,300 at the beginning of the growing-season to 1 part in 800 at its height. This rate had decreased but little by the end of August.

Tree No. 2 was $14 \mathrm{~cm}$. (5.4 inches) in diameter at the height at which the instrument was attached and was about 14 feet in height. It, as well as No. 1, stood in an open formation in which the amount of shading was negligible. At the time of the attachment of the instrument on May 14 the daily equalizing variation in the diameter of the trunk amounted to about $0.3 \mathrm{~mm}$., or 1 part in 450 . Some slight enlargement was noticeable on the 16th, which continued for about 72 days, with a total enlargement of 4.5 $\mathrm{mm}$. in diameter in this time. But little increase took place in the 12 days beginning July 27, but on August 8 the pen began to rise in its course, and during the following week a further accretion of about $0.5 \mathrm{~mm}$. was made. After this the increase was very slight. The total of the two layers in samples from opposite sides of the tree was about $6 \mathrm{~mm}$. The daily variation had increased slightly in the time of most rapid growth, amounting to 1 part in 350 in the first half of July. The amplitude of the variations had decreased to that shown at the beginning of the season by the latter part of August.

The period of enlargement in the larger tree was from June 1 to August 24 , or 85 days inclusive; that of the smaller and younger tree may not be determined so exactly. Enlargement began on May 16; an intermission of 12 days was seen at the end of July, and decisive increase ceased on August 15. The time between the two dates given would amount to 91 days. 
The record of the growth of a tree of Pinus ponderosa on the slopes of Pike's Peak in 1920 show that in this case a slight growth was displayed on June 14, before the buds awakened, but that the seasonal enlargement did not begin until August 12, and practically all of the season's formation of wood, amounting to an increase in diameter of $2 \mathrm{~mm}$., took place in the period of 23 days following. (See Growth in trees, Carnegie Inst. Wash. Pub. 307, p. 29, 1921.)

The behavior of an Arizona pine (Pinus arizonica) in 1922 was similar. A slight growth impulse was exhibited early in June, followed by a period in which only equalizing variations might be seen, then in mid-July actual enlargement of the trunk began, following the summer rains, the periods from the first display of activity to the end of enlargement being 88 to 90 days.

\section{THE CALIFORNIA REDWOOD.}

Some of the considerations presented in the preceding paragraph were taken into account in the arrangement of dendrographic observations of Sequoia sempervirens, the California redwood. This tree finds its best conditions for existence in the coastal region of northern California, where it formed dense and extensive forests in valleys with gentle slopes, in which it extended far back from the coast between latitudes $38^{\circ}$ to $41^{\circ} \mathrm{N}$. South of the Bay of Monterey, and between latitudes $36^{\circ}$ and $37^{\circ} \mathrm{N}$., the tree is found only in the deeply cut cañons with steep slopes which come down directly from the summits of the Santa Lucia Mountains, which are at no place more than a few miles from the shore. In every one of these cañons the tree extends up the laterals, actually reaching the crests at 1,600 to 1,800 feet in some cases. These outliers do not attain average normal size, and groves of dwarfed individuals of great age may be found on slopes exposed to the direct action of winds from the sea, which have some resemblance to the wind-blown and stunted trees of various pines which characterize the timber-line region of high mountains.

Measurement of redwood trees was carried on in Palo Colorado Cañon during 1921, 1922, and 1923. Five trees in all were kept under observation. All of these were about 2 miles from the sea, at an elevation of less than 1,000 feet, and at a point about 12 miles south of the Coastal Laboratory at Carmel. Furthermore, these trees were within 100 miles of the extreme southern limit of the species.

Tree No. 1 stood on a south-facing slope at the upper margin of the thin strip of forest which filled the cañon below. It was near the residence of Mr. H. B. Vandall, who gave the information that it had come up near an outflow of water within the memory of persons living, and probably had an age of about 30 years. This estimate is confirmed by a core taken out by an increment borer. The trunk was about 15 inches in diameter when the measurements were begun in April 1921, and some basal side-shoots were cut away in making arrangements of the dendrograph.

The floating frame of bario bars was first attached to the tree on April 8, 1921. The buds at this time were still quiescent on the uppermost branches, but those near the ground, where they were less exposed to the cool winds and might receive radiation from the ground warmed by the sun, showed an elongation of as much as $15 \mathrm{~mm}$. on some branches. 
Increase of diameter, with marked daily variations, continued at a vary. ing rate until October 21, giving a growing period of 190 days. The total increase in diameter was $24 \mathrm{~mm}$. The only actual interruption of the upward trend of the recording-pen was during a period of a few days of hot, dry weather the first week in July (fig. 5).

The instrument was taken down November 9. It was again put in place on April 5, 1922. Upward movement of the recording-pen, marking the beginning of the activity of the cambium, was shown on April 19. The activities of the buds began in some instances before the dendrographic

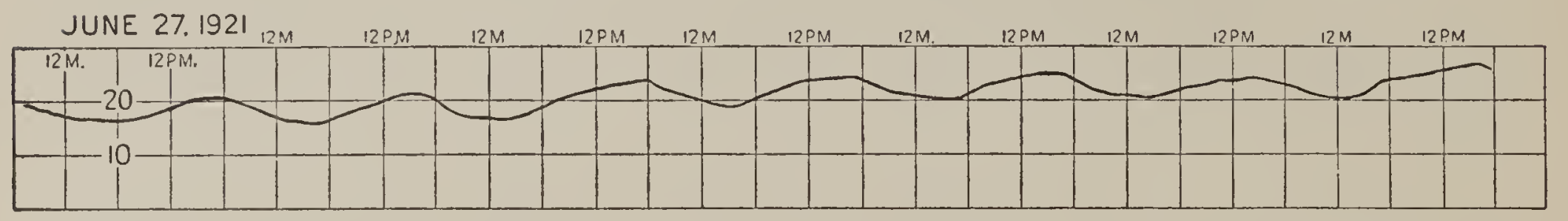

JUNE 20, 1921

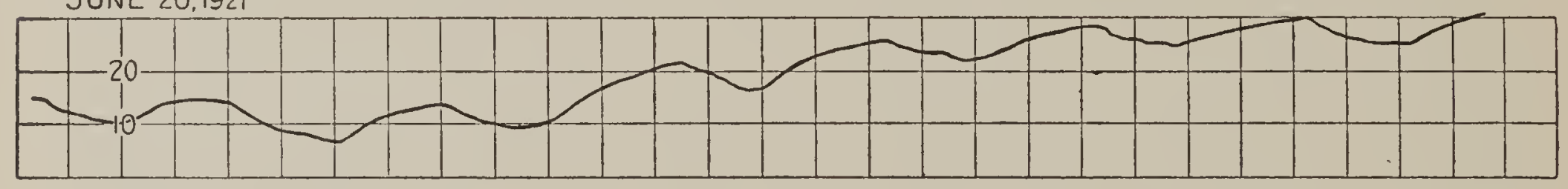

MAY 30, 1921

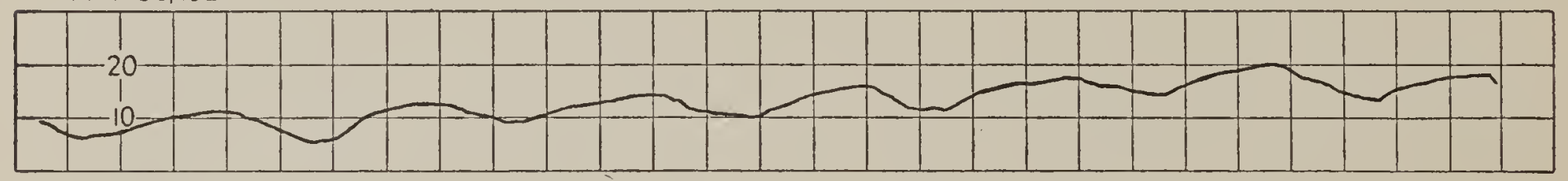

MAY 2,1921

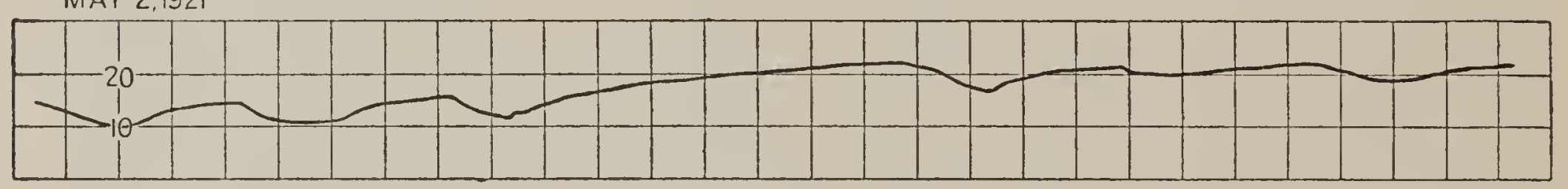

APRIL II. 1921

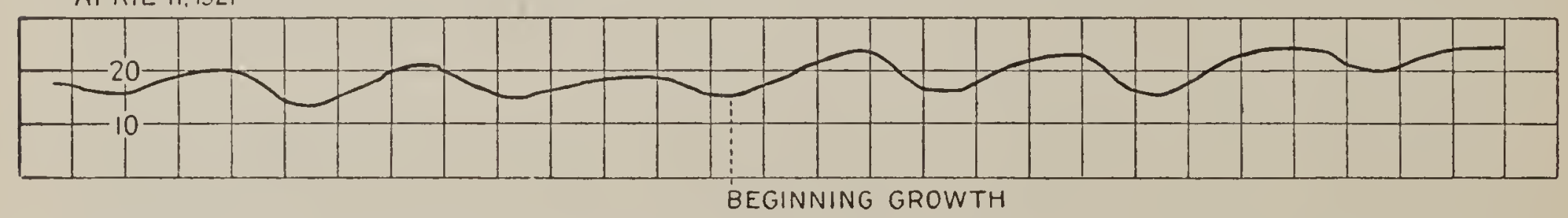

FIG. 5.-Facsimile of weekly dendrograph records of redwood No. 1. The beginning of the growing-season is seen in lowest record. The absence of daily contraction is recorded in week beginning May 2, during a rainy period of 2 days. The changing character of rates of growth and of character of daily variations with the advance of the season is illustrated by the other records. Horizontal intervals represent 6 hours, and vertical spaces $1 \mathrm{~cm}$. The actual variation of diameter of trunk is amplified 10 times.

increases were recorded, but on others awakening came later. Many branches were seen on May 8 which had recently made an elongation of 2 to $4 \mathrm{~cm}$. The increase was interrupted for a period of a few days early in July by hot, dry weather, but the period of growth extended to October 24 , and may thus be seen to include a period of 202 days. The total increase in diameter was $17 \mathrm{~mm}$., which, it is to be noted, was less than the accretion for 1921. The rainfall at Carmel, 12 miles to the northward, was $\mathbf{1 7 . 5}$ inches in the year terminating in midsummer of 1921, and as no rainfall occurred during the remainder of the growing-season, the reference to this measurement seems pertinent. The slope immediately above the tree was irrigated to some extent, however, and no direct connection may be taken 
for granted. The total amount for the second year was about 23 inches at Carmel. This higher precipitation is seen to be associated with a longer growing-period, but the matter of irrigation and the fact that the instrument used the first year was of a crude design makes it unsafe to make further comparisons.

Basal shoots arise freely from the trunks of the redwood, or from stumps of trees which have been broken off, cut down, or prostrated by the wind. A large proportion of the trees in such a forest as that in Palo Colorado Cañon probably thus arose as "suckers" on other trees. A stem of this type was taken as No. 2 of the redwood series. It had arisen from the surface of a large root of another tree slightly larger than No. 1, but standing only a few yards from it. The main trunk was $50 \mathrm{~cm}$. in diameter and the offshoot, which was to be measured, was $14 \mathrm{~cm}$. in thickness.

The dendrograph was attached on April 3, 1922. Daily equalizing variations only were apparent until June 6 , when a slight enlargement began which continued for a week only, resulting in an increase of about $0.5 \mathrm{~mm}$. The trunk of No. 1 had begun growth on April 19 and the main trunk of this one probably acted in the same way. After the first week the sucker showed only equalizing variations for a month, beginning to enlarge again on July 12 , at which time the daily variation was at a minimum.

The rate of increase was low and the growth which terminated on October 12 resulted in a total increase of but $5 \mathrm{~mm}$. The period from the beginning to the close of the growing-season was 128 days, but the trunk was active on only 100 days. Whether this restriction was due to the stronger competition of the main stem for the supply of moisture from the soil furnished by the common root-system is not known, but it is a reasonable inference.

The measurements of redwoods Nos. 4 and 5 were arranged to test this relation of two trees, one of which was borne as a younger offshoot of a large root of the other. This pair stood in a dense formation on the southward-facing slope of the cañon, in which the trees stand so closely together that the direct rays of the sun do not reach the ground and only the crowns of the trees are exposed to direct sunlight. This is in contrast with Nos. 1 and 2 , which stood fairly in the open.

The offshoot, No. 5, had a trunk which at a meter from the ground had a diameter of $27 \mathrm{~cm}$., including the bark. The bark was several centimeters in thickness and some of it had to be cut away under the support in order to get a firm bearing. It was trimmed away to a thickness of a millimeter under the bearing points, in the usual manner. The record was started March 29, 1923. Enlargement was not discernible until April 29, when it began and continued at a slow rate throughout the summer. An increase of $4 \mathrm{~mm}$. in diameter had been made by September 2 , the end of the seasonal activities.

No. 4, the parent of the older trunk of this pair, was $60 \mathrm{~cm}$. in diameter over the bark. Enlargement was coincident with that of No. 5, the smaller trunk coupled with it and supposedly arising from the same base. The features of growth were approximately identical with those of No. 5. An enlargement of $6 \mathrm{~mm}$. in diameter had taken place by September 2, at which time growth ceased. 
No. 3 was one of a small clump of six trunks of nearly equal thickness arising around an old stump. At the point of attachment of the dendrograph it had a diameter of $20 \mathrm{~cm}$. over the bark. The soil was packed about the bases of the young trunks, which received something more of illumination than those of Nos. 4 and 5. Enlargement was noticeable on May 1 and an increase of $9 \mathrm{~mm}$. in diameter had taken place by October 2 . It was noticeable that the daily variation in all of these trees was less than that of Nos. 1 and 2, which were measured in the previous season and stood in more exposed places where the transpiration might undergo wide fluctuations.

The seasonal period of activity of No. 1 was 190 days in 1921, and 202 days in 1922; that of No. 2 in 1922 was 128 days. The time elapsing between beginning and end of activity in 1923 was 153 days for No. 3, the smaller young trunk with some exposure to direct sunlight, and 156 days for the older trunks which stood on a densely wooded hillside, where the direct rays do not reach the ground or illumine anything except the uppermost part of the trunks and the crown.

\section{THE ARIZONA WALNUT.}

Nuts of Juglans major, the Arizona walnut, were collected from trees growing at the 8,000-foot level in the Santa Catalina Mountains, near the Desert Laboratory, in the autumn of 1908. These were germinated at the

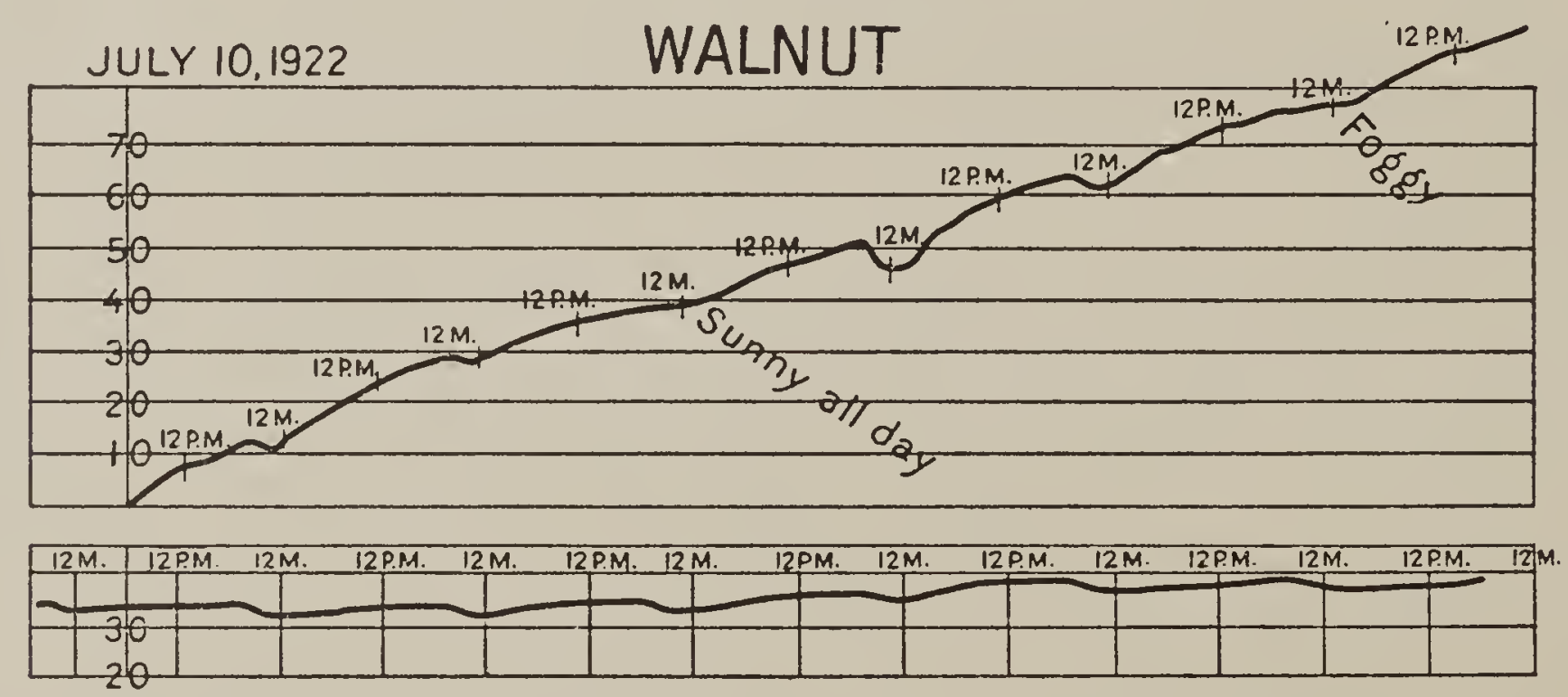

FIg. 6.-Facsimile of dendrographic record of trunk of Juglans (lower part of figure) and of a nut of the same tree in week beginning July 10, 1922. Noon $(\mathrm{Nn})$ and midnight $(\mathrm{Mt})$ are marked on the records. The vertical spaces are $10 \mathrm{~mm}$., the variations of nut and trunk are amplified 10 times. The coincident contraction and expansion of the two is to be seen, the changes being more abrupt in the nut (fig. 7 ).

Coastal Laboratory in 1909 and a few young trees were preserved for comparative experiments dealing with the activities of the species in the two places. In 1920, one tree, now 11 years old, had attained a thickness of 15 $\mathrm{cm}$. at a distance of $80 \mathrm{~cm}$. above the base. A dendrograph was attached at this point on February 13, 1920, and the tree kept under observation during the greater part of three seasons following. The first year the buds began to unfold in the week beginning March 15, but no expansion of the trunk showed until about May 3, when the tree was in full leafage and the 
branches showed much elongation. The flowers were matured during the week beginning May 17. About this time the daily equalizing variation, which had not been very marked, began to be apparent and was very noticeable on sunny or warm days.

Enlargement was at an end on August 10, a total increase of $6 \mathrm{~mm}$. in diameter having taken place. Some slight swelling was discernible after this date, but the resulting accretion was not more than a small fraction of a millimeter. The period in which growth occurred was therefore about 85 days.

\begin{tabular}{|c|c|c|c|c|c|c|c|c|c|c|c|c|c|c|}
\hline & & & & & & & & & & & & & & \\
\hline$A \cup C$ & GUST & 7.192 & & & & & & & & - & & & & $\therefore$ \\
\hline & & & & & & & & & & & & & & \\
\hline & & & & & & & & & & & & & & \\
\hline & & & & & & & & & & & & & & \\
\hline JUI & LY 10 , & 1922 & & & & & & & 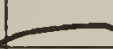 & & $\longrightarrow$ & & & \\
\hline- & & & & 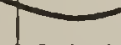 & & & & & & & & & & \\
\hline & & & & & & & & & & & & & & \\
\hline & & & & & & & & & & & & & & \\
\hline & & & & & & & & & & & & & & \\
\hline & & & & & & & & & & & & & & \\
\hline & & & & 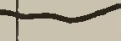 & & $\mathrm{R}$ & ain & 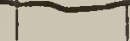 & & 工 & & - & & \\
\hline- & & & ain & & & & & & & & & & & \\
\hline & & & & & & & & & & & & & & \\
\hline & & & & & & & & & & & & & & \\
\hline JUL & $=3.1$ & 922 & & & & & & & 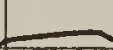 & & - & & L & \\
\hline & & 7 & & - & & 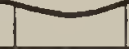 & & & & & & & & \\
\hline & & & & & & & & & & & & & & \\
\hline & & & & & & & & & & & & & & \\
\hline & & & & & & & & & & & & & & \\
\hline JUN & VE 12 , & 1922 & & & & & & & & & - & & 工 & \\
\hline & & & & & & & & & & & & & & \\
\hline
\end{tabular}

Fra. 7.-Facsimile of dendrographic records of Juglans in its habitat, Santa Catalina Mountains, Arizona. The varying rate of increase and minor variations, in addition to the daily changes, are illustrated. (Compare with fig. 6.) The vertical spaces are $10 \mathrm{~mm}$. The variations in diameter are amplified 10 times. The horizontal divisions are periods of 6 hours.

The instrument was taken down on October 7. It was again attached on April 11, 1921, and enlargement began on April 18. The flowers were mature in the week beginning May 16. Some enlargement continued until September 30, thus making a period of growth of 165 days, which was nearly double that of the preceding season, the total increase being also greater and amounting to nearly $10 \mathrm{~mm}$. The record was continued until October 24 (fig. 6).

The dendrograph was again attached to the trunk on April 6, 1922. The leaves were already unfolding, but no increase could be detected until May 18. This continued until September 15, a period of 120 days. The total increase in thickness during this time was $12 \mathrm{~mm}$.

A general correlation between the amplitude of variation in the trunk and in the nut was discernible, the greatest daily variations being in the second week in August, when the nut had attained nearly mature size and the greater part of the wood had been formed for the season. 
The variations from season to season in this tree are of no little interest. In being established at this place, it is put under conditions which tend to a much exaggerated activity in growth. Such acceleration was attended by wide variability from season to season. The single tree measured in the habitat of the plant, as described below, was a few years older, but made a growth of only $4 \mathrm{~mm}$. in diameter in a seasonal period of 95 days. The tree in the coastal location showed growing periods of 85,165 , and 120 days in succeeding seasons, with increases of 6,10 , and $12 \mathrm{~mm}$. in diameter. The period of full leafage, in which the formation of carbohydrates in the leaves might go on, was probably double that of trees in the native habitat, and may be held to account for the greater growth, which does not seem to be directly correlated with the duration of the growing-period.

In 1922, the arrangement was made to record the growth of one of these trees in the habitat from which the nut was obtained that grew into the tree, the growth of which for three seasons has been described above. A dendrograph was attached to the trunk of a tree, $20 \mathrm{~cm}$. in diameter, growing on the north slopes of the Santa Catalina Mountains at an elevation of 7,000 feet. The location was one very favorable to the species, but near the upper limit of its range. When the instrument was attached the leaves were beginning to unfold, but the bast seemed dry and inactive. This was on May 24, 1922. The cores taken from the trunk were difficult to interpret, but it may be safely taken for granted that the tree was between 15 and 20 years old, and hence older than the tree at the Coastal Laboratory which was measured (fig. 7).

Growth began on June 1, and flowers were mature in mid-July. The record was subject to various errors, but it is estimated that a total increase of about $4 \mathrm{~mm}$. in diameter was made during the growing period of 95 days.

\section{GROWTH OF NUTS OF JUGLANS MAJOR.}

Some measurements of the course of growth in nuts of Juglans californica quercina Babcock were made at Carmel in 1918, which have been previously described. ${ }^{1}$ Among other results, it was established that these bodies showed a retardation of growth after the manner of the aerial members of most mesophytic plants. It was also found that the developing nuts, the tissues of which are in a highly hydrated condition, receive water from stems in which there is a decided "negative" pressure. Sections of these stems were seen to absorb as much as 25 per cent of their volume upon being immersed in water. Sections of young nuts hydrated in water swelled but 1.4 per cent.

Similar measurements of a nut of Juglans major were made at Carmel, beginning July 3, 1922, and continuing until full size had been reached a month later. The nut had reached a diameter of $16 \mathrm{~mm}$. before it was brought into contact with the fused silica bearing-rod of a dendrograph lever-set, which was arranged to give an amplification of 17 . The age of the nut at the beginning of the record was probably about 10 days, or onefourth of its period of enlargement, with a volume of about $135 \mathrm{cu} . \mathrm{mm}$. At the end it had attained a diameter about double that given above and

\footnotetext{
${ }^{1}$ D. T. MacDougal. Hydration and growth. Carnegie Inst. Wash. Pub. No. 297. 1920. Especially pp. 162-166.
} 
had reached a volume of $1,070 \mathrm{cu}$. mm., or about 8 times the volume at the beginning of the experiment. The increase in diameter rose from $0.5 \mathrm{~mm}$. daily at the beginning of the first week to $0.55 \mathrm{~mm}$. daily; to $0.8 \mathrm{~mm}$. daily during the second week, then declined to $0.65 \mathrm{~mm}$. daily during the third week, and to $0.5 \mathrm{~mm}$. daily during the fourth week (fig. 6).

The most marked feature of growth was the cessation of enlargement early in the forenoon, followed by a shrinkage, which continued until midafternoon. Acceleration followed, so that by 3 or 4 p.m. the diameter of early morning was regained. The shrinkage, or falling off of the rate, was less marked on foggy days.

Stomata of the leaves showed an enlargement of their openings beginning about 8 a.m.-earlier on some days-which reached a maximum about 10 a.m., after which a diminution of the aperture began which brought the slits to dimensions equivalent to those of $8 \mathrm{a} . \mathrm{m}$. The shrinkage of the nut is therefore coincident with the period of greatest stomatal openings of the leaves. That it also includes some water-loss from the surface of the nut is probable, but the amount must be very slight. This is indicated by the fact that when the nut was shaded on a warm day the shrinkage was practically the same as when the nut was exposed. It would seem that the lessened diameter of the nut must be attributable to water drawn by the stem and leaves during the midday period. Bartholomew ${ }^{1}$ has shown that such a shrinkage may take place in lemons, due to withdrawal of water by the transpiring action of the leaves. Such withdrawal may result in the collapse of tissues in the lemon. No such effect was discernible in the walnut, but this result might be responsible for the failure of development of nuts in orchards.

\section{THE ARIZONA ASH.}

The record of the growth of Fraxinus arizonica for two seasons at Tucson, Arizona, has already been described. (See Growth in trees, Carnegie Inst. Wash. Pub. No. 307, 1921, pp. 34-36.) The dendrograph was kept in place on this tree at the close of 1920 and throughout the season of 1921 . It was notable that the daily equalizing variations in the trunk, which are so noticeable a feature of the behavior of this tree during the summer growingseason, had lessened with the quiescence of the growing layer and with the moist, cool weather of the desert winter. The record for the last few days of November and December 1920, and nearly all of January 1921, was but little deviation from a straight line (fig. 8).

Some daily variation was apparent in February. On February 23 the flower-buds were enlarging. This tree bore only staminate flowers. Two days later enlargement of the trunk began, but the leaves did not begin to unfold and the branches to elongate until March 1. So far, this and Parkinsonia aculeata are the only trees yet encountered which show enlargement of the trunk before the buds begin to show elongation of the branches. Vigorous growth continued until late in August, when short periods of a few days would occur when no increase was noted from the wide daily variations, alternating with other short periods when some enlargement

I E. T. Bartholomew. II. Growth-rate, water-content, and acidity of lemons at different stages of maturity. Amer. Jour. of Bot., 10, 117-126. 1923. 
occurred. The last of these terminated October 6 , which may be taken to be the end of the growing-season, which included 223 days, the longest yet recorded for any tree, although it is to be noted that its activity was some-

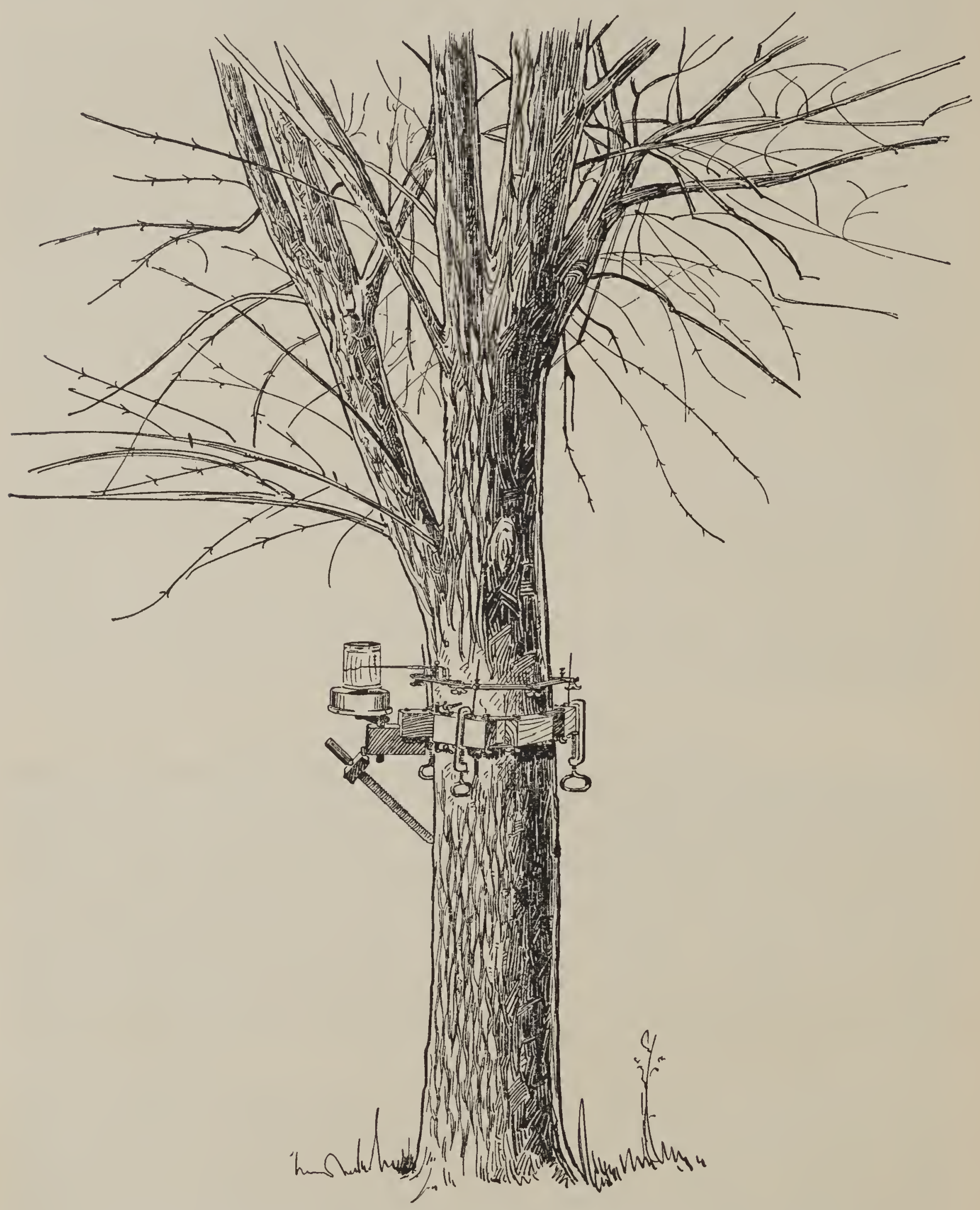

FIG. 8.-Arizona ash at Tucson, Arizona, with dendrograph by which a record for two years was obtained.

what fitful during 5 weeks of this period. The total increase in diameter during the season amounted to $19.5 \mathrm{~mm}$., which is to be compared with an increase of $26 \mathrm{~mm}$. in 1919 and $12 \mathrm{~mm}$. in 1920 . 


\section{THE PALO VERDE.}

The palo verde (Parkinsonia microphylla), of the Arizona and Sonoran deserts, is a small tree with a smooth green skin, which branches near the ground and survives in places with small water-supply. Its growth is extremely slow. The wood is soft, but, as shown by the records, the woody stems of this tree show but little variation, which was most marked in late summer.

A dendrograph was attached to the base of the trunk of a tree about $15 \mathrm{~cm}$. in diameter, in the patio of the Desert Laboratory, on January 7, 1920, and was closely attended until November 1 . No perceptible enlargement occurred within this time. This invariability seemed extraordinary, in view of the fact that in the period beginning in May the outer layers of the small trunk reached temperatures over $30^{\circ} \mathrm{C}$., and in June $40^{\circ}$ and $41^{\circ} \mathrm{C}$. were recorded.

It is evident that the growth of this tree is so slow that a much higher magnification would be necessary to follow its course.

The conditions under which the measurements were made were normal to the habitual range of the species.

\section{THE BAGOTE.}

This species (Parkinsonia aculeata) has its northernmost range in the vicinity of the Desert Laboratory, and it is cultivated extensively as a shade tree in Tucson. It makes a much taller trunk than P. microphylla and displays a higher rate of growth.

A dendrograph, with a floating frame of bario, was attached to the trunk of a tree about 16 years old in the grounds of the residence of Dr. H. W. Fenner, on February 16, 1921. The trunk had a diameter of $16 \mathrm{~cm}$., and an amplification of 10 was employed. The grounds were subject to such irrigation as is customary to keep grass and cultivated herbaceous plants in good condition in a desert climate.

Enlargement began on February 27, before any definite expansion of the leaves had been made. It was noted that these organs had reached lengths of 2 to $5 \mathrm{~cm}$. on March 12. An increase of about $2 \mathrm{~mm}$. in diameter had been made by April 5, when a period of actual shrinkage lasting 6 days ensued. Growth was again resumed, the daily variations being very slight and of a character resembling those of $P$. microphylla.

A second period of no growth came between June 12 and July 2, in which the hot, dry weather was accompanied by some slight increase in the daily variation. It is to be noted that the Arizona ash, as described in a separate section, did not cease to enlarge during this period, although it stood but a few yards away and was furnished with the same amount of water.

The growing-period was practically at an end on October 8, a total increase of $10.8 \mathrm{~mm}$. having been recorded. The period from the beginning to the end of the growing-season was 193 days, included in which were periods of no action or shrinkage amounting to 26 days. It is obvious that the increase in diameter was near the average for this tree. 


\section{THE SYCAMORE}

A dendrograph of the earliest design was attached to the trunk of a sycamore tree, $40 \mathrm{~cm}$. in diameter, in the Missouri Botanical Garden, during the growing-season of 1919 by the kind cooperation of Dr. George T. Moore and Professor B. M. Duggar. The faults of the assembly were such, however, that it was deemed advisable to repeat the measurements during the following year with a lever-set employing the sliding-rod contact, using material with a lower temperature coefficient.

Such an instrument was put in place on March 15, 1920. Low temperatures prevailed during the following 6 weeks, with much precipitation. During this time the pen traced a fairly direct line, there being almost no perceptible daily variation. The buds began to open in the week beginning April 5. The first actual enlargement began on May 10, when the leaves had not yet accomplished more than half of their final area. It is notable that the date was coincident with that of beginning growth of the Populus described in the following paragraph. Activity continued during the entire summer and until September 12, the total length of the growing-season thus being 125 days. The total increase in diameter is estimated to be about $10 \mathrm{~mm}$. The recording pens failed to ink properly during parts of several weeks, making defective records. It is notable here, as in the poplar measured at this place, that the daily variation was very small and did not occur as abruptly as in the pines, for example.

\section{THE CAROLINA POPLAR.}

A dendrograph was attached to a Populus deltoidea, with a trunk $35 \mathrm{~cm}$. in diameter, standing near the laboratory of the Missouri Botanical Garden, on December 27, 1919. The winter weather of this region is, of course, inclusive of rains and freezing weather. The record traced through January, February, and early March was irregular and broken and probably included some effects from ice formation on the instrument or in the bark. The measurements were under the supervision of Professor B. M. Duggar, to whom I am indebted for many interesting notes concerning the behavior of the tree.

The buds were observed to be opening at the end of March, at which time the surface and subsurface temperatures were observed to be ranging from $1^{\circ}$ to $23^{\circ} \mathrm{C}$. Actual enlargement was observable on May 10, at which time the leaves had not reached their full expansion, and temperatures ranged between $12^{\circ}$ and $26^{\circ} \mathrm{C}$. The growing-season terminated about July 2, after an increase of $8 \mathrm{~mm}$. in diameter had been made. The season was thus seen to extend over but 53 days. It is to be noted that the daily variations were of very restricted amplitude, even in the hottest weather, in which this tree is in agreement with the behavior of the other softwooded trunks, such as Parkinsonia and P. macdougalii.

\section{MACDOUGAL'S POPLAR.}

The growth of Populus macdougalii, which is native to the Colorado River Valley and of its tributaries, was carried on for two seasons. On February 23, 1920, an instrument was adjusted to a tree with a trunk 
$18 \mathrm{~cm}$. in diameter near the laboratory of the Agricultural Products Company at Continental, Arizona, which was run under the personal supervision of Dr. W. B. MacCallum. The floating frame was of invar and the recorder gave an amplification of 4.5, which is too little for a tree of this kind. The contacts were made by scraping away a thin external layer of the bark, exposing the green tissue underneath.

The leaves had made about one-fourth of their development and the tree stood near a ditch through which irrigation water flowed frequently. Some enlargement was noticeable on April 14, and increases continued until the end of August, with a total growing-period of about 140 days. During this time the trunk showed an increase of $17 \mathrm{~mm}$. in diameter.

On February 12, 1921, a dendrograph with a floating frame of invar was attached to a tree near the residence of Mr. B. R. Bovee in Tucson, and the observations were carried on by Mr. Bovee during the season. This tree had been grown from a cutting about 3 inches in diameter, and in the 10 years it had been in place had attained a diameter of $35 \mathrm{~cm}$. A core taken with an increment borer showed nine distinguishable layers of wood. The ground about the tree was subject to irrigation necessary to keep a coarse lawn in condition. Active enlargement began on March 5, at which time the fruits were full size and about mature, but the leaves had not attained more than three-fourths of their full expansion. The flowers were noted as opening on February 18, and the leaves as beginning to unfold a week later, or a few days before growth began.

The end of the period of activity came on September 20, 199 days after the beginning, with a total enlargement of $11 \mathrm{~mm}$. in diameter. It is to be noted that this period was not one of continuous enlargement. The first interruption occurred early in April, when a shrinkage occurred from the 5th to the 11th. This followed a snowfall on the night of the 4th, with temperatures under the bark of $8^{\circ}$ and $9^{\circ} \mathrm{C}$., which gradually rose within the week. A similar period of no growth was seen April 25 to May 1, following 3 days of high wind. Low temperatures caused a cessation of growth May 18 to 23. No growth occurred between May 27 and 30, enlargement being resumed after irrigation, suggesting lack of water as the inhibiting cause. The increase following irrigation, however, continued for 2 days only, to be followed by quiescence for 5 days. Irrigation on June 6 had a similar result, which was repeated with irrigation on the 14th, 20th, and 27th. When the summer rains began furnishing a more adequate supply on July 3 and 4 , the enlargement which resulted continued for a full week, but the week beginning July 11 was one of no growth. Increase following a supply of water by irrigation or by rains continued throughout the summer, it being evident that the tree was at all times existing on a marginal amount.

It is notable that the temperatures underneath the bark were at no time very high, $31^{\circ}$ C. being the maximum observation at $6^{\mathrm{h}} 30^{\mathrm{m}} \mathrm{p} . \mathrm{m}$. in June, $31^{\circ} \mathrm{C}$. at 6 p.m. in July, and $28^{\circ} \mathrm{C}$. in August. The maximum temperature during March at 5 p.m. was $25^{\circ} \mathrm{C}$., and in April $24^{\circ}$ C., while it went no higher than $27^{\circ} \mathrm{C}$. in May, these three months including the greater part of the enlargement. 
The daily variation was at no time very marked, as has been seen with other soft-wooded trunks. The interruptions in the growing-season suggest that the tree was near the limit of one of its environic components; what this might be can not be inferred unless it be an inadequate root-system or an impervious soil which did not allow ready penetration by the water. The behavior of the trees of this genus is of a character suggestive of wide variations in the water content of the trunks. An interesting example of this variation is given by Professor Craib, ${ }^{1}$ who found the water content of a trunk of Populus trichocarpa to vary with the wind in a singular manner.

\section{THE ARROYO WILLOW.}

A dendrograph was attached to the trunk of a Salix lasiolepsis growing on the margin of a small streamway in the garden of the Coastal Laboratory on January 13, 1922. The trunk was $14 \mathrm{~cm}$. in diameter and the tree reached a height of 8 meters. It was closely surrounded by a number of other trees of about the same size, but the crown was exposed to the general illumination.

Some daily variation was observable even during the moist weather of the spring months, with an ample supply of water about the roots. No enlargement was noticeable, however, until May 12, at which time a slight upward movement in the course of the recording pen could be seen. This was very gradual and ceased about August 4. The daily variations now balanced until August 27, when some increase was again noticeable, which continued until September 8. The growing-period, therefore, included a total of 119 days, with an interregnum of 12 days, as noted above. The increase in diameter amounted to $1.3 \mathrm{~mm}$.

\section{MEASUREMENT OF YEARLY INCREASE IN CIRCUMFERENCE OF TREE-TRUNKS BY MEANS OF THE DENDROMETER.}

A design for a dendrometer for registering the total increase in the circumference during any period, especially that of an entire growingseason, was presented in previous publication. Some extended use has been made of a few of these instruments during 1921 and 1922. The principal feature of such an apparatus is an encircling wire anchored at one end, the other being attached, as described, to a spindle turning freely on its axis, thereby lifting a weighted pointer upward along a scale which shows the increase in the circumference.

A complete belt of corrugated-brass strip of 30 or 32 gage is fastened snugly around the tree, so arranged that the increase in the tree will stretch and straighten this belt. The inward folds, which carry triangular supports for the encircling wire, are seated in the angles of these folds. As the tree increases these are pushed outward, carrying the encircling wire to a larger circumference, the accretion being duly registered by the pointer on the vertical scale. The selection of the encircling wire offered the chief mechanical problem in designing the instrument. As readings were to be made only at long intervals and would be of such magnitude as to make tem-

${ }^{1}$ W. G. Craib. Regional spread of moisture in the wood of trees. III. Notes from the Roy. Bot. Garden, Edinburgh, 14, No. 66, 1-8. 1923. 
perature coefficients of but little importance, chief attention was given to getting a wire that would be flexible enough to run through the guide loops and which would not corrode by exposure. Two suitable selections were found. One was the 10-carat gold wire of the dentist, and the other was Dr. Spechtenhauser's "wire silk" now used in surgery, being, in fact, fine cables composed of several minute bronze wires.

Two instruments of each were attached to trunks of trees in November 1922. One instrument, with the encircling or running wire of gold, was belted about Monterey pine No. 1 at B, near the dendrograph, and in October 1922 it showed an increase of circumference during the year of $4 \mathrm{~cm}$. The dendrometer encircled the tree below a whorl of branches and

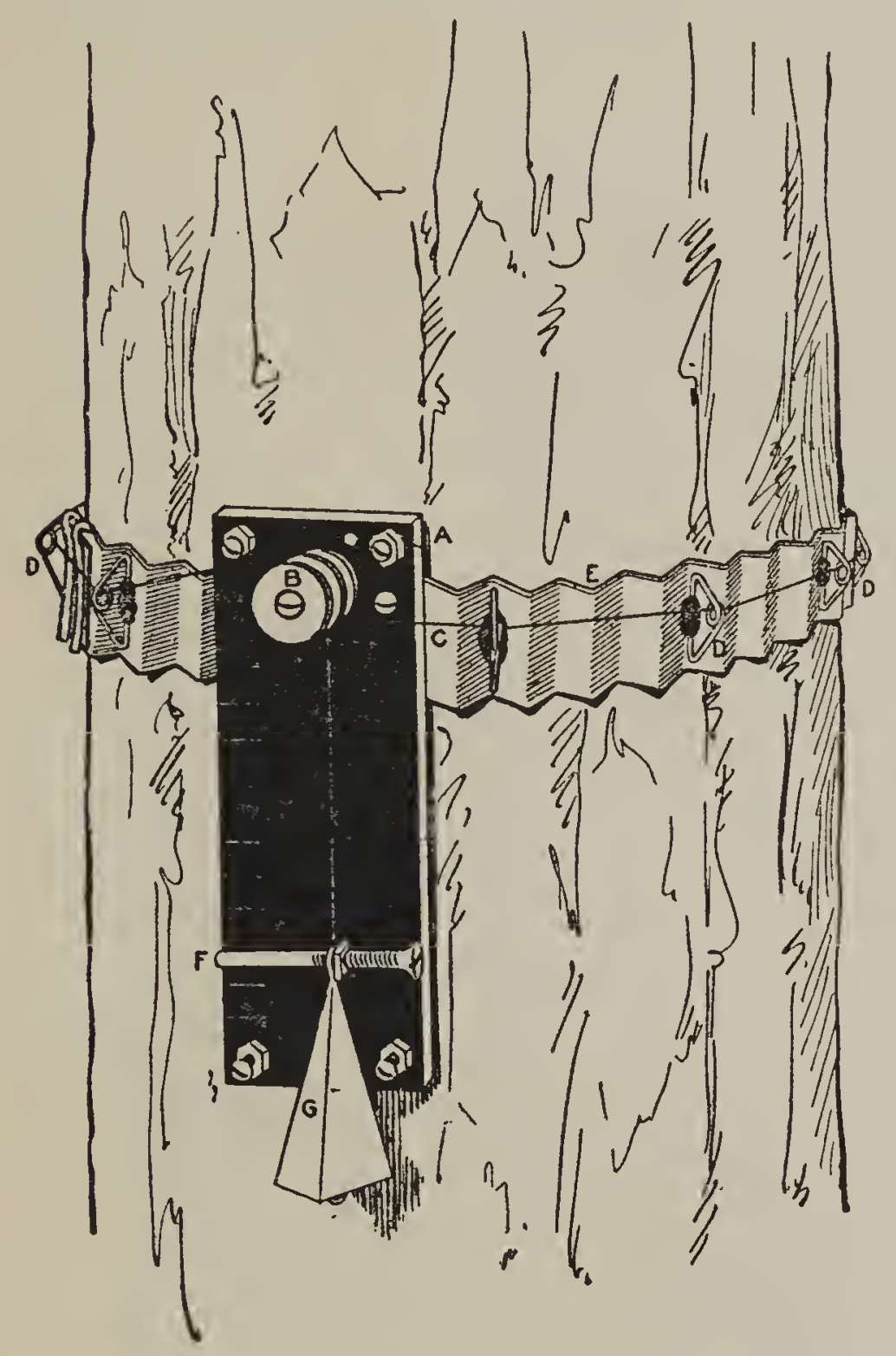
the diameter measured by the dendrograph was above, the two instruments being about $30 \mathrm{~cm}$. apart. The correspondence between the results was quite as close, as might be expected, when a single diameter and the circumference of an irregular trunk are used as a basis for comparison.

Another dendrometer, with an encircling bronze cable, fastened to the trunk of Quercus agrifolia about $18 \mathrm{~cm}$. in diameter, in October 1921 , showed an increase of $3.5 \mathrm{~cm}$. in circumference in October 1922,

FIG. 9.-Improved form of dendrometer. $A$, anchorage and adjusting-screw of encircling cable; $\mathrm{B}$, spindle with amplifying disks; $\mathrm{C}$, encircling cable of bronze or gold wire; D, D. $D$, guides for encircling cable; $E$. corrugated belt of sheet brass; $F$, indicator which has moved upward nearly two spaces, showing a similar increase in circumference, $X ; G$, weight for indicator and to keep encircling cable taut.

which would indicate an average increase of $1.3 \mathrm{~mm}$. during the intervening year. Such an increase is in harmony with the results of previous measurements by the dendrograph.

One instrument was fastened around the trunk of an oak of dimensions about the same as the one noted above, on a seaward slope, where it was exposed to fogs and winds. No more than the most minute amount of expansion could be detected during the year. The trunk was rough and covered with lichens, a condition suggestive of slow growth.

A fourth instrument, fastened around the trunk of a Monterey pine in the same locality and subject to the same exposure, showed an increase of $1.3 \mathrm{~cm}$. during the year. This indicated an increase of $4 \mathrm{~mm}$. in diameter, which is to be compared with an increase of $1.5 \mathrm{~mm}$. made by Monterey pine No. 12, which stood not far distant. 
An instrument, with the encircling wire of 10-carat gold, was attached to Monterey pine No. 1 at A (fig. 9) in January 1923, at the beginning of the growing-season. After the close of growth in September the indicator had been raised $42 \mathrm{~mm}$., which was 1.5 times the actual increase in. circumference. The calculation of the increase of the average diameter of the tree from these figures showed this to be nearly $9 \mathrm{~mm}$. The reduction of the dendrograph record showed that the diameter measured by this instrument during the period in question was $8.3 \mathrm{~mm}$. (fig. 9).

Another instrument, with an encircling cable of the wire silk, on a small tree of Quercus agrifolia, showed a movement on the scale of $70 \mathrm{~mm}$., which was 1.5 times the actual increase in circumference. This indicated an increase of $15 \mathrm{~mm}$. in the average diameter, which is often shown by young trees of this species in vigorous growth.

\section{THE SAHUARO.}

The measurements of growth of the cacti that have been made at the Desert Laboratory show that these plants undergo variations in volume which are determined by insolation, water-content of the soil, and other factors affecting transpiration and the water-balance. Mrs. E. S. Spalding found, as a result of her laborious measurements of the distance between the apices of the ridges of the trunks of Carnegiea gigantea, that the trunk expands with accumulated water and shrinks with desiccation, so that at a point 2 meters from the base the diameter of a sahuaro was 87 $\mathrm{mm}$. greater at one time in the year than in another in which the conditions had produced prolonged desiccation. ${ }^{1}$ I have determined the amount of water-loss that might take place from plants which were detached from the substratum and placed in a shaded room or in the open air. Thus a small plant $148 \mathrm{~cm}$. in length placed in a shaded room lost $8 \mathrm{~cm}$. in a year, during which time the weight fell from $32.5 \mathrm{~kg}$. to $28.7 \mathrm{~kg}$.

The general course of the changes in volume was followed by Mrs. Spalding throughout several seasons, and it was seen that variations of the greatest amplitude occurred in the median region of the trunk, but little change taking place at the base, while that at the summit was less than that in the thickest or most swollen part of the trunk.

The development of the design of the dendrograph and other apparatus for recording variations in volume of massive plants made possible the application of some new methods of determination of changes in volume by which the daily periodicity could be followed and a closer analysis made of the factors which cause such changes.

In the first of such measurements the contact-lever of an auxograph was brought into bearing on the bottom of the furrow at a point $15 \mathrm{~cm}$. from the apex of a Carnegiea $60 \mathrm{~cm}$. in height on January 4, 1919. A firm support was placed against the opposite side of the plant, by which arrangement changes in diameter were recorded.

The general trend of the record was to show a shrinkage through all of the period until May 21, with slight temporary increases following a rain

1 MacDougal and Spalding. The water balance of succulent plants. Carnegie Inst. Wash. Pub. No. 141. 1910. 


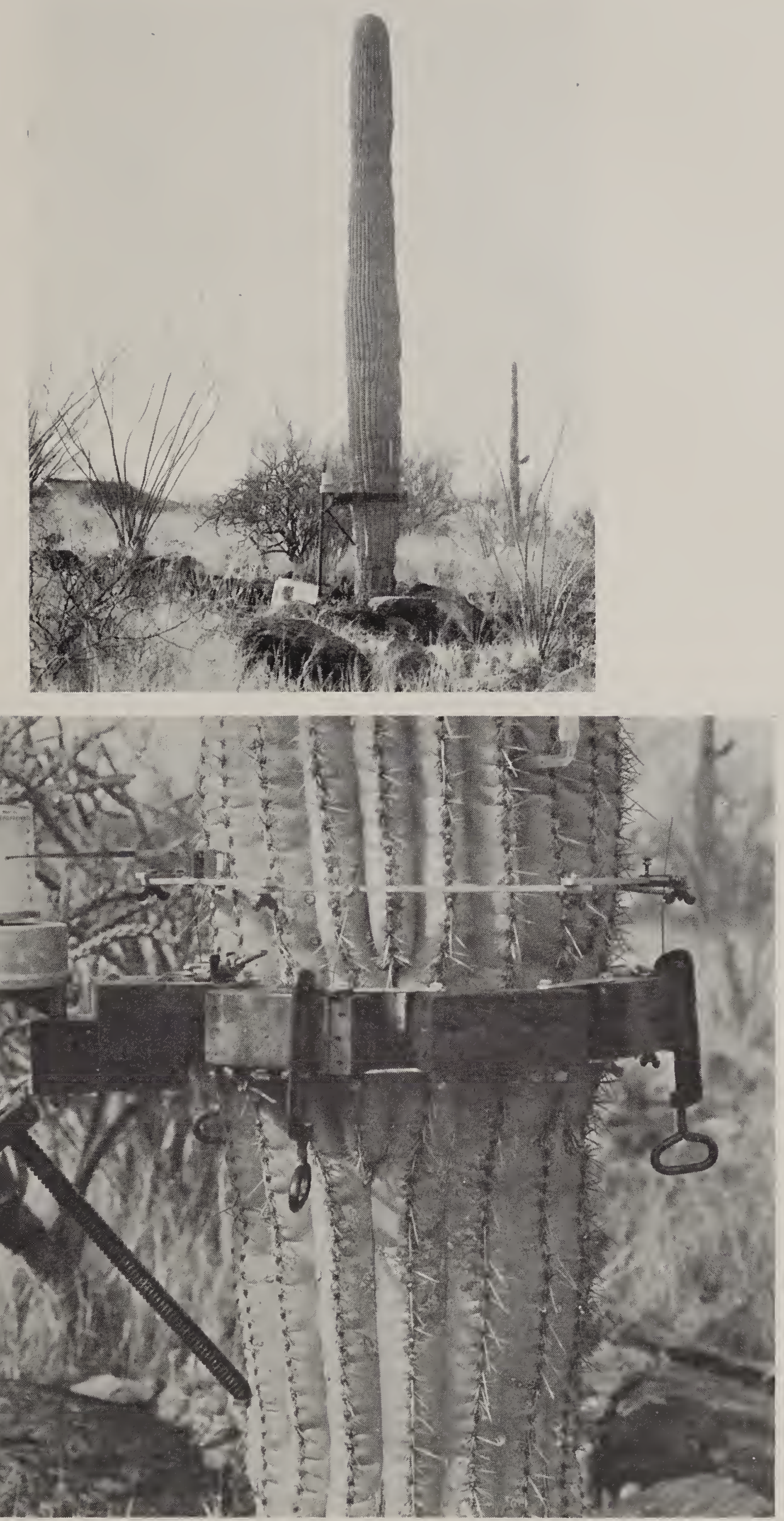

FIg. 10. A-Carnegiea No. 13, with dendrograph attached. B, Detail of attachment of instrument. The bearing points are in contact at bottom of the furrows. 
OHIVERSITY OF ILLWOIS LIORAR?

novanan 
and favorable temperatures. The daily equalizing variations became a marked feature by May 10. Increase of the diameter of the stem began about 9 a.m. and continued until sunset, when a gradual contraction ensued, which continued until after sunrise on the following morning. A rainfall of 0.75 inch on May 22 was followed by enlargement, which continued for three weeks. The record for the week beginning June 16 was faulty, but apparently the increase continued until June 27 , a period of over a month, before shrinkage again ensued, which continued until July 8, when the summer rains began. The supply of moisture was followed by increases which continued until July 28. A few days of shrinkage and enlargement again ensued. The arrangement of the instrument was crude and unsatisfactory, but the records made with it established the fact that the expansion and contraction sustained a relation to day and night the reverse of that of woody trees. It was also seen that in periods of drought actual contraction which resulted in shortening of the stem took place.

After some three years of experience with the dendrograph on the trunks of a wide variety of trees, it was thought possible to attach one of these instruments to the soft trunk of a tree cactus. The individual which had been No. 13 in the series of plants under observation by Mrs. Spalding was selected. Its height as recorded by her in 1910 was about 4 meters. At the close of the observations recorded below in 1923 its height was about 6.5 meters. The dendrograph was attached at a point about 1.2 meters above the base. The contact-screw of the instrument and the bearing-point of the recording-lever were both put into contact in the bottom of furrows, so that the diameter or distance between them was approximately $40 \mathrm{~cm}$.

The trunk at this point had a soft cortical layer several centimeters in thickness, a discontinuous woody ring, and a parenchymatous medulla, also several centimeters in thickness. It is to be seen that such a structure was one in which both growth and fluctuating variation could take place, although of lesser amplitude than in the upper parts of the trunk. The supporting belt of wooden blocks was kept firmly in place at all times by the additional use of a number of wedges of soft wood, which were thrust upward in the grooves of the trunk and were adjusted from time to time. This necessitated daily observation, which was done by Mr. B. R. Bovee, who also read temperatures from thermometers inserted in the trunks on the eastern and western sides at a level slightly above that of the contactpoints of the dendrograph (fig. 10).

The instrument was set to give an amplification of 9 , and even at this low multiplication the pen would run off the record-sheet within a week, the actual variation within this period being as much as $5 \mathrm{~cm}$. in some cases.

The measurements were begun on February 9, 1922. A slight shrinkage was in progress which continued at a varying rate until March 12. The daily variation during this time was very slight. The only check in the general course of the alteration was when three cloudy days, ending March 2 , were followed by warm weather, so that a small increase took place on three days. Shrinkage was resumed, but a snowfall of 4 or 5 inches on the night of March 11 began to melt the following afternoon. No change of any amplitude took place until the next day, when an increase set in which continued without interruption until April 12. Rainfall had occurred 
twice to increase the supply of soil moisture, and during this month the diameter of the stem had increased $34 \mathrm{~mm}$., which thus balanced the shrinkage of $8 \mathrm{~mm}$. which had occurred in February and March 11, and much beyond. Shrinkage of $6 \mathrm{~mm}$. now followed in the time ending May 3, with very great daily variations. Three days of swelling resulted in a gain of $1.3 \mathrm{~mm}$.

A week of shrinkage showed a loss of $2 \mathrm{~mm}$.; 3 days of swelling a gain of $3 \mathrm{~mm}$.; 28 days ending June 26 a loss of $14 \mathrm{~mm}$., which was checked twice but which was not stopped until a rain of 0.36 inch fell. The resulting increase of $2 \mathrm{~mm}$. was made within a week, to be followed by 2 days of equilibrium, then a rapid shrinkage of 6 days in which $8 \mathrm{~mm}$. in thickness were lost. Then ensued a gain of $2 \mathrm{~mm}$. in 4 days and a loss of $7 \mathrm{~mm}$. in 7 days, which was terminated by rains. The combination of rains and the high temperatures of mid-July caused a gain of $41 \mathrm{~mm}$. in the 9 days between July 20 and 29, and after a check for 2 days a further swelling of $2 \mathrm{~mm}$. followed. Beginning August 2 a shrinkage took place, ending August 25, which lessened the diameter $9 \mathrm{~mm}$. Heavy rains, amounting to 1.4 inches, caused an increase of $13 \mathrm{~mm}$. in 3 days, but after this time shrinkage followed which caused a loss of $4 \mathrm{~mm}$. in diameter. Rain was followed by a swelling of $3 \mathrm{~mm}$. A shrinkage now set in which continued from September 8 until November 17. At the end of this period a total loss of 33.6 $\mathrm{mm}$. had taken place. A gain of $3 \mathrm{~mm}$. was registered in the 3 following days. Contraction was resumed on November 20, which continued until February 5, 1923, then, on the anniversary of the beginning of the record, some expansion began. In the period from November 20 to this date a further decrease in diameter of $27 \mathrm{~mm}$. had taken place.

Features of interest during this period included a rain on October 28, which was not followed by any expansion, owing to the low air temperatures. No daily variations were exhibited on November 4 and under similar circumstances, as well as on November 13 to 16 , although the contraction was checked following this period.

If, now, the total expansions and contractions of the trunk as noted above are placed against each other, it will be found that the trunk had undergone total contractions of $118.6 \mathrm{~mm}$. and expansions of $106.3 \mathrm{~mm}$., so that at the end of the first year of measurement the trunk on the measured radii had a diameter about $12 \mathrm{~mm}$. less than on the same date of the previous year. The autumn and winter were deficient in rainfall, the total being below the average normal, and this deficiency continued during the spring and until midsummer.

An expansion began on February 6, 1923, which for a week was characterized by small daily variations. The swelling being due to rising temperatures rather than increased water-supply, the accentuated variations soon were visible, however. After an increase of $4 \mathrm{~mm}$., ending February 17 , a decrease began which had amounted to $9 \mathrm{~mm}$. at its termination on March 3.

Rains and rising temperature now resulted in a period of expansion by which an increase of $30 \mathrm{~mm}$. was recorded by March 20 . Of this amount $23 \mathrm{~mm}$. was gained in the week beginning March 5. Changes of such amplitude and speed made necessary daily adjustments of the instrument. A 
loss of $3 \mathrm{~mm}$. occurred in the period ending April 4; a gain of $1 \mathrm{~mm}$. in the following week; a loss of $3 \mathrm{~mm}$. in the following 3 days and a gain of $7 \mathrm{~mm}$. in a period of 6 warm days terminated by a cold rain; and a loss of $5 \mathrm{~mm}$. in the 10 days ending April 29. The daily variations were now becoming extremely accentuated, and after 3 days of uncertain action, expansion began, which had increased the diameter by $12 \mathrm{~mm}$. on May 11 . A loss of $2 \mathrm{~mm}$. took place in the 4 days ending May 14, after which a gain of $5 \mathrm{~mm}$. took place in the 5 days ending May 19; a loss of $1 \mathrm{~mm}$. ensued on the following 3 days; a gain of $1.5 \mathrm{~mm}$. on the next 3 days; a contraction beginning on May 25 was not checked until June 10 , a decrease of $10.5 \mathrm{~mm}$. having taken place. A gain of $2 \mathrm{~mm}$. was recorded in 2 days, then on June 12 contraction was resumed with a loss of $5 \mathrm{~mm}$., which was checked for 2 days with an indeterminate gain; a loss of $2 \mathrm{~mm}$. ensued in the following 3 days, and a gain of $2 \mathrm{~mm}$. in the 5 days ending June 26 . Then followed a week of slow loss with only slight daily variations, probably due to cloudiness, which terminated with a rain on July 5 , on which date a rapid contraction took place. The expansion which generally results from the increased soilmoisture by rains did not begin until July 11, or after the lapse of 5 days after the rainfall. The contraction in the previous 15 days amounted to $10 \mathrm{~mm}$. The rains now came at frequent intervals and the expansion was phenomenal, amounting to $42 \mathrm{~mm}$. in 4 days. The rate fell off rapidly in the fifth day, so that at the end of a further 5 days the total gain was but $7 \mathrm{~mm}$., 6 days with but little change followed, when a loss of $1 \mathrm{~mm}$. occurred in 6 days, followed by a gain of $7 \mathrm{~mm}$. by August 19, when a slow decrease set in with gently varying daily changes, so that on August 25 a loss of $2 \mathrm{~mm}$. had been recorded. An increase of $2 \mathrm{~mm}$. was noted by August 28, after which the variations for a few days were indeterminate. The trend of the variations was to lessen the diameter, however, so that a loss of 4 $\mathrm{mm}$. had taken place by September 24. A gain of $2 \mathrm{~mm}$. had taken place by October 1. If the losses and gains for 1923 up to this time be plotted against each other, an accretion of $68 \mathrm{~mm}$. is disclosed over the diameter of February 5, 1923, or $58 \mathrm{~mm}$. more than the diameter of February 1922 (fig. 11). ${ }^{1}$

Data obtained by Mrs. Spalding, which were put into a graph illustrating a paragraph by Professor V. M. Spalding ${ }^{2}$ on this subject, show that the trunk of this tree had a contraction from March until near the end of June 1906, and that the expansion following the summer rains did not bring the trunk back to its dimensions in the cooler season. The contraction in

1 The dendrograph record showed a shrinkage from October 1 to 2,1923 , during which period a loss of $14 \mathrm{~mm}$. in diameter occurred, the month being rainless. Rains beginning November 2 , with a total of 2.99 inches for the month, caused an increase of $17 \mathrm{~mm}$. during the first half of the month and a further slow increase which continued with but little interruption until December 31,1923 , despite the low temperature, with an additional gain of $6 \mathrm{~mm}$. The amplitude of the daily variations during December and also during the greater part of January 1924 was small. The total variation in January 1924 was slight, but during the last week in the month and in the first week in February, completing the two-year period of the observations, a shrinkage of $1 \mathrm{~mm}$. was recorded. If the net gain of the previous three months is added to that of October 1, 1923, it is found that the trunk had a diameter $66 \mathrm{~mm}$. (2.6 inches) greater than at the beginning of the observations, February 9, 1922.

2 V. M. Spalding. Distribution and movements of desert plants. Carnegie Inst. Wash. Pub. No. 113. 1909. See p. 58 and plate 23. 
the late summer terminated in November, after which expansion began which continued until February, at which time the circumference was practically that of March of the previous year.

It is to be seen from the foregoing that in Carnegiea the fluctuations in volume due to progressive water-loss or accumulation are so great that they may completely mask permanent accretions which constitute growth. The decrease in diameter of a trunk may continue for weeks, or even months, with but little interruption. An increase due solely to imbibition and accumulation of water may go on for similarly extended periods in such manner that an observer who directed his attention during such a period only might conclude that growth was taking place. The variation may affect the length as well as the diameter of the trunk.

These seasonal variations in volume, being due solely to the state of the water-balance of the trunk, rest solely on imbibition and transpiration, and hence may go on at temperatures and under cther conditions beyond the limits at which growth may take place.
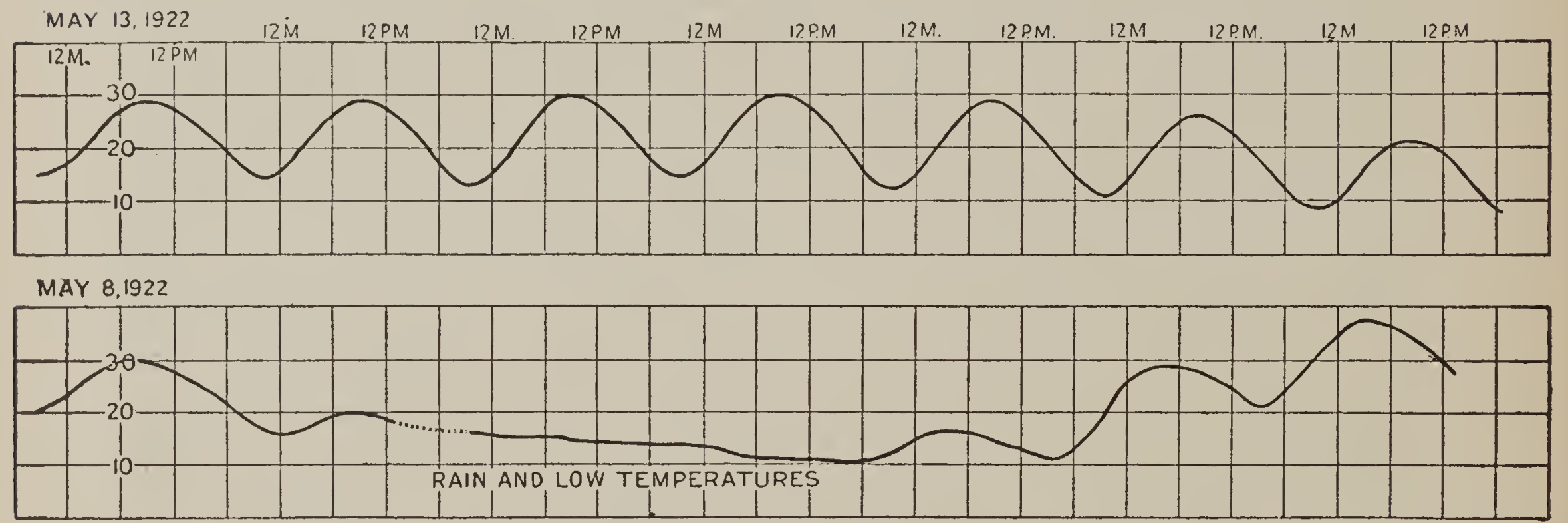

FIG. 11.-Facsimile of dendrographic record of Carnegiea for two weeks in May 1922. The lower record shows continued contraction after a rain with low temperatures. The upper illustrates the wide amplitude of daily variations in a period when no growth in diameter is taking place. Expansion begins before each noon day and ends before midnight. The horizontal intervals denote 6 hours and the vertical spaces $10 \mathrm{~mm}$. The actual variation is amplified 10 times.

A rise of temperature without addition to the soil-moisture may cause a swelling, as happened on 3 days ending March 2, 1922. A similar increase occurred in February 1923. A rain on October 28, 1922, however, was not followed by an increase. The temperature at this time being very low, the inaction may be ascribed to this factor.

The rainfall at the Desert Laboratory (table 7 ) is taken from a gage within 100 yards of the tree cactus. From the data for 1921, 1922, and 1923, given below, it may be seen that a decreasing series is formed. It is also evident that the soil-moisture resulting directly from the rainfall on the ground about the plant is the leading factor in determining growth.

Growth rests upon the separation of young cells from embryonal elements and their enlargement, first by accretion to the solid or continuous mass of the protoplasm, then by distention in which the osmotic action of the organic substances dissolved in the vacuolar solutions causes a ballooning, 
which greatly increases the volume of the cell without adding to its dry weight. Water is being taken in by imbibition chiefly during the first stage and by osmosis chiefly in the second stage, and is also being lost by evaporation from the external surface of the cell-masses at a varying rate all of the time. This water-loss is so marked, and the balance of water in the cortical cells of the Carnegiea is in such a critical condition that it is impossible to fix upon the period in which growth takes place. It is generally assumed that the enlargement which follows the increase of soilmoisture and relative humidity by the summer rains includes growth, but as all of the increase which takes place may be wiped out by the contraction in late summer and winter, this is not established.

TABLe 7.--Rainfall at Desert Laboratory, Tucson, Arizona.

\begin{tabular}{|c|c|c|c|c|c|c|c|}
\hline & 1921 & 1922 & 1923 & & 1921 & 1922 & 1923 \\
\hline $\begin{array}{l}\text { Jan.. } \\
\text { Feb.. } \\
\text { Mar. } \\
\text { Apr.. } \\
\text { May. } \\
\text { June. }\end{array}$ & $\begin{array}{r}\text { inches. } \\
0.25 \\
.29 \\
.15 \\
.56 \\
.00 \\
.65\end{array}$ & $\begin{array}{r}\text { inches. } \\
0.82 \\
.16 \\
.94 \\
.86 \\
1.10 \\
.85\end{array}$ & $\begin{array}{r}\text { inches. } \\
0.07 \\
.36 \\
.58 \\
.39 \\
.02 \\
.00\end{array}$ & $\begin{array}{l}\text { Aug.. } \\
\text { Sept.. } \\
\text { Oct.. } \\
\text { Nov.. } \\
\text { Dec.. }\end{array}$ & $\begin{array}{r}\text { inches. } \\
3.20 \\
3.44 \\
.31 \\
.44 \\
.18\end{array}$ & $\begin{array}{r}\text { inches. } \\
1.58 \\
1.44 \\
.14 \\
.31 \\
.14\end{array}$ & $\begin{array}{r}\text { inches. } \\
3.63 \\
0.30 \\
\text { Trace } \\
2.99 \\
2.24\end{array}$ \\
\hline July. & 6.46 & 2.19 & 2.02 & Total. & 15.93 & 10.53 & 12.61 \\
\hline
\end{tabular}

Enlargement in the apical part of a small plant in the open at the Desert Laboratory began in the latter part of April 1916, as indicated by the movement of spines upon which an indicator lever was resting. Another plant had been established in a box of soil in a glass house, and recording levers of an auxograph put into bearing on the tip of a young spine and upon the surface of an areole near its base. This was done on April 4. Both spine and tissue were already in a stage of enlargement. The plant had been kept supplied with water, and the chief alteration in the environment consisted in the rise of the temperature with the advance of the season, no artificial heat being supplied.

Temperatures were recorded by thermometers with the bulbs embedded in the cortex near the bearing-points, during growing periods of both spines and areoles. When the temperature fell to $13^{\circ} \mathrm{C}$. the areole ceased to grow, but the spine was still in a condition to elongate. The lowest temperature at which the mass of embryonic cells was found to enlarge was at $15^{\circ} \mathrm{C}$., and this may be taken to be near the minimum with soil and air conditions favorable. Growth was observed at $40^{\circ} \mathrm{C}$., which is probably not the maximum.

Growth was continuous during the month in which these records were kept, but the influence of stomatal action was as plainly apparent as in the variations of the diameter of the trunk as already described. The shrinkage of the cells due to excessive water-loss while the stomatal slits were at their widest on some days was greater than growth, so that an actual contraction appeared. Generally the influence of the excessive transpiration was to reduce the actual enlargement to a minimum, so that the recording-pen traced a line not far from horizontal. Acceleration, which is to be asso- 
ciated with closing stomatal slits, began between 8 and 10 a.m., and retardation was discernible by 6 or 8 p.m., which might in some measure be attributable to falling temperatures.

It would appear as highly probable that growth affecting the diameter of the trunks may take place as soon as the rise of temperatures in April furnishes suitable conditions. Some activity of the spines and apices is found at this time. The flower-buds also begin to develop in May, and come to maturity in June during the dry foresummer. The high rate of transpiration from the flowers may, in fact, affect the contraction of the trunks, by reason of the water which they withdraw from them.

While it was possible, as noted above, to interpret the variations in a small plant in such manner as to determine the general relation of growth to temperature, this could not be done satisfactorily with the larger one. Thermometers, with the bulbs thrust a few millimeters into the cortex on the eastern and western flanks of the trunk of the sahuaro, above the dendrograph, were installed, and these were read early in the morning and at midday for most of the two-year period during which the growth record was kept.

The morning reading was made shortly after 8 a.m., and as a result of the direct action of the sun that on the east side was generally higher than on the west; a similar difference was found at noon, although the maximum on the west side, as found by other observations, might be higher. Temperatures of $8^{\circ}$ to $21.5^{\circ} \mathrm{C}$. were found during February 1922, when shrinkage was in progress. Expansion followed a quickly melting snow on March 12, 1922, and continued for a month with readings of $6^{\circ}$ to $26.5^{\circ} \mathrm{C}$. After this, general action was one of contraction, lasting until the summer rains in July, with temperatures of the outer part of the trunk as high as $44.5^{\circ} \mathrm{C}$.

The notable expansion of mid-July took place after the rains, with readings of $24^{\circ}$ to $40^{\circ} \mathrm{C}$. Contraction in September took place at $24^{\circ}$ to $36^{\circ} \mathrm{C}$. After this the temperature fell with the advance of winter, so that readings between $4^{\circ}$ and $27^{\circ} \mathrm{C}$. were made in November, December, and January. A notable increase took place in March at temperatures between $5.5^{\circ}$ and $20.5^{\circ} \mathrm{C}$. The temperatures in June were again higher than those in the rainy period in July. The most marked gains of the season were at temperatures of $25^{\circ}$ to $38^{\circ} \mathrm{C}$.

It is evident that in such trunks the expansion and contraction of the cells by varying water-balance may be such as to mask the accretions due to growth.

The daily equalizing variations in diameter of the trunk of the sahuaro constitutes a very striking feature. Beginning at some time in the forenoon between 8 a.m. and noon, according to the external conditions and the state of growth, the trunk begins to enlarge and continues to do so until about midnight, when this is checked and the member passes into a condition of contraction, which continues until it is reversed on the following forenoon, to be turned into an expansion. Such a procedure may be followed day after day, at all times of the year, the upward or downward trend of the line traced by the recording-pen being determined by the resultant of the agencies which affect the size of the trunk. The principal factors con- 
cerned may be taken to include soil-moisture, as balanced against transpiration. When the trunk is receiving more water from the soil than is evaporated from its green surfaces, it will undoubtedly increase in size and

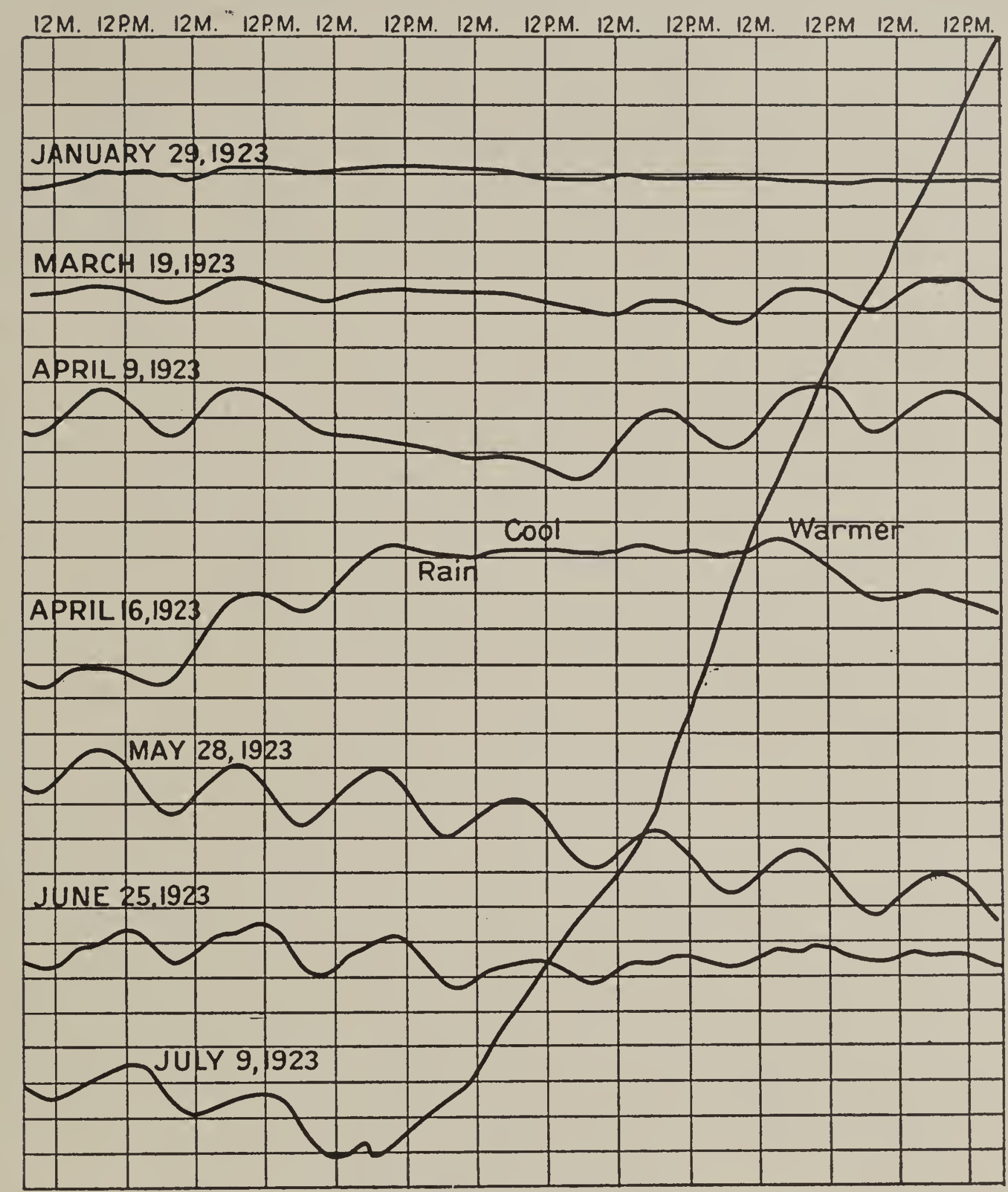

FIG. 12.-Facsimile of dendrographic records of Carnegiea in 1923. A period of reduced daily variation in the cool dry weather of January, one of increased variation in March, and still wider variation in April, are illustrated. Enlargement is seen in week beginning April 16, followed by continuous shrinkage in the dry, hot weather of May. The singular variations of the last week in June were produced by cloudy and humid weather. The abrupt expansion, amounting to $42 \mathrm{~mm}$. in diameter, during the week beginning July 9 , was caused by the absorption of soilmoisture from heavy rains falling on the 11th. The horizontal intervals denote 6 hours, and the vertical spaces $10 \mathrm{~mm}$. Actual variation is amplified 9 times.

the heavy layer of very thin-walled cortex forms a very readily acting expansion mechanism (fig. 12).

That temperature is not a direct factor is obvious from the fact that although the beginning of expansion of the trunk is coincident with high air 
temperatures, and with a rising temperature of the trunk, this enlargement continues until the temperatures have begun to fall, and for 5 or 6 hours more, in both the air and in the trunk. The period of expansion extending from midday until nearly midnight, the direct action of light may not be taken as a direct or primal cause in the matter.

Direct measurement of transpiration has not been made, but it is evident that with a surface the epidermis of which has a waxy outer wall the chief water-loss takes place through the stomata. The action of these organs, therefore, becomes a matter of prime interest. According to measurements made for me by Dr. Gorm Loftfield, in April, the stomata which are seen to be in a condition in which the slits are becoming narrower are most nearly closed about noon, and remain so until about 10 p.m., when they begin to open. It is probable that with the advance of summer that closure takes place earlier in the day. It is quite clear, however, that in any plant the expansion phase of the daily equalizing variation of a living member takes place during the period of least water-loss, and the contraction during that of the greatest. As may be seen by reference to the other sections of this paper, the period of closure of the stomata in Opuntia is between midforenoon and evening, with corresponding periods of expansion, while all of the woody trees upon which observations have been carried out show open stomata during the daytime, with this period characterized by a tendency more or less expressed to show a contraction. Such a periodicity was exhibited by fleshy fruits, legumes, nuts, and stems of herbaceous plants.

It is to be noted that when the trunk was in a general condition by which it was getting larger continuously, the expansion in the daily variation would be seen to begin as much as 2 hours before noon, while in periods in which a general decrease was taking place the daily expansion would not be manifest until as late as 2 p.m. The daily variation might be reduced to zero during periods of low temperature, while it reached the greatest amplitude in periods of high temperature in the drier parts of the year, particularly in May and June, when the air temperatures might reach $40^{\circ}$ to $45^{\circ} \mathrm{C}$. At such times the daily variation in a diameter might be as much as $2 \mathrm{~mm}$., or one part in 200 , which is a much higher proportion than the rate of variation in any tree with a woody trunk.

\section{GROWTH OF OPUNTIA.}

The general morphological features of the flattened joints of Opuntia and the course of their enlargement, together with many features or variation in length and thickness, have been described in previous publications. ${ }^{1}$

These joints have the form of flattened ovoids, the course of development of which may be followed from a length of 2 to $5 \mathrm{~cm}$. until maturity at 15 to $20 \mathrm{~cm}$. is reached in the species used. The joints are considered to consist of a number of fused internodes. The cambium remains active throughout the entire member, although the most active zone of elongation soon assumes a median position or nearer the apex.

Several features of the variation in length and thickness could not be explained on the basis of the facts previously obtained, and new series of

1 See especially, D. T. MacDougal. Hydration and growth. Carnegie Inst. Wash. Pub. ‘ȳ' pp. 128-144. 1920. 
measurements were desirable. The course of enlargement of some joints was followed at Tucson in April and May 1921, under the condition in which the plant was found growing as a native. Others were measured at the Coastal Laboratory, Carmel, California, where the equable conditions made possible an analysis of the relative action of various environmental factors.

In the earlier stages of growth the daily program is not like that of the stems of leafy shoots. Elongation was characterized by an acceleration beginning about 10 a.m., which continued until 2 p.m., when the rate diminished for an hour or two, then continued more or less uniformly at the lessened rate until the following morning.

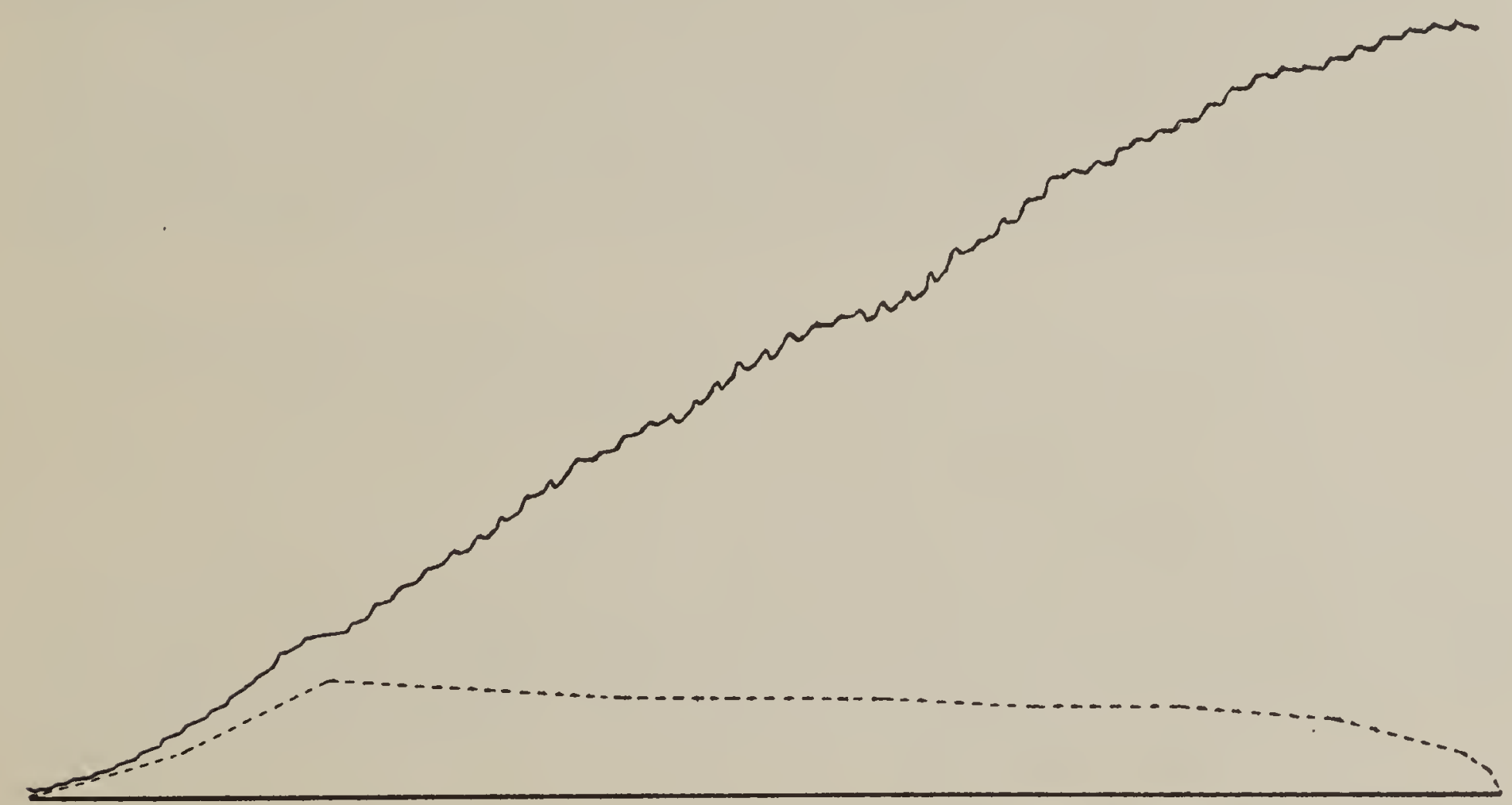

FIG. 13.-Auxographic record of joint Opuntia at Tucson during entire period of development March 23 to May 23, 1921, with rate of increase designated by broken line below. The baseline of the auxographic record was $240 \mathrm{~cm}$. long. (Drawing shows length of joint 2.) The marked contractions illustrated are not seen in figure 14.

The highest rate was coincident with the maximum temperatures of the joint during the midday period; that it is not unaffected by other factors is well proven by the fact that the lessened rate begins while the joint still stands at a temperature very favorable to growth. The acceleration does not ensue, except as initiated by rising temperature, as shown when young joints having temperatures of $9.5^{\circ}$ to $20.5^{\circ} \mathrm{C}$. for 44 hours, beginning on the afternoon of April 4, did not display the usual daily acceleration on the 5th. On the following day, when the temperature of the joint rose to $28^{\circ}$. C., the usual acceleration ensued.

At the end of the initial or embryonic period of the joint comes a juncture when growth is not only checked in mid-afternoon, but is totally canceled, and the cancellation a few days later is exaggerated into an actual shortening. The period of retardation is at first of about 3 hours' duration, terminating before 6 p.m. This is gradually extended, however, until shortening of the joint does not cease before 10 p.m. After this, elongation is resumed and proceeds at a slow rate until mid-afternoon, when acceleration sets in, which is slackened in mid-afternoon. 
The next feature which challenges attention is that of the stoppage of growth noted above, which becomes accentuated into shrinkage, and the amount of this shrinkage increases until it equalizes the daily elongation. (See fig. 13 in illustration of these phases of action.) During the last period the daily phases are not so well defined, and elongation may begin earlier in the day or be deferred, according to the water-supply given the plant.

The known factors which might influence the rate of growth of Opuntia, and which are contributory to the daily variations, are as follows: $(a)$ temperature; (b) water-supply and transpiration; (c) stomatal action; $(d)$ acidity of the sap; $(e)$ stage of development.

The rational interpretation of the marked daily variations in elongation of the joints of Opuntia may be made only when the bearing of all of the above factors or conditions are taken into account.

The records of Opuntia Nos. 2 and 5 of the series of 1921 have been selected for illustration of the action of this plant at Tucson in the present paper; Nos. 20 and 21 were measured in the equable climate at Carmel, California.

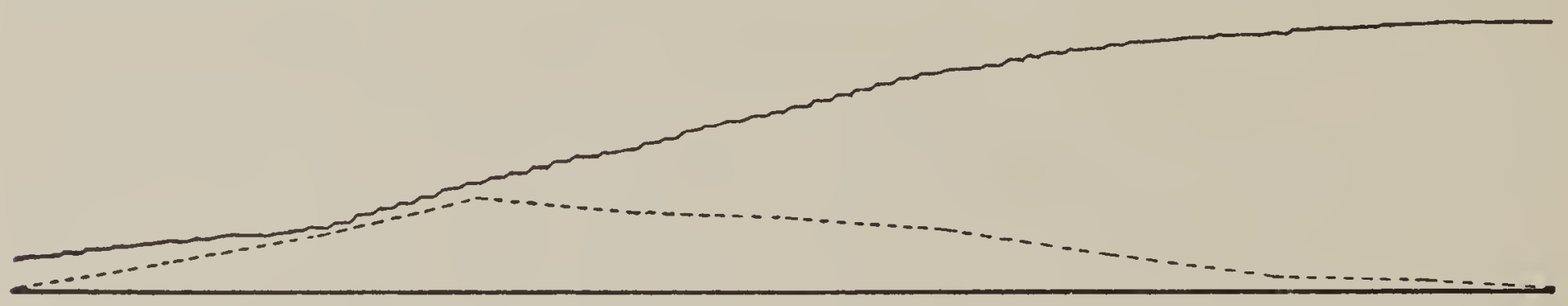

Frg. 14.-Auxographic record of Opuntia grown at Carmel May 21 to July 25, 1921, with rate of elongation denoted by broken line below. The base-line of original was $280 \mathrm{~cm}$. long. (Drawing shows dimensions $\times 0.5$.) Daily reductions of growth, but no contractions are seen.

The joint which developed in the more equable climate at Carmel, California, showed some departures from the above procedure, which is characteristic of plants in their native habitat. The most noticeable difference is that no actual shortening or shrinkage of the joint took place in the developmental or growing stage.

No definite difference in the duration of the growing-period was to be found in the plants grown in the two locations. Two joints at Tucson reached final lengths of 115 and $155 \mathrm{~mm}$. in 50 and 60 days. Two joints at Carmel reached lengths of 125 and $130 \mathrm{~mm}$. in 56 and 60 days.

The daily cycle included a period of more rapid growth between 9 a.m. and 2 p.m., at temperatures between $20^{\circ}$ and $37^{\circ}$ C. during the first 40 or 50 days of the earlier part of the development of the joint. This was followed by an abrupt change, in which elongation was reduced to a low rate at first and later in development to zero. Such retardation lasted until the following morning. As the joint approached maturity the duration of the daily more rapidly growing period lessened until it was not over 2 hours in length. After elongation by growth had come to an end for the season, a type of daily variation, which had been followed for many months, as described in previous publications, became apparent. By such daily equalizing variations the member was longest at midday, coming back to minimum dimensions early in the next day. 
If, now, all of the results of the measurements extending over many years, and of the transpirational and other studies made with Opuntia, are taken into consideration, the following summarized statement may be made as to growth and daily variations in volume. The temperature at which growth may proceed in these plants includes a range from $9^{\circ}$ to $58^{\circ} \mathrm{C}$, the maximum being the highest recorded for any seed plant. The highest rates of net elongation take place between $37^{\circ}$ and $49^{\circ} \mathrm{C}$. in plants in a habituated environment. These temperatures are taken from the shoots and may be at times higher and lower than that of the air. Operation at these high temperatures is connected with a high pentosanic content of the cells, which are not so easily coagulable, or their state of aggregation altered by high temperatures as albuminous emulsoids.

The seasonal variation in unsatisfied hydration capacity, which may be attributed chiefly to the relative changes in the main components of the plasmatic masses of the cells, are illustrated by the auxographic measurements of swellings of living sections and dried sheets of cells shown in table 8.

TABLE 8.-Seasonal variation in unsatisfied hydration capacity of Opuntia, at Tucson.

[Actual swelling at $18^{\circ}$ to $18^{\circ} \mathrm{C}$. in percentage of original thickness.]

\begin{tabular}{|c|c|c|c|c|c|c|c|c|}
\hline \multirow{2}{*}{ Date. } & \multicolumn{2}{|c|}{$\begin{array}{c}\mathrm{HCl} \\
0.01 \mathrm{~N} .\end{array}$} & \multicolumn{2}{|c|}{$\begin{array}{l}\mathrm{KOH} \\
0.01 \mathrm{~N} .\end{array}$} & \multicolumn{2}{|c|}{$\begin{array}{c}\text { Glycocoll } \\
0.01 \mathrm{M} .\end{array}$} & \multicolumn{2}{|c|}{ Water. } \\
\hline & Fresh. & Dried. & Fresh. & Dried. & Fresh. & Dried. & Fresh. & Dried. \\
\hline Feb. 12 1919.. & $\begin{array}{c}p . \\
146\end{array}$ & $\begin{array}{c}c t . \\
136\end{array}$ & $\begin{array}{c}p . \\
177\end{array}$ & $\begin{array}{l}c t . \\
175\end{array}$ & $\begin{array}{c}p . \\
208\end{array}$ & $\begin{array}{l}c t . \\
141\end{array}$ & $\begin{array}{c}p . \\
164\end{array}$ & $\begin{array}{c}c t . \\
168\end{array}$ \\
\hline Dec. $1919 \ldots \ldots$ & 23 & 164 & 29 & 253 & 28 & 200 & $\left\{\begin{array}{l}27 \\
20\end{array}\right\}$ & 200 \\
\hline Jan. 1920. . & 10 & 130 & 14 & 250 & 11.3 & 175 & 13 & 140 \\
\hline Feb. 1920. & 11 & 83 & 14.5 & 16 & & & 14 & 192 \\
\hline Mar. 1920. & 7 & 300 & 10 & 380 & 6 & 310 & 9 & 310 \\
\hline Apr. 1920. & 4.5 & 294 & 10 & 416 & 9.4 & 370 & 7 & 388 \\
\hline May 1920. & 36 & 170 & 44 & 215 & 44 & 110 & 32 & 135 \\
\hline Feb. 1921. & & 146 & & 17 & & 208 & & 164 \\
\hline Feb. 1, 1922 & 26 & 140 & 26 & 130 & & 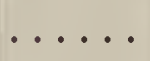 & 33 & 200 \\
\hline Feb. 1, 1923 . & 130 & 225 & 167 & 240 & & & 138 & 250 \\
\hline
\end{tabular}

The swelling of living sections is a resultant of the osmotic action of the cell-contents, alterations in permeability of wall and plasma, and the hydration capacity of the jellies of the cell in both wall and plasma. Increase in acidity by swelling living material in $\mathrm{HCl} 0.01 \mathrm{~N}$ was seen to result in a swelling less than in $\mathrm{KOH} 0.01 \mathrm{~N}$. Dried material gave similar results.

Later series show that at a concentration of $\mathrm{HCl} 0.001$ to $0.0002 \mathrm{~N}$ dried material showed a hydration greater than in water, and that this effect continued past the neutral point until a concentration of about $0.01 \mathrm{~N} \mathrm{KHO}$ was reached. This would indicate a protoplasm in which pentosans and soluble proteins were present in nearly equal quantities. As may be seen, the swelling capacity of the dead material is greatest in all the testing solutions in March and April in accordance with previous records, at which time the mucilages or pentosans had reached a high proportion. The course 
of the seasons is such that the water-deficit, or hydration capacity of living material, at the end of the winter dry season is often relatively enormous. By reference to table 8 and to previously published data, ${ }^{1}$ it is to be seen that sections of living joints of Opuntia swelled 214 per cent on January 3 , 1918; 164 per cent on February 12, 1919, and 138 per cent in 1923. The swelling for other years since 1918 in the corresponding period has been 13 and 33 per cent.

The relative action of acids and water and of three amino compounds is illustrated by the results obtained at the Coastal Laboratory, Carmel, in August 1919 (table 9).

TABLE 9.-Median slices of living material swelled at $15^{\circ} \mathrm{C}$.

[Increases expressed as percentages of original thickness.]

\begin{tabular}{|c|c|c|c|c|}
\hline & Propionic acid. & Alanine. & Phenyl-alanine. & Glycocoll. \\
\hline $\begin{array}{l}0.01 \mathrm{M} \\
0.001\end{array}$ & $\begin{array}{c}\text { p. ct. } \\
6 \\
7.3\end{array}$ & $\begin{array}{l}\text { p. ct. } \\
8 \\
7.5\end{array}$ & $\begin{array}{c}p . c t . \\
12 \\
6.5\end{array}$ & $\begin{array}{c}\text { p. ct. } \\
12 \\
10\end{array}$ \\
\hline Water. & \multicolumn{4}{|c|}{6 to $8 \mathrm{p}$. ct.; a verage of 9 sections, 7.3} \\
\hline Dried sections: & & & & \\
\hline 0.01 & 230 & 350 & 300 & 370 \\
\hline 0.001 & 267 & 320 & 310 & 220 \\
\hline Water & \multicolumn{4}{|c|}{250 to $300 \mathrm{p}$. ct.; average of 6 sections, 275 . } \\
\hline
\end{tabular}

These results also illustrate the action of the acid at $0.01 \mathrm{~N}$, and of the amino compounds at the same concentration. Alanine, phenyl-alanine, and glycocoll increase hydration beyond that possible in water alone in confirmation of results previously obtained. Such measurements have pertinent interest in the analysis of the daily variations, especially with respect to the acidity.

Richards and others have found that the acidity of the sap of growing joints increases through the night to a concentration where it is equivalent to $0.01 \mathrm{~N}$ malic acid at daybreak. Such a degree of acidity would evidently tend to reduce the hydration capacity of the cell colloids and hence lessen swelling or increase in size during the period in which the acids were accumulating.

There now remains to be considered the direct water relations as affecting absorption and transpiration.

The volume of the plant may at any time be affected by the balance between the intake at the roots and loss by transpiration. The coincidence of the open and closed conditions of stomata with phases of accelerated or slackened growth leaves but little doubt that these organs are concerned in an important way with the rate of water-loss and with consequent variations in volume. The stomata of the Opuntia used in these experiments were found by Dr. Gorm Loftfield to close in mid-forenoon and remain so until mid-afternoon. Opuntia versicolor closes the stomata on the surfaces

\footnotetext{
${ }^{1}$ Hydration and growth. Carnegie Inst. Wash. Pub. No. 297, pp. 131, 132. 1920.
} 
of its cylindrical green stems and does not open them until evening. The stomata of Carnegiea gigantea, the action of which is described in the previous section, are closed from about noon until 10 p.m.

If, now, the action of these various factors are correlated, it will be seen that the activity of a joint of Opuntia at any moment is a resultant of the complex agencies which may modify metabolism, but chiefly hydration of its colloids.

Beginning in the morning, the decreasing acidity of the sap allows greater hydration, which is also facilitated by the rising temperature. Respiration and the metabolic processes would also be speeded up. The closure of the stomata in mid-forenoon would lessen water-loss, while the rate of absorption was increasing. This conjunction would make for a maximum increase.

Now, in mid-afternoon, while all of the above factors are at an intensity which makes for accelerated growth, the stomata open and the rate of water-loss is so great that enlargement is balanced or canceled, and in the later stages of development the loss is so great as to exceed the amount of water which reaches the stem from its source of supply. That the deficit in the stem is a reality is accentuated by the fact that the shrinkage may take place in joints used as cuttings, the bases of which have roots depending in water, the joint having been habituated to such a culture method.

Plants measured in the equable temperatures of Carmel, and which did not reach the high temperatures of the desert, did not show actual shrinkage, but the cessation or slackening of growth was a daily occurrence coincident with stomatal action. The lower night temperatures tended to lessen transpiration, but the open stomata and the lessened hydration capacity of the protoplasm, due to accumulating acidity, tended to increase water-loss. A slower rate of growth, therefore, persists until the closing of the stomata on the following day.

Some elongation as secondary growth may take place in a joint of Opuntia in the season following its formation. The variations are of the type described.

One preparation was made by which the growth in thickness of such a mature joint rooted as a cutting in sand was recorded by the use of the dendrographic lever-set. This preparation stood on a bench near a window with a southern exposure. The record covered a period of 86 days, beginning February 28, 1922. The contact-rod was arranged to make a bearing on the basal part of the joint, which had a thickness of about $2 \mathrm{~cm}$. During the first 10 days of this period, before the adventitious absorbing roots had been formed, the joint showed a daily increase beginning shortly before 10 a.m., which ceased 2 hours later, when shrinkage ensued, which came to equilibrium in about 2 hours, to be repeated on the following day. Then followed 10 days of quiescence, after which steady enlargement began. The rate during the 3 weeks following was very low, but in April a thickening began which accelerated to $2 \mathrm{~mm}$. per week during the first week in May. A slow decrease brought the rate down to one-tenth this amount the last week in May. The daily increase during midday was discernible in the record on some days only, and appeared to be somewhat belated in comparison with similar variations in length due to similar causes on other days. In any case, the mechanical structure of the basal part of the stem 
would prevent any marked shrinkage, such as might occur on the terminal half of the joints in which the fibro-vascular tissue is not so heavy or so firm. The total actual increase in thickness in the joint measured was about $6 \mathrm{~mm}$., the original thickness being $20 \mathrm{~mm}$.

An additional series of measurements of the development of the flowerbud was made. The ovary in Opuntia may be taken to be sunken in a short member consisting of a modified stem. The chief feature of the earlier stage of development of the flower of the Opuntia studied consisted in the enlargement of this cylindrical ovoid body derived from the stem which ultimately forms the bulk of the fruit. About the time this has reached full size the sepals and petals, which are in a small, compact cone terminal to the ovular structure, begin to elongate, so that the auxographic record of the elongation of the flower shows two maxima, one of the ovular body or fruit, and the other that of the petals and sepals before opening.

Observations were made on flowers in the habitat of the plant at Tucson, and others in the equable climate of the Coastal Laboratory, at Carmel, California. A small flower-bud $4 \mathrm{~mm}$. in length was brought under the bearing-arm of an auxograph at Tucson in May 1922. Elongation was at the rate of $2 \mathrm{~mm}$. daily during the first 5 days, $1.4 \mathrm{~mm}$. daily during the next 5 days, $3.1 \mathrm{~mm}$. daily during the next 7 days, and $2 \mathrm{~mm}$. daily during the following week. The development of the petals now began, and an elongation of 3 to $4 \mathrm{~mm}$. daily ensued until they opened or separated. The entire period of development occupied a period of 26 days. The temperatures of joints during this time ranged from $10^{\circ}$ to $51^{\circ} \mathrm{C}$.

A similar bud, but slightly larger, was put under the auxograph at Carmel, June 8,1922 , and the flower did not open until 41 days later. The temperatures of the joints were much lower, ranging from $10^{\circ}$ to $37^{\circ} \mathrm{C}$. Elongation the first week was at the rate of $1 \mathrm{~mm}$. daily, $1.2 \mathrm{~mm}$. daily during the second week, $0.6 \mathrm{~mm}$. daily in the third week, and $0.7 \mathrm{~mm}$. daily in the fourth and fifth weeks. The awakening petals now brought into the record new zones of growth, and the rate now ran $1 \mathrm{~mm}$., $2 \mathrm{~mm}$., $5.5 \mathrm{~mm}$., $4.5 \mathrm{~mm}$., $4 \mathrm{~mm}$, and $4 \mathrm{~mm}$. on the days intervening before the opening of the flower.

A midday acceleration in both the ovular body and in the petals is to be seen in the record. Such a record would, of course, also include a similar increase in the flat joint bearing the flower. It was notable that the final stages of elongation of the petals was at a much higher rate in the flower at the lower temperatures of Carmel than in the flower developing under normal and habitual conditions at Tucson, a matter for which no adequate explanation presents itself.

\section{VARIATIONS IN LEAVES OF MESEMBRYANTHEMUM.}

In some studies of Mesembryanthemum the leaves of this succulent were found to show daily variations not parallel to those of the joints of Opuntia. It has since been found that the Opuntias differ among themselves as to the alterations in thickness, relative water-content, etc. These results, and those of other studies, show that the behavior of various succulents does not come under any single pattern, and it is seen that the discrepancy between the action of leaves of Mesembryanthemum and the joints of Opuntia is more divergent than seemed to be the case in previous experiments. 
Further tests were made in the summer of 1922 at Carmel, where this plant flourishes excellently. The leaves, which are triangular in crosssection, show faces which are 6 to $18 \mathrm{~mm}$. across. When one face is placed against a support and the bearing-lever of an auxograph is placed against the opposite angle, a thickness of about 8 to $10 \mathrm{~mm}$. of tissue is under measurement in a mature leaf.

An illustration of the action of this plant is to be had in the behavior of a young leaf which was arranged for measurement by a dendrograph lever on August 7, 1922. The thickness measured at the beginning was about $5 \mathrm{~mm}$. According to estimations previously made, the acidity of the sap of these leaves is greatest in the morning and decreases irregularly throughout the day, but not to an extent which could be taken as modifying seriously the hydration action of the cell colloids. ${ }^{1}$ The stomata, which were examined in connection with the experiments described below, were closed at sunrise and began to open shortly afterward, reaching a maximum width of slit about midday. Shortly afterward a diminution of the slit was observable, and as this was seen to continue during the afternoon, it was taken for granted that it continued to nearly complete closure by daybreak.

If the known agencies affecting the size or growth of the leaf be correlated, it will be seen that the rising temperatures of the forenoon accelerate growth, and consequently the leaf increases until about noon. The higher temperatures also cause increased transpiration, which is coincidently accelerated by the widening stomatal slits. A time is, therefore, reached in the midday period when water-loss is greater than the supply reaching the leaves, and shrinkage results. The high temperature continues to facilitate transpiration, but the closing of the stomata which sets in is accompanied or followed by lessened shrinkage, which gradually passes over into an increase of volume, which continues until the crisis made by the conjunctive action of open stomata and high temperatures next day at noon.

These phases of action are clearly recognizable in the records of the leaves of Mesembryanthemum in 1922, which were made by a type of apparatus different from that used in making the earlier measurements.

\section{GROWTH OF POTATO TUBERS.}

Since the variations in size or rate of growth of aerial stems and of other organs entails the possibility of the loss of water directly from their surfaces, in addition to the draft that may be made upon their water content by competing organs, it was thought advisable to obtain some information of the behavior of structures in which the loss from their own surfaces would be negligible.

The tubers of Solanum are short stems or sections of stems in which the medulla and the cortex undergo an enormous development and the epidermal system soon assumes a high protective value, and as the tubers are embedded in the soil, which is customarily very moist, the conditions offered are very good for testing this matter. I have already pointed out that the enlargement of tubers is checked or brought to a standstill during the midday

\footnotetext{
${ }^{1}$ D. T. MacDougal. Hydration and growth. Carnegie Inst. Wash. Pub. No. 297. 1820.
} See pp. 145-152. 
period, and that the rate of growth of a tuber may be accelerated by the removal of competing tubers.

The material used was of two varieties, "Salinas," which is grown extensively in the vicinity of the Coastal Laboratory, and "Ashleaf," grown from seed which was furnished by Suttons of Reading, England. The development of 22 tubers was recorded by the use of the auxograph during 1920 and 1921. The behavior of Nos. 16 and 21 will be discussed in detail, since the records of these two include all of the main features of growth, and are not exceptional in any way.

No. 16 was a Salinas and was brought under measurement June 3, 1920, at which time it was $10 \mathrm{~mm}$. in diameter and $15 \mathrm{~mm}$. in length. The auxographic record showed a period of enlargement of 84 days. Measurements were continued for 3 weeks longer. Allowing for the initial stage of development, the growth-period of the tuber may be taken as about 100 days (fig. 15).

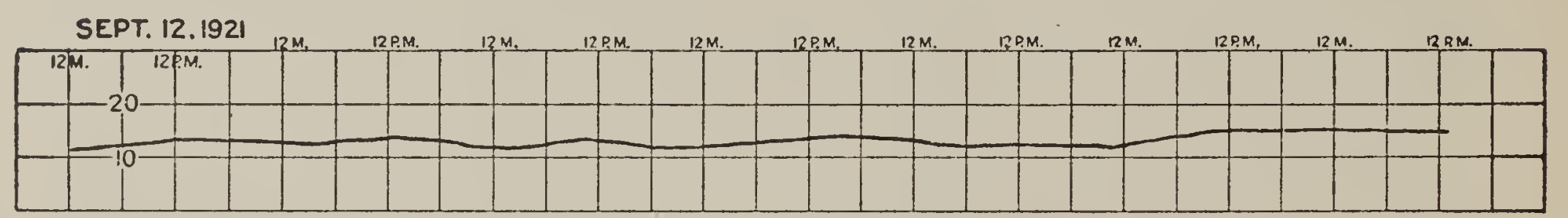

AUG. 22,1921

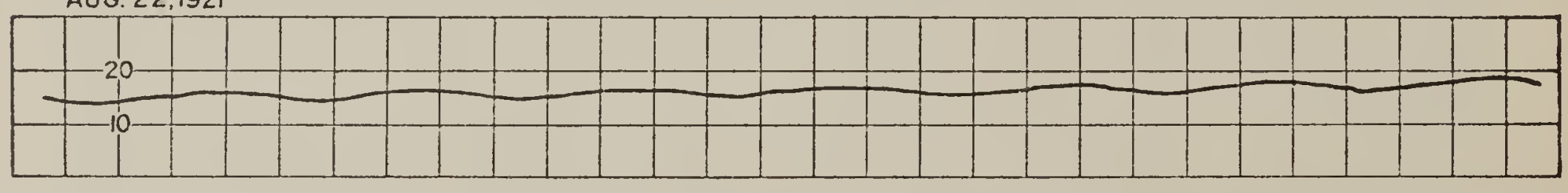

JUNE 27,1921 .

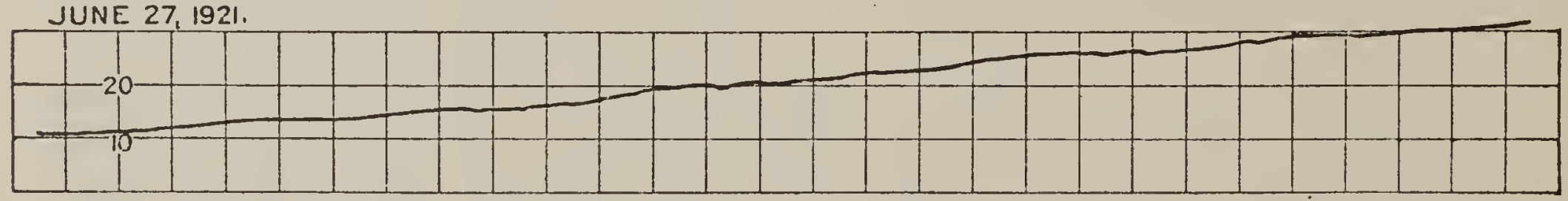

JUNE 6, 1921

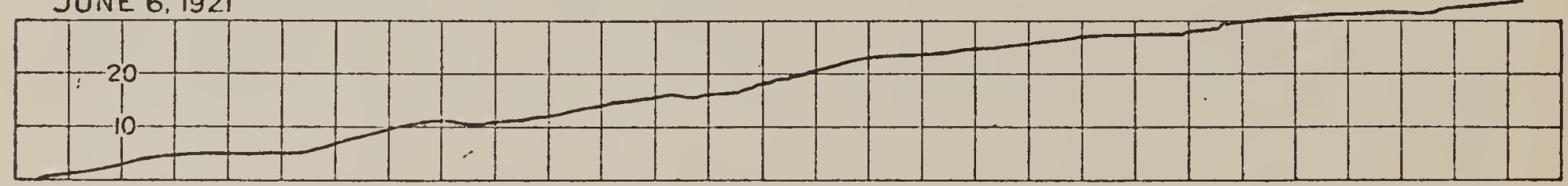

FIG. 15.-The four weekly records illustrate course of enlargement daily and other variations in early, middle, and late stages of growth. The horizontal intervals denote 6 hours, noon $(\mathrm{Nn})$, and midnight (Mt) being designated. The vertical spaces are $10 \mathrm{~mm}$., and the variations of the tuber are amplified 10 times.

In all of these experiments careful explorations were made of the lateral underground branches of plants cultivated in large barrels of rich soil. When a tuber suitable for measurement was found, a block of wood or cement was embedded in the soil under the tuber to afford a firm foundation. A support for the auxograph was constructed on the rim of the barrel, which had been cut down to the proper level. The vertical swinging arm of the lever, tipped with cork, was seated on the upper surface of the tuber and fine soil was sifted about it to a depth of 2 or $3 \mathrm{~cm}$.

Analysis of the record, week by week, of No. 16 showed increases in the vertical diameter at rates of $0.6 \mathrm{~mm}$., $0.55 \mathrm{~mm}$., $0.3 \mathrm{~mm}$., $0.3 \mathrm{~mm}$., $0.3 \mathrm{~mm}$., $0.3 \mathrm{~mm} ., 0.4 \mathrm{~mm}$., $0.3 \mathrm{~mm} ., 0.27 \mathrm{~mm}$., $0.35 \mathrm{~mm} ., 0.14 \mathrm{~mm}$., $0.14 \mathrm{~mm}$., and 
$0.03 \mathrm{~mm}$. daily. At the close of the test the tuber had taken a flattened cylindrical shape, the diameter measured having increased from 10 to 27 $\mathrm{mm}$., while the horizontal cross-diameter reached $34 \mathrm{~mm}$. The axial diameter increased during the same time from $15 \mathrm{~mm}$. to $57 \mathrm{~mm}$. As the shorter diameter measured increased but 2.7 times its earlier dimensions, and the length 3.8 times, it is evident that the auxographic record may not be taken as a direct record of total enlargement. Thus it is highly probable that the greatest extension in length took place during the third to eighth weeks, during which time the rate of increase of the diameter under measurement was equable. The maximum of this diameter occurred at a very early stage of development, in the first week of measurement, when the tuber was not more than 10 days old (fig. 16).

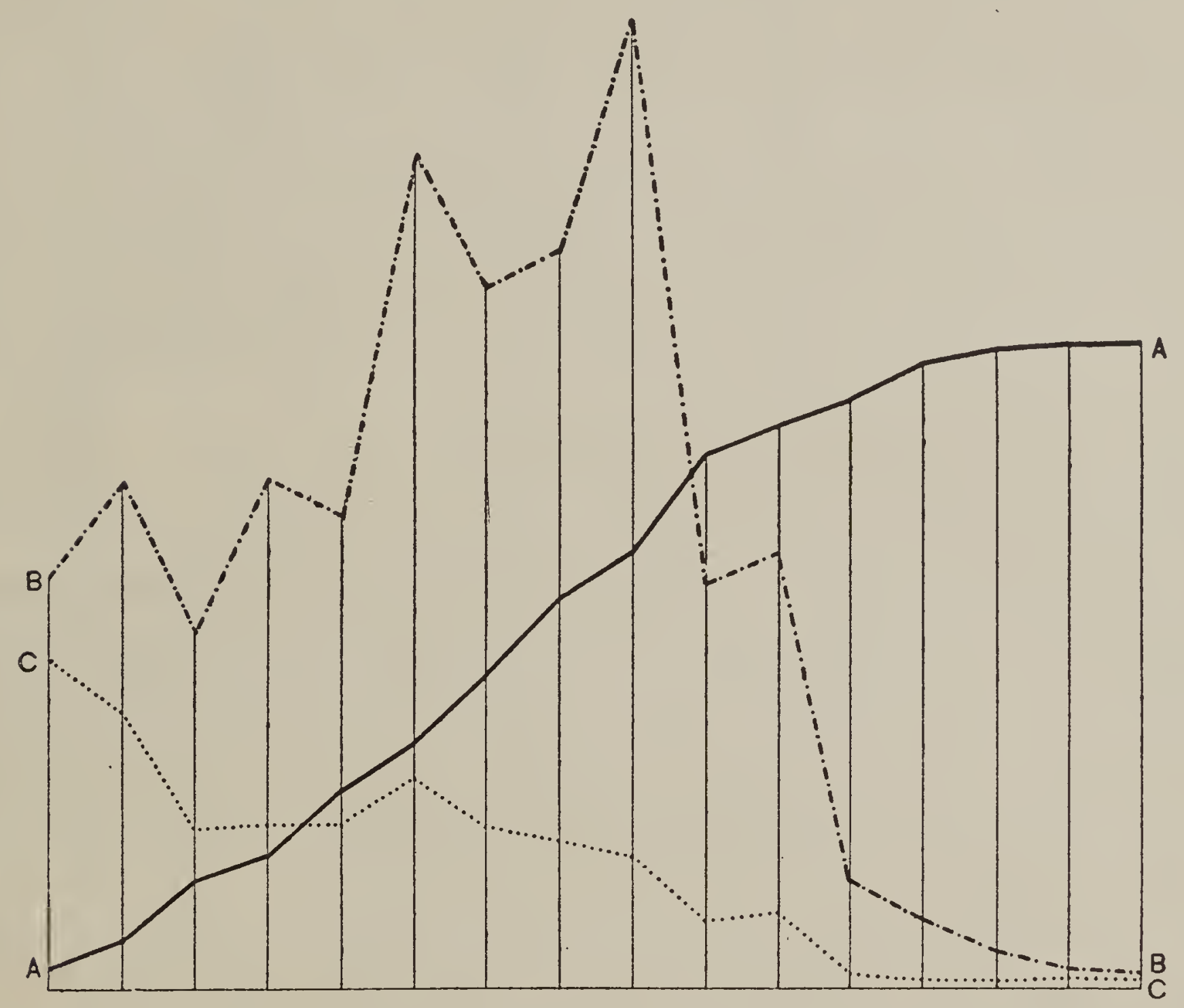

Frg. 16.-Graphs illustrating development of potato tuber No. 16 (see fig. 15) from June 3 to September 19, 1921. The solid line, A, denotes the course of increase in size or volume, the broken line, B, the rate of increase in volume; and the dotted line, $\mathrm{C}$, the rate of increase in diameter of the tuber.

The tubers were buried deep under a fine-grained layer of soil, which was kept moist, yet it was seen that the rate of increase slowed down during the daylight period, although the temperature was within the favorable range. That such slackened rate was not due to a lower soil moisture, or to increased transpiration from the surface of the tuber, was evidenced from the fact that when the soil was saturated by a water drip during this period the rate was not sensibly increased. The slowing down of the rate of growth of a tuber in the soil may, therefore, be taken to be directly connected with the increase of transpiration from the leaves and aerial surfaces, by which the supply available for the tubers is lessened. 
On the other hand, small tubers which developed on etiolated stems in dark rooms with equable temperature displayed a direct reaction to transpiration. Enlargement of these structures, which have a very thin epidermal system, was speeded up when they were covered with filter-paper running to a dish of water.

A somewhat more valuable set of records was obtained from Ashleaf No. 21. This tuber was more regularly cylindrical (8 by $12 \mathrm{~mm}$.) in the beginning on June 24. On September 4, 1921, it had reached dimensions of 37 by $41 \mathrm{~mm}$., the increase in the short diameter being almost wholly radial. It was possible to treat the increments as those of a cylinder occurring within a period of about 65 days. The increases by transverse diameter in successive weeks were as follows: $1.5 \mathrm{~mm}$, $2 \mathrm{~mm}$., $2.5 \mathrm{~mm}$., $1.5 \mathrm{~mm}$., 1.6 mm., $1.3 \mathrm{~mm}$., $0.8 \mathrm{~mm}$., $1.2 \mathrm{~mm}$., $0.4 \mathrm{~mm}$., $0.6 \mathrm{~mm}$., $0.3 \mathrm{~mm}$. The accretions by volume were calculated as follows: $1,625 \mathrm{cu}$. mm., 1,628 cu. mm., 1,600 cu. mm., 1,738 cu. mm., 3,317 cu. mm., 1,686 cu. mm., 1,870 cu. mm., 2,020 cu. mm., 1,296 cu. mm., $1,124 \mathrm{cu}$. mm. It is thus to be seen that while the maximum rate of increase of diameter was displayed in a very early stage of the tuber and in the third week of the observations, the maximum increase in volume took place much later, being in the fifth week. It is also to be seen that in the eighth week, when the increase in diameter was but one-half that of the maximum, the accretion-rate was greater than during the period of maximum diameter increase.

Facts are not available for establishing relations between the total carbohydrate production and storage, but it may be safely assumed that the accretion-rate represents a direct correlation.

In the earlier stages of development the higher midday temperatures resulted in a marked increase in diameter, and this reaction was characteristic of over 2 weeks of the observational period. This would imply that during the first 20 or 25 days of the development of the tuber such a reaction would prevail. After this, and beginning on July 6, a slight retardation of growth ensued, accompanied by positive shrinkage in some cases. Precisely similar reactions are displayed by young shoots, which show a very marked shrinkage on warm days with high evaporation. Such shrinkages take place when the temperature of the leaves, as determined by a thermocouple would be $20^{\circ}$ and $21^{\circ} \mathrm{C}$, and probably with open stomata. Dr. Loftfield has found a differential behavior of the stomata of the upper and lower surfaces of the leaves, and that they have a tendency to remain continuously open, closing tardily under the effects of a depletion of the water supply, ${ }^{1}$ a behavior which may be held to account for the gently gradual daily variations, also seen in Populus and in Parkinsonia aculeata.

The variations in volume of these tubers, like those of nuts of Juglans, and fruits, such as the tomato and squash, are affected by the transpiration from leafy surfaces not directly connected with these structures.

\section{THE GROWTH OF THE SQUASH.}

The examination of the growth of the tomato yielded some important conclusions as to the variations in volume and the physical basis of accre-

\footnotetext{
${ }^{1}$ G. Loftfield. The behavior of stomata. Carnegie Inst. Wash. Pub. No. 314. pp. 27-33. 1921.
} 
tions. These fruits were seen to be in the category of plant structures which show a greater increase in water than in solid matter as they enlarge and mature.

Auxographic records of a fruit of the melon type were undertaken in 1920 , to ascertain what parallelisms might be presented by these comparatively large formations in which a similar water and solid matter relation prevails.

Squash plants were grown in good soil and the vines were led into a sunken glass house, so that the fruits could be supported on solid tables. Auxographs with simple levers were arranged to be put in bearing on the upper surfaces, and growth proceeded in an apparently normal manner (fig. 17).

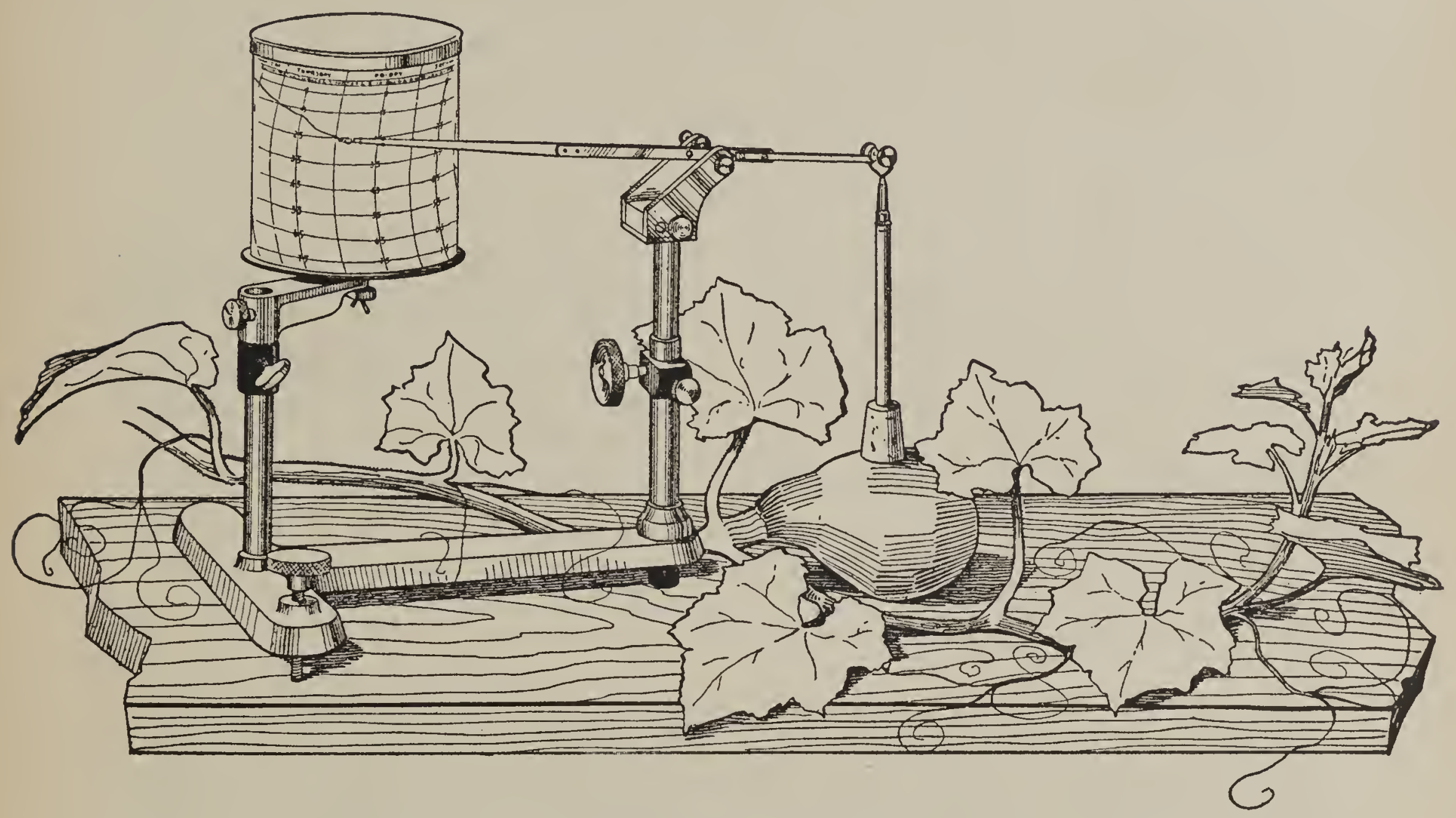

Fig. 17.-Auxographs arranged to record alterations in volume of squash.

Squash No. 1 was taken at a diameter of $13 \mathrm{~mm}$. on August 7, 1920, immediately after pollination, and record of its variation in diameter was kept until it reached maturity. The rate of increase calculated weekly was at the daily rates of $1.5 \mathrm{~mm}$., $3.6 \mathrm{~mm} ., 2.4 \mathrm{~mm}$., $2.0 \mathrm{~mm}$., $0.85 \mathrm{~mm}$., and $0.2 \mathrm{~mm}$. The maximum rate of increase was displayed about the eleventh or twelfth day of development. It will be obvious, however, that the actual accretions are not directly as those of the diameter but are in accordance with the formula $\left(\pi R^{2}\right) 4 / 3$. The total growth for successive periods may be visualized as shells on a globe of ever-increasing diameter, and such a shell on a globe $50 \mathrm{~mm}$. in diameter would imply a far greater amount of growth than a similar thickness laid on a globe $10 \mathrm{~mm}$. in thickness. The greatest rate of increase in diameter was about the eleventh or twelfth day, but the maximum accretions to the volume occurred on the twenty-fourth to twenty-sixth days, the relative value of the accretions, week by week, being $23,371,420,44$, and 240 (fig. 18). 
A second fruit, which was $14.5 \mathrm{~mm}$. in diameter on August 9, 1920, continued to show some enlargement over a period of nearly 70 days. The daily rates of increase calculated weekly ran $1.5 \mathrm{~mm}$., $3 \mathrm{~mm}$., $3.2 \mathrm{~mm}$., 1.6 mm., $0.6 \mathrm{~mm}$., $0.3 \mathrm{~mm}$., $0.3 \mathrm{~mm}$., $0.3 \mathrm{~mm}$., $0.4 \mathrm{~mm}$., $0.4 \mathrm{~mm}$., and $0.35 \mathrm{~mm}$. The greatest rate of increase in diameter occurred on the eighth to tenth days of observation, which began with pollination. The increments in volume calculated weekly ran as follows: $16,53,243,1,176,482,210,180$, $94,95,157,151$, and 103. The highest rate of growth or actual accretion of material took place many days after the highest rate in increase in diameter was noted. The chief feature of development of this fruit was its longcontinued activity and revived growth in the last 20 days of its development.

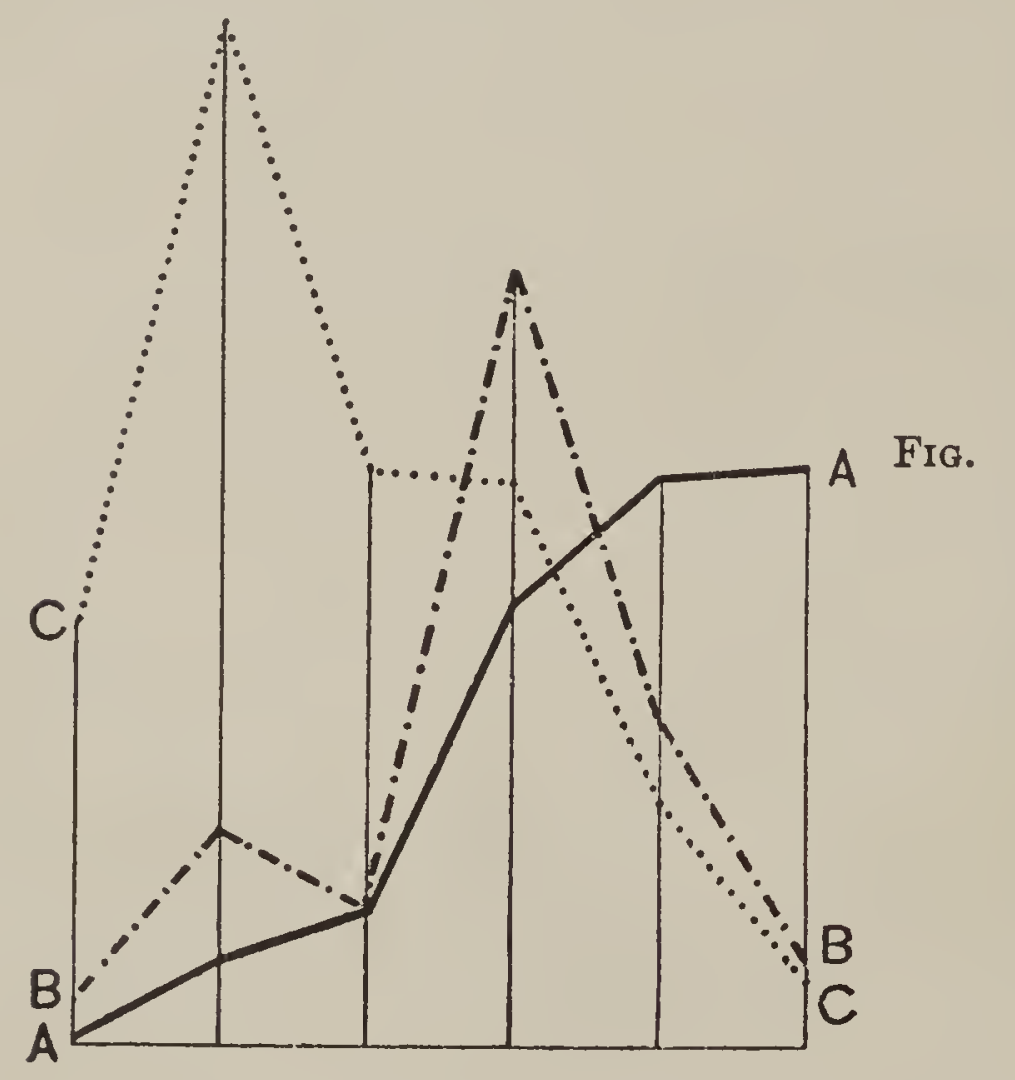

18.-Graphs illustrating development of squash No. 1 from August 7 to September 12, 1921. The solid line, $A$, denotes course of increase in size or volume, the broken line; $B$, the rate of accretion to volume, and the dotted line; $\mathrm{C}$, the rate of increase in diameter.

Dr. A. P. Anderson ${ }^{1}$ measured the growth of a large pumpkin in my laboratory at the University of Minnesota in 1898. He found that the fruit reached maturity in 34 days, and that the greatest increase in weight occurred on the eleventh day after pollination. The measurements were entirely by weight, being obtained by a continuously-weighing apparatus, and hence may be taken to be nearly identical with the accretions in volume noted above. The chief features of the course of growth consisted in a maximum rate at night, or at a time when transpiration was lowest, and a decrease during the daytime, when water-loss was greatest. The lessened rate during the daylight period became a daily loss in actual weight as the fruit approached maturity. Anderson's results gave foundation for conclusions to the effect that it was due to transpiration from the surface of the fruit and by the depletion of the supply from the stems by the heightened evaporation from the leaves.

1 A. P. Anderson. The grand period of growth in a fruit of Cucurbita pepo. Minn. Bot. Stud., part v, Bull. No. 9, 238-279. 1898. 


\section{SUMMARY.}

1. The observations on growth described in the preceding pages were made principally on plants growing in the open and under the full influence of their habitual environment. The experimental methods did not in any way modify the normal activity of the plants, especially with respect to trees.

2. Continuous dendrographic records of changes in volume of various species of trees have been extended to a total of 90 seasons, and many of the seasonal periods include the entire year.

3. In addition to species the growth-activities and variations of which have been previously described, and to which further contribution is made in the present paper, dendrographic records of Carnegiea gigantea, Pinus arizonica, $P$. strobiformis, Parkinsonia aculeata, Salix lasiolepis, and Sequoia sempervirens have been made. The results of extended studies of the growth of walnuts, potato tubers, and the squash are also included.

4. The records of the growth of the Monterey pine (Pinus radiata) comprise 20 years of the above total, the instruments attached to these trees being operated throughout the year in most cases. A continuous record of one tree since September 1918 by a dendrograph attached to its basal section has been made. A second record, beginning in January 1920 , has been made by an instrument at 8 meters from the base. A large number of trees have been used for dissections and incidental experiments.

5. The duration of seasonal growth is longest in young trees, no limits being observed in one Monterey pine in 1922-1923. Wide differences in this matter are exhibited by older trees standing in close proximity. The seasonal period for older trees at Carmel is from 57 to 225 days.

6. The thickness of the woody layer formed in any year shows a general correlation to the length of the growing-season, as measured in any single tree of the Monterey pine.

7. Two or more layers of wood may be formed in one year by the Monterey pine. So far it has not been possible to correlate the interrupted activity of trees observed by the dendrograph with the formation of such layers. Pauses in actual enlargement may result from the abrupt effect of cold storms or short periods of low relative humidity.

8. The thickness of the layers of wood formed, or the total increase as registered by the dendrograph, shows no constant relation to the total amount of rainfall in the Monterey pine. It is suggested that the thickness of a woody layer is the resultant of the favorable conjunction of a number of factors in which seasonal relative humidity may be an important agency.

9. The tips of the leaders and branches, and the tips of small roots, begin to elongate before enlargement of the trunk is discernible in the Monterey pine. No basis has been found for the prevalent conception that the activity which is first visible in the buds gradually descends to the trunk and down the trunk to its base. Growth in Monterey pine No. 1 began at the base and at a place 8 meters above on the same day in five separate years. Growth ceased earlier at the uppermost place in some years, but in 1923 cessation occurred on the same day in the two places on the trunk. 
The relation of bud activity and the encircling sheet of cambium is discussed in several trees in subsequent paragraphs.

10. The secondary thickening of a large root of the Monterey pine began some time after the enlargement of the trunk, and continued for a period of only a few weeks during the single season during which a record was made.

11. Interferences with the conducting and transpiratory systems were made by girdling, topping, and defoliation. The mechanical girdling of a small tree near the base by the removal of the bark and phloem during the growing-season checked enlargement, but did not materially alter the length of the season. Growth began in a second season and lasted until midsummer. No woody layer was formed below the girdling zone following the removal of the girdle. Food material, as indicated by starch, was reduced in the upper part of the tree and was most abundant at the end in a zone a meter or more in width immediately above the girdle. Growth continued longer in this region than in any other part of the tree. Mechanical girdling of the trunk some distance above the base ( 2 meters) checked enlargement of the trunk below temporarily, but enlargement was resumed within two weeks. Killing a basal section of a tree in midsummer by boiling oil resulted in the cessation of growth within a fortnight and the death and desiccation of the tree within a few weeks.

12. The removal of the upper part of a tree with all branches was followed by the cessation of growth within a fortnight and the death of the tree before the end of the season. A similar cutting of the trunk of another tree which left a few branches below the cut resulted in retarded growth, but the tree continued to live. Topping a young tree 2 meters from the base, leaving dense foliage on the many branches below, stopped growth at once and reduced daily variations to a minimum. Some awakening of dormant buds was seen.

13. Defoliation of a young tree of the Monterey pine in the middle of the growing-season (March) was followed by a cessation of growth, and a reduction of the daily equalizing variation. The young leaves failed to attain normal size. Defoliation in midsummer, in which the leaves nearing maturity were not removed, did not materially alter the course of growth or of the daily fluctuating variations.

14. The movement of solutions through the stem of the Monterey pine are found to be slow when compared with the rate in woody trunks with large open vessels. The rate found in June during the growing season was less than that of October at a time when activity was reduced to a minimum. The rate of conduction during the night was much less than during the daytime, corresponding to the comparative transpirational action of the leaves which show the stomatal slits opened wider in the day than at night. The removal of the terminal of a stem and its replacement by a vacuum-pump was found to have a distinct effect on the rate and distance in the conduction of dyes upward in the stems of the Monterey pine. This effect by a vacuum of $740 \mathrm{~mm}$. of mercury was exerted in stems as long as 6.5 meters. No tests were made with longer stems. Relatively large quantities of water may be pulled through short sections of the stem of the Monterey pine by the use of similar pressures. 
15. Practically all organs or members tested with the dendrograph show daily equalizing variations in size or volume, which are referable to their water-balances. The condition of the stomatal slits, with implied effects on the transpiration-rate, is seen to be the most important factor in these variations. The amplitude of the daily contractions and expansions is greatest in the young stems of the Monterey pine and in the upper or younger parts of older trees. The coefficient of variation is least in the thickened roots of this tree. The highest coefficient is reached in March and April, at the time when growth is near the maximum rate, and it is least in October or November, when activity is least. The coefficient of expansion of a large pine tree (No. 1) near the base is 1 part in 1,250; of the upper part, 1 part in 700. The coefficient of expansion of the woody cylinder of a similar tree inside the layers formed in the previous two years was 1 part in 2,000 , showing that the fluctuation was greatest in the outermost layers, the cortex, and the cambium.

16. Determination of the coefficient of expansion of the floating frame of a dendrograph of permant, which might constitute a correction in measurements in the variation in a tree-trunk, show that this error under extreme conditions is such as would be beyond the limits of experience in measurement of trees, the maximum deviation being no more than 1 part in 9,000. All of the measurements given in the preceding paragraphs 'were made'with floating frames of invar, permant, or of fused silica, in which the error would be so much reduced as not to be measurable with any profitable degree of exactness.

17. The general character of the daily equalizing variations is characteristic of each species (fig. 19). The suggestion first advanced that the amplitude of the daily variation would be found to depend upon the softness of the wood and the character of the bark is not borne out by the extended results available. The least variations are encountered in Populus, Platanus, Salix, Parkinsonia, and Fagus. Variations of wide amplitude are shown by Fraxinus and all of the coniferous trees. The greatest daily fluctuations are to be seen in the larger succulents, such as Carnegiea and Opuntia.

18. The leaders and tips of the branches of the Arizona pine (Pinus arizonica) begin to elongate some time before the cambium awakens. Enlargement of the trunk takes place with temperatures of $13^{\circ}$ to $31^{\circ} \mathrm{C}$. of the cambium, and the period of growth was found to be 88 to 90 days. The principal part of the growth takes place following the summer rains.

19. The Mexican pine (Pinus strobiformis) was similar to the Arizona pine in its growth habits, the seasonal activity extending over 65 days. The tips of the branches began to elongate before thickening of the trunk was seen.

20. The thickness of the woody layers formed by the Arizona and Mexican pines does not correspond directly to the rainfall of the midsummer season in which it takes place. The precipitation of the previous winter is followed by a dry period, so that the soil moisture is much reduced before the temperatures reach a favorable intensity. The woody layer of 1923 in these trees was very thick, and the season was one of continued cloudiness and high relative humidity, according to common report. 
21. The yellow pine (Pinus scopulorum) at 7,000 feet, Flagstaff, Arizona, showed seasonal periods of growth of 65 and 72 days in two trees in 1923. The daily variation was very marked, reaching an amplitude of 1 part in 350 at the time of most rapid growth. This tree also stands in a locality in which the soil-moisture resulting from the winter rains is much reduced before the temperatures reach a favorable intensity.

PINUS SCOPULORUM

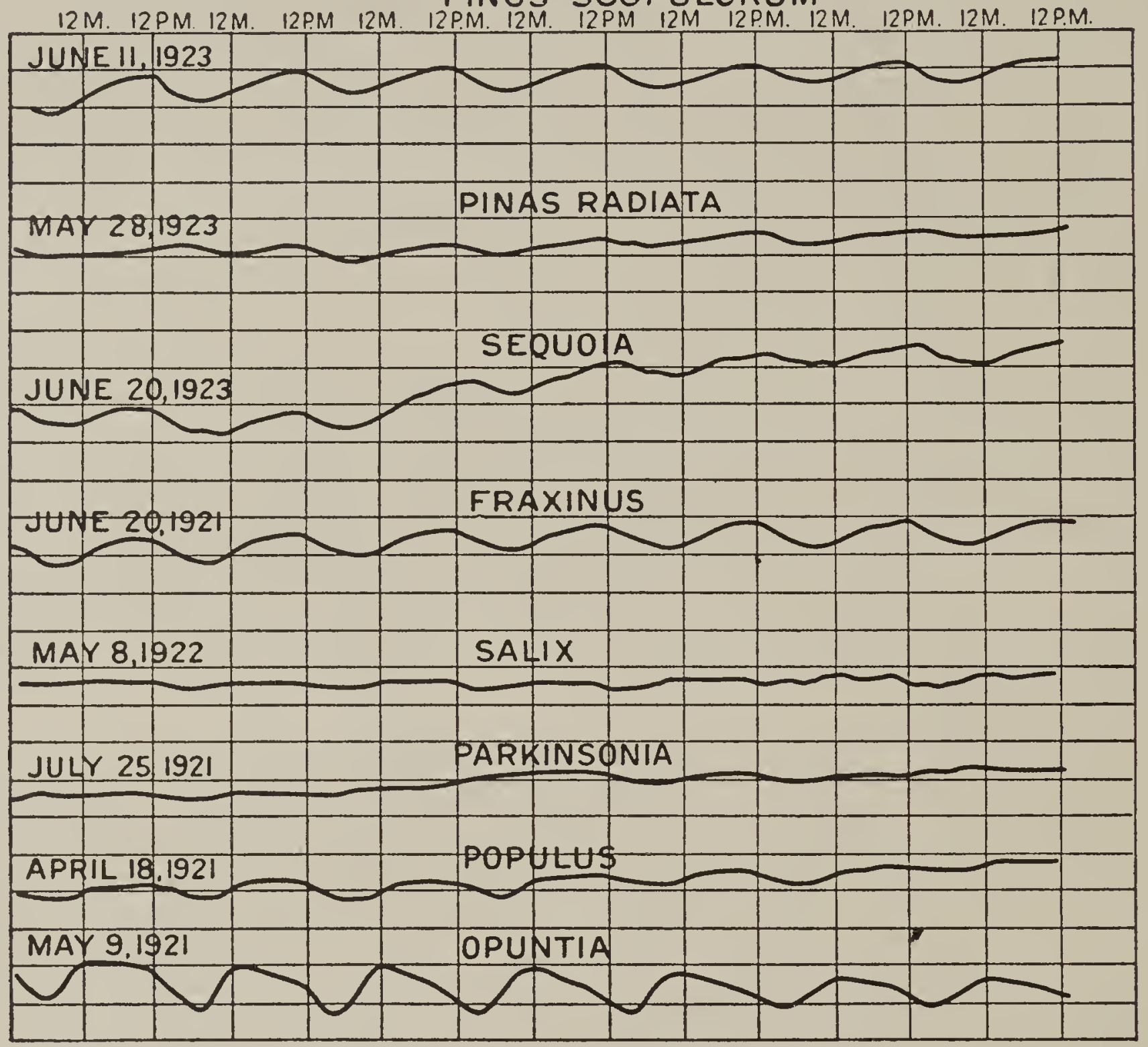

FIG. 19.-Facsimiles of a weekly dendrographic record of several trees and of Opuntia to illustrate the variations in volume characteristic of these plants. All are shown in a state of enlargement by growth except Opuntia. The horizontal intervals denote 6 hours, noon (Nn) and midnight (Mt) being designated. The vertical spaces are $10 \mathrm{~mm}$. on original record, and the variations are amplified 10 times, except Salix, which are $\times 16$.

22. The redwood (Sequoia sempervirens) inhabits the coastal drainage of the middle and northern parts of California, where some individuals reach ages calculated at more than 3,000 years. Six seasons of measurements of growth are now available, which were made on five trees. Difficulties in the way of instrumental manipulation has restricted the use of the dendrograph to smaller trees, the largest of which was probably not more than a century old. Equipment has been secured for recording the variations in trunks with a diameter of $150 \mathrm{~cm}$. The tips of some of the branches awaken before the cambium. The seasonal activity of the cambium varies from 128 to 202 days. Pauses in enlargement may occur in short periods of high temperature and low relative humidity. 
23. The growth of the trunks of the Arizona walnut (Juglans major) was measured in the habitat of this species at 8,000 feet in the Santa Catalina Mountains in Arizona and at the Coastal Laboratory. Seasonal activity lasted over 85 days in 1920, 165 days in 1921, and 120 days in 1922 at the Coastal Laboratory. Growth continued for 95 days in a similar tree in the Arizona habitat. Enlargement of the trunk did not begin until the young leaves were expanding. This occurred a month before the maturity of the flowers in the coastal location, and six weeks before in the mountain location. The daily variations of the trunk in the habitat of the tree were modified by minute disturbances, probably associated with cloudiness and storms. Reduction of such variations resulted at Carmel by the occurrence of fogs.

24. The development of a nut of the Arizona walnut was followed at Carmel. Enlargement was modified by a contraction beginning in midforenoon and lasting until mid-afternoon, coincident with the period of maximum opening of the stomatal slits on the leaves. Contractions are to be attributed to the withdrawal of water through the stems by the transpiring action of the leaves.

25. Enlargement of the trunk of the Arizona ash (Fraxinus arizonica) begins within two or three days after the awakening of the staminate flowers and about a week before the leaves start. The seasonal activity of a tree at Tucson, Arizona, lasted 223 days, which is the longest period recorded for any tree, except that of a young Monterey pine at the Coastal Laboratory. The daily equalizing variations were reduced to a minimum in the winter season, and were very marked during the period of maximum growth.

26. The variation in the small trunk of a palo verde (Parkinsonia microphylla) tree in the patio of the Desert Laboratory was so small during the season of 1920 as to be not discernible on the dendrograph record.

27. The bagote (Parkinsonia aculeata) was measured in 1921. Enlargement of the trunk occurred before the leaves began to unfold. Activity extended over 193 days, but several pauses, due to deficient water-supply, were included. This and the Arizona ash are the only trees observed by the writer to show activity of the cambium before the leaf-buds awoke. It is to be noted that an enlargement accompanying a rain was seen by Dr. Loftfield in Pinus ponderosa in 1920 before the buds awoke. ${ }^{1}$

28. The sycamore (Platanus occidentalis) measured in the Missouri Botanical Garden in 1920 had a seasonal activity of 125 days, enlargement beginning a month after the activity of the leaves. The daily variation, which is never great, is imperceptible in the time preceding the seasonal awakening, and was much like that of Parkinsonia (fig. 19).

29. The Carolina poplar (Populus deltoidea) measured at the Missouri Botanical Garden in 1920 had a seasonal period of but 53 days. Buds awakened at the end of March, but enlargement of the trunk was not observable until May 10, at which time the leaves had not yet reached full expansion.

30. MacDougal's poplar (Populus macdougalii) showed a growing-season of 124 days in a small tree under irrigation at Continental, Arizona, in 1920.

1 D. T. MacDougal. Growth in Trees. Carnegie Inst. Wash. Pub. No. 307, p. 28. 
A larger tree near the Desert Laboratory had a seasonal period of 199 days in 1921, but many interruptions or pauses were noted. The leaves had attained about three-fourths of their full expansion and the fruits were mature when enlargement began. The daily variations were very slight in the period of inactivity, and not very marked at any time. This fact has not been correlated with conclusions of other authors that the watercontent of the trunk may vary widely.

31. The arroyo willow (Salix lasiolepis) at the Coastal Laboratory did not begin growth until May 12 in 1922, at which time the leaves were mature, and showed a seasonal period of 119 days with an interregnum of 12 days. The daily variations were of small amplitude at all times.

32. The dendrometer design has been improved and materials found for its construction, so that it may be placed on a tree for periods of a year or more. The increase of the circumference of the trunk may be read from a scale at any time. Such instruments have been attached to trees for periods of two years.

33. A dendrographic record of the variations in diameter of the trunk of a sahuaro (Carnegiea gigantea) a meter from its base shows variations, due to varying water-balance, of such wide amplitude and long continuance that it is impossible to fix upon the time when growth, including the formation of new cells and their enlargement, began. It would appear by inference that the apex of these massive stems begins to elongate in April, before a similar enlargement takes place in the main part of the trunk. The daily variations are approximately the reverse of those of the woody trees and of the stems of most herbaceous plants. Swelling begins in mid-forenoon and continues until nearly midnight, when contraction sets in and continues until the next forenoon. This is coincident with the condition of the stomatal slits. These are in a closing condition during the morning hours and are narrowest by noon, remaining so until nearly midnight. The amplitude of the variation may amount to as much as 1 part in 200 of the diameter. Variations of all kinds may be much reduced by the action of low temperatures. Increase of soil-moisture by rains has an effect by which general enlargement of the trunk follows within a day after a rain in the warmer season. Such an increase in diameter, amounting to $42 \mathrm{~mm}$., took place in four days in July 1923. The general relation of the water-balance of the trunk to precipitation and soil moisture determined by Mrs. E. S. Spalding is confirmed. The diameter of a trunk in the basal portion was $66 \mathrm{~mm}$. greater on February 9, 1924, than the same day two years earlier.

34. Growth of the succulent joints of Opuntia has several distinctive features. In the younger stage, enlargement is continuous within the tonic range of temperature, an acceleration being seen at midday. At the end of the younger stage the records show that an acceleration of enlargement begins in mid-forenoon and continues until mid-afternoon, when a retardation takes place which is not relaxed in young joints before $6 \mathrm{p} . \mathrm{m}$. and in the older joints not until 10 p.m., when elongation is resumed or accelerated. The stomatal slits are found to be in a narrowed condition between mid-forenoon and mid-afternoon, which may be taken to account for the increased enlargement at this time in which the higher temperatures would 
also have a favorable effect. The lessened hydration capacity of the cell colloids resulting from the acidity, which increases through the night to such an extent that the sap is equivalent to $0.01 \mathrm{~N}$ malic acid at daybreak, would facilitate water-loss during the night, with its resultant action on the enlargement.

35. The proportionate swelling of living sections of Opuntia in water show that at the Desert Laboratory the water deficit is greatest in February, which may be considered as a cumulative effect of the desiccation of the previous autumn and of the lack of absorption during the period of low temperatures. The deficit decreases with rising temperatures and increases soil-moisture until April. An increase takes place in the dry foresummer. A decrease doubtless takes place during the summer rains, to be followed by an increase which lasts until midwinter, as noted.

36. The swelling of dried sections may be taken as an index of the imbibition capacity of the cell colloids. This feature in Opuntia is mainly determined by the proportion of pentosans or mucilages present. This material is present in greatest abundance in April and May, at which time its water-holding capacity causes living material to show the least water deficit and the greatest swelling when dried. The mixture of colloids in the cell is such that living sections attain the greatest volume or turgidity in solutions in which the $\mathrm{pH}$ ranges from 3.01 (that of $\mathrm{HCl} 0.001 \mathrm{~N}$ ) to 11.99 (that of $\mathrm{KHO} 0.01 \mathrm{~N}$ ). It is inferred that the pentosans and soluble proteins are present in nearly equal proportions.

37. Joints of Opuntia grown in the equable climate at Carmel carry out their entire development by a daily behavior similar to that of joints in the younger stage in a desert climate. No contractions ensue. The water deficit is low at all times, as indicated by the slight swelling of living material when placed in water. The swelling capacity of dried sections is as great or greater than that of similar material matured in the desert location; indicating a high proportion of mucilages.

38. The increase in thickness of the flattened joints of Opuntia, which may take place in the second and later seasons of their existence, shows a daily periodicity not parallel in all of its features with those of the increase in length of a young joint. The daily increase in thickness early in the season occurred only in a short period of about 2 hours, ending at midday. With the advance of the season the increase showed only during a later period in the day and later than the acceleration in growth in length.

39. The auxographic record of the development of a flower-bud shows two maxima, one in which the elongation of the ovular body or fruit is elongating most rapidly, and later when activity in this member is slowing down the sepals and petals, which are in a compact terminal cone, show an acceleration which holds until they are separated in the opening flower and can not be measured by the auxograph conveniently. Flower-buds at Carmel attained maturity in 41 days at temperatures of $10^{\circ}$ to $37^{\circ} \mathrm{C}$., and those at the Desert Laboratory opened in 26 days at temperatures which ranged from $10^{\circ}$ to $51^{\circ} \mathrm{C}$.

40. Some evidence confirmatory of the earlier findings, that growth of Opuntia may go on at temperatures between $9^{\circ}$ and $58^{\circ} \mathrm{C}$., was obtained. The highest rates of elongation are shown at temperatures between $37^{\circ}$ and $40^{\circ} \mathrm{C}$. This is the highest recorded for any seed plant. 
41. The variations of the growing leaves of another succulent, Mesembryanthemum, offer some features of interest in contrast with the variations in Opuntia. The stomatal slits begin to open at sunrise, reach a maximum width at midday, then begin to narrow. Growth accelerates with the rising temperatures of the forenoon until the increasing transpiration masks or cancels growth and a contraction results. Transpiration being checked in the afternoon by the narrowing of the stomatal slits, enlargement is again seen, which, with favorable temperatures, continues through the night and until the opening stomata on the following day again reduce the waterbalance and cause a contraction.

42. The development of 22 potato tubers was recorded by auxographic apparatus. These organs have a period of enlargement which may be estimated at 90 to 100 days. As they are deeply buried in moist soil, the water-loss from their surfaces is slight. Transpiration from the leaves may reduce the supply within the plant to such an extent that a mid-day slackening of growth or contraction may result. The maximum rate of increase in volume is not coincident with the highest rate of increase in diameter, but generally follows a week or two later. The behavior of tubers is comparable to that of nuts and fruits.

43. Growth of the squash was characterized by the widely prevalent variations by which the greatest increase took place at night, with slackened growth or loss during the daylight period, when the transpiration rate was highest. The features described are in agreement with those found by Dr. A. P. Anderson in 1898. These fruits are included in a type or formations in which the proportion of water to the solid material increases toward maturity, in contrast with members of the shoot in which the reverse relation prevails. The proportion of solid matter to water present in joints of Opuntia may not be readily ascertained for comparison, but it seems that a similar increase in the water-content takes place during the initial and main period of development of these members. Increase in dry weight ensues in the following seasons by secondary formations. 


\section{THE GROWTH RECORD IN TREES. \\ BY}

Forrest Shreve. 


\section{CONTENTS.}

PAGE.

Introduction ....................................... 91

Monterey pine (Pinus radiata) ................................. 91

Stump analyses................................. 92

Height growth of saplings............................. 94

Seasonal march of growth............................ 95

Correlation of height growth and diameter growth . . . . . . . . . . . 96

Diameter growth at different heights in the trunk................ 97

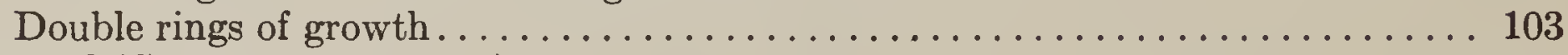

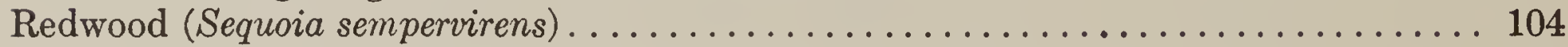

Correlation of growth and rainfall................................ 106

Correlation in individual trees............................ 107

Correlation in groups of trees................................. 111

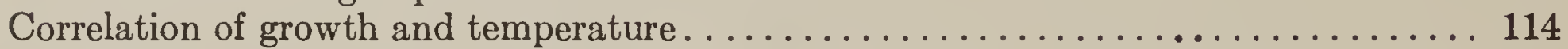

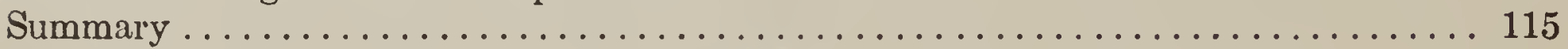




\title{
THE GROWTH RECORD IN TREES.
}

\author{
INTRODUCTION.
}

The annual formation of a hollow cone of woody tissue, enveloping the trunk and all its ramifications, is the most important exponent of the physiological activity of trees. The nature of wood formation, and the internal and external conditions which affect its character and rate, comprise a field of the greatest scientific and economic importance. Much of our knowledge of the physiology of growth has been learned from trees, and in many respects they present the most favorable material with which to investigate the many problems that still require solution. Not only is the tree an organism with obvious practical advantages for the study of the physiology of growth, but it supplies equally favorable material for the study of the influence of environmental conditions on fluctuations in growth-rate and on geographic distribution. In general, the distribution of trees is much more fully and accurately known than that of other plants, so that they lend themselves to work in which the physical causes of distributional limitations are being sought. Furthermore, the growth of the trees of temperate regions leaves each year a record of the total annual accomplishment. The ease with which this record may be read, and the remote antiquity into which it sometimes extends, have recently given to the tree an added interest in kindred sciences as a source of precise chronology with respect to conditions known to influence growth.

The work presented in the succeeding pages has been undertaken with a view to enlarging our knowledge of the growth record in trees, with particular reference to the Monterey pine (Pinus radiata), and with additional work on the redwood (Sequoia sempervirens). Although a great deal of material is available with reference to the relation of age to diameter for almost all trees in the silva of the United States, it has seemed important to amplify our knowledge of the growth record for these two trees, on which other workers have also been engaged. It is of great importance to learn more of the life-history of the tree, and its comparative growth performances at different ages; to keep in view the fact that the tree has three dimensions, and that its growth record can not be read from a single plane surface; and with regard to growth influences, that these are composite, and not to be determined by consideration of any one environmental condition.

\section{MONTEREY PINE (PINUs RAdiata).}

There is probably no one of our native pines which has as little commercial importance and at the same time as much interest to the botanist and the forester as the Monterey pine. It is found in three localities on the coast of California and on two of the coastal islands, these isolated occurrences giving some ground to the view that it is an old species formerly extending continuously over a larger area. The most northerly locality is between Año Nuevo Point and Santa Cruz. The largest body of forest formed by this pine lies in the Monterey Peninsula, and along the coast southward from there for a distance of about 6 miles. After a break of 
nearly 100 miles, the tree again appears in the vicinity of Cambria, where there were originally several hundred acres of pure stands, as well as many scattering trees. In the neighborhood of Monterey it is found from sealevel to 815 feet, and reaches its best development in close proximity to the sea. In the other localities it is more abundant at half a mile or more from the strand. In all places it becomes very infrequent and local at distances of more than 3 miles from the coast.

Owing to the limited occurrence of Monterey pine, little has been done in studying its silvicultural habits and rate of growth. Larsen has published ${ }^{1}$ some figures on the relation of height and diameter, the results of 30 stem analyses, and a general discussion of the characteristics of the tree. It has long enjoyed a reputation for phenomenally rapid growth, based on its behavior in cultivation and on the observation of exceptional trees in its natural range. In spite of its restricted occurrence, the Monterey pine is successfully cultivated in all but the arid portions of California, as well as in the Eastern States and in Europe. In New Zealand and Australia it has been planted on a commercial scale with conspicuous success.

During the summer of 1919, the writer made a number of stump analyses in recent cuttings near Monterey, measured the height growth of young saplings for the growing-season of 1919, kept four young trees under observation and measured them at several intervals from March to October, and made a comparison of height-growth and diameter-growth in a few vigorous young saplings. The data that were secured are presented in the following paragraphs:

\section{STUMP ANALYSES.}

The stump measurements were made at whatever height from the ground cutting had taken place, usually about 1 foot, and an allowance of one year was made in each case for the attainment of that height. The average diameter was secured both outside and inside bark, the total number of rings was counted, and on a radius of average length the increment of radius was measured for successive 10 -year periods, beginning from the center.

TABLE 10.-Average increase of diameter and area for 125 trees of Pinus radiata, determined by decades from center of trunk.

\begin{tabular}{|c|c|c|c|c|c|c|c|}
\hline $\begin{array}{c}\text { Decade. } \\
1\end{array}$ & $\begin{array}{c}\text { Number } \\
\text { of trees. } \\
102\end{array}$ & \multicolumn{2}{|c|}{$\begin{array}{l}\text { Average increase } \\
\text { of diameter. }\end{array}$} & \multicolumn{2}{|c|}{$\begin{array}{l}\text { Total area at } \\
\text { end of decade. }\end{array}$} & \multicolumn{2}{|c|}{$\begin{array}{l}\text { Increase in area } \\
\text { in last decade. }\end{array}$} \\
\hline $\begin{array}{l}1 \\
2 \\
3 \\
4 \\
5 \\
6 \\
7 \\
8\end{array}$ & $\begin{array}{r}102 \\
102 \\
64 \\
37 \\
23 \\
5 \\
2 \\
2\end{array}$ & $\begin{array}{r}c m . \\
9.6 \\
12.8 \\
10.2 \\
8.0 \\
7.6 \\
6.6 \\
4.8 \\
3.6\end{array}$ & $\begin{array}{l}\text { in. } \\
3.8 \\
5.2 \\
4.0 \\
3.2 \\
3.0 \\
2.6 \\
2.0 \\
1.4\end{array}$ & $\begin{array}{r}\text { sq. } \mathrm{cm} . \\
75.4 \\
400.9 \\
844.7 \\
1,306.2 \\
1,840.0 \\
2,358.1 \\
2,807.2 \\
3,155.4\end{array}$ & $\begin{array}{r}\text { sq. in. } \\
11.8 \\
62.6 \\
132.0 \\
204.1 \\
287.5 \\
368.5 \\
438.6 \\
489.2\end{array}$ & $\begin{array}{r}s q . \mathrm{cm} . \\
75.4 \\
325.5 \\
519.2 \\
787.0 \\
1,053.0 \\
1,305.1 \\
1,502.1 \\
1,653.3\end{array}$ & $\begin{array}{r}\text { sq. in. } \\
11.8 \\
50.8 \\
81.1 \\
122.9 \\
164.5 \\
203.9 \\
234.9 \\
258.3\end{array}$ \\
\hline
\end{tabular}

${ }^{1}$ Louis T. Larsen. Monterey pine. Proc. Soc. Amer. Forester., vol. 10, pp. 68-74. 1915. 


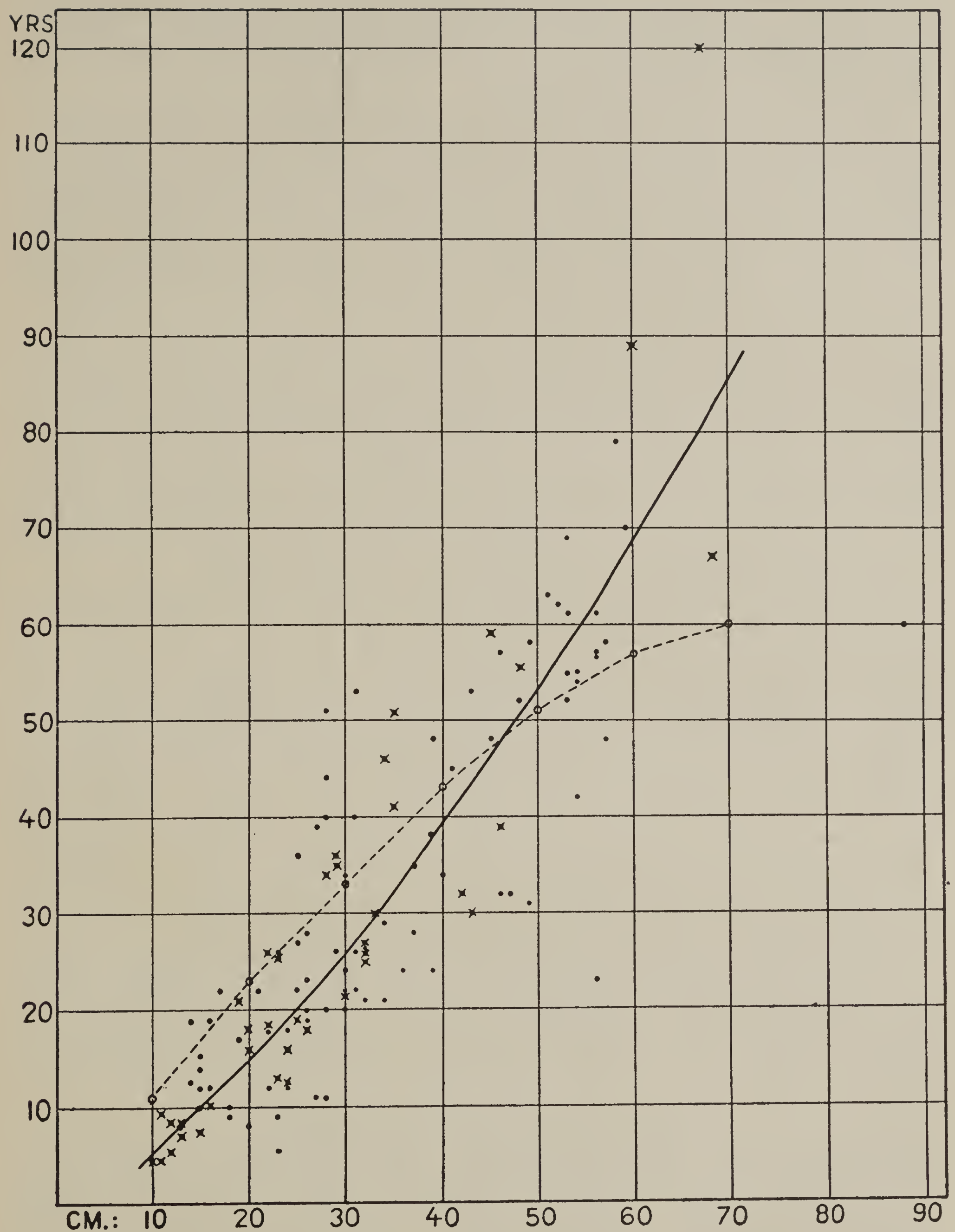

FIG. 20.-Graph showing relation of age to diameter in Monterey pine. Solid line, average for 125 trees, broken line, average based on decades of growth in 125 trees; dots indicato trees growing on adobe soil, crosses trees growing on sand. 
Analyses were made for 125 trees, scattered as well as possible through the different size classes, and all away from the influence of streams, springs, or lakes. The stumps measured were in seven different localities, from Asilomar to Carmel Highlands.

The results of the stem analyses are given in table 10 and shown in graphic form in figure 20, for the diameters inside bark. The greatest age, 120 years, was found in an individual $67 \mathrm{~cm}$. in diameter, while the largest tree, $84 \mathrm{~cm}$. in diameter, was 101 years old. The most rapid growth was found in two trees aged 51 and 53 years, which had attained diameters of 28 and $31 \mathrm{~cm}$. respectively, equal to an average diameter-growth of about $6 \mathrm{~cm}$., or 2.5 inches per decade, which can scarcely be regarded as a phenomenal rate of growth.

In one of the above-mentioned trees it was found that the inside diameter at the end of the first decade was $19.8 \mathrm{~cm}$. (7.75 in.). The five years of most rapid growth in this decade resulted in a diameter increase of $17 \mathrm{~cm}$. (6.75 in.). The thickest of these five rings was $1.8 \mathrm{~cm}$., indicating a growth in diameter of $3.6 \mathrm{~cm}$., or nearly 1.5 inches in a single year. That this rate of growth is very exceptional appears obvious from the fact that it is 6 times as great as the average lifetime rate of the two most rapidly growing trees in the entire series of 125 that were measured.

The solid line of figure 20 indicates the average age-diameter relation, based on the one inside bark measurement of each tree. The diameter of each tree at the end of each decade of its life was determined from the measurements of radius, and these diameters were averaged for the 125 trees. The broken line of figure 20 indicates the age-diameter relation as based on the one to seven measurements on each tree. Neither of these graphs departs very far from a straight line except at the upper ends, where both are based on a very small amount of material. It appears from these data that the rate of growth of the Monterey pine is maintained rather uniformly into its period of advanced maturity. If the customary fall in rate at advanced ages takes place in this tree, it does so only in those extremely rare trees which survive more than 100 years.

In the vicinity of Carmel, 3 miles south of Monterey, the pine grows on the sandy soil of old stabilized dunes and also on a stiff adobe. The trees embraced in this analysis were selected about equally in sites with these two types of soil, in order to determine any influence that this marked difference might exert on the rate of growth. In figure 20 the crosses indicate the trees growing on sand and the dots those growing on adobe. It will be seen that there is only a very slight indication of any difference between the rates of diameter growth in the two groups of trees. This is probably due to the fact that in the months when the pines are making their greatest growth the two soils are very similar with respect to their water-content, although they must always differ in facility of aeration as well as in their mechanical resistance to root growth.

\section{HEIGHT GROWTH OF SAPLINGS.}

It is generally true of all pines that a single whorl of lateral branches arises annually at the summit of the shoot of the preceding season. This usually takes place in the Monterey pine, and furthermore, a second, and 
even a third whorl of lateral branches appears in the great majority of vigorous saplings, springing from the shoot of that season, and appearing at any time from July to September. The writer has been informed by Mr. G. A. Pearson that this behavior is also characteristic of the Southern long leaf pine (Pinus palustris).

By reason of these supernumerary whorls, it is impossible to determine the age of the false internodes of the stem by counting back from the tip and allowing one year for each whorl of branches, as may be done in other pines. It is easy, however, to distinguish the growth of the year from that of the preceding year by the color of the bark, which remains greenish even after the appearance of a second whorl of branches above it.

Measurement of the height-growth of 300 saplings was made in late August and early September. Owing to the facts just related, it was not possible to do more than measure the height-growth of the current year, then approaching its close, and the height of the sapling at the commencement of growth in the spring. In table 11 are given the results of these

TABLE 11.-Average height (in centimeters) of 300 saplings at the end of 1918 and average growth in 1919, by height classes, and the percentage of the latter on the basis of the former.

\begin{tabular}{|c|c|c|c|c|c|c|c|c|c|}
\hline $\begin{array}{l}\text { Height } \\
\text { of } \\
\text { group. }\end{array}$ & $\begin{array}{l}\text { No. } \\
\text { meas- } \\
\text { ured. }\end{array}$ & $\begin{array}{c}\text { Average } \\
\text { height, } \\
1918 .\end{array}$ & $\begin{array}{c}\text { Average } \\
\text { growth, } \\
1919 .\end{array}$ & $\begin{array}{c}\text { Per- } \\
\text { centage. }\end{array}$ & $\begin{array}{l}\text { Height } \\
\text { of } \\
\text { group. }\end{array}$ & $\begin{array}{l}\text { No. } \\
\text { meas- } \\
\text { ured. }\end{array}$ & $\begin{array}{c}\text { Average } \\
\text { height, } \\
1918 .\end{array}$ & $\begin{array}{c}\text { Average } \\
\text { growth, } \\
1919 .\end{array}$ & $\begin{array}{c}\text { Per- } \\
\text { centage. }\end{array}$ \\
\hline 10 to 19 & 27 & 15 & 13 & 86 & 90 to 99 & 11 & 95 & 31 & 38 \\
\hline $20 \quad 29$ & 34 & 25 & 19 & 76 & $100 \quad 109$ & 9 & 104 & 25 & 24 \\
\hline $30 \quad 39$ & 44 & 35 & 20 & 57 & 110 & 6 & 113 & 34 & 30 \\
\hline 40 & 45 & 45 & 21 & 47 & 120 & 4 & 125 & 34 & 27 \\
\hline 50 & 46 & 54 & 24 & 44 & 130 & 3 & 131 & 32 & 24 \\
\hline 60 & 32 & 65 & 29 & 45 & 160 & 1 & 160 & 48 & 30 \\
\hline 70 & 24 & 74 & 33 & 44 & 210 & 1 & 211 & 29 & 14 \\
\hline $80 \quad 89$ & 11 & 85 & 30 & 35 & & & & & \\
\hline
\end{tabular}

measurements, grouped in height classes by increments of $10 \mathrm{~cm}$., on the basis of the height at the commencement of the season. The percentage of the growth of the year to all previous growth is found to fall from 86 per cent in seedlings 10 to $19 \mathrm{~cm}$. high to 24 per cent in saplings 130 to $132 \mathrm{~cm}$. in height. There are, of course, many exceptional cases in which height is nearly doubled in a single year by trees 2 to 3 meters in height, particularly in moist situations or in trees left alone in clearing.

\section{SEASONAL MARCH OF GROWTH.}

In March 1919 measurements were made of the length of the main shoot on several vigorous saplings, which had already made a growth of 32.5 to $65 \mathrm{~cm}$. The same shoots were measured at several intervals until the middle of October, and the results in four cases are given in table 12 . It will be seen that in the case of tree B, more than half of the year's height growth had taken place prior to March 30, while in trees $\mathrm{E}$ and F, 40 per cent of it had taken place by that date. The amount of growth from August to October is very small in all of the cases, and this appears to be true of the larger trees as well as the saplings. Although the season favorable for growth is exceptionally long on the California coast, the Monterey pine 
appears to have a habit similar to that of all other pines in accomplishing the principal part of its height-growth in the earliest weeks of the growingseason, although it grows slowly throughout at least 10 months of the year.

TABLE 12.-Height (data in centimeters) of main shoot formed in 1919, as measured at intervals during the growing-season.

\begin{tabular}{|l|r|r|r|r|r|r|}
\hline & Mar. 30 & June 12 & July 12 & Aug. 6 & Sept. 3 & Oct. 12 \\
\hline & & & & & \\
B & $\ldots \ldots$ & 65.0 & 70.0 & 77.5 & 82.5 & 82.5 \\
C & $\ldots \ldots \ldots$ & 32.5 & 87.5 & 97.5 & 102.5 & 102.5 \\
E & 40.0 & 82.5 & 96.0 & 97.5 & 97.5 & 100.0 \\
F & 32.5 & 72.5 & 81.0 & 90.0 & 97.5 & 100.0 \\
\hline
\end{tabular}

\section{CORRELATION OF HEIGHT GROWTH AND DIAMETER GROWTH.}

For the comparison of height-growth with diameter-growth a number of vigorous saplings from 4.5 to 6 meters in height were chosen. Owing to the

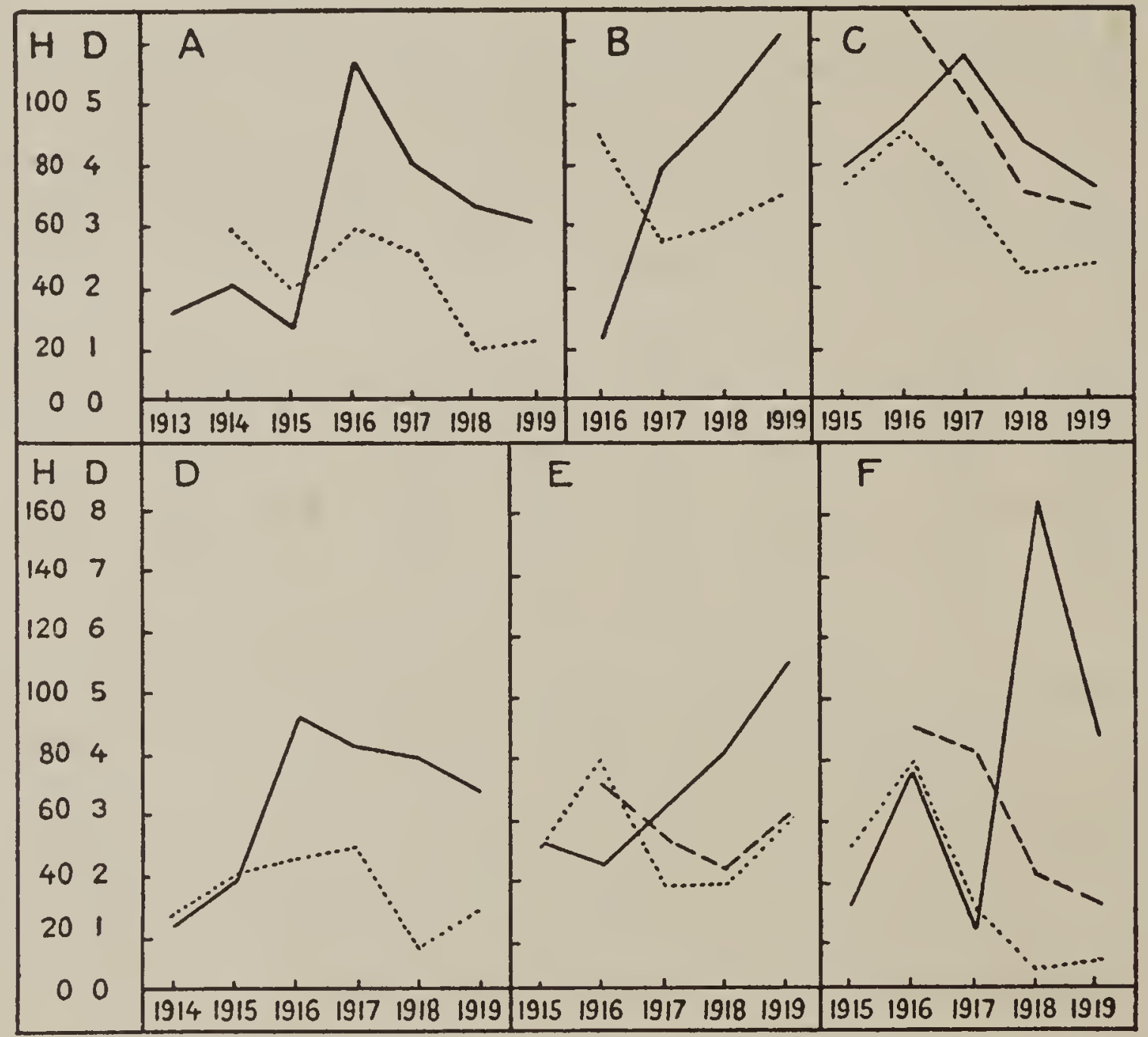

Fra. 21.-Graphs showing relation between growth in height (solid line), in diameter at base (dotted line), and diameter half way between base and top (broken line) for 6 young trees of Monterey pine.

previously mentioned appearance of more than one whorl of branches per annum, it was necessary to cut across each of the false internodes and count the rings in order to determine the number of internodes involved in the height-growth of each year. The growth in diameter was measured on the stumps about $10 \mathrm{~cm}$. from the ground, and also, in a few cases, at one of the cross-sections midway between the top and base of the trunk.

The comparison of height-growth with diameter-growth for six representative individuals is shown graphically in figure 21. It might be presumed 
on a priori grounds that there would be (1) a positive correlation between the two phases of growth, due to an identity between the conditions favoring each of them; (2) a negative correlation, due to the diversion of materials to the one phase of growth at the expense of the other; or (3) a mixture of positive and negative correlations, due to the complexity of the conditions governing growth, the dissimilar conditions prevailing in different years, and the differences of behavior in different individuals due to shading, crowding, or other local conditions. Enough data were secured to show that the third of these hypothetical cases is apparently the one characterizing the Monterey pine. In tree $\mathrm{A}$ there is a considerable degree of correlation, at least qualitatively. In tree $\mathrm{B}$ there is a strong negative correlation with respect to the growth for 1918 and 1917, and a positive correlation in the following years. In tree $\mathrm{C}$ there is an alternation of positive and negative correlations in the successive years. Trees D and $\mathrm{E}$ show similar irregular behavior. In tree $\mathrm{F}$ there is a close correlation for two successive intervals, followed by a sharp negative correlation in the two succeeding intervals. The exceptionally great growth in height in 1918 was accompanied by a very small growth in diameter.

In comparing the graphs for the diameter-growth at the base of the trunk and those for growth in diameter halfway up the trunk, it will be seen that there is a close correlation in all cases except the last interval in tree F, in which an increase of basal diameter-growth was accompanied by a decrease of mid-stem diameter-growth.

\section{DIAMETER-GROWTH AT DIFFERENT HEIGHTS IN THE TRUNK.}

Our knowledge of the diameter-growth of individual trees and our information regarding the total increment of forest stands have been based chiefly on data secured below a level of 5 feet on the trunk of the tree. Such data include increment borings, caliper measurements made at breastheight, and the great majority of the dendrograph records thus far secured. In order to secure material for comparing the relation of height and diameter growth in a large tree, and for comparing the diameter-growth at different heights, a special investigation was undertaken.

After careful selection, a tree was found which had reached the mature height of 20 meters, but had not yet lost the excurrent habit of branching which is typical of the early life of the pine. This tree was situated on a slope overlooking the sea 4 miles south of Carmel, California, and was growing in a normal stand of trees of approximately the same diameter. The tree was felled in the early part of July 1921, and the trunk was carefully cut away on one side by a skilled woodsman until the median line of pith was revealed. The trunk was then cut transversely into sections 1 meter long, and both the longitudinal and transverse sections were smoothed so as to make easy the following and identification of all rings of growth.

The age of this tree was found to be 38 years. The diameter at the stump was $43.5 \mathrm{~cm}$. outside bark and $39 \mathrm{~cm}$. inside bark. The diameter 18 meters above the stump was $7.5 \mathrm{~cm}$. outside bark and $7.2 \mathrm{~cm}$. inside bark. The height-growth of 1921 had been $14 \mathrm{~cm}$., that of $1920,6 \mathrm{~cm}$.

The thickness of the individual rings was measured at each of the 20 transverse sections. In all cases the measurements were made along either 
two or three radii and in the case of the stump along six radii, and the averages recorded. The entire growth history of the tree was thus secured, by years and by heights from the stump, and in every section the longitudinal face of the trunk was used to verify the identity of the rings. The figures secured are shown in table 4 , being increments in radius only and requiring to be doubled to secure diameter increments.

The period of most rapid growth in height was the first 10 years in the life of the tree, from 1884 to 1894, in which it attained a height of 10 meters. In the 16 years from 1894 to 1910 there was an additional height-growth of 8.8 meters. In the 11 years from 1910 to the felling of the tree the growth in height was only 1.2 meters. The greatest increment in diameter in a single year was $33 \mathrm{~mm}$. recorded in 1891 at a height of 5 meters, and in 1892 at a height of 3 meters, these cases being respectively at and near the center of the tree. The greatest increases in diameter occurred during the first half of the life of the tree and during the period which was also marked by the greatest height-growth. During the last 10 years, and after the growth in height had become very slow, the radial increments of growth had become small, exceptional cases indicating a diameter increase of $8 \mathrm{~mm}$., the majority of cases an increase of less than $5 \mathrm{~mm}$., and very many cases diameter increments of less than $2 \mathrm{~mm}$. An inspection of the table of annual growth increments shows that the greatest radial increase in a given year is generally found in the upper half of the trunk and most commonly within 5 or 6 meters of the top. There are a few exceptional cases, as 1901, 1904, and 1913, in which the greatest growth was near the base of the trunk, but in each of these cases there is a region of active growth near the top in which a submaximum may be found. An inspection of the table with respect to the year of greatest growth at a given cross-section of the trunk will show that this is commonly to be found at or near the center of the trunk, and very rarely more than four rings from the center.

A marked characteristic of the Monterey pine is the frequent alternation of light and heavy rings of autumnal wood, the light ring invariably lying nearer to the heavy ring outside it than it does to the ring inside it. The existence of double rings necessitates caution in determining the age of examples of the Monterey pine, but there are few cases in which the comparative heaviness of the ring, and an examination of the entire circumference of the section, will not definitely establish their nature. In the case of the bisected trunk the longitudinal faces afforded an additional means of making sure as to the dating of all rings. In making the measurements, a record was kept of all years in which there was an intercalary ring, and these are indicated in the table by heavy-faced numerals. It will be seen that the double nature of the growth for a given year is not always apparent at all levels in the tree. In 1897, for example, there was a double ring from the stump up to a height of 7 meters, and the sections from 8 to 12 meters failed to show any indication of double rings. In other cases, as 1903 and 1905, there were weakly developed intercalary rings at the base of the trunk and more strongly developed ones toward the top. The nature of the double rings will be discussed further in a later section.

The data presented in table 13 afford an opportunity to determine the relative thickness of the cone of wood laid down at different levels on the 
trunk in a given year, and also to compare the relative thickness of any two layers at different levels. As already noted, the maximum thickness is usually in the upper part of an annual cone and in general the thickness of the upper half is greater than that of the lower half. The difference between the thickness of the upper and lower portions was less in the early life of the tree and became greater during its last ten years. A comparison of the

TABLE 13.-Average thickness of annual rings of growth in bisected Monterey Pine measured on sections taken at 10-meter intervals.

The figures in the headings represent the height (in meters) from stump.

The figures in the body of the table represent the growth in centimeters.

\begin{tabular}{|c|c|c|c|c|c|c|c|c|c|c|c|c|c|c|c|c|c|c|c|c|c|c|}
\hline & 19.8 & 19.6 & 18.8 & 18.0 & 17.0 & 16.0 & 15.0 & 14.0 & 13.0 & 12.0 & 11.0 & 10.0 & 9.0 & 8.0 & 7.0 & 6.0 & 5.0 & 4.0 & 3.0 & 2.0 & 1.0 & 0.0 \\
\hline 1921 & 2.0 & 1.5 & 2.2 & 0.7 & 1.0 & 1.0 & 1.0 & 2.0 & 1.0 & 0.4 & 0.5 & 0.4 & 0.3 & 0.2 & 0.1 & 0.2 & 0.2 & 0.3 & 0.5 & 0.5 & 0.5 & 0.5 \\
\hline 1920 & $\ldots$ & 3.0 & 2.3 & 2.4 & 1.4 & 1.2 & 1.0 & 1.8 & 0.7 & 0.4 & 0.4 & 0.2 & 0.4 & 0.2 & 0.1 & 0.2 & 0.2 & 0.3 & 0.5 & 0.5 & 0.5 & 0.7 \\
\hline 1919 & $\ldots$ & 2.5 & 3.0 & 2.5 & 2.1 & 2.1 & 1.5 & 1.8 & 0.1 & 0.6 & 0.5 & 0.5 & 0.9 & 0.2 & 0.2 & 0.1 & 0.2 & 0.3 & 0.5 & 0.5 & 0.4 & 0.5 \\
\hline 1918 & $\ldots$ & $\ldots$ & 2.4 & 2.5 & 2.0 & 2.4 & 0.9 & 1.6 & 1.5 & .9 & 1.2 & 1.1 & 1.7 & 0.4 & 0.7 & 1.0 & 0.4 & 0.5 & 0.5 & 0.4 & 1.2 & 1.2 \\
\hline 1917 & $\ldots$ & $\ldots$ & 2.7 & 2.7 & 3.0 & 2.5 & 1.9 & 2.2 & 1.9 & 1.6 & 1.5 & 0.9 & 2.4 & 0.7 & 0.8 & 1.9 & 1.6 & 1.2 & 1.1 & 0.8 & 1.0 & 1.3 \\
\hline 1916 & $\ldots$ & $\ldots$ & 1.6 & 1.4 & 1.9 & 1.5 & 2.5 & 2.8 & 3.6 & 3.5 & 4.0 & 2.8 & 3.2 & 1.0 & 1.2 & 1.7 & .8 & 1.6 & 1.5 & 1.0 & 1.9 & 2.1 \\
\hline 1915 & $\ldots$ & $\ldots$ & 1.5 & 1.8 & 1.9 & 1.9 & 3.5 & 3.6 & 3.8 & 3.7 & 4.0 & 2.6 & 2.8 & 2.5 & 1.8 & 2.1 & 1.8 & 2.0 & 2.5 & 2.0 & 3.0 & 2.9 \\
\hline 1914 & $\ldots$ & $\ldots$ & 1.0 & 1.2 & 2.0 & 3.0 & 4.8 & 4.6 & 3.9 & 3.5 & 3.1 & 0.9 & 1.6 & 2.0 & 2.7 & 3.0 & 2.5 & 2.3 & 3.0 & 3.0 & 2.1 & 2.0 \\
\hline 1913 & & $\ldots$ & 1.0 & 2.0 & 0.8 & 1.5 & 2.0 & 2.1 & 4.1 & 2.2 & 2.5 & 1.5 & 3.0 & 1.5 & 2.0 & 1.6 & 2.0 & 1.7 & 1.5 & 4.5 & 2.0 & 1.5 \\
\hline 1912 & & & 0.5 & 2.0 & 1.8 & 2.2 & 3.7 & 3.0 & 3.0 & 2.5 & 2.4 & 1.5 & 2.5 & 1.5 & 2.1 & 1.7 & 2.2 & 1.6 & 2.1 & 1.5 & 1.5 & 2.0 \\
\hline 1911 & & $\ldots$ & 1.5 & 1.2 & 3.0 & 2.6 & 3.0 & 2.8 & 3.2 & 2.7 & 2.0 & 2.5 & 2.7 & 1.7 & 1.7 & 1.5 & 1.5 & 1.5 & 1.7 & 2.5 & 2.0 & 2.0 \\
\hline 1910 & . . & $\ldots$ & 1.5 & 1.4 & 2.2 & 2.3 & 3.8 & 4.6 & 3.8 & 2.6 & 3.0 & 2.0 & 2.7 & 2.4 & 2.2 & 2.3 & 2.4 & 1.9 & 2.0 & 3.0 & 2.1 & 1.6 \\
\hline 1909 & & $\ldots$ & $\ldots$ & 3.0 & 3.0 & 3.2 & 4.2 & 3.2 & 3.9 & 3.2 & 3.0 & 0.8 & 1.0 & 2.0 & 2.8 & 2.7 & 2.4 & 1.8 & 2.0 & 2.9 & 2.5 & 2.4 \\
\hline 1908 & & $\ldots$ & $\ldots$ & 3.6 & 3.0 & 4.3 & 4.0 & 3.5 & 6.5 & 6.2 & 7.0 & 5.0 & 6.0 & 1.0 & 1.2 & 1.0 & 1.1 & 1.2 & 1.0 & 3.0 & 2.5 & 2.6 \\
\hline 1907 & & & $\ldots$ & 3.0 & 3.5 & 4.1 & 6.0 & 6.1 & 7.0 & 7.5 & 8.0 & 7.7 & 6.8 & 4.5 & 6.4 & 5.2 & 4.6 & 3.8 & 3.6 & 1.2 & 1.6 & 3.8 \\
\hline 1906 & & & & $\ldots$ & 2.1 & 4.0 & 7.0 & 7.0 & 6.2 & 7.0 & 7.5 & 6.5 & 6.0 & 5.0 & 6.5 & 5.6 & 5.8 & 5.0 & 5.5 & 3.5 & 4.5 & 6.0 \\
\hline 1905 & & & $\cdots$ & $\cdots$ & 3.0 & 4.5 & 4.6 & 6.5 & 5.0 & 5.5 & 5.6 & 1.4 & 1.5 & 6.2 & 6.8 & 4.5 & 6.0 & 5.0 & 6.0 & 5.5 & 5.0 & 6.4 \\
\hline 1904 & & 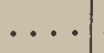 & $\ldots$ & & 7.0 & 3.6 & 4.4 & 5.5 & 4.9 & 4.5 & 4.5 & 4.3 & 3.5 & 1.4 & 1.5 & 1.0 & 1.0 & 1.0 & 1.0 & 7.0 & 7.1 & 4.0 \\
\hline 1903 & & & $\ldots$ & $\ldots$ & $\cdots$ & 5.0 & 3.1 & 3.4 & 5.0 & 4.8 & 5.0 & 5.0 & 4.5 & 3.5 & 5.0 & 2.6 & 2.5 & 2.0 & 2.5 & 3.5 & 4.6 & 3.9 \\
\hline 1902 & & & & $\ldots$ & . & $\ldots$ & 3.5 & 4.4 & 4.5 & 6.0 & 7.0 & 4.8 & 4.0 & 3.5 & 3.0 & 3.5 & 3.5 & 3.0 & 3.5 & 3.2 & 3.0 & 5.1 \\
\hline 1901 & & & & & $\ldots$ & & 6.0 & 5.5 & 3.0 & 2.5 & 5.6 & 6.0 & 5.5 & 4.5 & 4.5 & 4.8 & 5.0 & 3.2 & 3.5 & 4.0 & 4.3 & 6.2 \\
\hline 1900 & & & & & $\cdots$ & & $\ldots$ & 7.5 & 5.0 & 4.5 & 5.0 & 6.0 & 4.0 & 5.5 & 5.4 & 5.0 & 5.0 & 4.2 & 4.8 & 5.5 & 5.0 & 2.0 \\
\hline 1899 & & & & & & & $\ldots$ & 4.5 & 4.0 & 4.1 & 4.5 & 5.2 & 6.0 & 4.5 & 4.0 & 5.2 & 4.2 & 4.5 & 3.4 & 5.0 & 3.0 & 4.2 \\
\hline 1898 & & & 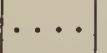 & $\cdots$ & . & & $\ldots$ & $\cdots$ & 5.8 & 8.0 & 9.8 & 3.5 & 4.5 & 5.6 & 4.8 & 5.6 & 4.8 & 4.5 & 4.0 & 5.0 & 4.1 & 3.5 \\
\hline 1897 & & & & $\ldots$ & $\cdots$ & & $\ldots$ & $\ldots$ & $\ldots$ & 4.0 & 5.0 & 9.0 & 8.0 & 4.5 & 4.5 & 3.5 & 3.0 & 3.0 & 5.0 & 3.5 & 3.0 & 3.2 \\
\hline 1896 & & & & $\ldots$ & & & $\ldots$ & $\ldots$ & $\ldots$ & $\ldots$ & 6.0 & 6.5 & 8.5 & 8.8 & 8.0 & 6.5 & 10.3 & 8.7 & 9.5 & 8.0 & 9.0 & 8.5 \\
\hline 1895 & & & & & . & & & . & $\cdot$ & $\cdots$ & $\ldots$ & 8.0 & 10.5 & 9.5 & 10.5 & 11.2 & 9.0 & 7.5 & 7.5 & 8.0 & 6.0 & 7.0 \\
\hline 1894 & & & & & 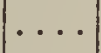 & $\cdots$ & & 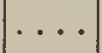 & 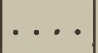 & & & 5.5 & 13.5 & 12.0 & 11.5 & 12.3 & 9.5 & 10.0 & 9.5 & 9.5 & 7.8 & 9.0 \\
\hline 1893 & & . & & $\cdots$ & . & $\ldots$ & & $\ldots$ & $\ldots$ & & $\ldots$ & $\ldots$ & $\cdots$ & 9.0 & 11.5 & 10.0 & 9.8 & 8.5 & 8.0 & 9.6 & 6.5 & 7.6 \\
\hline 1892 & & & & & & 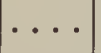 & & $\ldots$ & $\ldots$ & $\ldots$ & . . & $\cdots$ & $\ldots$ & 9.0 & 9.7 & 11.0 & 15.0 & 14.0 & 16.5 & 13.0 & 9.5 & 12.5 \\
\hline 1891 & & & & & & & & & $\ldots$ & $\ldots$ & $\cdots$ & $\ldots$ & $\ldots$ & $\ldots$ & 7.0 & 12.0 & 16.5 & 13.5 & 12.8 & 11.0 & 8.0 & 7.7 \\
\hline 1890 & & & & & & . & & $\ldots$ & $\ldots$ & $\ldots$ & $\cdots$ & $\ldots$ & $\cdots$ & $\cdots$ & $\ldots$ & $\ldots$ & $\ldots$ & 8.8 & 12.0 & 11.5 & 10.5 & 11.0 \\
\hline 1889 & & & & $\cdots$ & $\cdot$ & .. & 1 & $\ldots$ & $\ldots$ & $\ldots$ & $\cdots$ & $\cdots$ & *. & $\cdots$ & $\ldots$ & $\cdots$ & $\ldots$ & 9.0 & 11.0 & 10.5 & 13.6 & 14.5 \\
\hline 1888 & & & & & & & & & & & & & & & $\ldots$. & & $\cdots$ & $\ldots$ & $\cdots$ & 10.0 & 6.5 & 10.0 \\
\hline 1887 & & & & & & & & & & $\ldots$ & . & & $\ldots$ & . & $\cdots$ & & $\ldots$ & $\ldots$ & $\ldots$ & 7.0 & 2.0 & 6.7 \\
\hline 1886 & & & & & & & & & $\cdots$ & $\ldots$ & $\cdots$ & & $\cdots$ & $\cdots$ & ... & . & $\cdots$ & $\cdots$ & $\ldots$ & $\ldots$ & $\ldots$ & 6.5 \\
\hline 1885 & & & & & . & $\cdots$ & $\cdots$ & 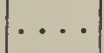 & . & $\cdots$ & $\cdots$ & 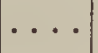 & $\cdots$ & $\cdots$ & $\cdots$ & $\cdots$ & $\cdots$ & $\ldots$ & $\ldots$ & $\ldots$ & $\ldots$ & 4.7 \\
\hline 1884 & & & & & & & & & & 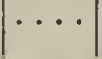 & & & 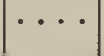 & 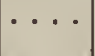 & 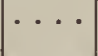 & & & & & & & 9.0 \\
\hline
\end{tabular}

relative thickness of the wood of any two years discovers many cases of great variability. In fact, it is seldom that a ring is continuously greater or less than an adjacent ring when they are followed for several meters up the trunk. The growth for 1894 and 1895 shows a very constant relation, in which the former year left a thicker ring than the latter from the base of the tree up to the highest level at 10 meters, where there was a reversal of this relation. In comparing 1903 and 1904, the latter year is found to exhibit greater growth at the three lowest levels, while for the next six levels above these the former year shows a much greater growth than the latter. Numerous cases can be found throughout the table in which there is great 
irregularity in the relation between the growth of two adjacent or separate years.

In order to make more graphic the relations between the annual progress of growth at different heights in the trunk, figure 22 has been drawn to show the average increments at the stump and at heights of 5,10 , and 15 meters. The four graphs in this figure show how rarely there is a coincidence between the maxima and minima of growth, and how frequently there is a dissimilarity of pitch between the lines in each vertical series, indicating a lack of uniformity in the thickening of the same cone of wood at these levels. There is a somewhat better correspondence between the graphs for the stump and the 5 -meter level than there is between those for 5,10 , and 15 meters. This indicates that the portions of the trunk above the lowest existing branches, and above the branches which existed 5 to 10 years ago, may have had their growth influenced by the position of the foliage from which their supplies of metabolic material were drawn.

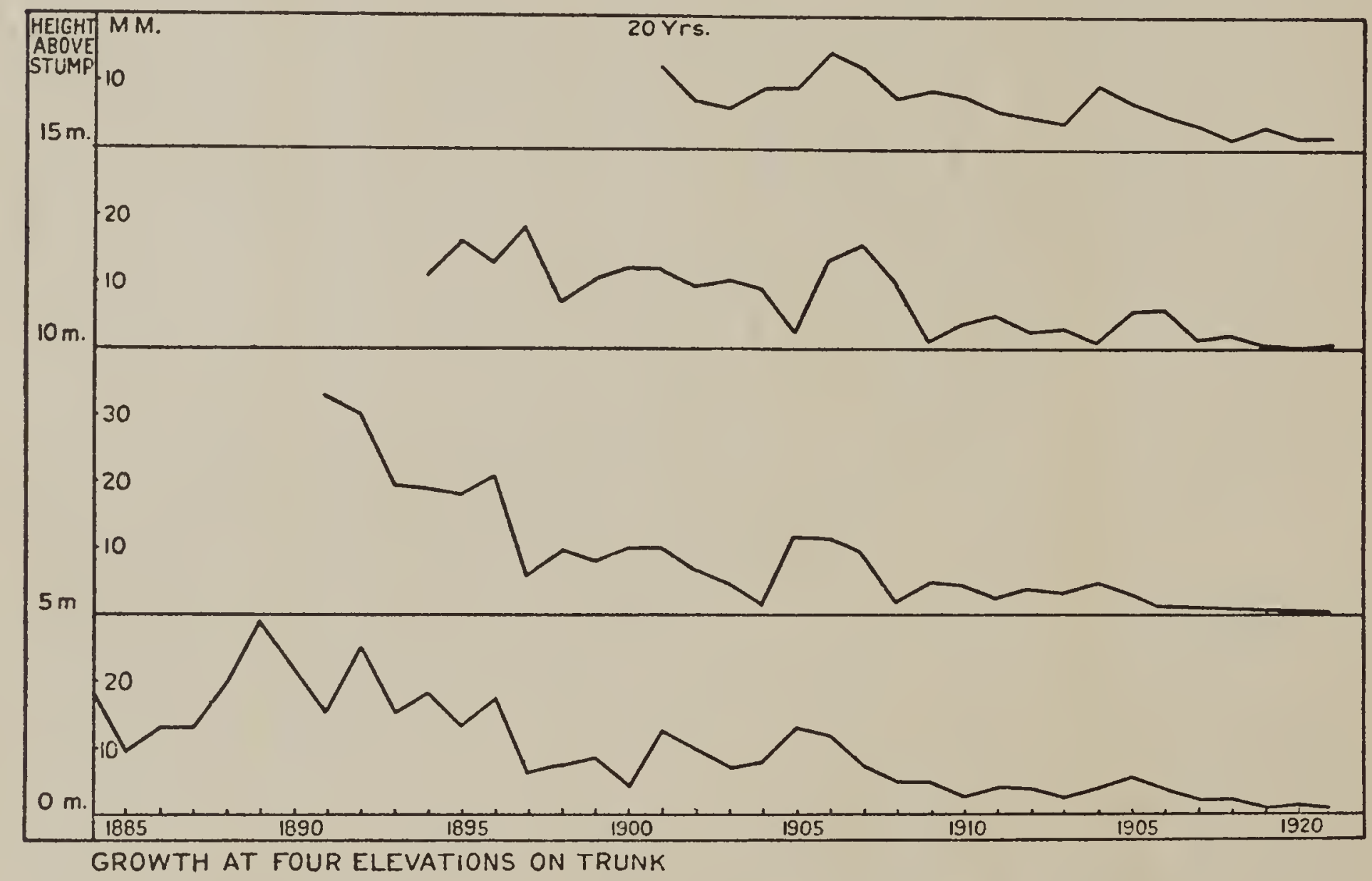

Frg. 22.-Graphs showing annual increase in diameter in trunk of bisected Monterey pine at stump and at heights of 5,10 , and 15 meters.

A more graphic delineation of the irregularity in thickness of certain annual layers of growth has been attempted in figure 23, which illustrates a stump 6 meters in height, from which a sector has been removed so as to reveal the median surface, on which have been drawn to scale the thickness of the annual layers for the years 1903 to 1908. It is obvious from this diagram that sections of the trunk made at any two levels would indicate very dissimilar marches of growth from year to year.

In the summer of 1923 a second pine was felled and examined in a manner similar to that employed in the bisected tree that has just been described. This tree was growing in close proximity to the Coastal Laboratory, on the steep inward face of the old stabilized dune on which Carmel is situated. 
Its height was 55 feet and its age 28 years. The tree was felled by a cut 6 inches from the ground, and transverse cuts were made at intervals of 3

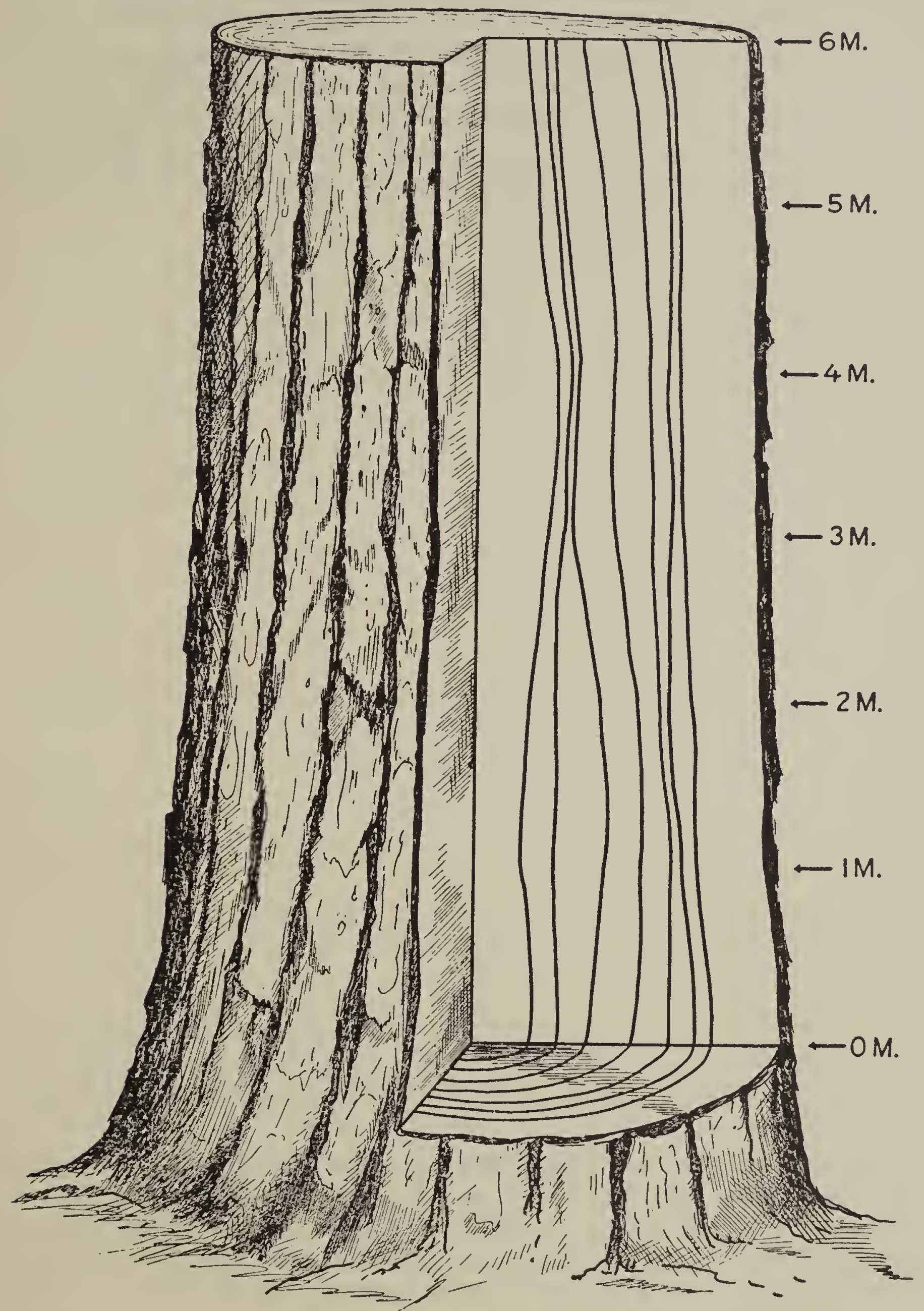

FIg. 23.-Schematic illustration of vertical variation in thickness of annual rings of bisected Monterey pine for years 1903 to 1908.

feet throughout the trunk. The rings were so legible at all of the cuts that bisection was necessary only in the case of the lowest piece. In table 5 are shown the average measurements of the thickness of the rings on the 19 
surfaces. In figure 24 are shown the graphs of growth at the stump and at heights of 9,18 , and 27 feet from the stump.

The vigorous condition of the tree is attested by the fact that it had grown in height at an average of 3 feet per annum for the last 21 years, not yet having reached the stage of matured crown. The statements made with regard to the first tree hold true of this one with respect to the times and regions of most active wood formation. There is in this tree, however, a greater uniformity in the relative thickness of the various rings at each level in the trunk, as will be seen by a comparison of figure 22 and figure 24.

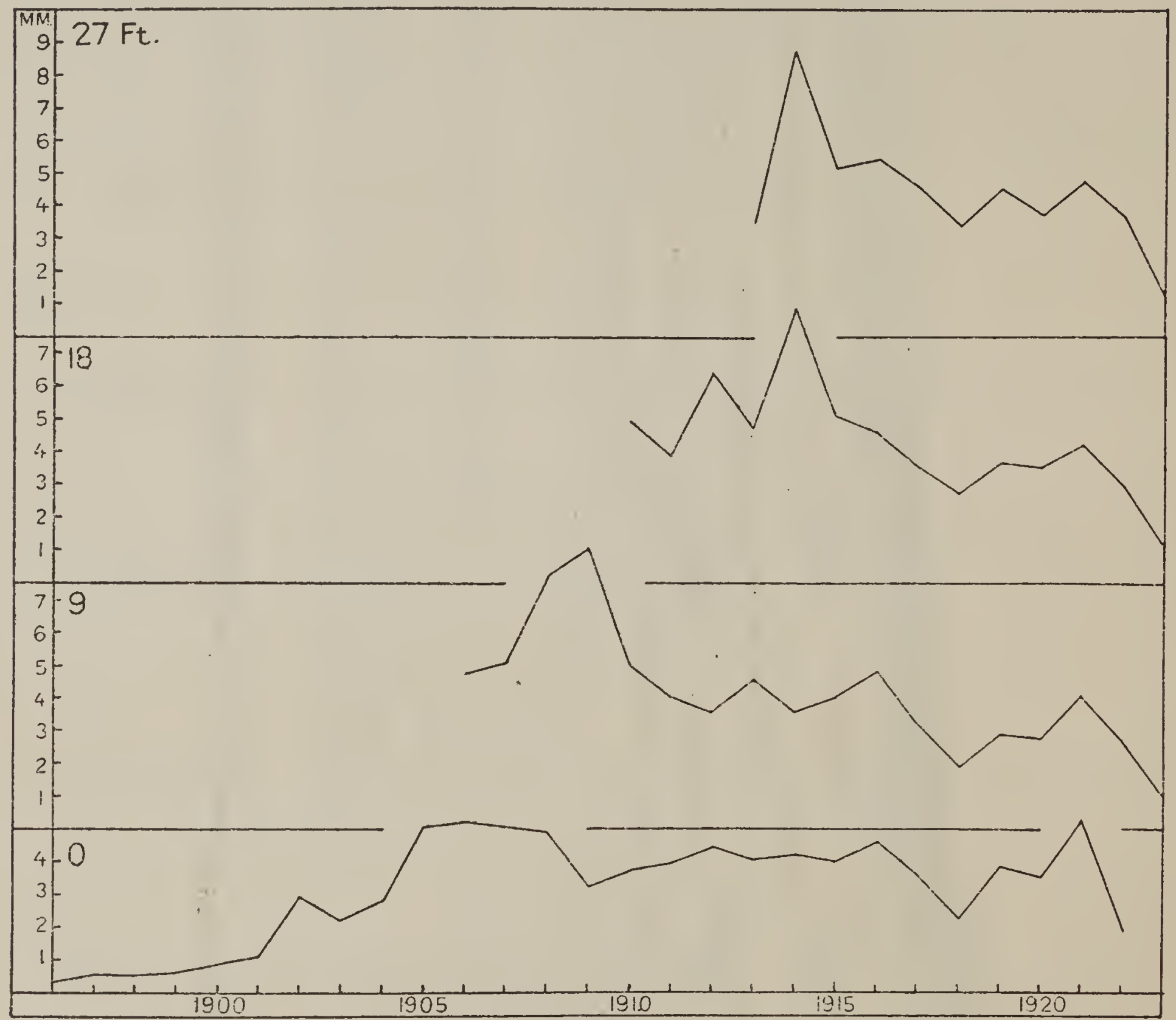

Fra. 24.-Graphs showing increase in diameter in trunk of Monterey pine at stump and at heights of 9,18 , and 27 feet.

There is also a closer correspondence throughout the trunk between the annual fluctuations of growth. During the last 20 years of the life of the former tree there were only 3 years in which the growth graphs corresponded in direction at the four levels. In the last 10 years of the latter tree there were 7 years in which the growth graphs corresponded in direction. There are nevertheless some conspicuous cases in the second tree in which a less growth or a very slight increase of growth in the lower half of the trunk was accompanied by a marked increase over the preceding year in the upper half of the trunk.

The factors concerned in causing the observed differences in wood increment at different levels in the same year are probably deep-seated ones 
that could be discovered and investigated only through the aid of a much fuller knowledge of the physiology of the tree and the mechanism of the transport of foodstuffs than we now possess. The history of the survival and death of the lowest branches is also concerned in these differences. It remains to be learned, also, whether such irregularity is of constant occurrence in the Monterey pine and whether it is characteristic of other pines and of other tree species as well. No literature has been found which makes it possible to institute such a comparison.

\section{DOUBLE RINGS OF GROWTH.}

The only piece of direct evidence as to the nature and cause of the double annual rings of growth has been secured by MacDougal in his dendrographic records for the Monterey pine for 1918. In that year in mid-September there occurred an exceptionally early and heavy rain of 5.59 inches, lasting for 3 days. Although the growth of the pine had slowed down almost to a standstill, this heavy rain caused renewed activity, as exhibited by the

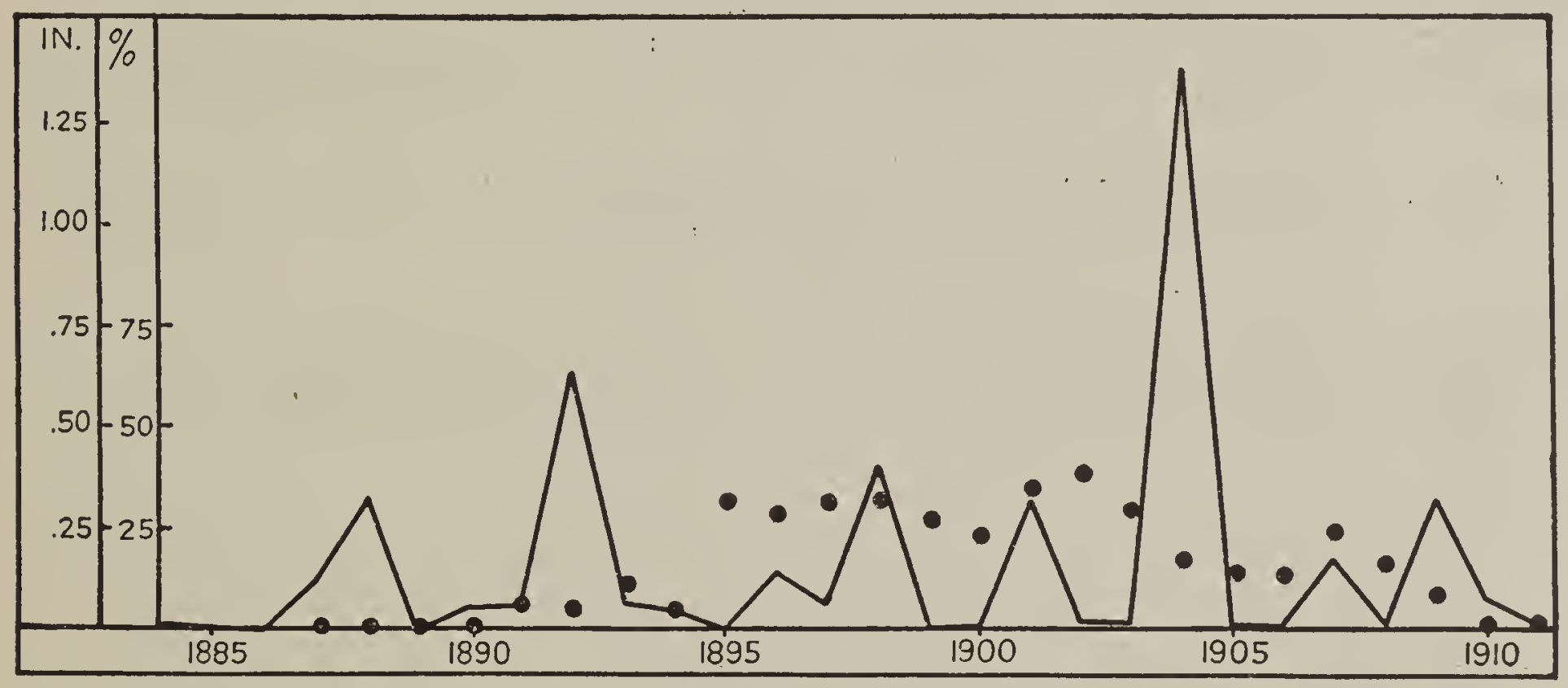

Frg. 25.-Graph showing September rainfall (solid line) and percentages of cross-sections of trunk showing double rings of growth for corresponding years (dots).

dendrograph. Increment borings taken the following year from the tree on which the dendrograph had been mounted showed that a second annual ring of growth had been formed, with its thickness corresponding to the dendrographic measure of the September activity. Boring and sections of many other trees have shown the occurrence of a secondary ring for 1918.

The probability that all cases of double rings could be explained by the occurrence of late summer or early autumnal rain on the years in which the secondary rings occur led to an effort to correlate the two phenomena in the data from the bisected pine, with the result shown in figure 25 . It will be seen that the higher September rainfall of 1892 and 1904 did not cause an increase in the percentage of cross-sections of the tree showing double rings for those years. The absence of September rain in 1895 and in 1902 and 1903 was concurrent with a relatively high percentage of sections showing double rings for those years. Correlations involving the October rainfall alone or the sum of the September and October rainfall are no stronger. Further investigation will be required to determine all of 
the factors involved in what is very obviously a result of the occurrence of two seasons with favorable growing conditions, separated by several weeks of unfavorable conditions.

\section{REDWOOD (SEquoIA SEMPERVIRENS).}

In the summer of 1922 a redwood was felled and the trunk bisected longitudinally and then cut transversely into lengths of 1 meter each, in the same manner employed in the pine. The redwood was growing near the drainageway of a small cañon tributary to Rocky Creek, at a distance of about 3 miles from the coast and about 17 miles south of Carmel. Like so many of the younger redwoods, the origin of this tree was as a sucker from a large tree no longer standing. The stump of the tree from which this sucker and three accompanying ones originated was still legible and indicated that it had been felled at the age of 75 years. The trunk taken for bisecting was 17 meters high and $26 \mathrm{~cm}$. thick at the stump, which was cut flush with the surface of the ground. The age was 15 years. The bole was straight and indicated a vigorous and uninterrupted growth.

The figures for annual increments of radius at the various heights are shown in table 14. It will be seen that a fairly uniform growth in height

TABLE 14.-Average thickness (in millimeters) of annual rings of growth in Monterey pine measured on sections taken at intervals of 3 feet.

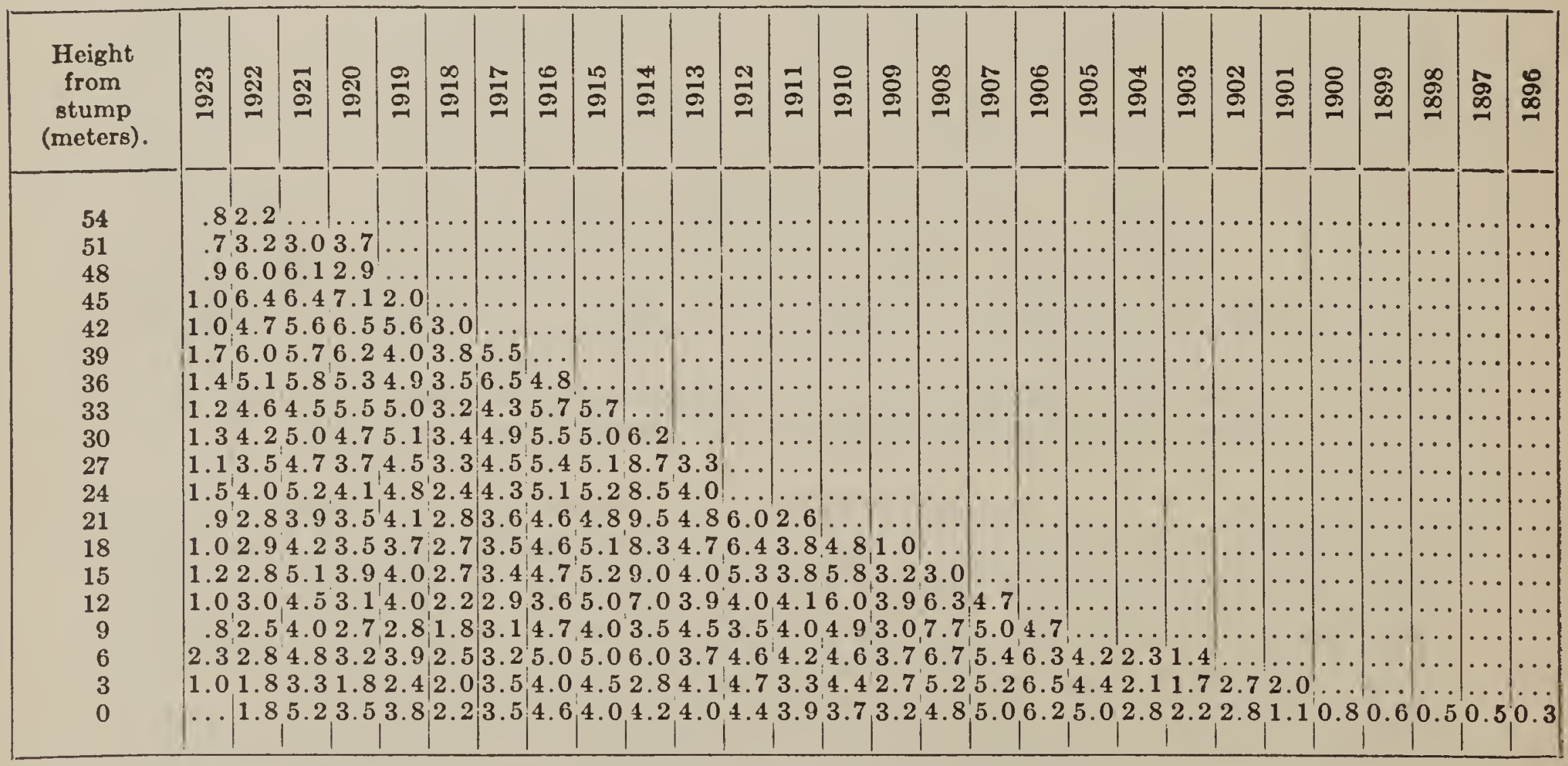

of a little more than 1 meter per year was maintained throughout the life of the tree. In four of the 1-meter sections of the trunk the age was the same at both ends of the section. In all other sections the lower end was one year older than the upper. The maturing of the crown, and the accompanying decrease in rate of growth, first begin in the redwood at a greater height and age.

During the first five years the greatest growth in thickness was in the basal or middle portion of the trunk, but after the sixth year it is to be found almost invariably in the uppermost part of the trunk. In the exami- 
nation of each transverse section the maximum growth is found, in all cases but one, to have taken place near the center of the trunk, as was likewise the case in the pine.

In order to compare the redwood and the pine with respect to the comparative growth behavior at different elevations, graphs have been drawn for the redwood which are shown in figure 26. The lowest graph shows the annual increments of radius at the stump, and the upper graphs show the increments at 3-meter intervals up to a height of 12 meters. A comparison of these graphs with those for the pine, in figure 22, shows a somewhat greater uniformity at the different levels in the redwood. At the stump and at 3 and 6 meters there was a progressive slowing-down of growth from

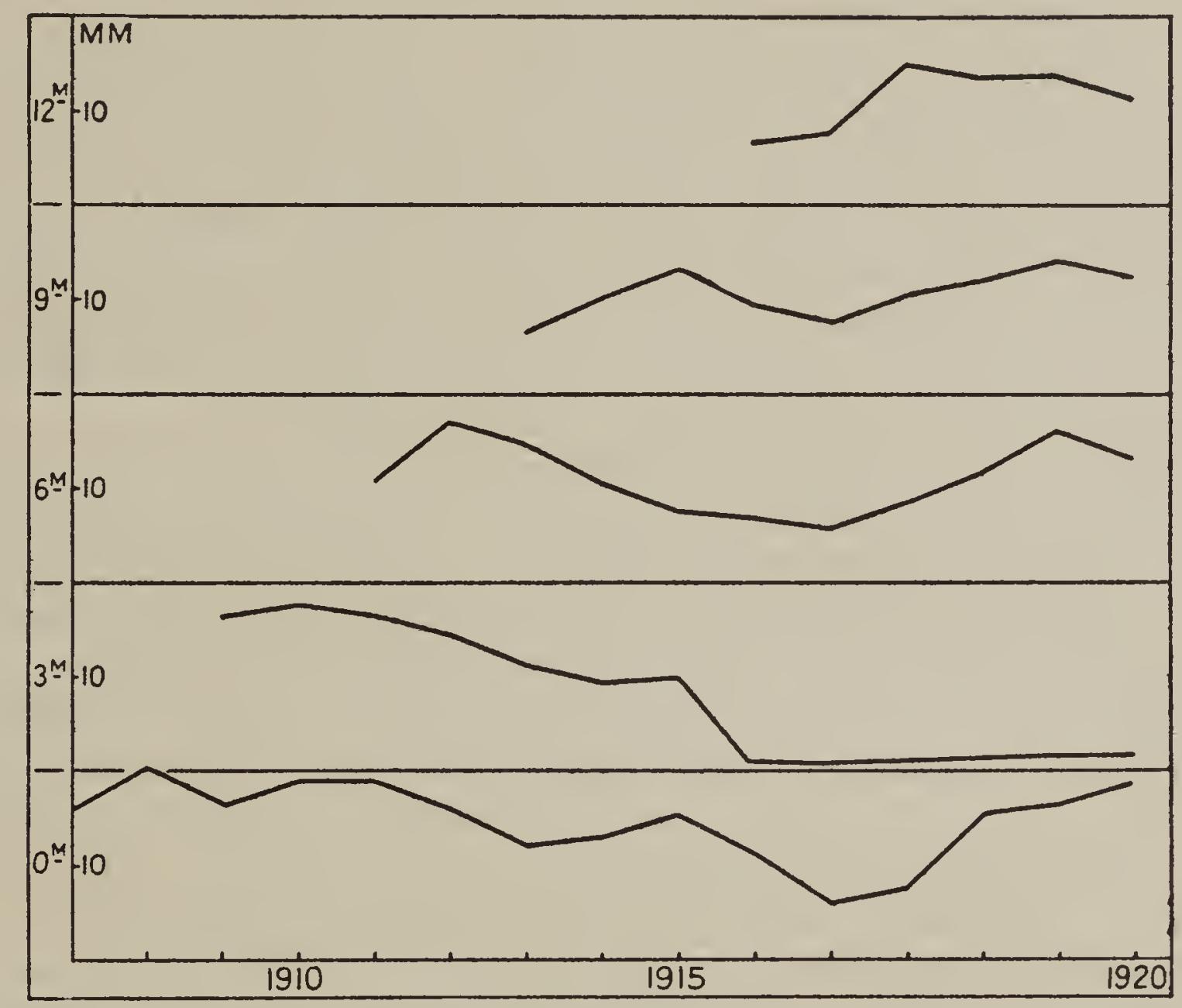

FIG. 26.-Graphs showing annual increase in diameter in trunk of bisected redwood at stump and at heights of $3,6,9$, and 12 meters.

1912 until 1917, a year in which the rate was low throughout the trunk. From 1917 until 1920 there was an increase of growth-rate to the height of 9 meters. There are, nevertheless, some conspicuous irregularities in the several graphs. At each of the five levels it will be seen that one or two years are required to bring the growth rate of the young trunk up to a maximum, and this rate is scarcely attained again, and only once exceeded, in the later growth at these levels. From 1916 until 1921 the growth was very slight at 3 meters, although a normal rate was maintained at the stump and at 6 meters. In 1921 the growth at the stump exceeded that of 1920, while at all of the higher levels it was less or the same.

Double rings, similar to those described in the pine, were found in the redwood in the outer portion of the trunk at levels of 8 to 7 meters, but were not discovered in wood of the same years at the higher levels. 
In view of the difference in the annual march of growth at the various levels in the trunk, it would seem that a measure of a given tree could best be secured by averaging the data from several successive elevations. If such an average were taken of the portion of the trunk that lies below the largest branches that survive until maturity is reached, the resulting figures should give a very accurate indication of the annual wood increment. In view of the discrepancy between the rate of growth at the stump and at the higher levels, such an average should have greater value than data secured from the stump section only in determining the total annual growth performance of the tree.

\section{CORRELATION OF GROWTH AND RAINFALL.}

It has long been well known that the growth of plants depends upon conditions of temperature, light, and moisture, and upon the supply of materials for the manufacture of food. For a plant growing in its natural environment the normal fluctuations of these conditions will result in unequal amounts of growth in a given unit of time. There is rarely justification for attributing inequalities of growth under natural conditions to the fluctuations of a single environmental condition. So complex is the interaction of the several conditions that the fluctuations of one must always be interpreted or investigated in terms of the others.

With respect to the influence of rainfall and temperature on the growth of trees, there is some evidence that very similar rates of growth may be maintained by the same tree under different rainfall conditions, providing there is a compensating difference in temperature. The writer has shown that the Arizona yellow pine in the Santa Catalina Mountains, in southern Arizona, maintains nearly the same average rate of growth at $6,000,7,000$, and 8,000 feet elevation up to the age of 175 years. The rainfall of the growing-season is nearly twice as great at 8,000 feet as it is at 6,000 feet, while the average extremes of temperatures are $10^{\circ}$ higher at 6,000 feet than at 8,000 feet. The failure of this tree to accomplish greater growth with the greater rainfall at 8,000 feet is apparently to be attributed in part to the lower temperature, although the shorter growing-season at the higher altitude is also a factor of importance. Individual trees growing at 6,000 feet in close proximity to streams exhibit a rate of growth much greater than that of any tree at 8,000 feet.

The Monterey pine is indigenous to a region in which there is a very low rainfall, or an absence of rain, for four months in the middle of the growing season. For this tree, and for almost all of the conifers of California, Arizona, New Mexico, Nevada, Utah, and Colorado, the growing-season presents longer or shorter periods in which the water-supply is inadequate for the most rapid growth. Since these periods of drought or semidrought are coincident with temperatures that are favorable for growth, it follows that the inequalities of rainfall and soil moisture from year to year subject these trees to conditions in which the single environmental condition of watersupply may become the dominant one in determining the total growth per-

\footnotetext{
${ }^{1}$ Forrest Shreve. The density of stand and rate of growth of Arizona yellow pine as influenced by climatic conditions. Jour. of Forestry, 15, 695-707. 1917
} 
formance. Douglass ${ }^{1}$ has investigated the relation of rainfall to the growth of the yellow pine near the lower altitudinal edge of its range in the vicinity of Prescott, Arizona. In data covering the years 1870 to 1910 he has shown a close correlation between precipitation and the thickness of the annual rings. The material investigated by Douglass was not only growing near the distributional limit that is placed upon the yellow pine by moisture conditions, but was in a region in which the growing-season is characterized by a high percentage of clear days and by a relatively regular march of humidity conditions. It remains to be determined whether such a close correlation between growth and precipitation is also found in this tree in other localities which are not so near its moisture-controlled distributional limit, and whether in other trees and in other localities the conditions of cloudiness, temperature, and humidity serve to modify the important influence of the moisture supply.

An adequate investigation of the influence of fluctuations of rainfall in causing inequalities of growth in the Monterey pine should be based upon a large body of data with respect to both rainfall and growth. Even with the small amount of such material secured in the present investigation it has seemed desirable nevertheless to make a correlation of rainfall and growth, especially as it is planned to carry on a further investigation of the matter. It is of paramount importance to determine whether rainfall, through its agency in replenishing the soil moisture, is indeed the principal condition responsible for fluctuations of growth from year to year, even in the regions where it appears to be the most critical condition for trees and other plants. It remains as a possibility that we shall be able to discover an expression of moisture conditions, or of moisture conditions combined with some aspect of temperature, by which we will be able to demonstrate, much more exactly than at present, the determining influences that underlie the annual fluctuations of growth.

\section{CORRELATION IN INDIVIDUAL TREES.}

In view of the difference discovered in the present work between the annual march of growth at different levels in the tree, it appeared desirable to learn whether a closer correlation between rainfall and growth is secured by using stump data or by using the average data for the growth of the entire trunk. It is also important to determine what portion of the growingseason is of greatest importance in wood formation, through the method of determining which months yield a rainfall total that is mostly closely correlated with the growth.

A rainfall record is available for Monterey, California, covering the life of the investigated trees up to the year 1911. The record for Carmel covers the years 1899 to 1922, with a break from 1907 to 1909. In the year for which the records overlap it appears that the precipitation at Carmel is slightly greater than that for Monterey. It is unfortunate that there are no records for localities in closer proximity to the trees with which the correlations are to be made. The bisected pine grew 7 miles from Carmel

A. E. Douglass. Evidence of climatic effects in the annual rings of trees. Ecology, vol. I, 24-32. 1920. 
and 10 miles from Monterey, the bisected redwood grew 17 miles from Carmel and 20 miles from Monterey.

For purposes of correlation with growth the rainfall, graphs have been worked out which are shown in figure 27 . These comprise the annual rainfall, and the rainfall for the following portions of the year, in each case inclusive of the months mentioned-March to August, January to August, February to September, and December (of the preceding year) to September. Each of these graphs is drawn to cover the life of the trees investigated, and is formed by supplementing the Monterey record with that for Carmel.

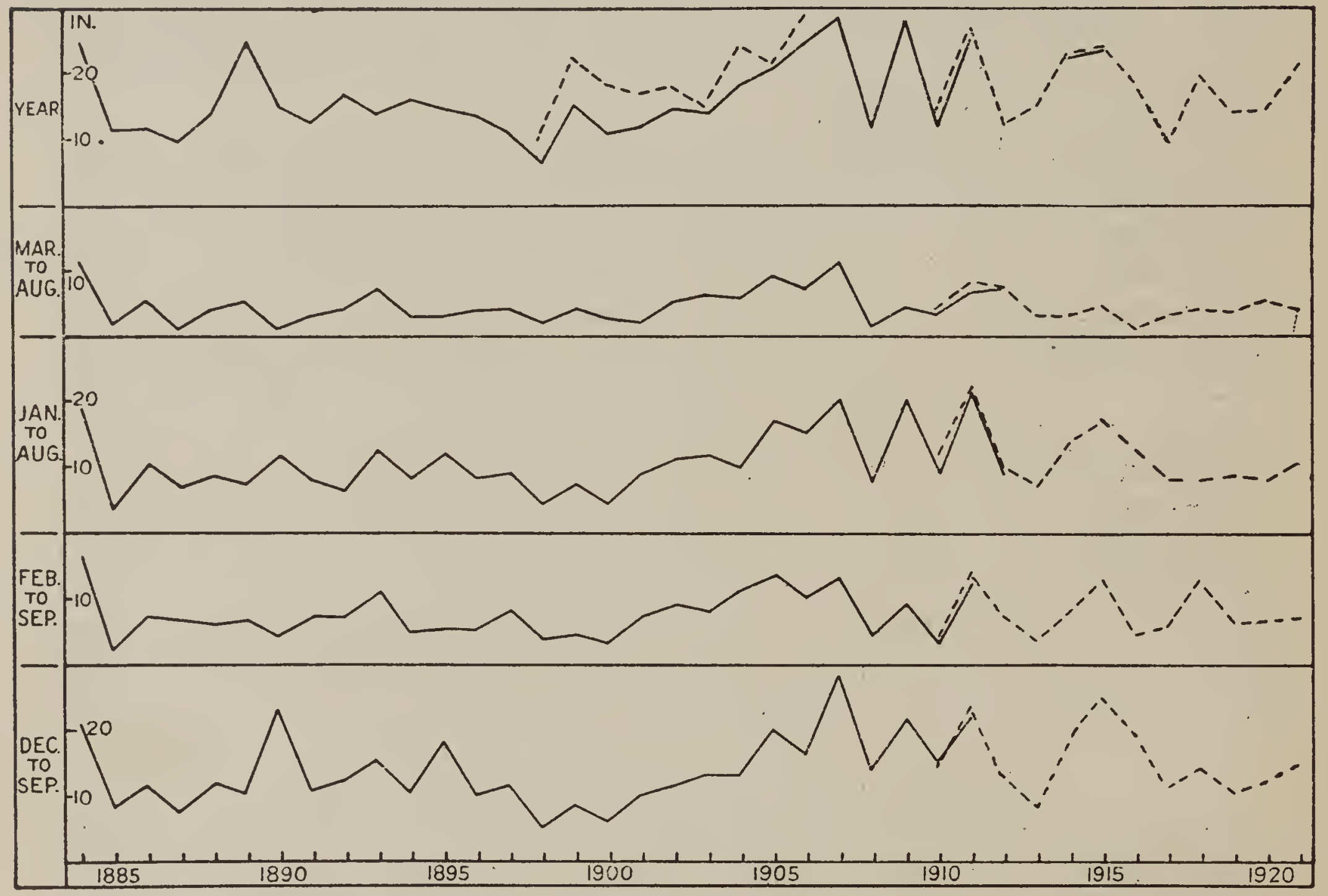

FIG. 27.-Graphs showing annual rainfall and seasonal rainfall, for periods indicated, for Monterey (solid line) and Carmel, California (broken line).

The correlation of growth with rainfall has been made for the pine and for the redwood, and in each case the growth data from the stump section and from the average of the 10 lowest sections have been used. With respect to rainfall, the four sets of growth data have been correlated with the total rainfall and with the four sets of seasonal rainfall mentioned above. The method of correlation used with this small series of data has been the simple one of counting the number of cases in which the compared graph of growth and rainfall agree in direction, and recording this in terms of the percentage of years showing agreement. For example, if the growth of 1891 was greater than that of 1890 in a particular case, and the rainfall of 1891 was also greater than that of 1890 , the agreement was recorded as a positive correlation. By use of this method no account is taken of the actual numerical relation between the correlated data. If a doubling 
of the rainfall was accompanied by a doubling of growth in one case and by a very slight increase in another, the two were recorded as positive correlations. More intensive work on this problem should be directed to taking account of the quantitative aspects of the correlations.

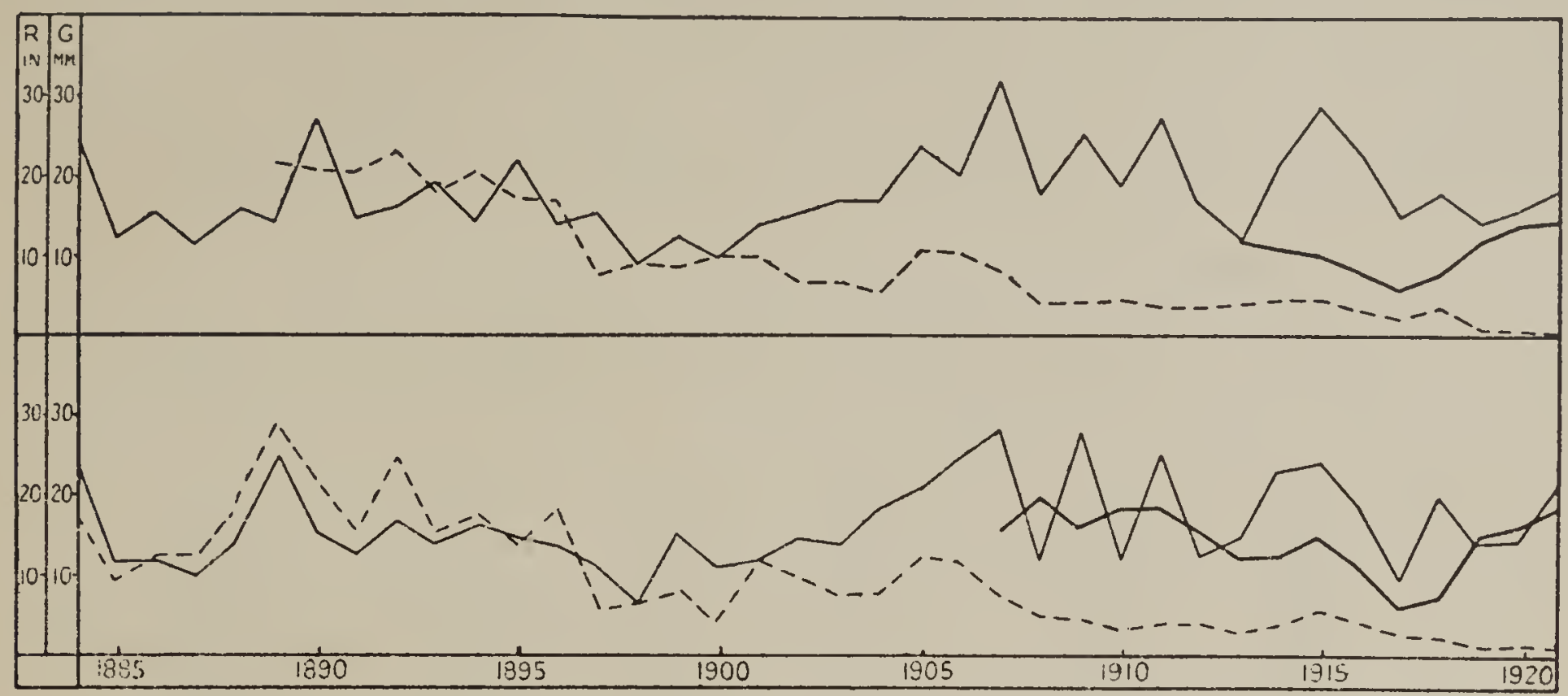

FIG. 28.-Graphs showing rainfall (solid line) and growth in diameter of Monterey pine (broken line) and redwood (heavy line) for corresponding years. Above, rainfall for December and September, and average growth of trunks; below, annual rainfall, and growth at stump,

The growth data have been derived from the figures given in tables 13 and 14, and the rainfall data are presented in tables 15 and 16 . In figure 28 is a graphic comparison of the growth and rainfall data, and in table 8 are given the percentage of correlation in all cases.

TABLE 15.-Average thickness (in meters) of annual rings of growth in bisected redwood measured on sections taken at 1-meter intervals.

\begin{tabular}{|c|c|c|c|c|c|c|c|c|c|c|c|c|c|c|c|}
\hline $\begin{array}{l}\text { Height from } \\
\text { stump } \\
\text { (meters). }\end{array}$ & 1921 & 1920 & 1919 & 1918 & 1917 & 1916 & 1915 & 1914 & 1913 & 1912 & 1911 & 1910 & 1909 & 1908 & 1907 \\
\hline 17 & 4.5 & & & 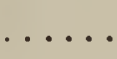 & & & . . & - & $\cdots$ & $\ldots \ldots \ldots$ & $\cdots$ & . . . . & $\cdots$ & $\cdots$ & $\cdots$ \\
\hline 16 & 6.0 & 4.0 & & $\ldots \ldots$ & $\ldots \ldots$ & $\ldots \ldots$ & $\ldots \ldots$ & . . . . & ...... & $\ldots \ldots$ & $\ldots \ldots$ & $\ldots . .$. & $\ldots \ldots$ & ...... & $\ldots$ \\
\hline 15 & 7.0 & 6.9 & 3.5 & $\ldots \ldots$ & $\ldots \ldots$ & $\ldots \ldots$ & $\ldots \ldots$ & $\ldots \ldots$ & $\ldots .$. & $\ldots \ldots$ & $\ldots \ldots$ & $\ldots \ldots$ & $\ldots \ldots$ & ...... & $\ldots$ \\
\hline 14 & 7.1 & 8.8 & 8.7 & $\ldots \ldots$ & $\ldots \ldots$ & $\ldots \ldots$ & $\ldots \ldots$ & $\ldots \ldots$ & ...... & $\ldots \ldots$ & $\ldots \ldots$ & $\ldots \ldots$ & ...... & ...... & $\ldots$ \\
\hline 13 & 6.0 & 6.2 & 7.3 & 5.1 & 3.7 & $\ldots \ldots$ & $\ldots \ldots$ & $\ldots \ldots$ & ...... & $\ldots \ldots$ & $\ldots \ldots$ & $\ldots \ldots$ & $\ldots \ldots$ & ...... & 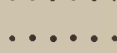 \\
\hline 12 & 5.7 & 6.9 & 6.7 & 7.5 & 3.8 & 3.2 & $\ldots \ldots$ & $\ldots \ldots$ & ...... & $\ldots \ldots$ & $\ldots$ & ... & . & $\ldots$ & \\
\hline 11 & 6.9 & 7.2 & 7.2 & 7.5 & 5.5 & 5.0 & 3.3 & $\ldots \ldots$ & $\ldots \ldots$ & $\ldots \ldots$ & $\ldots \ldots$ & $\ldots \ldots$ & $\ldots \ldots$ & $\ldots \ldots$ & \\
\hline 10 & 6.1 & 6.2 & 6.4 & 5.8 & 3.7 & 6.5 & 6.7 & $\ldots \ldots$ & $\ldots \ldots$ & $\ldots \ldots$ & $\ldots \ldots$ & $\ldots \ldots$ & $\ldots \ldots$ & $\ldots \ldots$ & \\
\hline 9 & 6.2 & 7.0 & 6.0 & 5.2 & 3.8 & 4.6 & 6.5 & 5.0 & 4.2 & $\ldots$ & ...... & $\ldots \ldots$ & $\ldots \ldots$ & ...... & .. \\
\hline 8 & 6.6 & 6.8 & 6.3 & 4.2 & 3.0 & 4.7 & 6.5 & 7.2 & 9.0 & $\ldots \ldots$ & $\ldots \ldots$ & $\ldots \ldots$ & $\ldots \ldots$ & ..... & \\
\hline 7 & 6.6 & 6.4 & 6.1 & 3.2 & 2.7 & 4.0 & 4.5 & 6.5 & 7.8 & 7.2 & $\ldots \ldots$ & $\ldots \ldots$ & ... & ... & \\
\hline 6 & 6.7 & 8.0 & 5.8 & 4.2 & 2.9 & 3.5 & 3.8 & 5.3 & 7.3 & 8.3 & 5.3 & $\ldots \ldots$ & $\ldots \ldots$ & ... & \\
\hline 5 & 6.3 & 6.0 & 5.3 & 4.0 & 2.8 & 3.2 & 3.9 & 5.0 & 6.4 & 9.0 & 6.9 & 4.9 & $\ldots \ldots$ & & \\
\hline 4 & 7.2 & 6.5 & 5.3 & 4.0 & 2.6 & 3.5 & 4.6 & 4.6 & 5.2 & 8.4 & 8.7 & 7.0 & 3.9 & $\cdots$ & \\
\hline 3 & 7.2 & 6.5 & 4.9 & 3.8 & 2.7 & 3.1 & 4.9 & 4.7 & 5.6 & 7.2 & 8.2 & 8.7 & 8.1 & & \\
\hline 2 & 7.8 & 5.7 & 4.8 & 3.2 & 2.2 & 3.8 & 4.5 & 5.3 & 4.8 & 6.5 & 6.6 & 10.0 & 9.1 & 7.2 & 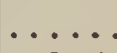 \\
\hline 1 & 8.0 & 8.0 & 6.7 & 3.5 & 2.7 & 3.7 & 3.7 & 4.2 & 4.5 & 6.0 & 6.5 & 8.5 & 9.5 & 11.7 & 3.6 \\
\hline 0 & 9.4 & 8.2 & 7.6 & 3.7 & 3.0 & 5.6 & 7.6 & 6.4 & 6.2 & 8.0 & 9.5 & 9.4 & 8.1 & 10.1 & 7.9 \\
\hline
\end{tabular}

In the correlation of growth data from the stump sections of the pine with the different seasonal groups of rainfall, it will be seen that in all cases there are very nearly the same number of agreements and disagreements, represented by correlations of 49 per cent to 54 per cent. The corre- 
lation with the annual rainfall is stronger, 65 per cent, in spite of the fact that this includes rain which fell after the cessation of the growth of the year. The correlation of growth for the entire life of the tree with the rainfall for the period from December of the preceding year to September is 51 per cent, indicating no positive relation between the two phenomena. When the first 20 years of the life of the tree and the last 16 years are separately considered, however, there is a decided negative correlation for the early years and strong positive correlation for the later years.

TABLE 16.-Rainfall (in inches) for Monterey, California.

\begin{tabular}{|c|c|c|c|c|c|}
\hline Year. & Annual. & Mar.-Aug. & Jan.-Aug. & Feb.-Sept. & Dec.-Sept. \\
\hline 1884 & 26.47 & 11.99 & 18.93 & 16.36 & 20.12 \\
\hline 1885 & 11.92 & 2.34 & 3.65 & 2.43 & 8.98 \\
\hline 1886 & 12.30 & 5.99 & 10.22 & 7.13 & 11.95 \\
\hline 1887 & 10.47 & 1.81 & 7.08 & 6.98 & 7.63 \\
\hline 1888 & 14.54 & 4.33 & 9.37 & 6.07 & 11.83 \\
\hline 1889 & 25.14 & 5.95 & 7.70 & 6.89 & 10.46 \\
\hline 1890 & 15.96 & 1.54 & 11.88 & 4.31 & 23.52 \\
\hline 1891 & 13.26 & 3.48 & 8.22 & 7.27 & 11.35 \\
\hline 1892 & 17.01 & 4.70 & 6.86 & 7.45 & 12.86 \\
\hline 1893 & 14.76 & 7.65 & 12.72 & 11.11 & 15.88 \\
\hline 1894 & 16.49 & 3.28 & 8.58 & 5.41 & 10.53 \\
\hline 1895 & 15.32 & 3.41 & 12.26 & 5.96 & 18.13 \\
\hline 1896 & 14.21 & 5.29 & 8.65 & 5.68 & 10.38 \\
\hline 1897 & 11.70 & 4.50 & 9.23 & 8.25 & 11.86 \\
\hline 1898 & 7.24 & 2.51 & 4.48 & 4.38 & 6.52 \\
\hline 1899 & 15.05 & 4.21 & 7.66 & 4.87 & 8.63 \\
\hline 1900 & 11.77 & 2.99 & 4.99 & 3.65 & 6.38 \\
\hline 1901 & 12.93 & 2.63 & 9.22 & 7.36 & 10.94 \\
\hline 1902 & 14.60 & 5.59 & 11.27 & 9.45 & 11.79 \\
\hline 1903 & 14.67 & 6.78 & 12.09 & 8.66 & 13.26 \\
\hline 1904 & 18.34 & 6.23 & 10.17 & 11.75 & 13.33 \\
\hline 1905 & 21.63 & 9.23 & 17.08 & 13.69 & 20.14 \\
\hline 1906 & 25.03 & 7.56 & 15.64 & 10.68 & 16.66 \\
\hline 1907 & 28.98 & 11.16 & 20.41 & 13.74 & 28.55 \\
\hline 1908 & 12.21 & 1.87 & 9.21 & 4.65 & 14.12 \\
\hline 1909 & 28.39 & 4.29 & 20.43 & 9.38 & 22.04 \\
\hline 1910 & 12.35 & 3.60 & 9.82 & 4.82 & 15.38 \\
\hline 1911 & 25.39 & 6.92 & 21.86 & 12.65 & 22.41 \\
\hline
\end{tabular}

In using the average growth data from the 10 lowest trunk sections it is found that the correlation with the annual rainfall is 63 per cent, or almost identical with the 65 per cent found for the stump data. In the case of all periods of seasonal rainfall there is a negative correlation with the average growth of the trunk. Even the growth of the last 16 years shows in this case a correlation of 50 per cent, indicating that the rainfall conditions, which appear to have been significant in the growth of the tree so far as concerns the stump record, were without importance to the formation of wood in the tree as a whole. In brief, when the rainfall of the period most nearly coinciding with the growth-season for Monterey pine, and embracing the rain of the month preceding the commencement of growth, is correlated with the average growth of the entire trunk up to 30 feet, the result indicates that the precipitation exerts no influence upon growth. 
For the redwood the correlation of stump-growth with the annual rainfall is 64 per cent, and is the same in the case of the February to September rainfall. As in the pine, the negative correlations are in the majority for the shorter periods of seasonal rainfall. When stump-growth is correlated with the rainfall for the period from December to September, there is a correlation of 71 per cent, indicating that the late rain of the winter is of considerable significance in the growth of this tree during the succeeding spring. The average growth data for the 10 lowest sections of the redwood show a weaker correlation with all but one of the seasonal groups of rainfall than do the data from the stump alone. With the annual rain and with the December to September rainfall the correlation is the same, 62 per cent. Contrasting the correlations for the pine and the redwood, for both groups of growth-data, gives 51 per cent for the former tree and 71 per cent for the latter on stump data, and 40 per cent for the former and 62 per cent for the latter on trunk data. This indicates that rainfall is of more importance in determining the rate of growth of the redwood than it is in influencing that of the Monterey pine.

\section{CORRELATION IN GROUPS OF TREES.}

It was desired to make a somewhat more extended examination into the possibile relation of precipitation to growth by using data on the growth of a larger number of trees. The use of measurements from a very large number of stumps, such as are often available after logging operations, gives no opportunity to determine the character of the trees that have been felled. Those with mature and immature crowns must be taken together, those growing alone and those more or less suppressed by neighboring trees, those that are perfect and those that show obvious signs of damage by storm or lightning. It is only by the use of a very large body of such data that a good set of averages can be secured, in which the results from the defective trees are suppressed by a supposedly larger number of data from trees in vigorous and perfect condition. With these considerations in mind, it was decided to secure data by means of an increment borer from a small number of trees, all possessing perfect excurrent crowns, all of nearly the same size $(20 \mathrm{~cm}$. diameter), all growing in the same type of soil and the same topographic site, in close proximity to each other and to the rainfall station for Carmel. It is believed that such data afford the optimum basis for comparison of growth with environmental conditions. In addition, measurements were made of the stumps of four large trees of approximately the same size $(60$ to $68 \mathrm{~cm}$.) that had been felled adjacent to the six small trees.

In figure 29 are shown the graphs of annual march of growth in the six small trees, together with the rainfall for December to September. Although these trees were living under as nearly identical conditions as is possible under a state of nature, it will be noted that there is not a close correspondence between their growth records. In the 19 years covering the life of the youngest of the group there were only 6 years in which all six of the trees rose and fell together in their change of total growth from year to year. It is worth noting that in all of these six cases the graphs of growth rose or 
fell in accord with the graph of rainfall. The added lengths of life of the six trees are 108 years. Out of the 108 cases in which the growth could be compared with rainfall, it was found that there were 68 cases in which there was a positive correlation between them, amounting to 62.9 per cent. In the case of the four large trees, the total length of life was 112 years, and of these there were 57 in which there was a positive correlation with rainfall, amounting to 50.9 per cent. These figures indicate a very slight

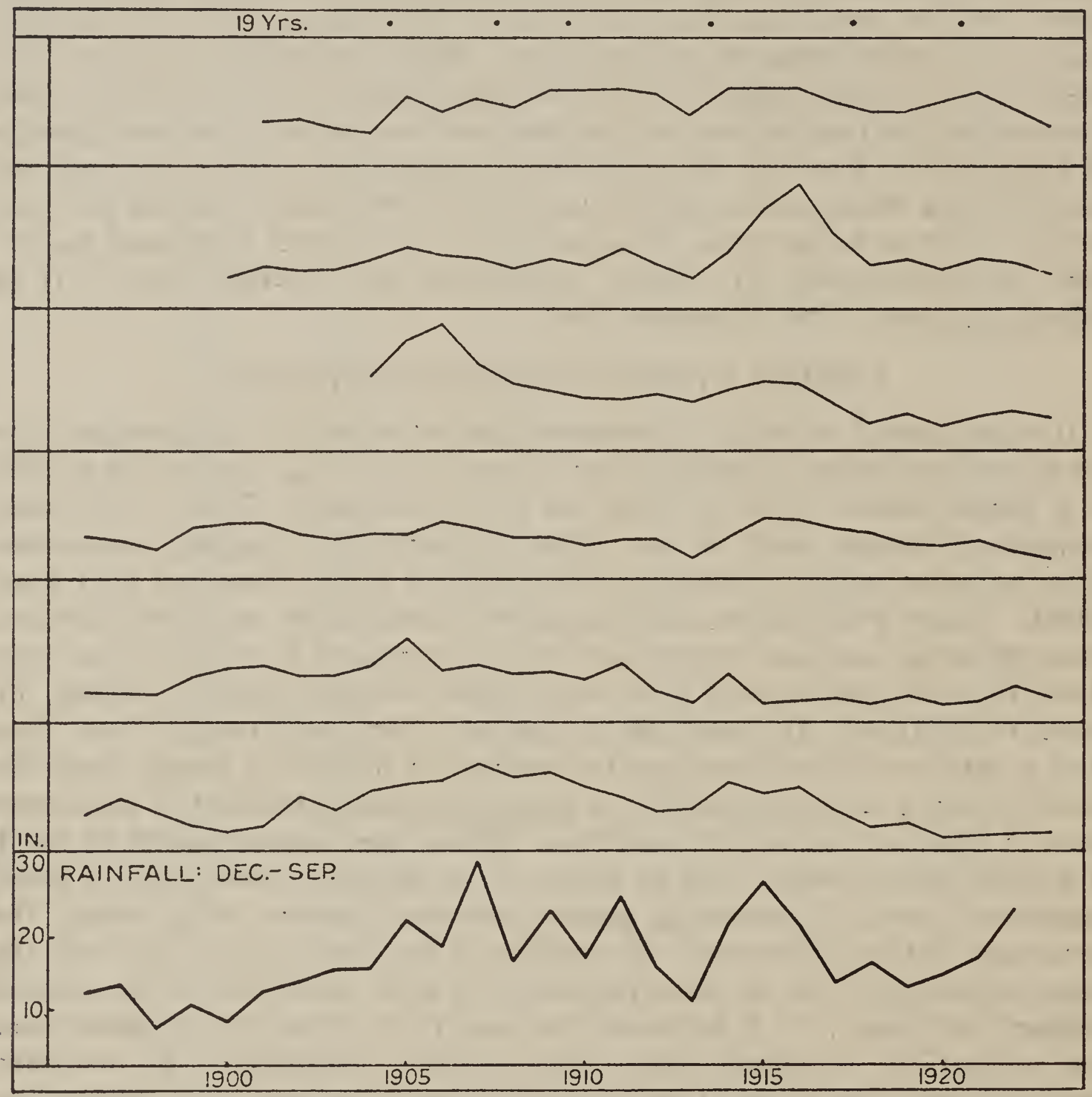

Frg. 29.-Graphs showing rainfall for December to September and course of growth in 6 small trees of Monterey pine. Dots at top indicate years of accordant behavior.

influence by rainfall on the growth of the younger trees, and none at all on the older trees. This is directly opposed to the evidence from the first bisected pine, in which there was a much stronger correlation in the later life of the tree than in its earlier life (table 18).

In view of the numerous conditions which affect the growth of plants, it appears highly probable that small differences in rainfall might have their influence obscured by the operation of some of the other conditions, and that the influence of precipitation would be exerted most clearly in the 
years that were far above or below the normal rainfall. On this basis an examination was made of the average rates of growth of the two groups of trees in the four wettest and the two driest years between 1900 and 1922. The results are shown in table 19. For the small trees, the growth was less

TABLE 17.-Rainfall (in inches) for Carmel, California.

\begin{tabular}{|c|c|c|c|c|c|}
\hline Year. & Annual. & Mar.-Aug. & Jan.-Aug. & Feb.-Sept. & Dec.-Sept. \\
\hline 1898 & 10.37 & 3.19 & 6.43 & 6.49 & 14.42 \\
\hline 1899 & 22.92 & 8.22 & 13.13 & 8.78 & 14.57 \\
\hline 1900 & 18.75 & 4.90 & 9.58 & 6.44 & 12.49 \\
\hline 1901 & 17.34 & 3.91 & 12.68 & 9.42 & 15.47 \\
\hline 1902 & 18.13 & 6.31 & 13.34 & 11.25 & 14.01 \\
\hline 1903 & 15.43 & 4.16 & 11.43 & 6.82 & 13.27 \\
\hline 1904 & 24.54 & 9.01 & 14.90 & 16.15 & 18.55 \\
\hline 1905 & 21.67 & 9.44 & 17.44 & 17.07 & 14.42 \\
\hline 1906 & 29.44 & 9.22 & 18.01 & 14.52 & 20.01 \\
\hline 1907 & $\ldots \ldots$ & $\ldots \ldots$ & $\ldots \ldots$ & $\ldots \ldots$ & $\ldots$ \\
\hline 1908 & & & & & \\
\hline 1909 & & 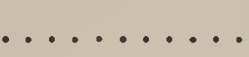 & & $\cdots$ & \\
\hline 1910 & 14.30 & 4.18 & 12.08 & 5.21 & 14.97 \\
\hline 1911 & 27.07 & 8.22 & 22.97 & 14.66 & 23.64 \\
\hline 1912 & 12.31 & 7.31 & 10.17 & 7.94 & 13.38 \\
\hline 1913 & 15.47 & 3.73 & 7.87 & 4.34 & 8.79 \\
\hline 1914 & 22.88 & 3.63 & 14.39 & 8.39 & 19.16 \\
\hline 1915 & 24.09 & 4.42 & 17.97 & 13.25 & 25.12 \\
\hline 1916 & 18.86 & 1.20 & 13.47 & 5.79 & 20.48 \\
\hline 1917 & 9.91 & 2.84 & 8.41 & 6.49 & 11.33 \\
\hline 1918 & 19.79 & 4.04 & 8.10 & 13.00 & 14.27 \\
\hline 1919 & 14.04 & 3.65 & 8.89 & 7.11 & 10.74 \\
\hline 1920 & 14.70 & 5.21 & 8.26 & 7.61 & 12.53 \\
\hline 1921 & 21.20 & 4.09 & 10.87 & 7.72 & 13.97 \\
\hline 1922 & 19.40 & 4.27 & 12.72 & 9.93 & 21.73 \\
\hline
\end{tabular}

TABLE 18.-Relation of rainfall to growth of Monterey pine and redwood.

[Qualitative correlations based on Monterey rainfall record 1884 to 1911 and Carmel record 1912 to 1921.1

\begin{tabular}{|c|c|c|c|c|}
\hline & \multicolumn{2}{|c|}{$\begin{array}{l}\text { Growth data from stump } \\
\text { section only. }\end{array}$} & \multicolumn{2}{|c|}{$\begin{array}{l}\text { Average growth data from } \\
10 \text { lowest trunk sections. }\end{array}$} \\
\hline & Pine. & Redwood. & Pine. & Redwood. \\
\hline $\begin{array}{l}\text { Annual rainfall } \ldots \ldots \ldots \\
\text { March to August. . . . . } \\
\text { January to August. } \\
\text { February to September..... } \\
\text { December to September. } \\
\text { Same for years } 1884 \text { to } 1904 \\
\text { Same for years } 1905 \text { to } 1921 .\end{array}$ & $\begin{array}{l}\text { per cent. } \\
65 \\
54 \\
49 \\
49 \\
51 \\
35 \\
70\end{array}$ & $\begin{array}{l}\text { per cent. } \\
64 \\
43 \\
50 \\
64 \\
71\end{array}$ & $\begin{array}{l}\text { per cent. } \\
63 \\
38 \\
34 \\
40 \\
40 \\
31 \\
50\end{array}$ & $\begin{array}{l}\text { per cent. } \\
62 \\
50 \\
25 \\
50 \\
62\end{array}$ \\
\hline
\end{tabular}

in the dry year 1900 than in any of the wet years, but in the dry year 1913 it was greater than in two of the wet years and nearly as great as in any of them. For the large trees, the growth in each of the two dry years was greater than in any of the wet years. In order to secure a quantitative 
measure of the relation between growth and rainfall, a calculation was made of the growth per inch of rain for both groups of trees in both groups of years. These figures indicate that for both the large and the small trees there is far more wood formed per inch of rainfall in the dry years than in the wet ones.

TABLE 19.-Growth of Pinus radiata (in millimeters) in wet and dry years.

[Average rainfall, December to September, 14.17 inches.]

\begin{tabular}{|c|c|c|c|c|c|c|}
\hline & \multicolumn{5}{|c|}{ Total rain December to September. } \\
\cline { 2 - 7 } & \multicolumn{4}{|c|}{ Wet years. } & \multicolumn{2}{c|}{ Dry years. } \\
\cline { 2 - 7 } & 1907 & 1909 & 1911 & 1916 & 1900 & 1913 \\
\hline & 28.55 & 22.04 & 22.41 & 20.48 & 6.38 & 8.79 \\
Six small trees: & 4.6 & 4.1 & 3.9 & 4.7 & 2.7 & 4.5 \\
Average growth...... & .17 & .18 & .18 & .23 & .43 & .28 \\
$\begin{array}{c}\text { Growth per inch of rain. } \\
\text { Four large trees: } \\
\text { Average growth...... }\end{array}$ & 6.2 & 6.0 & 5.3 & 7.0 & 7.8 & 7.4 \\
Growth per inch of rain. & .22 & .27 & .24 & .34 & 1.22 & .84 \\
\hline
\end{tabular}

The failure to find a strong and uniform correlation between rainfall and growth in the wettest and driest years appears to be one of the most important pieces of evidence secured in this work against the possibility of using the growth record of trees as a universal criterion of rainfall conditions.

\section{CORRELATION OF GROWTH AND TEMPERATURE.}

The absence of a correlation between rainfall and growth in the Monterey pine suggested the possibility of a closer correlation between growth and some other important condition affecting it. The principal of these is temperature. In order to ascertain whether it would be worth while to undertake a serious investigation of the correlation between growth and temperature, a single determination was made in a critical case that fell within the range of the climatic records for the Coastal Laboratory. It happened that the rainfall for the growing-season of the years 1912 and 1921 was nearly the same in total amount (13.38 inches and 13.97 inches respectively) and very similar in its seasonal distribution. In these years the growth of the four large trees was nearly identical $(5.6 \mathrm{~mm}$. and $5.7 \mathrm{~mm}$. respectively), while the growth in the six small trees was greater in $1912(3.2 \mathrm{~mm}$.) than in $1921(2.6 \mathrm{~mm}$.).

The temperature datum used in the comparison of 1912 and 1921 was a summation of all temperatures above $40^{\circ} \mathrm{F}$., this being about the lowest minimum temperature at the time of the year when growth begins in the pine. The summation was made by tracing the thermograph curves on stout paper and determining the total area by weighing. The summations were made by months, so as to make it possible to compare the totals for the months of most active growth and also for the entire growing-season. The 
resulting figures, in hour-degree units, are shown in table 20, together with the growth and rainfall data for the same years. In both groups of months the temperature summation was less in 1912 than in 1921, but the difference is not very great, the figures for 1912 being less than 3 per cent below those for 1921. Such a slight difference is to be expected in a locality with the equable maritime climate of Carmel. In this particular instance the group of small trees grew more in the year with the smaller temperature total. The almost negligible difference between the growth of the four large trees in the two years was in accord with the small temperature difference, but the probable error in both determinations is great enough to make this correlation mean very little.

TABLE 20.-Growth of Pinus radiata in relation to temperature. Summation of temperature above $40^{\circ} \mathrm{F}$. in hour-degree units.

\begin{tabular}{|c|c|c|} 
& 1912 & 1921 \\
\cline { 1 - 2 } & & \\
Average growth, six small trees..... & 3.2 & 2.6 \\
Average growth, four large trees... & 5.6 & 5.7 \\
Rainfall, December to September... & 13.38 & 13.97 \\
Temperature summation. & & \\
January to April.............. & 28,253 & 30,261 \\
January to September.......... & 92,950 & 94,969 \\
\hline
\end{tabular}

The failure to secure evidence for a temperature influence in the two years with nearly equal rainfall, and the discovery of such a close correspondence between the temperature summations for the two years, have discouraged further investigation of this correlation.

\section{SUMMARY.}

The Monterey Pine (Pinus radiata) occupies a restricted area along the coast of central California, and has been investigated in the region of its greatest abundance in the vicinity of Monterey, California. The redwood (Sequoia sempervirens) has been investigated south of Monterey, near the southern limit of its range.

The reputation of the Monterey pine for very rapid growth is based on the observation of exceptional young trees. Out of 125 stumps examined, the two most rapidly growing trees, age 51 and 53 years, had made an annual average diameter growth of $6 \mathrm{~mm}$. (0.25 inch). The greatest growth observed in any year in the 125 trees was a diameter increase of $3.6 \mathrm{~cm}$. (0.43 inch). The maximum age attained rarely exceeds 100 years.

The age-diameter curve for the Monterey pine is nearly a straight line, and is the same for trees growing on sand and trees on adobe soil. The fall in the curve that is commonly found in other trees has not been detected in this pine.

In young trees, 5 to 15 years old, supernumerary whorls of branches are frequently formed, sometimes formed two or three times, on the shoot of the year. Seedlings from 10 to $19 \mathrm{~cm}$. in height add an average of 86 per cent to their height in a single year; young trees 130 to $139 \mathrm{~cm}$. in height add 24 per cent to their height. 
In young trees 100 to $200 \mathrm{~cm}$. in height from 40 per cent to 50 per cent of the annual growth in height is accomplished before the end of March.

In young trees 4.5 to 6 meters in height there is no correlation between growth in height and growth in diameter.

Trunks of pine and redwood sectioned at intervals of 1 meter or 3 feet show that the annual march of growth is not the same at the stump and at different heights in the trunk. Growth at a given section is greater toward the center than towards the periphery, and in a given year is greater within 5 or 6 meters of the top than at other heights.

Correlations have been made between rate of growth and amounts of annual and seasonal rainfall. The growth data used have been those from the stump section and the average from the 10 lowest 1-meter sections. The rainfall data used have been the totals for the year and for the following periods: January to August, February to September, March to August, and December (of the preceding year) to September. The results indicate a negative correlation between growth and the rainfall of the shorter periods in the growing-season, and a small positive correlation between growth and the annual rainfall. Data from the stump show no correlation with the rainfall of the period from December to September, and the averaged data for the trunk show a negative correlation with the rainfall of the same period. The correlation with annual rainfall is the same for Monterey pine and redwood, but the correlation with the rainfall of the growingseason is greater for the redwood.

Correlations of growth with rainfall were made in six small and four large trees of Monterey pine, selected for equality of size and stage of development and for apparent identity of environmental conditions. Using the rainfall of December to September, a weak correlation was found in the small group and no correlation in the large group.

The driest years at Carmel since 1900 have had about one-third as much seasonal rainfall as the wettest years. In the six small trees the average growth in one of the dry years was less than in any of the wet years.

In the other dry year it was greater than in two of the wet years and nearly as great as in the other two wet years. In the four large trees the growth was greater in both of the dry years than in any of the four wet ones. The growth per inch of rainfall was in all cases much greater in the dry years than in the wet ones.

The correlation of growth with temperature in two years with nearly the same rainfall shows a slight negative correlation for the entire growingseason and for the months of greatest growth in the case of the small trees, and a very slight positive correlation in the case of the large trees.

The collective results of this work confirm our knowledge of the dependence of growth on the entire constellation of environmental conditions, and indicate that the annual march of growth is not correlated with the march of individual conditions. Future investigations may make it possible to formulate a composite expression of the leading conditions, with which the march of growth would be in close correlation. 


$$
7_{2}
$$




UNIVERSITY OF ILLINOIS-URBANA

581.134M14GR COO1

GROWTH IN TREES AND MASSIVE ORGANS OF PL

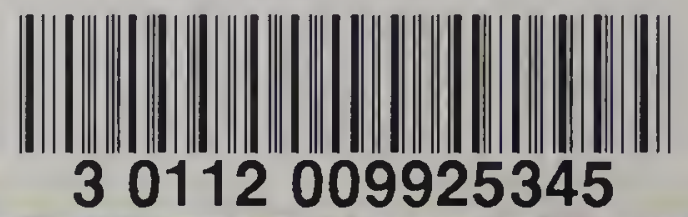

